\title{
LIGAÇÃO PILAR-FUNDAÇÃO POR MEIO DE CÁLICE EM ESTRUTURAS DE CONCRETO PRÉ-MOLDADO COM PROFUNDIDADE DE EMBUTIMENTO REDUZIDA
}

\section{Kenneth de Borja Jaguaribe Junior}

\begin{abstract}
Dissertação apresentada à Escola de Engenharia de São Carlos da Universidade de São Paulo, como parte dos requisitos para obtenção do título de Mestre em Engenharia de Estruturas.
\end{abstract}

ORIENTADOR: Prof. Dr. Mounir Khalil El Debs

São Carlos 
Candidato: Engenheiro KENNETH DE BORJA JAGUARIBE JÚNIOR

Dissertação defendida e julgada em 17-11-2005 perante a Comissão Julgadora:

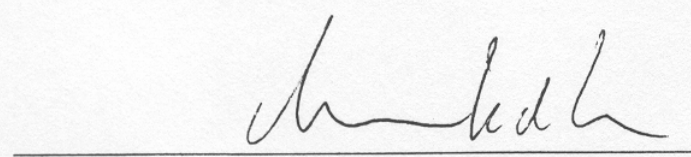

Prof. Associado MOUNIR KHALIL EL DEBS (Orientador)

(Escola de Engenharia de São Carlos/USP)

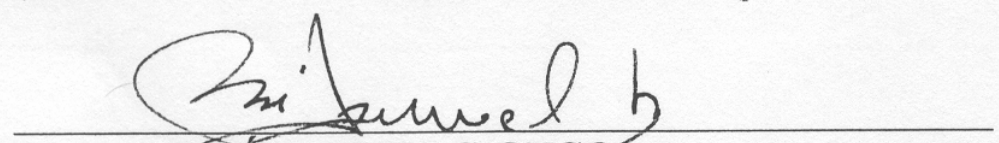

Prof. Dr. JUSE SAMUEL GIONGO

(Escola de Engępharia de São Carlos/USP)

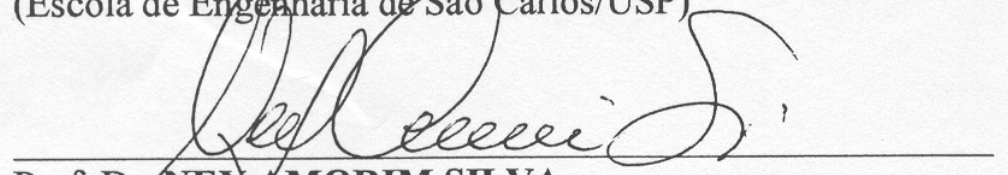

Prof. Dr. NEYAMORIM SILVA

(Universidade Federal de Minas Gerais/UFMG)
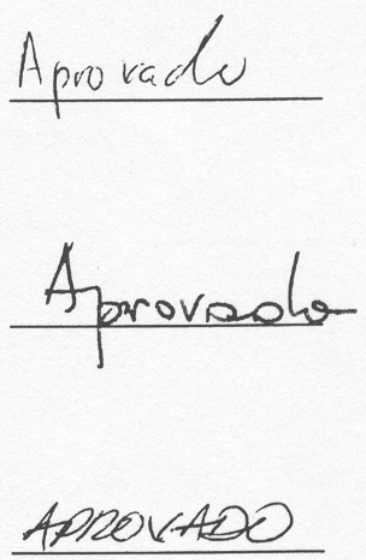
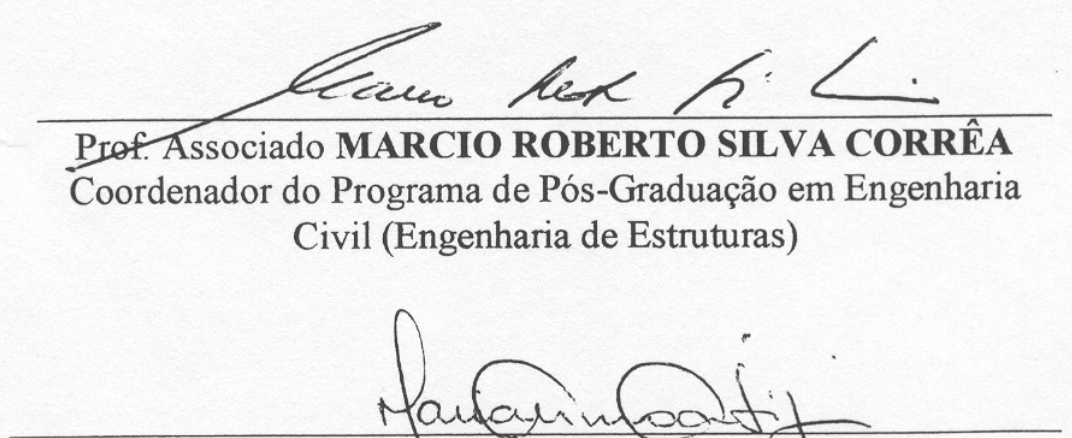

Profa. Titular MARIA DO CARMO CAGIJURI

Presidente da Comissão de Pós-Graduação 
Ao meu pai Kenneth (in memorian), minha mãe Maria do Socorro, meus irmãos Washington (in memorian) e Rarene, minha tia Nilza e meus primos Lucas e Ludmila. 


\section{AGRADECIMENTOS}

A Deus, por estar sempre do meu lado.

Ao Mounir Khalil El Debs, pela sua orientação, amizade e paciência.

As pessoas mais importantes da minha vida, minha querida mãe, pela educação passada, por todo o amor, pela extrema dedicação e confiança depositada em mim, e ao meu irmão Rarene, por sempre estar do meu lado, apesar da distância que nos separa há um bom tempo.

Ao meu pai (in memorian), que apesar de não estar mais presente fisicamente, sempre esteve em meu coração e no qual teve uma enorme influência na profissão que escolhi.

A uma pessoa muito especial e a qual sinto muita saudade, meu irmão do meio Washington (in memorian), por ter me amado tanto, mesmo que do seu jeito e por ter feito parte da minha vida.

A minha querida avó paterna Petronilha (in memorian), por tantos mimos e ensinamentos.

Aos meus avós maternos Manuel e Zita, por sempre me apoiarem.

A minha segunda mãe, tia Nilza, por ter me ajudado durante anos e ter me acolhido em sua casa com muita dedicação e amor como se fosse seu filho, tendo uma enorme participação em tudo que conquistei.

Aos meus irmãos “postiços”, meus primos Lucas e Ludmila, pela amizade, amor e por fazerem parte da minha vida.

A Renata, pelo amor, carinho, compreensão e por ter acreditado em mim.

Aos amigos mais próximos que convivi em São Carlos, em especial ao Vladimir, Anselmo, Sudano e Abner, que tiveram uma grande participação para o desenvolvimento desta pesquisa, com conversas, troca de conhecimentos e apoio moral.

A galera das Pimentas, praticamente minha família em São Carlos: Danu, Fernanda, Thais e o agregado da república, Danilo, pela amizade, pela enorme força que me deram e pelos melhores momentos que passei durante esses anos. 
Aos professores do Departamento de Estruturas da EESC-USP, que contribuíram no meu crescimento pessoal e profissional.

A Rejane, por fornecer algumas figuras dessa Dissertação.

A todos os funcionários do Departamento de Estruturas da EESC-USP, pela competência na execução dos seus serviços.

A toda equipe do Laboratório de Estruturas: Amaury, Luiz Vareda, Mário, Maury, Valdir, Fabiano e Romeo pelo apoio, paciência, dedicação e competência com que realizaram os serviços para o desenvolvimento da pesquisa experimental.

A CAPES, pelo apoio financeiro da bolsa.

A FAPESP, pelo apoio financeiro repassado a essa pesquisa.

Aos funcionários da Marcenaria da EESC-USP, pela confecção das fôrmas.

A Gerdau, pela doação da armadura longitudinal do pilar.

A Resinor, pela doação das placas de EPS utilizada na confecção das chaves do modelo rugoso. 


\section{SUMÁRIO}

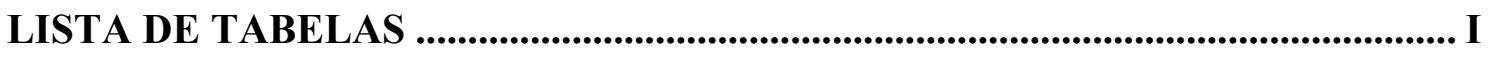

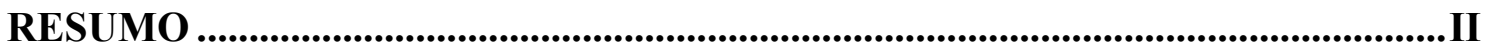

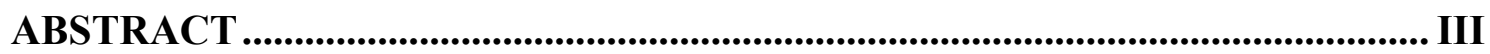

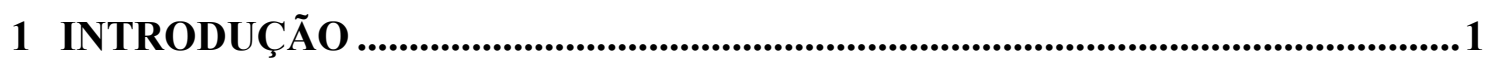

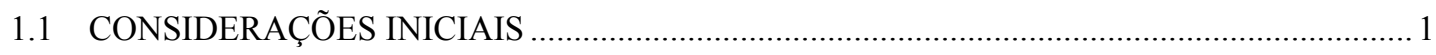

1.2 OBJETIVO

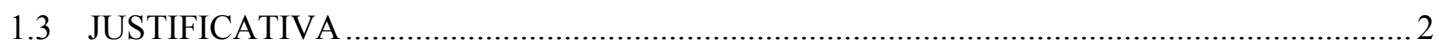

1.4 METODOLOGIA

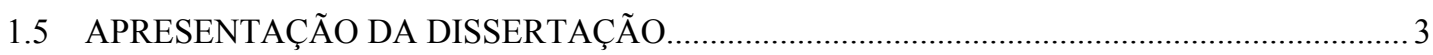

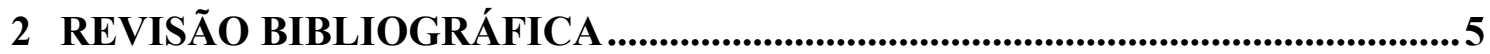

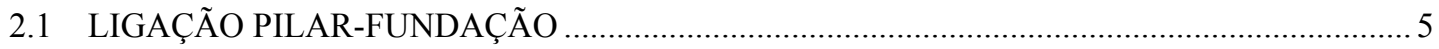

2.2 ASPECTOS GERAIS DO CÁLICE DE FUNDAÇÃO ……......................................................

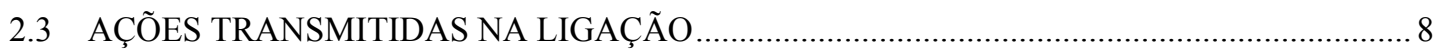

2.4 ESTUDOS EXPERIMENTAIS E MODELOS DE PROJETO_....................................................... 10

2.4.1 RECOMENDAÇÕES DE PROJETO SEGUNDO LEONHARDT \& MÖNNIG (1977), NBR 9062:

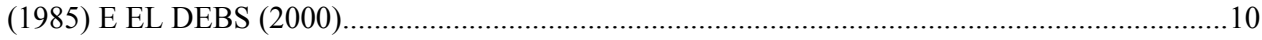

2.4.1.1 PROPRIEDADES GEOMÉTRICAS E RESULTANTES DE FORÇAS NO CÁLICE ........................ 10

2.4.1.2 COMPORTAMENTO E DIMENSIONAMENTO DAS PAREDES DO CÁLICE ............................... 13

2.4.1.3 ARRANJO DAS ARMADURAS DO CÁLICE ................................................................................ 16

2.4.1.4 RECOMENDAÇÕES REFERENTES ÀS AÇÕES NA BASE DE FUNDAÇÃO E NA PARTE

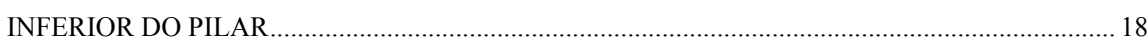

2.4.2 MODELO DE PROJETO DE WILLERT \& KESSER (1983) ......................................................20

2.4.3 MODELO E RECOMENDAÇÕES DE PROJETO APRESENTADOS EM OLIN ET AL. (1985)

2.4.3.1 DISTRIBUIÇÃO DE FORÇA NA LIGAÇÃO ............................................................................... 23

2.4.3.2 TENSÕES DE CISALHAMENTO ATUANTES NAS PAREDES DO CÁLICE …….......................... 25 
2.4.3.3 CÁLCULO E ARRANJO DAS ARMADURAS DO CÁLICE

2.4.4 MODELO DE PROJETO DE ELLIOTT (1996) _.........................................................................29

2.4.4.1 MÉTODO DE CÁLCULO CONSIDERANDO APENAS FORÇA NORMAL EXCÊNTRICA.......... 30

2.4.4.2 MÉTODO DE CÁlCULO CONSIDERANDO FORÇA NORMAL EXCÊNTRICA E FORÇA CORTANTE HORIZONTAL ..................................................................................................... 31

2.4.5 PESQUISA EXPERIMENTAL E MODELO DE PROJETO DE OSANAI ET AL.(1996)..............32

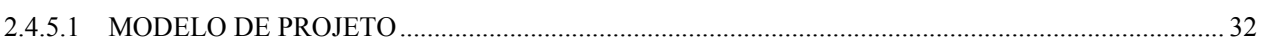

2.4.5.2 PESQUISA EXPERIMENTAL ................................................................................................ 39

2.4.6 MODELO E RECOMENDAÇOES DE PROJETO SEGUNDO A CNR 10025 (1998) ..................41

2.4.6.1 PROPRIEDADES GEOMÉTRICAS E RESULTANTES DE FORÇAS NO CÁLICE......................... 41

2.4.6.2 COMPORTAMENTO E DIMENSIONAMENTO DAS PAREDES DO CÁLICE …........................... 42

2.4.7 RECOMENDAÇOES PARA PROJETO SEGUNDO CERIB (2001) ............................................46

2.4.7.1 PROPRIEDADES GEOMÉTRICAS E RESULTANTES DE FORÇAS NO CÁLICE ......................... 46

2.4.7.2 COMPORTAMENTO E DIMENSIONAMENTO DAS PAREDES DO CÁLICE ............................... 49

2.4.8 MODELO E RECOMENDAÇOES DE PROJETO DA EMPRESA MUNTE APRESENTADOS

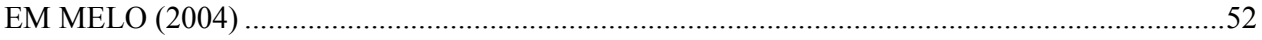

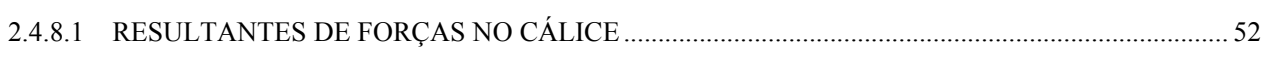

2.4.8.2 COMPORTAMENTO E DIMENSIONAMENTO DAS PAREDES DO CÁLICE .............................. 54

2.4.9 MODELO DE PROJETO PROPOSTO POR CANHA (2004) .....................................................56

2.4.9.1 PROPRIEDADES GEOMÉTRICAS E RESULTANTES DE FORÇAS NO CÁLICE.......................... 56

2.4.9.2 CRITÉRIOS PARA O DIMENSIONAMENTO DAS ARMADURAS .................................................. 63

2.5 RESUMO DOS PRINCIPAIS PARÂMETROS DOS MODELOS DE PROJETO....................64

3 INVESTIGAÇÃO EXPERIMENTAL ............................................................68



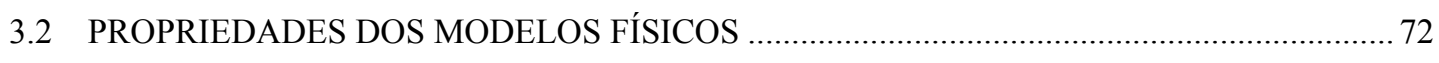

3.2.1 DIMENSIONAMENTO E DETALHAMENTO DAS ARMADURAS ..........................................72

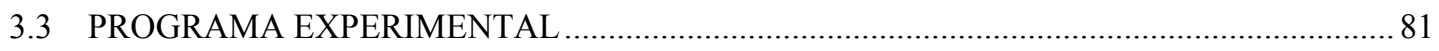

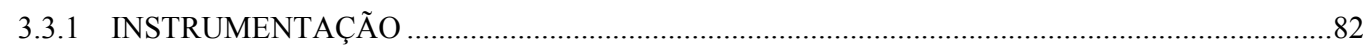

3.3.2 CONSTRUÇÃO DOS ELEMENTOS E MONTAGEM DOS PROTÓTIPOS .................................87

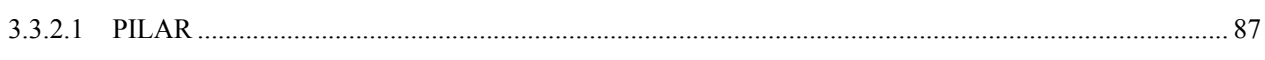

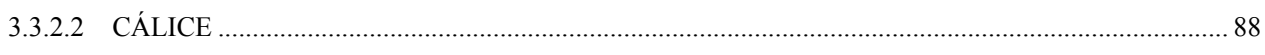

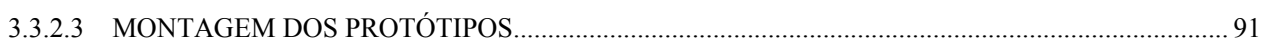

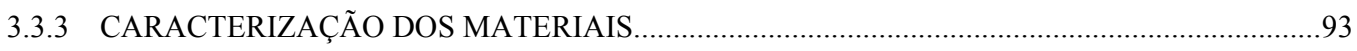

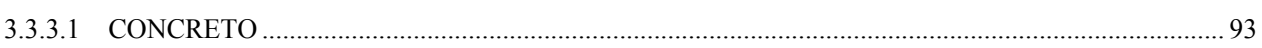

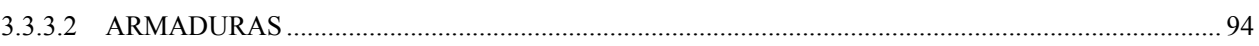

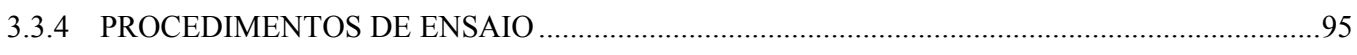

3.3.5 DISPOSITIVOS, INSTRUMENTOS E EQUIPAMENTOS UTILIZADOS NOS ENSAIOS.........98 
4 RESULTADOS E ANÁLISES

4.1 CICLOS DE PRÉ-CARREGAMENTO E ENVOLTÓRIAS. 101

4.2 RESISTÊNCIA DOS MODELOS E DESCOLAMETO ENTRE A JUNTA E OS ELEMENTOS DO MODELO IL4 102

4.3 COMPORTAMENTO DA REGIÃO SUPERIOR DA PAREDE TRANSVERSAL 1 ............. 106

4.3.1 DEFORMAÇÃO NA ARMADURA HORIZONTAL PRINCIPAL .................................................106

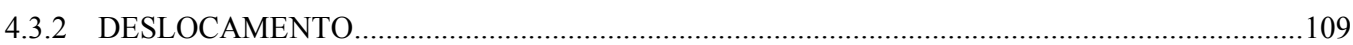

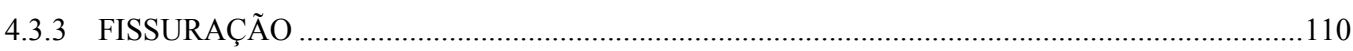

4.4 COMPORTAMENTO DA REGIÃO SUPERIOR DA PAREDE TRANSVERSAL 2 ….......... 111

4.4.1 DEFORMAÇÃO NA ARMADURA HORIZONTAL PRINCIPAL ..................................................111

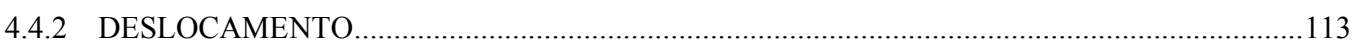



4.5 COMPORTAMENTO DA REGIÃO SUPERIOR DAS PAREDES LONGITUDINAIS 3 E 4

4.5.1 DEFORMAÇÃO NA ARMADURA HORIZONTAL PRINCIPAL ...............................................117

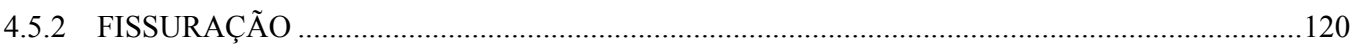

4.6 COMPORTAMENTO DAS ARMADURAS VERTICAIS PRINCIPAIS E SECUNDÁRIAS

4.6.1 FISSURAÇÃO

4.7 DESLOCAMENTO HORIZONTAL E VERTICAL DAS EXTREMIDADES DAS PAREDES LONGITUDINAIS 3 E 4

4.8 COMPORTAMENTO GERAL DOS MODELOS 129

4.8.1 COMPORTAMENTO CONJUNTO DAS ARMADURAS ………………………………….......129

4.8.2 ANÁLISE DA FISSURAÇÃO...................................................................................................131

5 ANÁLISE COMPARATIVA ENTRE OS MODELOS DAS SÉRIES IL E IR 137

5.1 CONSIDERAÇÕES INICIAIS 137

5.2 PROPRIEDADES FÍSICAS E GEOMÉTRICAS DOS MODELOS E A RESISTÊNCIA EXPERIMENTAL ALCANÇADA PELAS LIGAÇÕES.

5.3 COMPORTAMENTO DOS MODELOS NO QUE SE REFERE ÀS ARMADURAS DO COLARINHO

5.3.1 SÉRIE IL

5.3.2 SÉRIE IR.

5.4 APLICAÇÃO DOS MODELOS DE PROJETO DA LITERATURA NOS MODELOS FÍSICOS 
5.4.2 SÉRIE IR.

5.4.3 COMPARAÇÃO ENTRE AS RESISTÊNCIAS EXPERIEMNTAIS DOS PROTÓTIPOS.

6 CONSIDERAÇÕES FINAIS E CONCLUSÕES ...........................................160

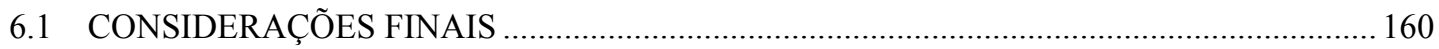

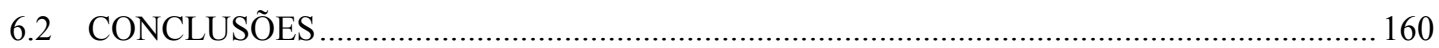

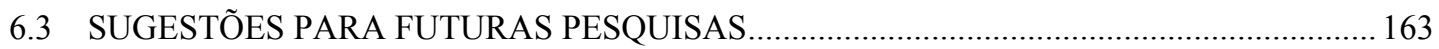

REFERÊNCIAS BIBLIOGRÁFICAS ............................................................. 164 


\section{LISTA DE TABELAS}

Tabela 2.1 - Valores de comprimento de embutimento segundo LEONHARDT \& MÖNNIG (1977) e NBR 9062: (1985) ................................................ 12

Tabela 2.2 - Coeficientes relativos a qualidade da interface - EUROCODE (2001).....51

Tabela 2.3 - Resumo dos principais parâmetros dos modelos de projeto ......................66

Tabela 3.1 - Resumo das propriedades geométricas dos modelos físicos ensaiados .....72

Tabela 3.2 - Propriedades mecânicas do concreto do cálice .......................................94

Tabela 3.3 - Propriedades mecânicas do concreto do pilar .......................................... 94

Tabela 3.4 - Propriedades mecânicas do concreto da junta............................................94

Tabela 3.5 - Propriedades mecânicas das armaduras ...................................................95

Tabela 3.6 - Equipamentos e instrumentos utilizados na investigação esperimental... 100

Tabela 4.1 - Resistência experimental dos modelos ensaiados ................................. 103

Tabela 5.1 - Resumo das propriedades geométricas dos modelos físicos ensaiados ... 138

Tabela 5.2 -Valores das principais armaduras do cálice ............................................ 140

Tabela 5.3 - Propriedades mecânicas do concreto dos elementos e da junta ................ 141

Tabela 5.4 - Propriedades mecânicas das principais armaduras do cálice ................... 141

Tabela 5.5 - Resistência experimental.............................................................. 141 


\section{RESUMO}

JAGUARIBE JR., K. B. (2005). Ligação pilar-fundação por meio de cálice em estruturas de concreto pré-moldado com profundidade de embutimento reduzida. São Carlos. Dissertação (Mestrado) - Escola de Engenharia de São Carlos, Universidade de São Paulo.

Este trabalho consiste na análise experimental da ligação pilar-fundação por meio de cálice em estruturas de concreto pré-moldado, com profundidade de embutimento reduzida em relação a recomendada pela NBR 9062: (1985). No programa experimental, foram ensaiados dois protótipos sob ação de força com grande excentricidade, variando-se o tipo e condição de interface: um com interface lisa e outro com interface rugosa. Em ambos os modelos, procurou-se eliminar a adesão na interface da ligação para representar a situação mais adequada de projeto. Com os resultados experimentais, foi possível analisar o comportamento da cada modelo no que diz respeito as deformações nas armaduras, os deslocamentos no cálice, a configuração das fissuras ocorridas durante o ensaio e a resistência última alcançada por cada modelo. Foi apresentada também uma análise comparativa entre estes modelos e os analisados em trabalho anterior sobre o mesmo tema, sendo que nestes os cálices possuíam profundidades de embutimento recomendados pela norma brasileira. Aplicou-se também os principais modelos de projeto encontrados na literatura com o objetivo de verificar a eficácia de cada um no que diz respeito a capacidade resistente da ligação, comparando-a aos obtidos experimentalmente. Com base em todas estas análises, pôdese concluir que com a redução da profundidade de embutimento a capacidade resistente do protótipo também diminuiu e os modelos de projeto que melhor representaram os protótipos com comprimento de embutimento maior, não forneceram bons resultados para os cálices com profundidade reduzida.

Palavras-chave: ligação, cálice de fundação, concreto pré-moldado, colarinho, chave de cisalhamento, investigação experimental, profundidade de embutimento. 


\section{ABSTRACT}

JAGUARIBE JR., K. B. (2005). Column-foundation connection through socket of precast concrete structures with reduced depth. São Carlos. Dissertação (Master Degree Thesis) - Escola de Engenharia de São Carlos, Universidade de São Paulo.

This research is an experimental analysis of column-foundation connection through socket of precast concrete structures, with the reduced depth of the socket comparing to that recommended by the NBR 9062: (1985). The experimental program included two models submitted to normal load with large eccentricity, changing the type and the condition interface: one model had smooth interface and other had rough interface. At both models, it was tried to eliminate the bond on the interface to represent the more appropriate situation of design. With the experimental results, it was possible to analyze each model behavior concerning reinforcements deformation, the socket displacement, cracks configuration during the tests and the maximum strength reached by each model. A comparative analysis was made of these models with those studied at a previous research, that had a depth of the socket recommended by the Brazilian normalization. The main design models found at the technical literature were also applied to verify the efficiency of each one for strength capacity of the connection, comparing the results with those obtained experimentally. Based on all analysis, it was possible to conclude that with the depth reduction of the socket, the strength capacity also reduced and the design models that better represented the sockets with the recommended depth no more represented the reduced one.

Keywords: connection, socket foundation, precast concrete, pedestal walls, shear keys, experimental investigation, socket depth. 


\section{INTRODUÇÃO}

\subsection{CONSIDERAÇÕES INICIAIS}

A principal diferença entre uma estrutura pré-moldada e a moldada no local é a existência de ligações entre seus elementos, nas quais são realizadas na obra. Estas ligações constituem um ponto delicado no que se refere ao dimensionamento e montagem dessas estruturas, por possuírem grande influência no comportamento estrutural das mesmas. Em outras palavras, pode-se dizer que o comportamento de um sistema estrutural de concreto pré-moldado está diretamente relacionado ao conhecimento do comportamento de suas ligações, que são responsáveis, entre outros, pela redistribuição dos esforços da estrutura.

O que impede a superação dos métodos construtivos convencionais pelos prémoldados, conforme alguns especialistas, é o fato da influência das ligações na construção pré-moldada ser predominante por causa da dificuldade em seu projeto e em sua execução. Por isso é que estas ligações merecem uma especial atenção por parte dos pesquisadores com o intuito de melhor compreender esse assunto, e assim, colaborar para que este tipo de estrutura ganhe um maior espaço no mercado da construção civil.

No que se refere à transmissão de carga para fundação, a ligação pilar-fundação por meio de cálice é uma das mais empregadas no Brasil e bastante utilizada no mundo inteiro. Este tipo de ligação apresenta facilidades de montagem, boa transmissão de momentos e facilidades de ajustes.

Neste trabalho será dado continuidade a pesquisa de doutorado realizado por CANHA (2004) referente a ligação pilar-fundação por meio de cálice em estruturas prémoldadas, onde serão apresentados resultados teóricos e experimentais de modelos físicos utilizando comprimentos (ou profundidades) de embutimento inferiores aos recomendados na norma brasileira, podendo assim avaliar o comportamento desses cálices e sua possível utilização para projetos. 


\subsection{OBJETIVO}

O objetivo principal desta pesquisa consiste em aprimorar o conhecimento a respeito do comportamento da ligação pilar-fundação por meio de cálice em estruturas pré-moldadas, por intermédio de ensaios em modelos físicos, fornecendo com isso resultados experimentais e dando continuidade às pesquisas realizadas sobre o mesmo tema.

Este trabalho tem como objetivo específico, a partir desses resultados experimentais e com os obtidos dos modelos físicos analisados na pesquisa de doutorado de CANHA (2004), avaliar o comportamento de transferência de ações do pilar para as paredes do cálice com comprimentos de embutimento menores que os recomendados pela NBR 9062: (1985).

\subsection{JUSTIFICATIVA}

Conforme foi dito, a ligação pilar-fundação por meio de cálice é bastante utilizada no mundo inteiro e uma das mais empregadas no Brasil. Apesar disso, existe uma carência de resultados experimentais e um modelo de projeto mais consistente baseado em pesquisas experimentais, principalmente no que diz respeito aos valores do comprimento de embutimento do pilar no cálice de fundação recomendados na literatura técnica.

Este trabalho se justifica por aumentar a quantidade de dados disponíveis referentes ao funcionamento desta ligação, podendo-se avaliar a influência das armaduras do colarinho, da rugosidade da ligação e principalmente de uma possível utilização de comprimento de embutimento menores que os indicados nas normas, tornando o dimensionamento da ligação menos conservativo. Com isso, dá-se continuidade aos estudos a respeito de ligações em estruturas de concreto pré-moldado no Departamento de Engenharia de Estruturas da EESC-USP, contribuindo assim, para o meio técnico e acadêmico.

\subsection{METODOLOGIA}

Para atingir os objetivos mencionados, a seguinte metodologia foi utilizada: 
a) Revisão bibliográfica

Por meio da revisão bibliográfica foi feito um levantamento dos principais modelos teóricos e experimentais a respeito da ligação pilar-fundação por meio de cálice em estruturas pré-moldadas, incluindo a pesquisa mais recente sobre o assunto.

\section{b) Ensaios físicos}

Foram realizados ensaios físicos em dois protótipos na escala 1:1 com grande excentricidade, variando a altura do colarinho, com valores inferiores aos recomendados na NBR 9062: (1985), e as condições de interface, lisa e rugosa.

c) Apresentação e análise dos resultados

Os resultados experimentais dos protótipos ensaiados foram apresentados e analisados levando em consideração o comportamento das armaduras, os deslocamentos sofridos pelo modelo, o desenvolvimento das fissuras e a capacidade resistente alcançada por cada protótipo.

d) Comparação com os resultados dos modelos ensaiados por CANHA (2004)

A partir dos resultados obtidos neste trabalho, foram feitas algumas análises comparativas entre esses resultados e o os obtidos por CANHA (2004) cujos protótipos possuíam comprimentos de embutimento recomendados pela NBR 9062: (1985). Por último, aplicaram-se em todos os protótipos os principais modelos de projeto apresentados na revisão bibliográfica de forma a avaliar sua aplicação e também a possibilidade de utilização nos modelos analisados neste trabalho.

\subsection{APRESENTAÇÃO DA DISSERTAÇÃO}

No Capítulo 1, são apresentados os objetivos, as justificativas e a metodologia para desenvolvimento desta pesquisa.

O Capítulo 2 ilustra inicialmente os principais tipos de ligação pilar-fundação e posteriormente apresentam-se as propriedades da ligação por meio de cálice assim como as variáveis que influem no seu comportamento. Por final, são ilustrados os principais modelos de projeto encontrados na literatura.

No Capítulo 3 são descritos todos os aspectos da pesquisa experimental, tais 
como: definições das variáveis, detalhamento, instrumentação, seqüência executiva, caracterização dos materiais, procedimento de ensaio, entre outros.

São apresentados no Capítulo 4 os resultados obtidos da investigação experimental, tais como: deformações nas armaduras, deslocamentos observados nos modelos e as fissuras surgidas durante o ensaio.

No Capítulo 5 é feita a comparação entre os modelos analisados nessa pesquisa com os modelos estudados anteriormente no que diz respeito as armaduras, a capacidade resistente e também a aplicação dos modelos de projeto, apresentados no Capítulo 2, nos modelos que compõe a Série IL (Interface Lisa) e IR (Interface Rugosa).

E por último, no Capítulo 6, são apresentadas as considerações finais, as conclusões e algumas sugestões para futuras pesquisas relacionadas ao cálice de fundação. 


\section{REVISÃO BIBLIOGRÁFICA}

\subsection{LIGAÇÃO PILAR-FUNDAÇÃO}

Esta classe de ligação, como qualquer outra, tem a finalidade de transmitir ações entre seus elementos (pilar e estrutura de fundação), sendo projetadas para transferir forças verticais, horizontais e momentos.

Existem basicamente quatro tipos de ligações entre o pilar e a fundação, apresentados na Figura 2.1.

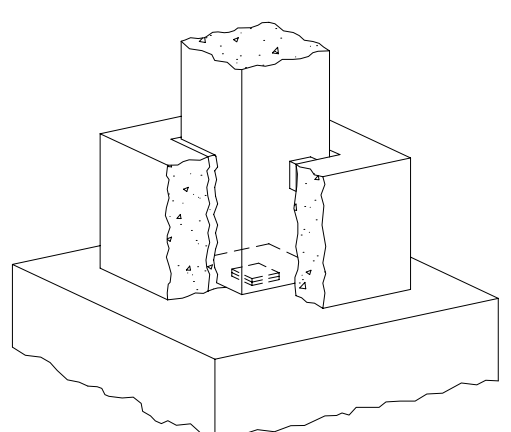

Cálice

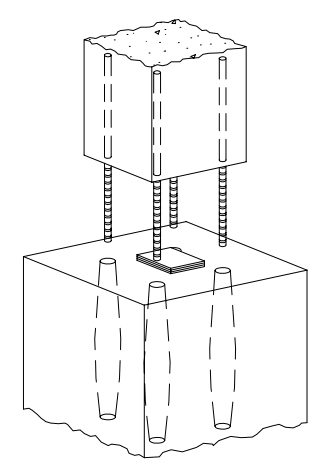

Emenda da armadura com bainha e graute

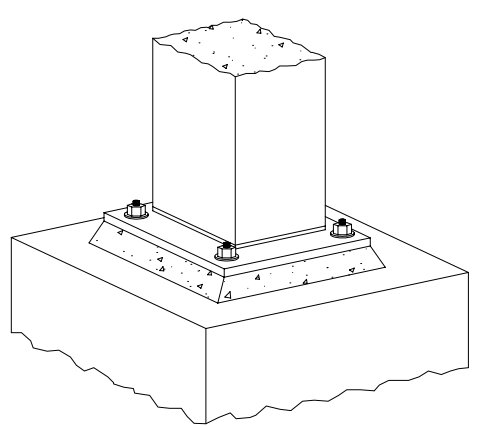

Chapa de base

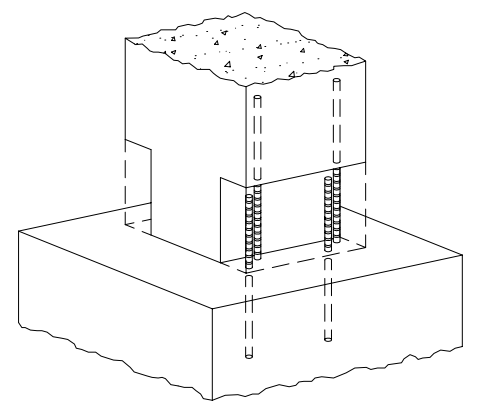

Emenda da armadura saliente e concretagem posterior

Figura 2.1 - Tipos de ligações pré-moldadas pilar fundação - PCI (1988) adaptado por CANHA (2004)

A ligação por meio de cálice é realizada embutindo-se um trecho do pilar 
(comprimento de embutimento) em uma abertura do elemento de fundação que possibilite o seu encaixe. Algumas variantes dessa ligação serão mostradas no item seguinte. Após a colocação do pilar a ligação é efetivada com o preenchimento, com concreto ou graute, do espaço remanescente entre o pilar e o cálice. O posicionamento do pilar em planta e em nível é feito por meio de dispositivos de centralização, sendo que a fixação temporária, antes da concretagem da junta, é feita por intermédio de cunhas dispostas nos quatro lados do cálice, impedindo assim, que o pilar se desloque do centro da ligação.

$\mathrm{Na}$ ligação por meio de chapa de base, as forças atuantes no pilar são transmitidas para a fundação por meio de uma chapa metálica soldada na base do pilar unida a sua armadura principal, que por sua vez é encaixada em chumbadores dispostos no elemento de fundação. O nível e o prumo do pilar são ajustados por um sistema de porcas e contra-porcas. $\mathrm{O}$ espaço entre a chapa e o elemento de fundação é preenchido com argamassa seca ou graute.

No caso da ligação por emenda da armadura com graute e bainha, a armadura do pilar ou da fundação projeta-se para fora do elemento. A ligação é executada a partir da penetração da armadura em bainha previamente colocada no elemento adjacente, que posteriormente será preenchida com graute, bem como o espaço entre o pilar e a fundação, sendo que neste caso, é necessário o escoramento provisório para a concretagem da ligação.

Outro tipo de ligação pilar-fundação é mediante a união por meio de solda ou com acopladores da armadura saliente do pilar com a armadura saliente da fundação. Após a montagem, faz-se a concretagem da emenda.

\subsection{ASPECTOS GERAIS DO CÁLICE DE FUNDAÇÃO}

As principais vantagens na utilização deste tipo de ligação são:

- Rapidez na etapa de montagem;

- Facilidade nos ajustes aos desvios de execução, por ser menos sensível às imprecisões de projeto;

- Boa capacidade de transmissão de forças normais e momentos fletores, com um comportamento próximo ao de uma ligação monolítica; 
- Não requer cuidados especiais com agentes corrosivos e em relação ao fogo, pelo fato de não ter armaduras expostas neste tipo de ligação.

Como principais desvantagens têm-se:

- Esse tipo de fundação é usualmente escondida por ser bastante pronunciada;

- Só é possível o uso em divisas quando houver uma determinada distância entre o pilar e a divisa;

- Há a necessidade de maiores cuidados na concretagem da cavidade de encaixe, principalmente na vibração do concreto.

Algumas variantes dessa ligação estão apresentadas na Figura 2.2.

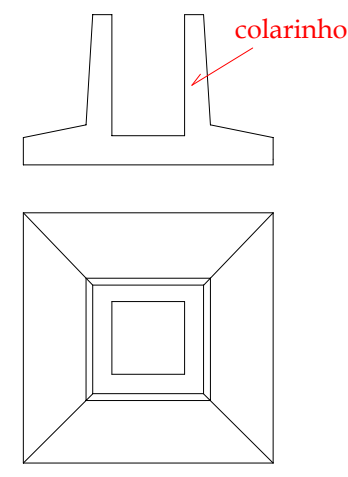

sapata

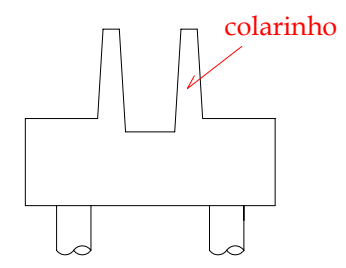

sobre o bloco

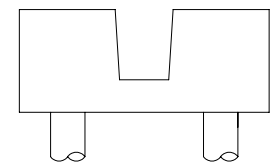

embutido no bloco

bloco sobre estacas

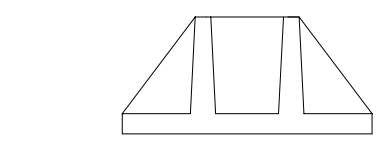

nervuras

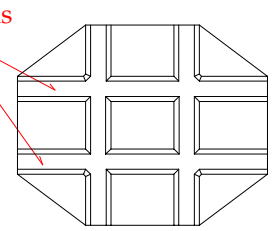

com nervuras e sapata
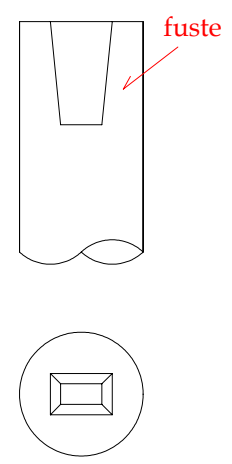

embutido no fuste de tubulão

Figura 2.2 - Formas do cálice de fundação - EL DEBS (2000)

Estas ligações são diferenciadas pelo tipo de fundação e pela presença ou não de colarinho. A escolha do tipo de ligação está relacionada com as forças a serem transmitidas por esta. Vale lembrar que este trabalho é direcionado para os tipos de 
cálice com colarinho.

\subsection{AÇÕES TRANSMITIDAS NA LIGAÇÃO}

No que se refere às forças atuantes na ligação, a Figura 2.3 ilustra o mecanismo de transferência destas forças para as paredes do cálice, considerando interface lisa entre o pilar e o colarinho.

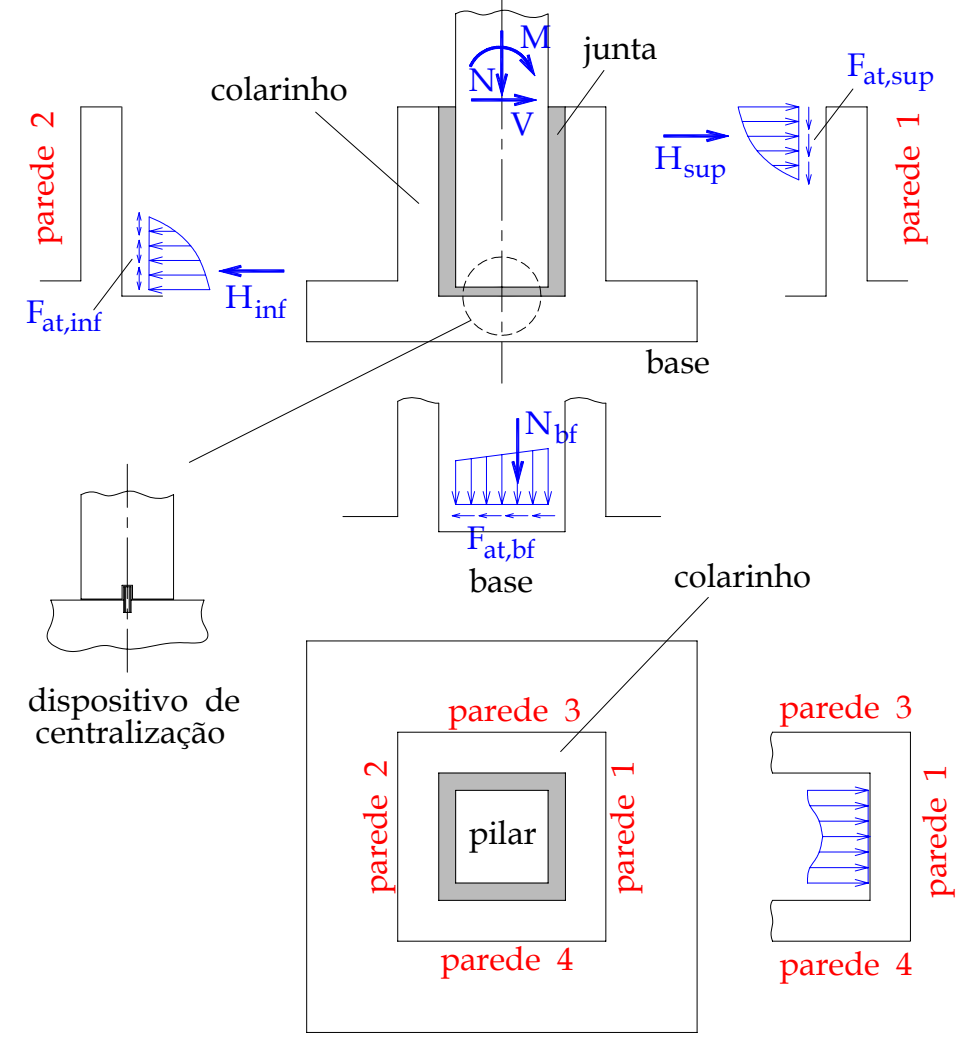

Figura 2.3 - Transferência das ações no cálice de fundação com interface lisa - EL DEBS (2000) adaptado por CANHA (2004)

Basicamente, as solicitações $M$ e $V$ são transferidas para as paredes transversais 1 e 2 por meio das resultantes de pressões $H_{\text {sup }}$ e $H_{i n f}$. Essas resultantes, por sua vez, mobilizam forças de atrito nas paredes transversais 1 e 2 , sendo que o sentido dessas forças, na parede transversal 1 , é sempre o mesmo da força normal, enquanto na parede 2, está vinculado com a relação entre as solicitações e a geometria.

A força normal $N$ é reduzida pelas forças de atrito, ou seja, é transmitido para a base do cálice apenas a parcela resultante desta redução.

Todo esse mecanismo de transferência de ações na ligação se dá por meio do 
concreto de preenchimento, que, no entanto, deve ter qualidade equivalente ou superior à do concreto do pilar, segundo LEONHARDT \& MÖNNIG (1977).

As forças atuantes na parede transversal 1 , são então transferidas para as paredes longitudinais 3 e 4, como mostra a Figura 2.4 (a), pois estas possuem uma maior rigidez para transmitir as ações para a base. As paredes 3 e 4, por sua vez, se comportam como consolos engastados na fundação (Figura 2.4(b)), sendo dimensionadas como tal.

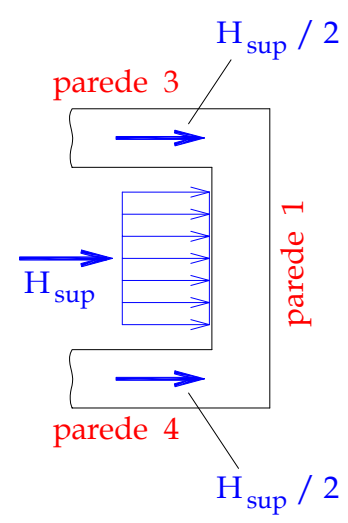

(a)

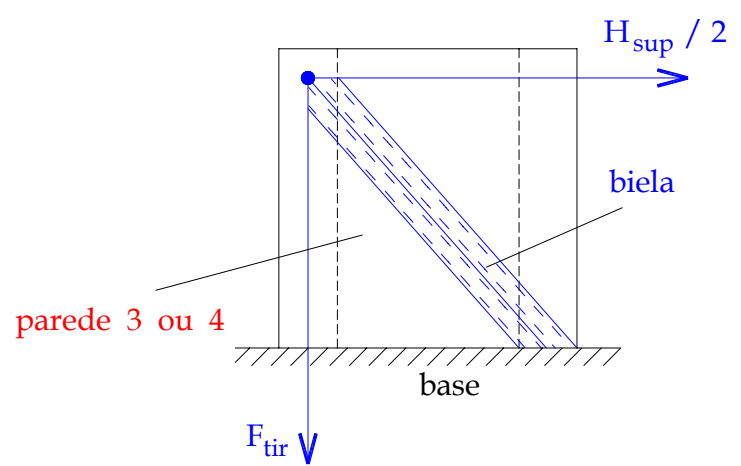

(b)

Figura 2.4 - Transferência dos esforços no colarinho - LEONHARDT \& MÖNNIG (1977) adaptado por EL DEBS (2000)

Quanto a transferência de forças para a parede transversal 2, pode-se considerar que, em virtude da pequena distância entre a resultante de pressão e a base, essa pressão é transmitida diretamente para a base.

Para melhorar a transferência das forças, utiliza-se o artifício da rugosidade entre as faces externas do pilar e as paredes internas do colarinho, conforme mostra a Figura 2.5 .



Figura 2.5 - Emprego de rugosidade no pilar e no cálice - EL DEBS (2000)

Com isso, além das forças de atrito geradas pelas pressões horizontais, há 
também a transmissão das forças por dentes de cisalhamento praticamente em toda altura das paredes 1 e 2 e uma transmissão do cisalhamento diretamente para as paredes longitudinais 3 e 4 . Além disso, a força normal é transmitida para a base da fundação na área correspondente ao pilar mais o colarinho, diminuindo assim o efeito da punção na base da sapata. Portanto, pode-se dizer que há um funcionamento conjunto do pilar com a fundação.

\subsection{ESTUDOS EXPERIMENTAIS E MODELOS DE PROJETO}

\subsubsection{RECOMENDAÇÕES DE PROJETO SEGUNDO LEONHARDT \& MÖNNIG (1977), NBR 9062: (1985) E EL DEBS (2000)}

Serão mostradas a seguir as principais recomendações para o dimensionamento do cálice de fundação segundo LEONHARDT \& MÖNNIG (1977) e NBR 9062: (1985), com o objetivo de abranger e comparar os parâmetros referentes a cada um deles. Serão também acrescentadas algumas sugestões apresentadas em EL DEBS (2000).

\subsubsection{Propriedades geométricas e resultantes de forças no cálice}

$\mathrm{Na}$ Figura 2.6, estão ilustradas as propriedades geométricas do cálice de fundação e as resultante das pressões atuantes no colarinho.

A NBR 9062: (1985) determina que as faces externas do pilar tanto quanto as internas do cálice devem ter a mesma característica superficial. O espaçamento entre o pilar e o colarinho $h_{j}$ deve ser projetado levando em conta o equipamento de vibração que será utilizado na concretagem, com o valor mínimo recomendável de $50 \mathrm{~mm}$, exceto quando o graute for autoadensável. Quanto a espessura do colarinho $h_{c}$, em LEONHARDT \& MÖNNIG (1977) recomenda-se que seja maior ou igual a $1 / 3$ da menor distancia interna entre as paredes do colarinho $\left(h_{i n t}\right.$ ou $\left.b_{i n t}\right)$, e no mínimo igual a $100 \mathrm{~mm}$. De acordo com a NBR 9062: (1985), a espessura da base do cálice $\ell_{b f}$ não deve ser inferior a $200 \mathrm{~mm}$ e o comprimento de embutimento $\ell_{e m b}$ a $400 \mathrm{~mm}$.

No que se refere ao dimensionamento, os elementos de fundação devem ser calculados para resistir à totalidade das forças verticais e horizontais e dos momentos transmitidos pelos pilares. 


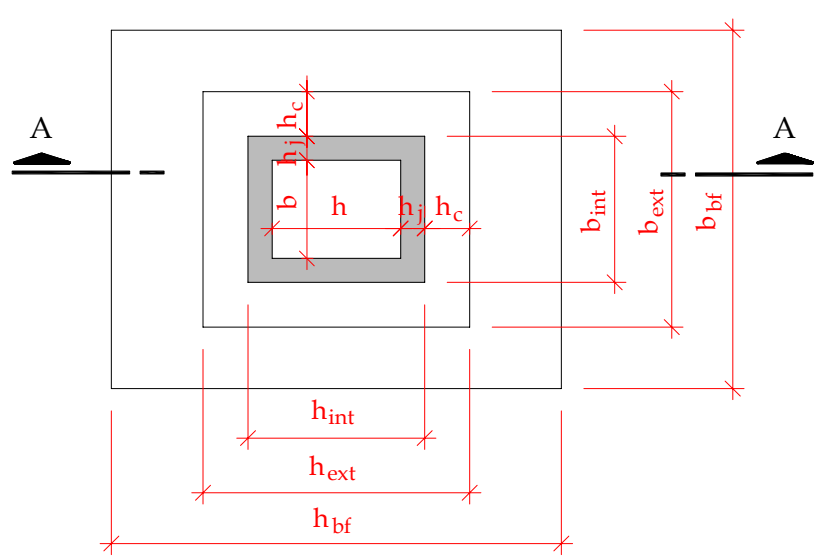

PLANTA

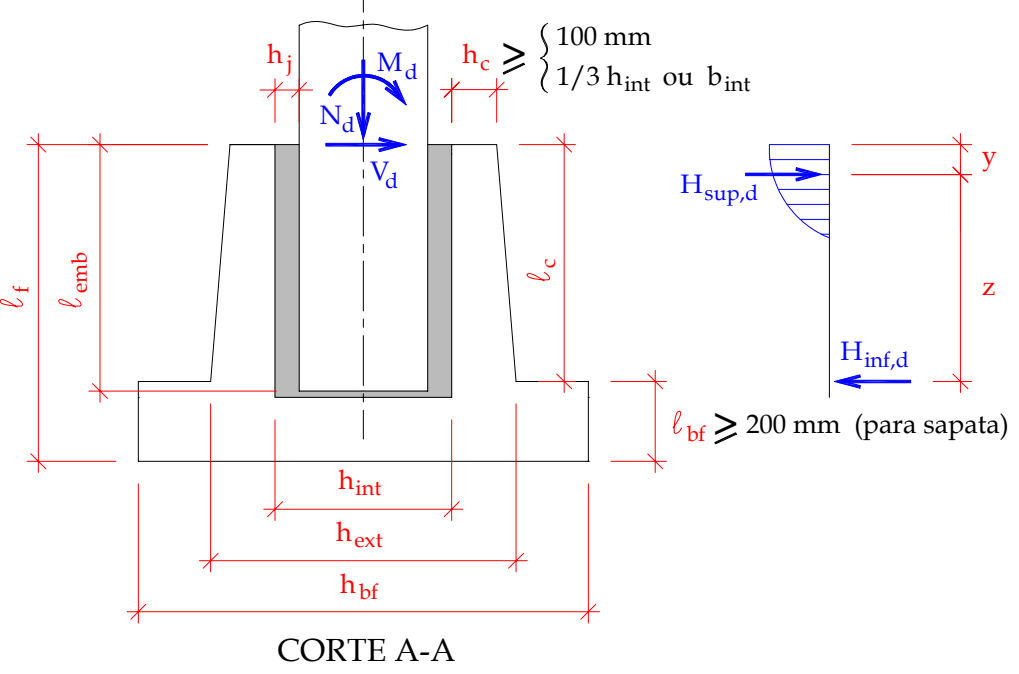

Figura 2.6 - Propriedades geométricas e resultantes de forças no cálice - EL DEBS (2000) adaptado por CANHA (2004)

O modelo proposto por LEONHARDT \& MÖNNIG (1977) apresentado na Figura 2.7 tem muita aceitação no meio técnico, apesar de levar a resultados conservativos.

Este modelo considera separadamente dois casos limites quanto à conformação das superfícies das paredes do pilar e do colarinho: muito rugosa e lisa. Isto significa que não são considerados no cálculo as forças de atrito que foram apresentadas na Figura 2.3, ou seja, não se pode dimensionar, por meio deste modelo uma situação intermediária utilizando valores diferentes de coeficientes de atrito. No entanto, no modelo com interface rugosa, admite-se que a resultante de pressão inferior $H_{i n f, d}$ é concentrada e se transmite ao fundo da parede transversal 2 (Figura 2.3), conseqüentemente aumentando a distância entre as forças e reduzindo assim a intensidade das resultantes de pressão. Isto se deve pelo fato do atrito desenvolvido pela 
reação vertical na base $F_{a t, b f}$ (Figura 2.3) compensar a resultante de pressão inferior $H_{i n f, d}$.

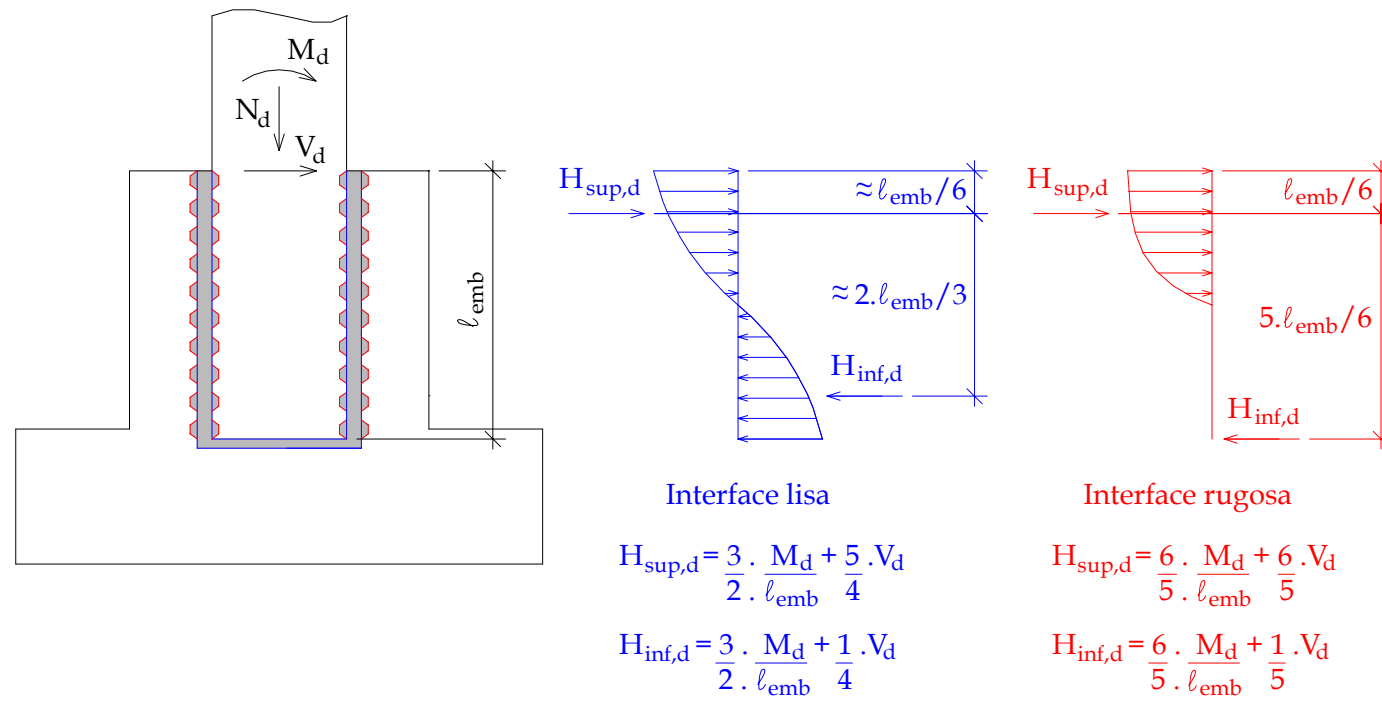

Figura 2.7 - Ações no colarinho conforme o modelo de LEONHARDT \& MÖNNIG (1977) adaptado por CANHA (2004)

A única diferença desse modelo para o da NBR 9062: (1985) é que neste, o ponto de aplicação de $H_{\text {sup,d }}$ correspondente a interface rugosa é de $0,15 \ell_{e m b}$ da parte superior do colarinho.

Quanto ao comprimento de embutimento mínimo do pilar, as recomendações segundo a NBR 9062: (1985) e LEONHARDT \& MÖNNIG (1977) estão apresentadas na Tabela 2.1, para pequena e grande excentricidade, sendo que para valores intermediários deve-se ser feito a interpolação. Verifica-se que os valores recomendados por LEONHARDT \& MÖNNIG (1977) são mais conservativos, exceto para interface rugosa com pequena excentricidade.

Tabela 2.1 - Valores de comprimento de embutimento segundo LEONHARDT \& MÖNNIG (1977) e NBR 9062: (1985)

\begin{tabular}{|c|c|c|c|c|}
\hline \multirow{3}{*}{ Paredes } & \multicolumn{2}{|c|}{$M_{d} / N_{d} \leq 0,15 h$} & \multicolumn{2}{c|}{$M_{d} / N_{d} \geq 2,00 h$} \\
\cline { 2 - 5 } & $\begin{array}{c}\text { NBR 9062: } \\
(1985)\end{array}$ & $\begin{array}{c}\text { LEONHARDT \& } \\
\text { MÖNNIG (1977) }\end{array}$ & $\begin{array}{c}\text { NBR 9062: } \\
(1985)\end{array}$ & $\begin{array}{c}\text { LEONHARDT \& } \\
\text { MÖNNIG (1977) }\end{array}$ \\
\hline Lisas & $1,50 h$ & $1,68 h$ & $2,00 h$ & $2,80 h$ \\
\hline Rugosas & $1,20 h$ & $1,20 h$ & $1,60 h$ & $2,00 h$ \\
\hline
\end{tabular}




\subsubsection{Comportamento e dimensionamento das paredes do cálice}

Como foi dito no item 2.3, as forças atuantes na parede transversal 1 , são transferidas para as paredes longitudinais 3 e 4 , e estas, por sua vez, se comportam como consolos engastados na fundação transferindo as ações diretamente para a base, seguindo o modelo de consolo.

Por consequência da elevada rigidez à flexão das paredes longitudinais 3 e 4, e admitindo que a pressão inferior na parede transversal 2 seja transferida diretamente para a base da fundação, apenas a parede transversal $l$ é solicitada significantemente à flexão. Isto ocorre apenas nas paredes lisas, não se aplicando portanto para o caso de interfaces rugosas. Baseado na antiga Norma Italiana CNR-10025 (1984), é apresentado em EL DEBS (2000) um procedimento para o dimensionamento da armadura de flexão $A_{s, h f t}$ como ilustra a Figura 2.8 .



Figura 2.8 - Flexão e disposição da armadura $A_{s, h f t}$ na parte superior da parede transversal 1 EL DEBS (2000)

De acordo com o modelo, a flexão que ocorre na parede transversal 1 se desenvolve apenas numa faixa equivalente a $\ell_{e m b} / 3$, e a partir dos momentos fletores calculados para esta faixa, determina-se a armadura $A_{s, h f t}$ a ser disposta nessa mesma região. Recomenda-se ainda que a tensão de contato, nesta parte, seja limitada a $0,6 f_{c d}$. As paredes longitudinais 3 e 4 são dimensionadas como consolo, a partir da força $H_{\text {sup,d }}$ transmitida pela parede transversal 1 . 
A Figura 2.9 ilustra o esquema da distribuição das armaduras no cálice de fundação e também a nomenclatura que será utilizada em todo este trabalho.

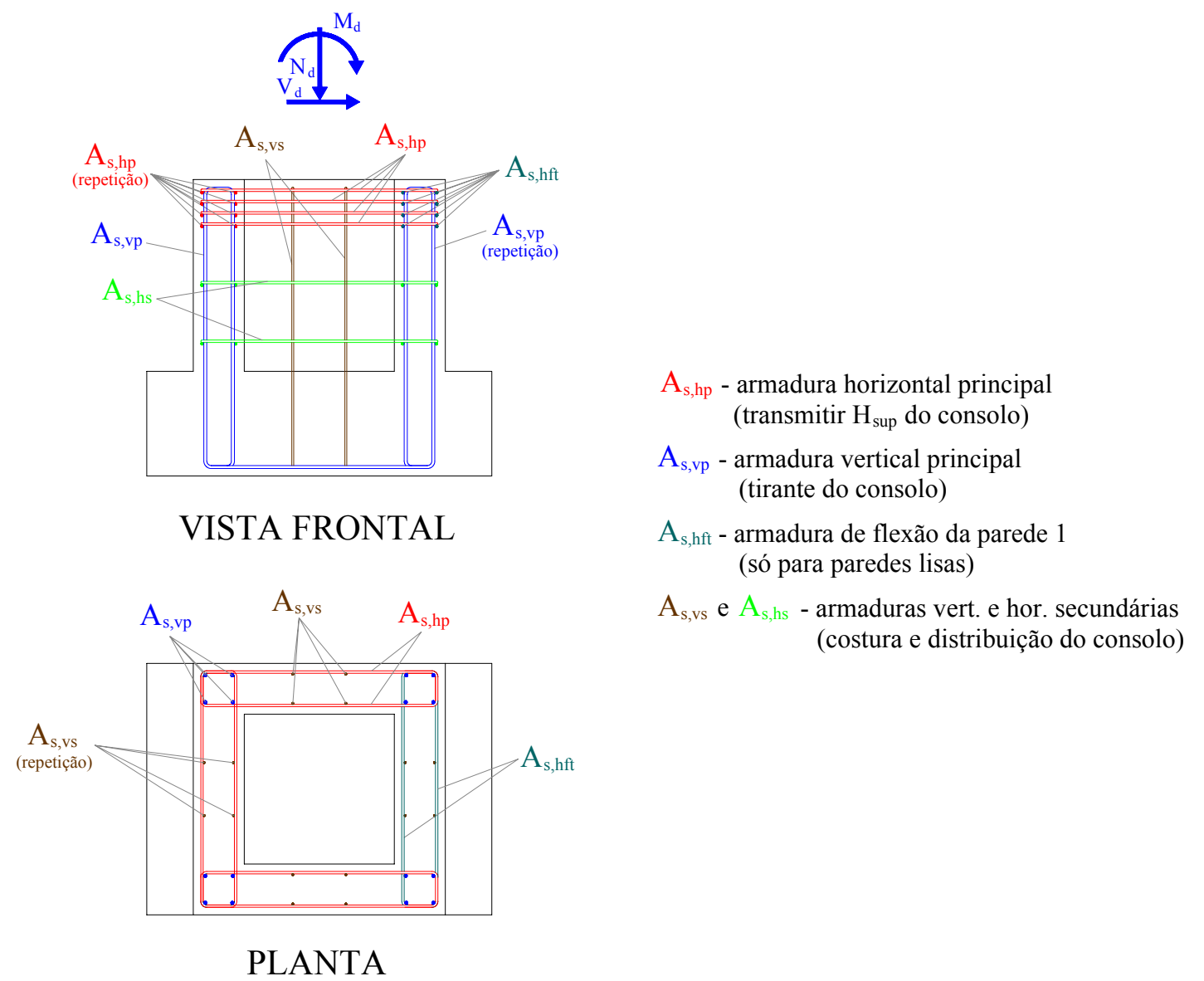

Figura 2.9 - Esquema das principais armaduras do cálice

Este arranjo é utilizado tanto para interface lisa quanto rugosa, com exceção da armadura localizada no topo da parede transversal 1, que como foi comentado, só se aplica para o caso de ligação com interface lisa.

A armadura horizontal principal $A_{s, h p}$ responsável pela transmissão da força $H_{\text {sup,d }}$ por intermédio das paredes longitudinais 3 e 4 , é distribuída igualmente entre estas paredes e é calculada conforme:

$$
A_{s, h p}=\frac{H_{s u p, d}}{2 f_{y d}}
$$

onde deve ser disposta em uma altura igual a $2 y$, sendo $y$ a distância entre a extremidade superior da parede transversal 1 e a resultante de pressão $H_{\text {sup,d }}$ (Figura 2.6). 
A determinação das outras armaduras tais como: armadura vertical principal, armaduras verticais e horizontais secundárias dependem do tipo de consolo que se aplicará para as paredes longitudinais 3 e 4. Para cada tipo de consolo, há um determinado modelo para o cálculo dessas armaduras. Os três tipos de consolos e seus respectivos modelos de cálculo são:

- Consolo curto $(1 \geq \operatorname{tg} \beta \geq 0,5)$ : Modelo de bielas e tirantes;

- Consolo muito curto $(\operatorname{tg} \beta \leq 0,5)$ : Modelo de atrito-cisalhamento;

- Consolo longo ( $\operatorname{tg} \beta \geq 1$ ): Modelo da teoria de flexão.

Pelo fato da maioria dos casos recaírem em consolo curto, neste trabalho será apresentado apenas o modelo de bielas e tirantes para o dimensionamento das paredes longitudinais 3 e 4 , já que os outros dois modelos (modelo de atrito-cisalhamento e modelo da teoria de flexão) estão bem demonstrados em CANHA (2004).

As indicações do modelo de bielas e tirantes aplicadas ao consolo curto estão ilustradas na Figura 2.10.

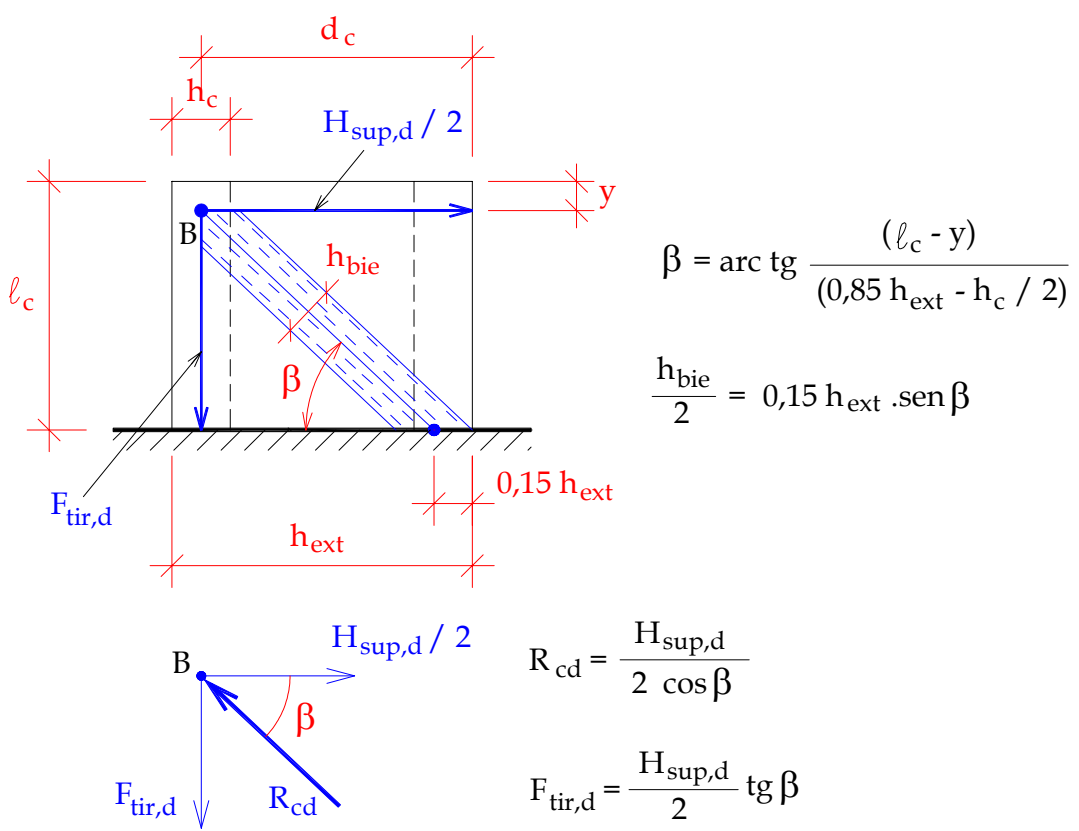

Figura 2.10 - Indicações para o dimensionamento das paredes 3 e 4 como consolo curto - EL DEBS (2000)

Com isso, pode-se determinar a armadura vertical principal $\left(A_{s, v p}\right)$ e verificar o esmagamento na biela comprimida por meio das seguintes equações: 


$$
\begin{aligned}
& A_{s, v p}=\frac{F_{t i r, d}}{f_{y d}} \\
& \sigma_{c d}=\frac{R_{c d}}{h_{b i e} \cdot h_{c}} \leq 0,85 \cdot f_{c d}
\end{aligned}
$$

Deve-se ainda determinar as armaduras verticais e horizontais secundárias ( $A_{s, v s}$ e $A_{s, h s}$ ), ou seja, armaduras de costura e distribuição do consolo, distribuídas nas paredes longitudinais 3 e 4 conforme as seguintes equações:

$$
\begin{aligned}
& A_{s, v s}=0,4 \cdot A_{s, v p} \\
& A_{s, h s} \geq\left\{\begin{array}{l}
0,15 \% h_{c} \cdot h_{e x t} \\
0,2 \cdot A_{s, v p}
\end{array}\right.
\end{aligned}
$$

Estas armaduras são também distribuídas nas paredes transversais 1 e 2 .

\subsubsection{Arranjo das armaduras do cálice}

O arranjo das armaduras está ilustrado na Figura 2.11 para as situações de grande e pequena excentricidade.

A armadura $A_{s, h f t}$, calculada apenas para interface lisa, conforme já mencionado, deve ser disposta no topo da parede transversal 1 numa altura igual a $\ell_{e m b} / 3$, adotandose a maior entre $A_{s, h f t}$ e $A_{s, h p}$. Resumidamente, calculam-se as áreas das armaduras, escolhe-se a maior entre elas e as distribuem igualmente nas quatro paredes do cálice.

Conforme LEONHARDT \& MÖNNIG (1977), para interface rugosa, quando se dispuser de comprovações experimentais, a armadura $A_{s, h p}$ pode ser reduzida por causa da aderência mecânica entre o pilar e o colarinho, causando uma inclinação na biela de compressão $(\beta)$ em relação a horizontal maior que a considerada no cálculo do consolo, como indica a Figura 2.12. Além disso, nas paredes transversais deve ser disposta a mesma armadura $A_{s, h p}$ calculada para as paredes longitudinais 3 e 4 , embora, em virtude também da aderência mecânica, somente parte de $H_{\text {sup,d }}$ atue no topo da parede transversal 1 , formando-se nessa região um arco atirantado. 
O espaçamento entre as armaduras secundaria $A_{s, v s}$ e $A_{s, h s}$ deve ser entre $15 \mathrm{~cm}$ a $30 \mathrm{~cm}$.

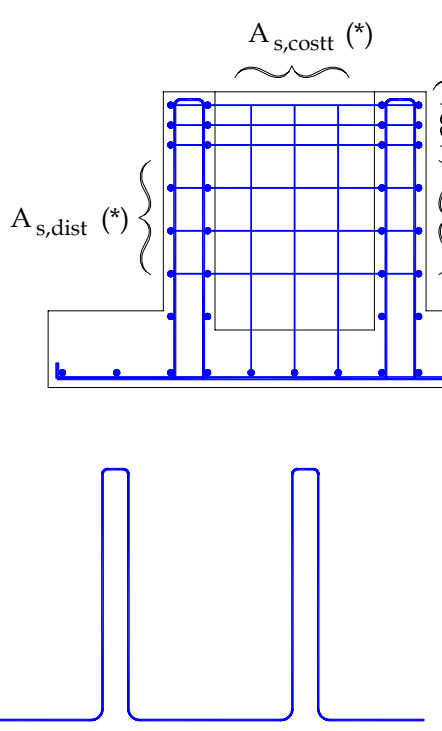

Alternativa 1

não é necessário superpor

$$
\text { superpor }
$$

$A_{\text {s, hsup }}$

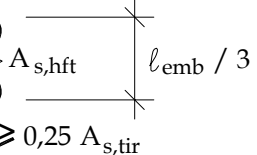

$\mathrm{A}_{\mathrm{s}, \mathrm{dist}} \geqslant 0,25 \mathrm{~A}_{\mathrm{s} \text {, tir }}$

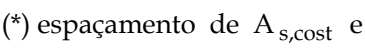

$A_{\text {s,dist }}$ de 150 a $300 \mathrm{~mm}$

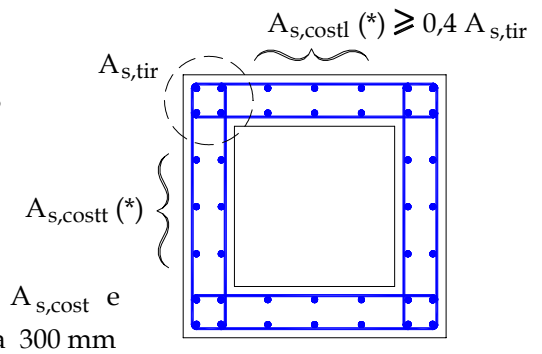

armadura disposta na direção vertical

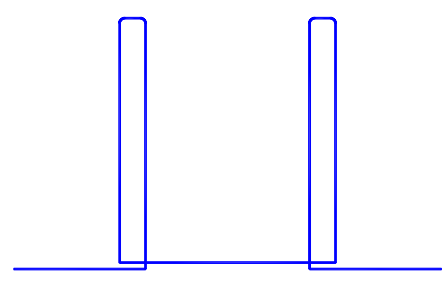

Alternativa 2

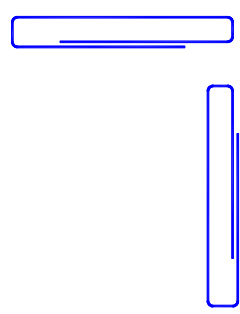

armadura disposta na direção horizontal

\section{Situação geral}
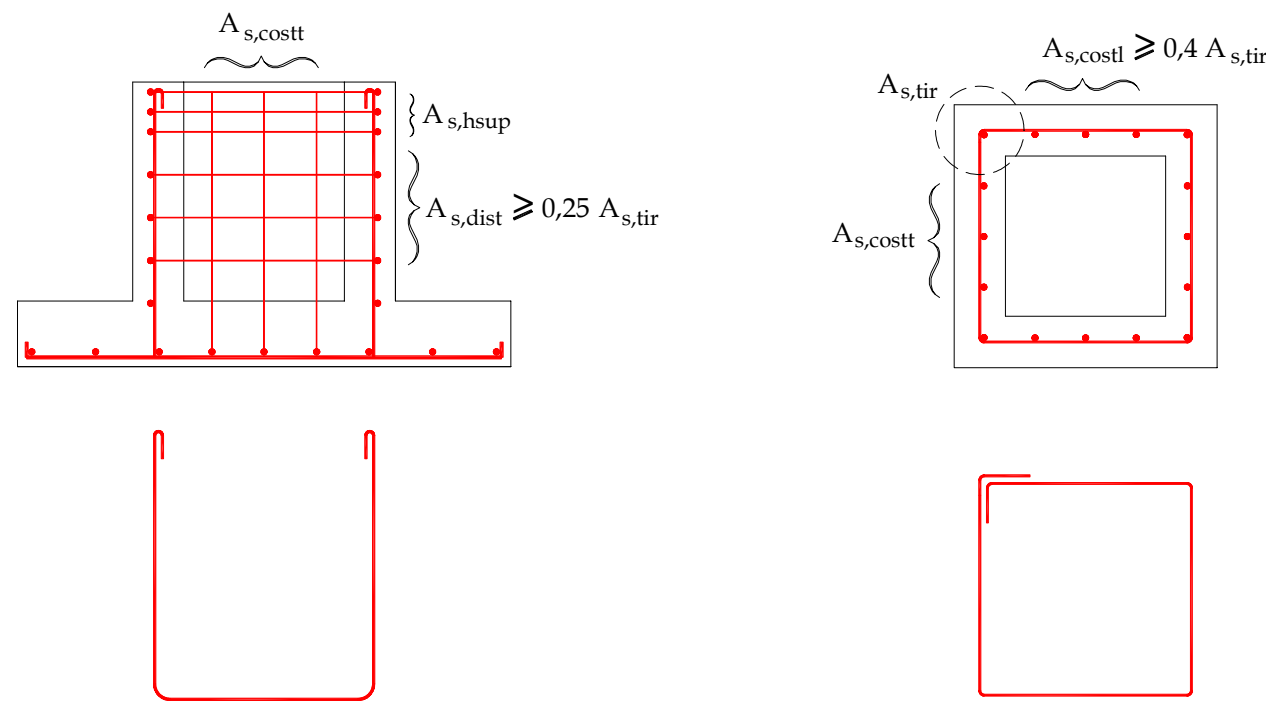

armadura disposta na direção vertical

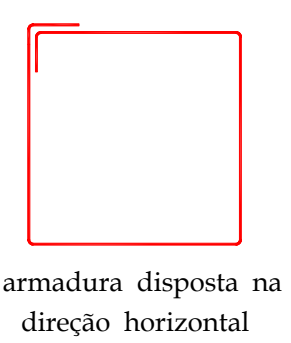

Situação de $\mathrm{M}_{\mathrm{d}} /\left(\mathrm{N}_{\mathrm{d}} \cdot \mathrm{h}\right)<0,15$

Figura 2.11 - Arranjo da armadura do cálice - LEONHARDT \& MÖNNIG (1977) adaptado por EL DEBS (2000) 


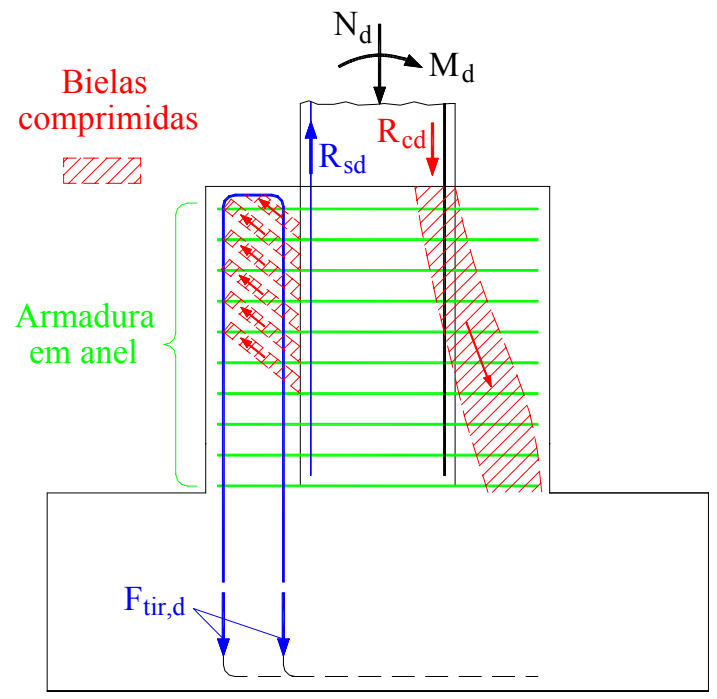

Figura 2.12 - Transmissão das forças de tração e compressão excêntrica para a fundação com interface pilar-colarinho rugosa - LEONHARDT \& MÖNNIG (1977) adaptado por CANHA (2004)

\subsubsection{Recomendações referentes às ações na base de fundação e na parte inferior do pilar}

Normalmente, no caso de paredes lisas, admite-se que toda força normal do pilar seja aplicada a base, e que a verificação da punção da sapata seja feita pela área equivalente a seção transversal do pilar. No entanto, se houver a atuação simultânea de $N_{d}$ e $M_{d}$, esta força normal pode ser reduzida pelo atrito mobilizado pelo colarinho, conforme mostrado na Figura 2.13.

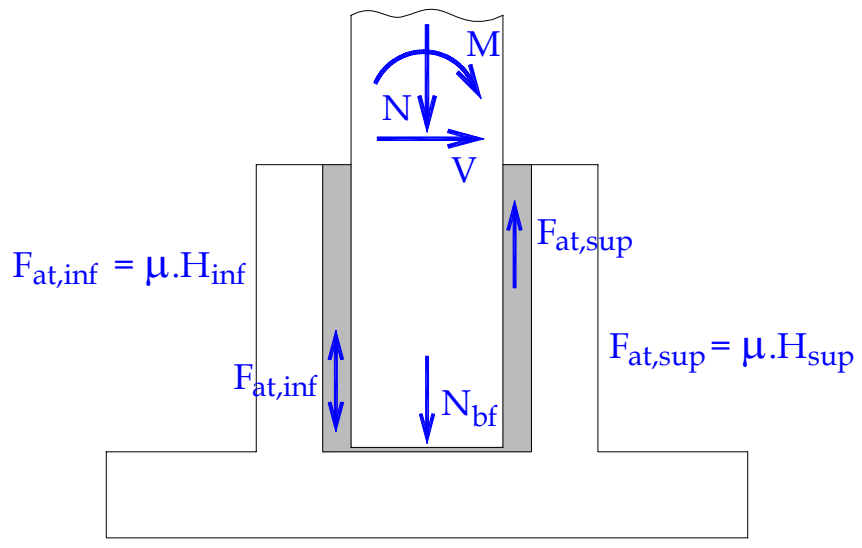

Figura 2.13 - Mobilização do atrito no cálice com interface lisa - EL DEBS (2000)

Em relação à armadura do pilar na região de embutimento (Figura 2.14), no caso ainda das paredes lisas, recomenda-se a utilização de uma armadura transversal 
(estribos) de maior área nesta região e a disposição de uma armadura $A_{s, b}$ em forma de $\mathrm{U}$ na base do pilar, ambas para resistir à força $H_{i n f, d}$. Esta armadura $A_{s, b}$, por sua vez, deve ser adequadamente ancorada a partir da posição $y$ da resultante $H_{\text {sup,d }}$, ou seja, a partir da distância entre a extremidade superior da parede transversal $l$ e a resultante de pressão $H_{\text {sup }, d}$.

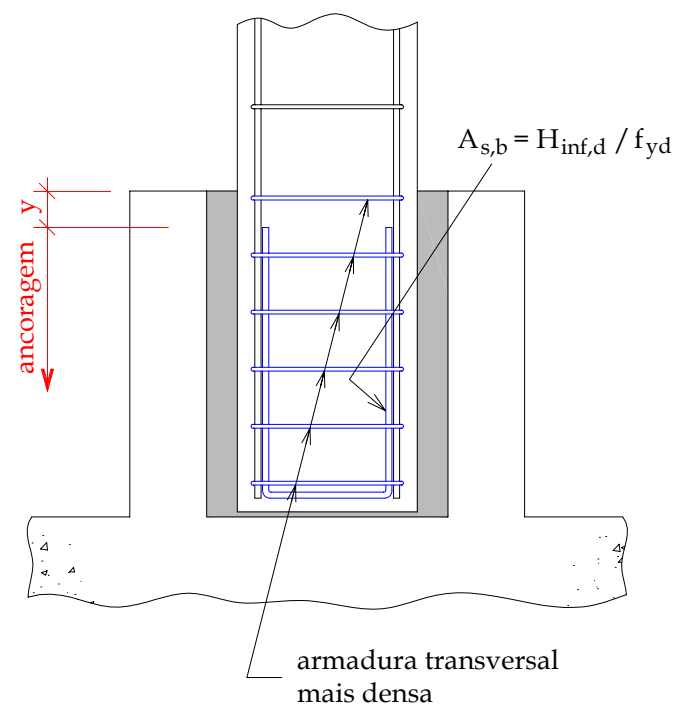

Figura 2.14 - Detalhes da armadura do pilar junto ao cálice com paredes lisas - OLIN et al. (1985)

Quanto as ligações com interface rugosa, no que diz respeito à verificação a punção da base da sapata, admite-se que as solicitações sejam transmitidas pelo conjunto pilar mais colarinho, adotando como largura do pilar as dimensões externas do colarinho, conforme a Figura 2.15.



Figura 2.15 - Punção na base do cálice com interface pilar-colarinho rugosa - EL DEBS (2000) 


\subsubsection{MODELO DE PROJETO DE WILLERT \& KESSER (1983)}

WILLERT \& KESSER (1983) apresentam um modelo de projeto para cálice com interface lisa, mas no entanto considera a rugosidade da interface em função de um coeficiente de atrito $\mu$, ou seja, podendo ser utilizado para interface rugosa com o ajuste adequado desse coeficiente. O coeficiente de atrito sugerido pelos autores no caso da interface lisa é igual de $2 / 3$.

Na Figura 2.6 está ilustrado o modelo de transferência de esforços na ligação com interface lisa.



Figura 2.16 - Transmissão de forças na ligação com interface lisa - WILLERT \& KESSER (1983) adaptado por CANHA (2004)

As forças de atrito são consideradas apenas quando forem aplicadas simultaneamente forças verticais, ou seja, segundo os autores as forças de atrito na interface da ligação só são mobilizadas quando o pilar for solicitado por flexocompressão, e não apenas pela atuação de força horizontal.

Quanto ao comprimento de embutimento recomendado pelos autores, tem-se a seguinte relação:

$$
1,5 h \leq \ell_{e m b} \leq 3,0 h
$$

As condições básicas de equilíbrio são dadas pelas seguintes equações:

Equilíbrio das forças verticais: 


$$
N_{b f, d}-F_{a t, i n f, d}+F_{a t, s u p, d}-N_{d}=0
$$

Equilíbrio das forças horizontais:

$$
H_{s u p, d}-H_{i n f, d}+F_{a t, b f, d}-V_{d}=0
$$

Equilíbrio de momentos no ponto $O$ :

$$
\frac{5 \cdot F_{a t, b f, d} \cdot \ell_{e m b}}{6}+\frac{2 \cdot H_{i n f, d} \cdot l_{e m b}}{3}+\frac{h}{2} \cdot\left(F_{a t, s u p, d}+F_{a t, i n f, d}\right)-M_{d}-\frac{V_{d} \cdot l_{e m b}}{6}=0
$$

As relações complementares são:

$$
\begin{aligned}
& R_{i n f, d}=H_{i n f, d}+F_{a t, b f, d} \\
& F_{a t, s u p, d}=\mu \cdot R_{i n f, d} \\
& F_{a t, i n f, d}=\mu \cdot H_{i n f, d} \\
& F_{a t, b f, d} \leq \mu \cdot N_{b f, d} \\
& N_{b f, d} \geq 0
\end{aligned}
$$

Quanto ao braço de alavanca $z$, seu valor é definido com base na excentricidade da força $e / h$ por meio do fator $\beta_{z}$, que representa a variação desse braço pela função exponencial conforme a expressão abaixo:

$$
\beta_{z}=1-\exp ^{\left(\frac{-2 e}{3 h}\right)} \quad \operatorname{com} \quad 0<\beta_{z} \leq 1
$$

- Para excentricidade pequena $(e / h<1 / 6)$ :

$$
\beta_{z} \approx 0 \quad z \approx \frac{5 \cdot \ell_{e m b}}{6}
$$

- Para excentricidade média $(e / h \approx 1)$ :

$$
\beta_{z} \approx 0,5 \quad z \approx \frac{3 \cdot \ell_{e m b}}{4}
$$

- Para excentricidade grande $(e / h>6)$ : 


$$
\beta_{z} \approx 1 \quad z \approx \frac{2 \cdot \ell_{e m b}}{3}
$$

com:

$$
\frac{e}{h}=\frac{M_{0}}{N_{d} \cdot h}=\frac{6 \cdot M_{d}+V_{d} \cdot l_{e m b}}{6 \cdot N_{d} \cdot h}
$$

A distância do ponto de aplicação da força $R_{i n f, d}$ á base da fundação é dada por:

$$
y^{\prime \prime}=\beta_{z} \cdot \frac{\ell_{e m b}}{6}
$$

Portanto, para determinação do braço $z$ foi levada em conta as seguintes considerações:

- No caso de pequena excentricidade, ou seja, quando a força normal for predominante, a força de atrito na base $F_{a t, b f, d}$ é elevada e a força $H_{i n f, d}$ na parede transversal 2 é pequena, resultando num valor pequeno para $\beta_{z} \mathrm{e}$ consequentemente para $y^{\prime \prime}$, aumentando o braço de alavanca $z$.

- Mas no caso de grandes excentricidades, com o momento predominando sobre o esforço normal, a resultante de pressão $H_{i n f, d}$ aumenta e a força de atrito $F_{a t, b f, d}$ torna-se pequena, resultando num valor maior para $\beta_{z}$ e $y^{\prime \prime}$ diminuindo com isso o braço de alavanca $z$.

Escrevendo $z$ em função de $\ell_{e m b}$ e $\beta_{z}$, tem-se:

$$
z=\frac{\ell_{e m b}}{6} \cdot\left(5-\beta_{z}\right)
$$

Fazendo as devidas substituições para obter a força cortante resultante $R_{i n f, d}$ na base do pilar obtêm-se:

$$
R_{i n f, d}=\frac{6 \cdot M_{d}+V_{d} \cdot \ell_{e m b}}{\ell_{e m b} \cdot\left(5-\beta_{z}\right)+3 \cdot \mu \cdot h \cdot\left(1+\beta_{z}\right)}
$$

As outras reações são dadas por: 


$$
\begin{aligned}
& H_{s u p}=R_{i n f, d}+V_{d} \\
& F_{a t, s u p, d}=\mu \cdot R_{i n f, d} \\
& H_{i n f, d}=\beta_{z} \cdot R_{i n f, d} \\
& F_{a t, i n f, d}=\mu \cdot H_{i n f, d}=\mu \cdot \beta_{z} \cdot R_{i n f, d} \\
& F_{a t, b f, d}=R_{i n f, d}-H_{i n f, d}=\left(1-\beta_{z}\right) \cdot R_{i n f, d} \\
& N_{b f, d}=N_{d}-F_{a t, s u p, d}+F_{a t, i n f, d}=N_{d}-\mu \cdot\left(1-\beta_{z}\right) \cdot R_{i n f, d}
\end{aligned}
$$

\subsubsection{MODELO E RECOMENDAÇÕES DE PROJETO APRESENTADOS EM OLIN ET AL. (1985)}

\subsubsection{Distribuição de força na ligação}

O modelo apresentado por OLIN et al. (1995) mostra uma maneira diferente de analisar a ligação entre o cálice e o pilar. Segundo os autores, a capacidade da ligação é claramente maior que as referenciadas pelos outros métodos, por conseqüência principalmente das tensões de aderência e o deslocamento da reação na extremidade inferior do pilar, conforme ilustrado na Figura 2.17.

No Estado Limite Último, o momento resultante que atua na região de embutimento ocasiona uma excentricidade na reação normal na extremidade inferior do pilar. Esta excentricidade depende de alguns fatores, tais como, a intensidade da força aplicada e as dimensões do cálice, sendo que nos casos mais comuns de ligação rígida, pode-se usar $h / 6$ como sendo uma boa aproximação para a distância entre a reação e o eixo do pilar, considerando o Estado Limite Último.

Com o equilíbrio de momento em relação ao ponto A, chega-se ao seguinte valor para força $H_{\text {sup,d }}$ :

$$
H_{\text {sup,d }}=\frac{M_{d}-0,17 \cdot h \cdot N_{d}+0,9 \cdot \ell_{e m b} \cdot V_{d}}{0,8 \cdot \ell_{e m b}+0,33 \cdot \mu \cdot h}
$$

Nota-se que na Equação (2.26) aparece uma parcela referente à força normal e 
uma parcela referente à força de atrito, ambas minorando a intensidade da força $H_{\text {sup,d }}$.

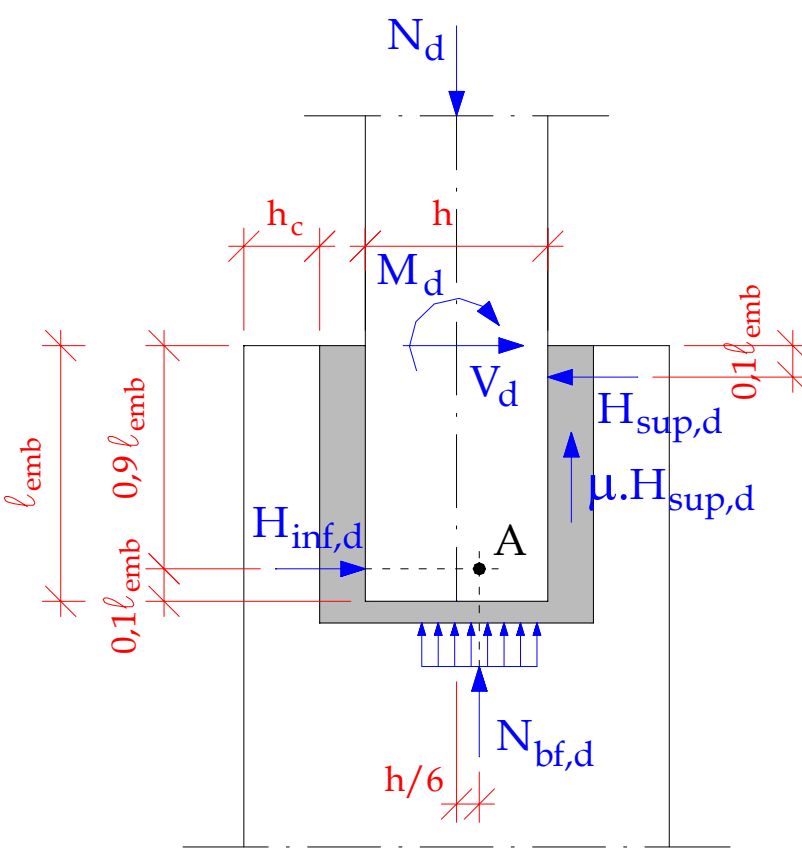

Figura 2.17 - Forças atuando na ligação do pilar com a fundação pelo cálice - OLIN et al. (1995) adaptado por CANHA (2004)

Como foi dito anteriormente, levando em conta esses fatores, a ligação dimensionada sem esta consideração, conduz a resultados maiores no que diz respeito a sua capacidade.

A força de atrito é mobilizada por causa da atuação da força $H_{\text {sup,d }}$ na parede transversal 1 , ou seja, para que haja força de atrito é necessário que tenha a atuação de uma força de compressão aplicada perpendicularmente a esta. Já a força de atrito atuante na extremidade inferior do pilar não é levada em consideração, pois não se desenvolve necessariamente uma força plena nesta região.

Quanto ao coeficiente de atrito utilizado para o dimensionamento, os autores consideram duas condições limites: interface lisa $(\mu=0,3)$ e interface rugosa $(\mu=0,6)$.

É proposto que se utilize um comprimento de embutimento aproximadamente igual a 1,3 do maior lado da seção transversal do pilar $\left(\ell_{e m b}=1,3 h\right)$.

Para ligação com interface lisa, fazendo as convenientes substituições, tem-se para a força $H_{\text {sup,d }}$ : 


$$
H_{\text {sup }, d}=1,14 \cdot \frac{M_{d}}{\ell_{\text {emb }}}+1,03 \cdot V_{d}-0,15 \cdot N_{d}
$$

Fazendo o equilíbrio das forças horizontais, chega-se a seguinte expressão para $H_{i n f, d}:$

$$
H_{i n f, d}=H_{\text {sup }, d}-V_{d}
$$

\subsubsection{Tensões de cisalhamento atuantes nas paredes do cálice}

As tensões de cisalhamento atuantes na interface entre o pilar e o concreto de preenchimento, são produzidas pela força de atrito e de adesão nesta superfície. Como foi comentado anteriormente, a força de atrito é desenvolvida pela atuação da força de compressão produzida pelas forças externas. Isto é levado em consideração utilizando o coeficiente de atrito $\mu$ correspondente ao tipo das superfícies em questão.

Já nas paredes laterais do cálice, não há atuação de forças horizontais, ou seja, as tensões de cisalhamento são por causa da adesão entre as superfícies do pilar e o concreto de preenchimento. A direção e magnitude dessas tensões são determinadas pelo deslocamento imposto ao pilar na região de embutimento no Estado Limite Último. Nos casos mais comuns de carregamento, esses deslocamentos são para baixo e para frente ao mesmo tempo, ou seja, estas tensões são subdivididas nas componentes vertical e horizontal. Como em OLIN et al.(1995) é mencionado a tensão de adesão com a ocorrência do deslizamento, torna-se conveniente denominá-la de tensão de aderência.

Por causa da magnitude do deslizamento entre as superfícies no Estado Limite Último, a componente horizontal da tensão de aderência $F_{b u, x}$ é assumida como uniformemente distribuída em uma certa área, conforme Figura 2.18.

Nota-se que não há uma grande diferença entre a posição de $F_{b u, x}$ e a da resultante de pressão superior $H_{\text {sup,d }}$, ou seja, poderia adotar boa aproximação considerando as duas forças atuando no mesmo ponto de aplicação, pois não influenciaria no dimensionamento da ligação. Segundo os autores, estas tensões distribuídas ao longo da parede do colarinho exigem praticamente o mesmo tipo de armadura quando se considera a força concentrada $H_{\text {sup,d }}$, portanto, o comportamento da ligação é bem similar ao mostrado na Figura 2.17 


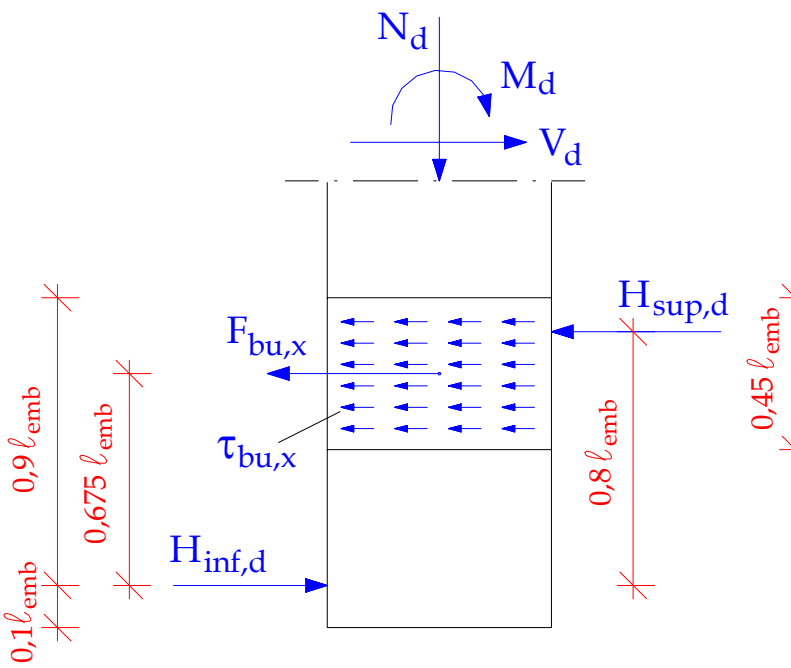

Figura 2.18 - Tensões horizontais de aderência nas superfícies laterais do pilar - OLIN et al. (1995) adaptado por CANHA (2004)

Com relação a componente vertical, é difícil conhecer com precisão o valor exato desta tensão nas diferentes partes da ligação.

Levando em consideração grandes deslizamentos no Estado Limite Último e a ligação como sendo dúctil, a força provocada pela tensão vertical de aderência pode ser determinada conforme a Figura 2.19.
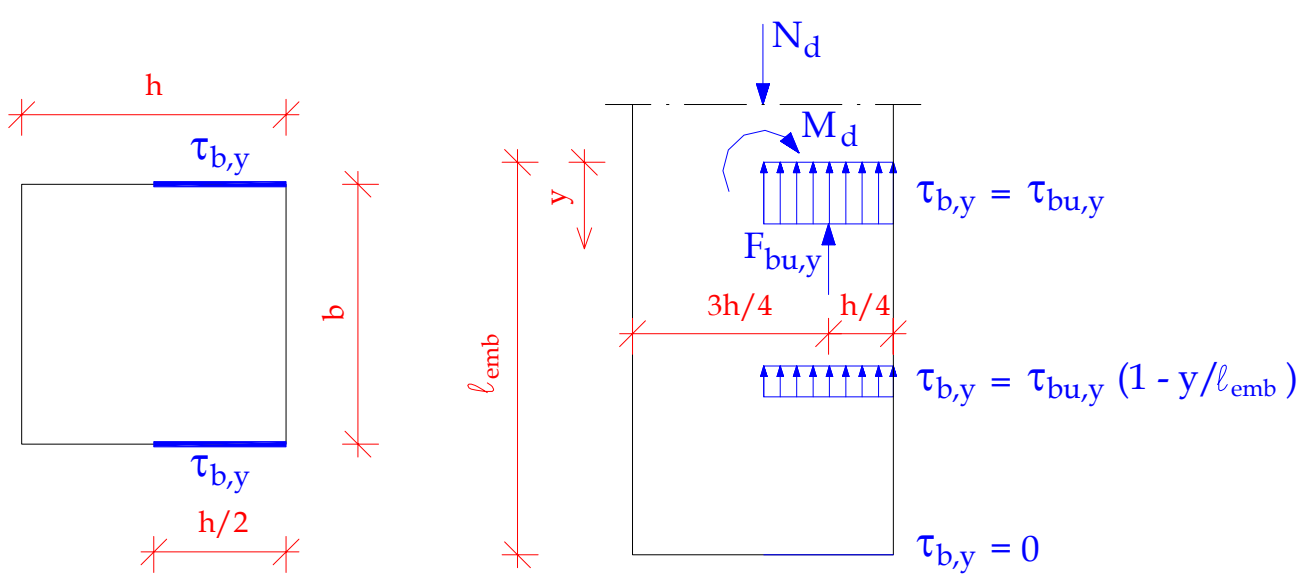

Figura 2.19 - Tensões verticais de aderência nas superfícies laterais do pilar no E.L.U OLIN et al. (1985) ) adaptado por CANHA (2004)

A força provocada pela tensão vertical de aderência é determinada da seguinte forma:

$$
F_{b u, y}=0,5 \cdot \tau_{b u, y} \cdot \ell_{e m b} \cdot h
$$

Esta tensão permanecerá inalterada, ainda que ocorra o escorregamento relativo 
entre as superfícies em contato, ou seja, a ligação apresentará um comportamento dúctil.

Em virtude dos efeitos de retração, há a ocorrência de fissuras no concreto de preenchimento que são da ordem de 0,05 a $0,1 \mathrm{~mm}$, ou seja, com uma pequena rugosidade na interface da ligação consegue-se manter os efeitos da aderência. De acordo com NATIONAL BUILDING CODE of FINLAND apud OLIN et al. (1985), para que a ligação seja considerada rugosa, é necessário que a profundidade das nervuras sejam entre 2 e $5 \mathrm{~mm}$. Portanto, a força de aderência só poderá ser levada em consideração quando se tratar de ligações com interfaces rugosas. Neste caso, considerando apenas a tensão de aderência vertical, a Equação (2.29) será incorporada no equilíbrio das forças (Equação (2.26)).

Substituindo-se os valores do coeficiente de atrito para interface rugosa $(\mu=0,6)$ e o comprimento de embutimento $\left(\ell_{e m b}=1,3 . h\right)$, resultará para força horizontal $H_{\text {sup,d }}$ :

$$
H_{\text {sup }, d}=1,05 \cdot \frac{M_{d}}{\ell_{e m b}}+0,95 \cdot V_{d}-0,13 \cdot N_{d}-0,06 \cdot F_{b u, y}
$$

De acordo com RUNKO-BES-TUTKIMUS ${ }^{1}$ apud OLIN et al.(1985), a tensão ultima de aderência é uma função da resistência a tração do concreto de preenchimento conforme a seguinte equação:

$$
\tau_{b u, y}=\tau_{b u}=0,3 \cdot f_{c d}
$$

Esse valor substituído na Equação (2.29) fornece o seguinte valor de $F_{b u, y}$ :

$$
F_{b u, y}=0,15 \cdot f_{c t d} \cdot l_{e m b} \cdot h
$$

\subsubsection{Cálculo e arranjo das armaduras do cálice}

Para evitar o fendilhamento das paredes do colarinho, provocado pela força normal aplicada no pilar em ligações com interface rugosa e com isso prejudicando a aderência na ligação, os autores recomendam a colocação de uma armadura em forma de estribo ao longo da altura do colarinho cuja área mínima é dada por:

${ }^{1}$ Runko-BES-Tutkimus. Helsinki 1983, Suomen Betoniteollisuuden Keskusjarjesto, Julkaisut $1-7.188$ p. 


$$
A_{s, d i s t}=0,17 . h . s . \frac{f_{c t k}}{f_{y k}}
$$

sendo:

$h$ : altura da seção transversal do pilar

$s$ : espaçamento entre estribos

$f_{c t k}:$ resistência característica do concreto à tração

$f_{y k}:$ resistência característica ao escoamento do aço

A armadura necessária para suportar a força no topo do colarinho $H_{s u p, d}$ é semelhante ao disposto em LEONHARDT \& MÖNNIG (1977), dado por:

$$
A_{s, h p}=\frac{H_{s u p, d}}{2 \cdot f_{y d}}
$$

Já a armadura localizada na região inferior do colarinho pode ser calculada considerando a seguinte equação:

$$
A_{s, h i n f}=\frac{H_{i n f, d}-\mu \cdot N_{b f, d}}{2 \cdot f_{y d}}
$$

sendo a força $H_{i n f, d}$ é determinada segundo a Equação (2.28) e $N_{b f, d}$ é a reação na base da fundação, cujo valor é dado por:

$$
N_{b f, d}=N_{d}-\mu . H_{s u p, d}-F_{b u, y}
$$

A parcela $\mu . N_{b f, d}$ é referente à força de atrito entre a seção inferior do pilar e a base do cálice, que quando muito grande, equilibrará a força $H_{i n f, d}$ e conseqüentemente não será necessária a determinação desta armadura. Portanto, este modelo é indicado quando a excentricidade da força normal for grande o suficiente para produzir uma reação $H_{i n f, d}$ positiva, embora haja a força de atrito na extremidade inferior do pilar.

A armadura vertical do cálice deve ser calculada como se a ligação fosse monolítica, para que haja a transferência do momento na ligação colarinho-base da fundação. 
Na Figura 2.20, é visualizado o esquema das armaduras do colarinho.

$$
\mathrm{A}_{\mathrm{s}, \mathrm{hp}}
$$

$$
\mathrm{A}_{\mathrm{s}, \mathrm{vp}}
$$

Figura 2.20 - Armadura do colarinho - OLIN et al. (1985) adaptado por CANHA (2004)

\subsubsection{MODELO DE PROJETO DE ELLIOTT (1996)}

No modelo proposto por ELLIOTT (1996), são analisadas duas situações referentes aos esforços solicitantes na ligação pilar fundação por meio de cálice: uma apenas com força normal excêntrica (Figura 2.21 (a)) e outra incluindo também a força cortante horizontal (Figura 2.21 (b)).



(a)



(b)

Figura 2.21 - Método de projeto do cálice de fundação: (a) com força normal excêntrica; (b) com força normal excêntrica e a força cortante horizontal - ELLIOTT (1996) adaptado por CANHA (2004)

As pressões de contato mobilizam forças de atrito verticais $\mu . H_{\text {sup, }}$ e $\mu . H_{\text {inf,d }}$ 
nas paredes transversais do colarinho e também forças de atrito horizontais $\mu . N_{b f, d}$ na região da base do pilar. O mínimo valor para o comprimento de embutimento $\ell_{e m b}$ recomendado pelo autor é igual a $1,5 h$. Este comprimento não deve ser inferior a $h$, pois necessita-se que seja formado uma biela de compressão no pilar para resistir as forças cortantes. Os autores recomendam que a distância entre o pilar e as paredes do colarinho deve ser de no mínimo $75 \mathrm{~mm}$ no topo do cálice e $50 \mathrm{~mm}$ na parte inferior.

\subsubsection{Método de cálculo considerando apenas força normal excêntrica}

Por motivo da ausência da força cortante horizontal (Figura 2.21 (a)), a resultante de pressão superior $H_{\text {sup,d }}$ e inferior $H_{i n f, d}$ são iguais e portanto há a formação de dois binários resistentes na ligação entre o pilar e o cálice, um formado por essas resultantes de pressão e o outro formado pelas forças de atrito verticais $\mu . H_{\text {sup }, d}$.

O "braço de alavanca" $z$ do binário formado pela força $H_{s u p, d}$ é determinado adotando o maior valor resultante entre as seguintes expressões:

$$
z=\frac{\left(\ell_{e m b}-0,1 \ell_{e m b}\right)}{2}=0,45 \ell_{e m b}
$$

ou

$$
z=\frac{\left(\ell_{e m b}-c\right)}{2}
$$

onde $c$ é o cobrimento da armadura $A_{s, h p}$ referente ao topo do colarinho.

Considerando o equilíbrio entre momentos em relação ao ponto $A$ da Figura 2.21 (a), tem-se:

$$
\begin{aligned}
& N_{d} \cdot e-\mu \cdot H_{s u p, d} \cdot h-0,45 \ell_{e m b} \cdot H_{s u p, d}=0 \\
& H_{\text {sup }, d}=\frac{N_{d} \cdot e}{\mu \cdot h+0,45 \ell_{e m b}}<0,4 f_{c d} \cdot . b\left(0,45 \ell_{e m b}\right)
\end{aligned}
$$

onde $0,4 . f_{c d}{ }^{\prime}$ é a tensão limite de compressão do concreto de preenchimento.

Como foi dito anteriormente, o autor sugere que se adote $\ell_{\text {emb }}=1,5 \mathrm{~h}$ e no caso de interface lisa, $\mu=0,7$. Com isso chega-se a seguinte expressão: 


$$
H_{s u p, d}=\frac{N_{d} \cdot e}{1,375 h}<0,27 f_{c d}{ }^{\prime} \cdot b \cdot h
$$

Simplificando essa ultima equação, obtêm-se um valor limite para a excentricidade da força normal:

$$
e=\frac{0,375 f_{c d}{ }^{\prime} \cdot b \cdot h^{2}}{N_{d}}
$$

\subsubsection{Método de cálculo considerando força normal excêntrica e força cortante horizontal}

Neste método é considerado também o efeito da força cortante horizontal $V_{d}$ (Figura $2.21(b)$ ).

A tensão de pressão atuante na parede do cálice referente a esta força horizontal tem como limite a tensão de compressão do concreto de preenchimento, cujo valor é igual a $0,4 . f_{c d}{ }^{\prime}$ atuando na largura do pilar $b$. Conseqüentemente, a altura de influencia da ação da força horizontal $\ell_{v}$ (Figura 2.21 (b)) é determinada pela seguinte expressão:

$$
\ell_{v}=\frac{V_{d}}{0,4 f_{c d}^{\prime} \cdot b}
$$

onde $\ell_{v}$ é medido a partir de $0,1 . \ell_{e m b}$.

Para determinar o valor da faixa de influencia referente à força $H_{\text {sup,d }}$, faz-se o equilíbrio de momentos em relação ao ponto $A$ da Figura 2.21(b) como mostrado a seguir:

$$
\begin{aligned}
N_{d} \cdot e+V_{d} \cdot\left(\mu \cdot h+0,5 \ell_{v}\right)= & \left(\mu \cdot 0,4 f_{c d}{ }^{\prime} \cdot b \cdot h \cdot \ell_{h}\right)^{\prime}+ \\
& +\left[0,4 f_{c d}{ }^{\prime} \cdot b \cdot \ell_{h}\left(0,9 \ell_{e m b}-\ell_{v}-\ell_{h}\right)\right]
\end{aligned}
$$

ou seja, $\ell_{h}$ é calculado a partir da equação do segundo grau abaixo:

$$
\ell_{h}^{2}-\left(\mu \cdot h+0,9 \ell_{e m b}-\ell_{v}\right) \cdot \ell_{h}+\frac{M_{d}+V_{d} \cdot\left(0,1 \ell_{e m b}+0,5 \ell_{v}\right)}{0,4 f_{c d} \cdot . b}=0
$$

Vale ressaltar que se o valor de $0,1 \ell_{e m b}$ for menor que o cobrimento $c$, utiliza-se então o valor do cobrimento. 
Segundo o autor, as forças de atrito verticais atuam apenas no comprimento $\ell_{h}$, pois elas são mobilizadas apenas com a existência dos esforços de flexão.

As tensões nas interfaces opostas não devem se sobrepor, ou seja:

$$
\ell_{v}+2 \ell_{h}<0,9 .\left(0,9 \ell_{e m b}\right)
$$

A armadura horizontal principal disposta na região superior das paredes longitudinais 3 e $4 A_{s, h p}$ deve ser determinada para resistir à força $H_{\text {sup,d }}$ somado a força lateral $N_{d} \cdot \tan 5^{\circ}$ devido à inclinação das paredes do colarinho:

$$
A_{s, h p}=\frac{\left[0,4 f_{c d}{ }^{\prime} \cdot b\left(\ell_{v}+\ell_{h}\right)+N_{d} \cdot \tan 5^{\circ}\right] / 2}{0,87 f_{y k}}
$$

\subsubsection{PESQUISA EXPERIMENTAL E MODELO DE PROJETO DE OSANAI ET AL.(1996)}

Neste trabalho, OSANAI et al. (1996) propõem um modelo de cálculo para o dimensionamento do cálice de fundação e posteriormente apresenta uma comparação com outros modelos segundo DIN $1045^{2}$ e $\mathrm{AIJ}^{3}$. É apresentada também uma investigação experimental cujos resultados servirão para validar o modelo de projeto proposto pelos autores.

\subsubsection{Modelo de projeto}

Neste modelo, considera-se uma força normal $N_{d}$ e uma horizontal $V_{d}$ atuando no pilar. Conseqüentemente, surge na ligação forças horizontais, forças de atrito e reação normal na base do pilar conforme a Figura 2.22.

Com a finalidade de facilitar a resolução das equações de equilíbrio, os autores propõem dividir o modelo total em duas partes denominadas modelo 1 e modelo 2 , considerando o equilíbrio, conforme apresentado na Figura 2.23.

\footnotetext{
${ }^{2}$ DIN 1045 (1972). Cálculo e execução de obras de concreto armado. (Norma alemã).

${ }^{3}$ AIJ (1990). Recommendations for the design and fabrication of tubular structures in stell. Architectural Institute of Japan. P.237-42
} 


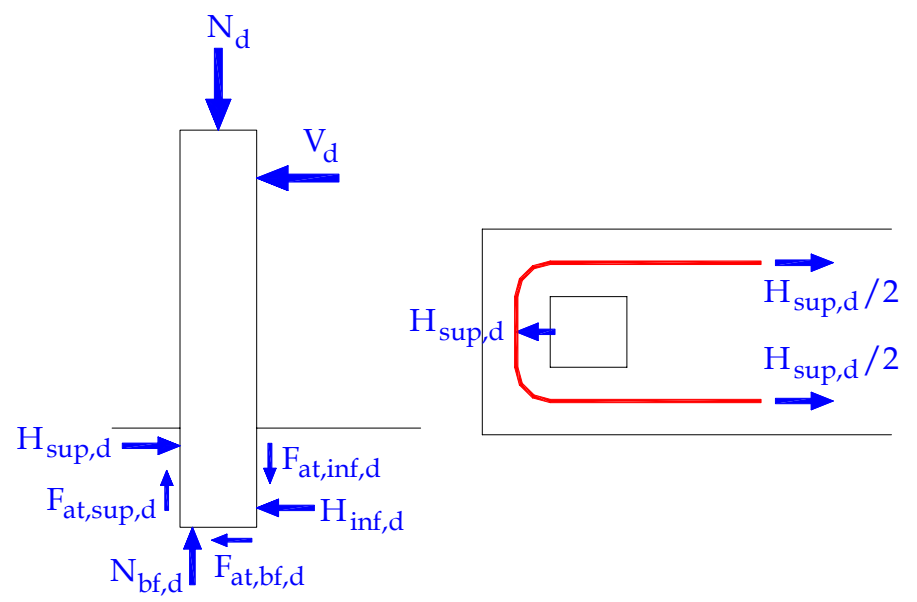

Figura 2.22 - Equilíbrio das forças na ligação e transmissão de tensão do pilar para a fundação - OSANAI et al. (1996) adaptado por CANHA (2004)

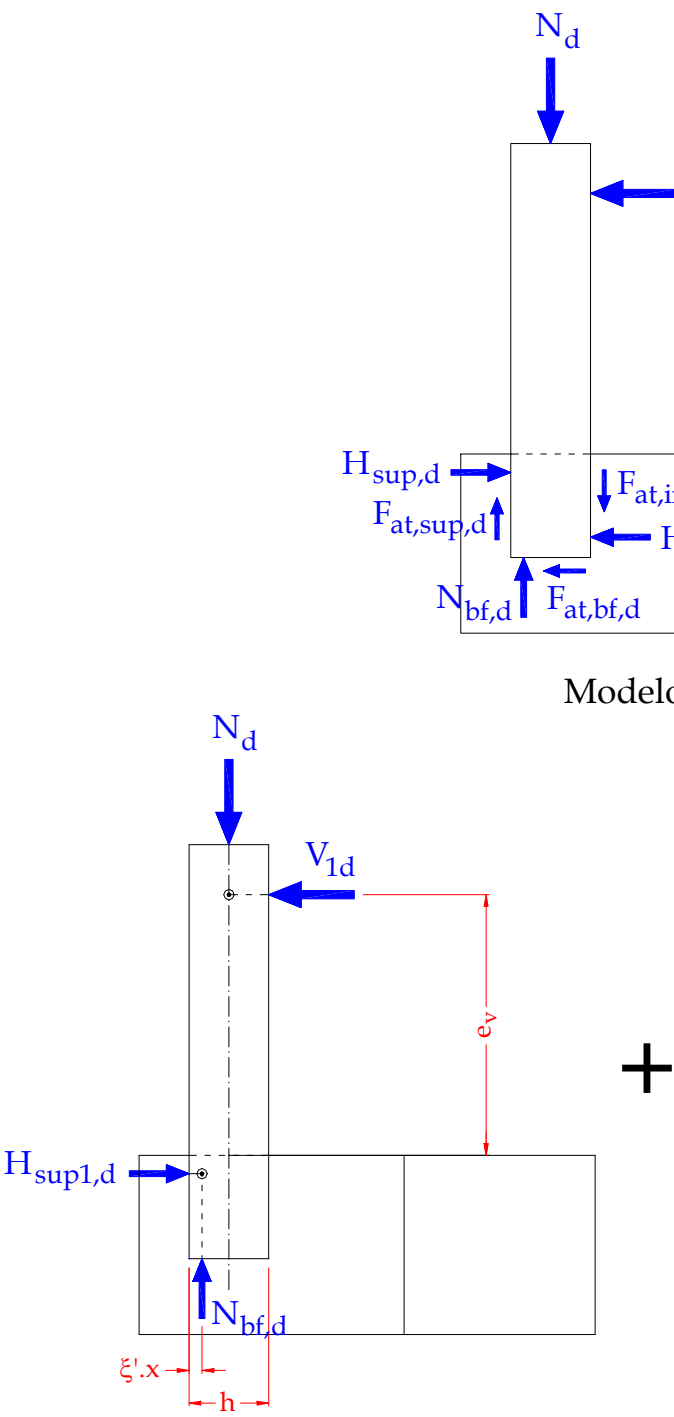

Modelo 1



Modelo 2

Figura 2.23 - Modelo teórico - OSANAI et al. (1996) adaptado por CANHA (2004) 
No modelo 1, o pilar é solicitado por parte da força horizontal e pela força normal, que será então resistido pela reação horizontal e reação normal na base da fundação. Já no modelo 2, apenas a parte remanescente da força horizontal atua no pilar, mobilizando as forças horizontais nas paredes do colarinho e forças de atrito na interface da ligação.

As equações de equilíbrio são formuladas levando em consideração as seguintes hipóteses:

- A resistência à tração do concreto do bloco é ignorada;

- É levada em consideração apenas a armadura principal da fundação para resistir a tração, desconsiderando as armaduras secundárias;

- São consideradas as forças de atrito mobilizadas na interface pilar-colarinho;

- As forças verticais de reação e as forças normais atuantes no pilar são consideradas agindo na face inferior do pilar.

De acordo com a Figura 2.24, a distância entre a resultante de compressão $R_{c d} \mathrm{e}$ a fibra mais comprimida da seção transversal do pilar submetido à flexo-compressão $\left(\xi^{\prime} . x\right)$, é determinada analisando-se os esforços nessa seção para o carregamento horizontal $V_{d}$ considerando o Estado Limite Último e admitindo a hipótese que as seções planas permanecem planas após as deformações.

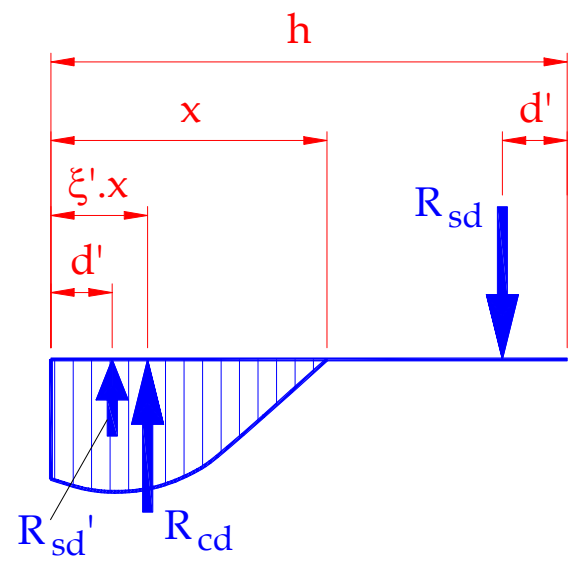

Figura 2.24 - Distribuição de tensões na seção do pilar - OSANAI et al. (1996)

onde:

- $R_{c d}$ : Força de compressão do concreto causada pela força normal do pilar e o momento atuante na seção do pilar; 
- $R_{s d}{ }^{\prime}$ : Força de compressão da armadura do pilar causada pela força normal do pilar e o momento atuante na seção do pilar;

- $h$ : Altura da seção transversal do pilar;

- $d^{\prime}$ : Distância da fibra extrema tracionada e comprimida ao centróide da armadura de tração e compressão, respectivamente;

- $R_{s d}$ : Força de tração na armadura do pilar causada pela força normal do pilar e o momento atuante na seção do pilar;

- $x$ : Distância da fibra externa de compressão à linha neutra;

- $\xi^{\prime} . x$ : Distância da fibra externa de compressão ao ponto de atuação de $R_{c d}$.

Com isso, a reação $H_{\text {supl,d }}$ fica então determinada por intermédio das condições de equilíbrio, levando em consideração o modelo 1:

$$
H_{\text {supl } 1,}=V_{l d}=\frac{M_{l d}}{e_{v}+y} \cong \frac{M_{l d}}{e_{v}}=\left(\frac{h}{2}-\xi^{\prime} \cdot x\right) \cdot \frac{N_{d}}{e_{v}}
$$

onde $N_{d}=N_{b f, d}$ e $y$ é desprezível comparado com $e_{v}$.

Para determinar as outras forças atuantes no cálice de fundação, considera-se a distribuição de tensões na região de embutimento do pilar mostradas na Figura 2.25 conforme o modelo 2 .

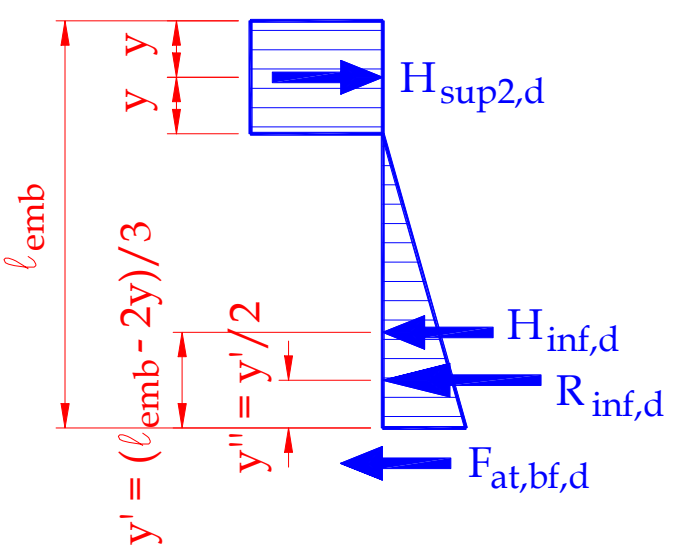

Figura 2.25 - Distribuição de tensões na região de embutimento do pilar do modelo 2 OSANAI et al. (1996) adaptado por CANHA (2004)

A soma da resultante de pressão $H_{i n f, d}$ com a força de atrito mobilizada na base 
do pilar $F_{a t, b f, d}$, resulta em uma força atuando na posição $y^{\prime \prime}$ :

$$
\begin{aligned}
& R_{i n f, d}=H_{i n f, d}+F_{a t, b f, d} \\
& y^{\prime \prime}=\frac{\left(\ell_{e m b}-2 \cdot y\right)}{6}
\end{aligned}
$$

Considerando as condições de equilíbrio, têm-se as seguintes relações:

- Equilíbrio de momentos:

$$
M_{2 d}+V_{2 d} \cdot \ell_{e m b}+R_{i n f, d} \cdot y^{\prime \prime}-H_{s u p 2, d} \cdot\left(\ell_{e m b}-y\right)-F_{a t, s u p, d} \cdot h=0
$$

onde $M_{2 d}$ é o momento de flexão na seção crítica do pilar, dado por:

$$
M_{2 d}=V_{2 d} \cdot e_{v}
$$

- Equilíbrio de forças verticais:

$$
F_{a t, s u p, d}=F_{a t, i n f, d}
$$

- Equilíbrio de forças horizontais:

$$
H_{\text {sup } 2, d}=V_{2 d}+R_{i n f, d}
$$

As forças de atrito na interface do pilar com o colarinho são determinadas por:

$$
\begin{aligned}
& F_{a t, s u p, d}=\mu_{\text {sup }} . H_{\text {sup } 2, d} \\
& F_{a t, i n f, d}=\mu_{i n f, d} \cdot H_{i n f, d}
\end{aligned}
$$

A reação total $H_{\text {sup,d }}$ é obtida por:

$$
H_{\text {sup }, d}=H_{\text {sup } 1, d}+H_{\text {sup } 2, d}
$$

ou seja, é derivada da soma da Equação (2.48) com a combinação das Equações (2.51) a (2.56).

Com a finalidade de comparar a outros modelos, CANHA (2004) desenvolve a equação final para $H_{\text {sup,d }}$ levando em conta a atuação da força normal, momento fletor e força cortante, já que o modelo de OSANAI et al. (1996) foi formulado para força 
normal centrada e cortante.

Denominando-se a excentricidade da reação normal na base do pilar em relação ao seu centro de gravidade $e_{n b}=0,5 \ell_{e m b}-\xi^{\prime} . x$, tem com equação final para $H_{\text {sup }, d}$ :

$$
H_{\text {sup,d }}=\frac{M_{d}-\left[e_{n b}-\frac{\mu^{2}\left(0,5 h+e_{n b}\right)}{1+\mu^{2}}\right] \cdot N_{d}+\left[\frac{5 \ell_{e m b}}{6}+\frac{y}{3}+\frac{\mu\left(0,5 h+e_{n b}\right)}{1+\mu^{2}}\right] \cdot V_{d}}{\frac{5 \ell_{e m b}}{6}-\frac{2 y}{3}+\mu . h}
$$

Como foi escrito anteriormente, serão apresentados outros dois modelos de dimensionamento do cálice segundo AIJ e DIN1045.

O modelo proposto pela AIJ, considera a transferência de forças na ligação conforme o esquema apresentado na Figura 2.26(a), resultando nas seguintes equações para $H_{\text {sup,d }}$ e $H_{i n f, d}$ :

$$
\begin{aligned}
& H_{\text {sup }, d}=\frac{M_{d}+V_{d} \cdot\left(0,5 \ell_{e m b}-y^{\prime}\right)}{\ell_{e m b}-y-y^{\prime}} \\
& H_{i n f, d}=H_{s u p, d}-V_{d}
\end{aligned}
$$



(a)

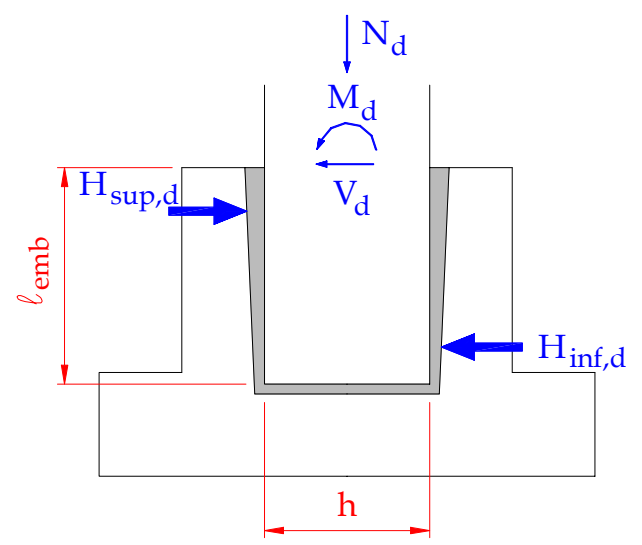

(b)

Figura 2.26 - Transferência de forças: (a) AIJ; (b) DIN1045 adaptado por CANHA (2004)

$\mathrm{Na}$ Equação (2.59) pode-se observar que não foi considerado o momento referente ao esforço cortante $V_{d}$, pois no lugar da parcela $\left(0,5 \ell_{e m b}-y^{\prime}\right)$ deveria ser $\left(\ell_{e m b}-y^{\prime}\right)$.

A DIN1045 considera as duas situações extremas: interface lisa e rugosa (Figura 
2.26 (b)) resultando nas seguintes expressões para $H_{\text {sup,d }}$ :

- Superfície rugosa:

$$
H_{\text {sup,d }}=\frac{6}{5} \cdot \frac{M_{d}}{\ell_{\text {emb }}}+\frac{6}{5} \cdot V_{d}
$$

- Superfície lisa:

$$
H_{\text {sup }, d}=\frac{2}{3} \cdot \frac{M_{d}}{\ell_{e m b}}+\frac{5}{4} \cdot V_{d}
$$

Na Figura 2.27 encontra-se os resultados teóricos referentes ao modelo de OSANAI et al. (1996), da DIN1045 e da AIJ.

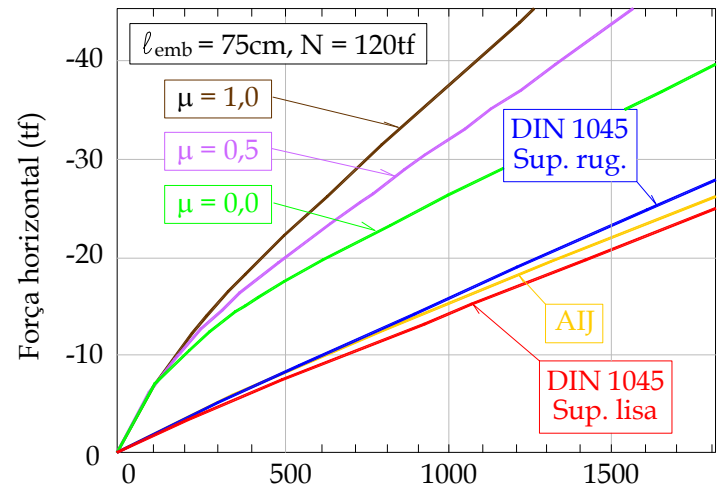

Deformação da armadura horizontal superior $(\mu \varepsilon)$ (a)

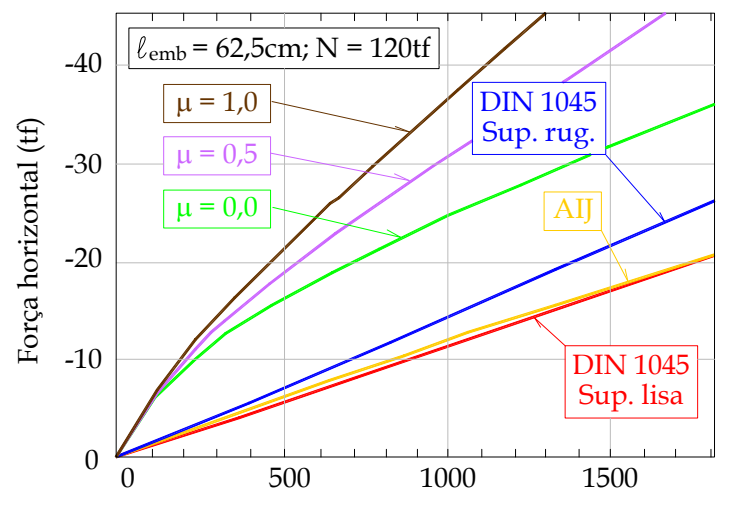

Deformação da armadura horizontal superior $(\mu \varepsilon)$

(c)



Deformação da armadura horizontal superior $(\mu \varepsilon)$

(b)

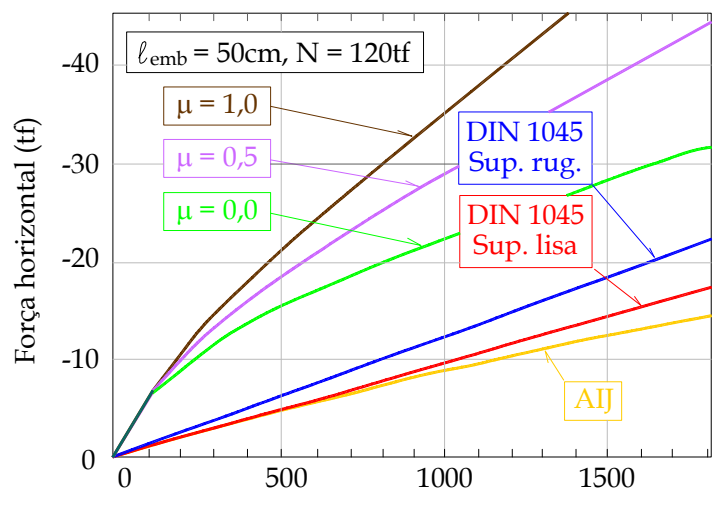

Deformação da armadura horizontal superior $(\mu \varepsilon)$

(d)

Figura 2.27 - Resultados teóricos e das recomendações da DIN 1045 e AIJ: curva força horizontal versus deformação na armadura horizontal superior do cálice - OSANAI et al. (1996) adaptado por CANHA (2004)

Os valores de $\ell_{e m b}$ e $N$ são relacionados aos modelos da investigação experimental realizada pelos autores, na qual será detalhada a seguir. 
Como se pode notar, os resultados da norma AIJ apresentam boa concordância com os obtidos pela DIN1045. No entanto, o método teórico proposto por OSANAI et al. (1996), com exceção dos resultados fornecidos na Figura 2.27 (b) com coeficiente de atrito nulo, resultou em menores deformações para as armaduras do cálice para o mesmo carregamento com o crescimento do coeficiente de atrito. Portanto, com o aumento da força normal e do coeficiente de atrito, a força gerada na armadura horizontal principal disposta no topo das paredes longitudinais 3 e 4 da ligação decresce.

\subsubsection{Pesquisa experimental}

Na Figura 2.28, está apresentado o detalhamento dos modelos ensaiados por OSANAI et al. (1996).

Foi realizada uma investigação experimental em modelos com duas condições de superfície na interface: lisa e rugosa. Variou-se também o comprimento de embutimento nos seguintes valores: $\ell_{\text {emb }}=h(50 \mathrm{~cm}) ; \quad \ell_{\text {emb }}=1,25 h(62,5 \mathrm{~cm})$ e $\ell_{e m b}=1,5 h(75 \mathrm{~cm})$. Com os resultados obtidos na investigação experimental, pode-se fazer a comparação com as previsões teóricas apresentadas anteriormente, conforme mostram os gráficos da Figura 2.29.

Com isso, os autores chegaram a algumas conclusões importantes a respeito do comportamento da ligação, tais como:

- Se o comprimento de embutimento for igual ou superior a $1,5 h$, a ligação pode ser considerada rígida mesmo sem a presença de chaves de cisalhamento (interface lisa);

- A capacidade da ligação pode ser aumentada com a utilização de interface rugosa. A ligação com comprimento de embutimento igual ou superior a $h$ com interface rugosa fornece resultados parecidos com aquelas cujo comprimento de embutimento é igual a $1,5 h$ e interface lisa, podendo também alcançar a resistência ultima do pilar;

- A ligação com interface lisa não possui rigidez suficiente quando o comprimento de embutimento é menor que $1,25 h$, no entanto o pilar pode alcançar sua resistência ultima a flexão para situações de grandes flechas; 

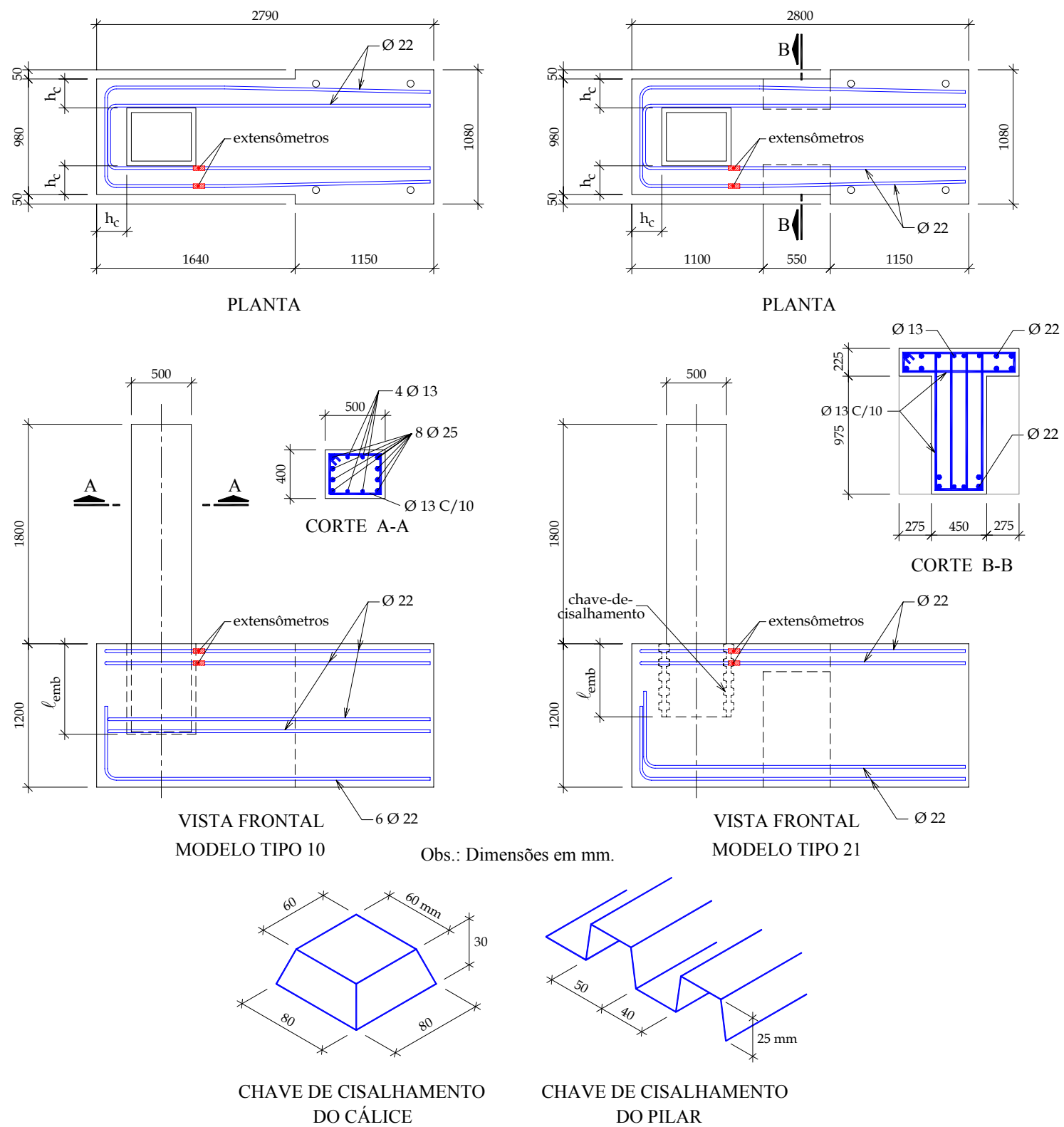

Figura 2.28 - Detalhamento dos modelos ensaiados por OSANAI et al. (1996)

- Quando o comprimento de embutimento for igual ou superior a $1,5 \mathrm{~h}$ e a interface da ligação for lisa, ou quando o comprimento for igual ou superior a $1,25 \mathrm{~h}$ com interface rugosa, recomenda-se que o valor do coeficiente de atrito seja igual a 1. Já no caso de comprimento de embutimento igual a $h$ com interface rugosa o valor do coeficiente de atrito recomendado é igual a 0,5

- O inicio da degradação da rigidez pode ser retardada para ligações com interface rugosa;

- As equações teóricas propostas por OSANAI et al. (1996) forneceram 
resultados mais próximos dos valores experimentais que os da AIJ e DIN1045. As curvas tensão versus deformação da armadura horizontal superior do cálice ficaram próximas dos valores experimentais quando se aproximou da força ultima para coeficientes de atrito iguais a 0,5 e 1 .

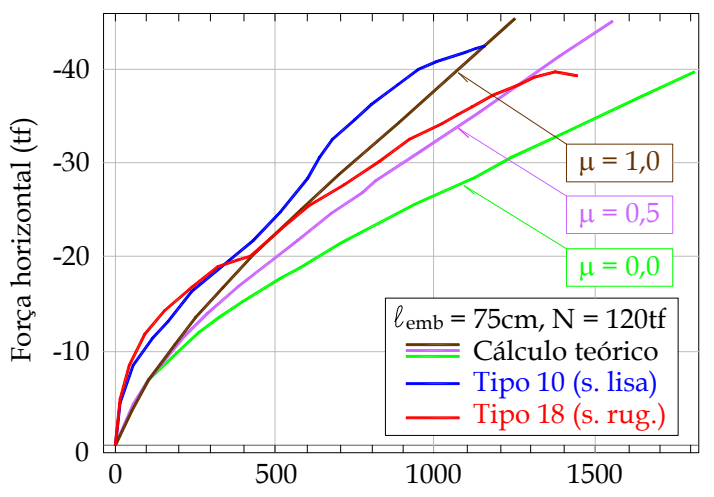

Deformação da armadura horizontal superior $(\mu \varepsilon)$

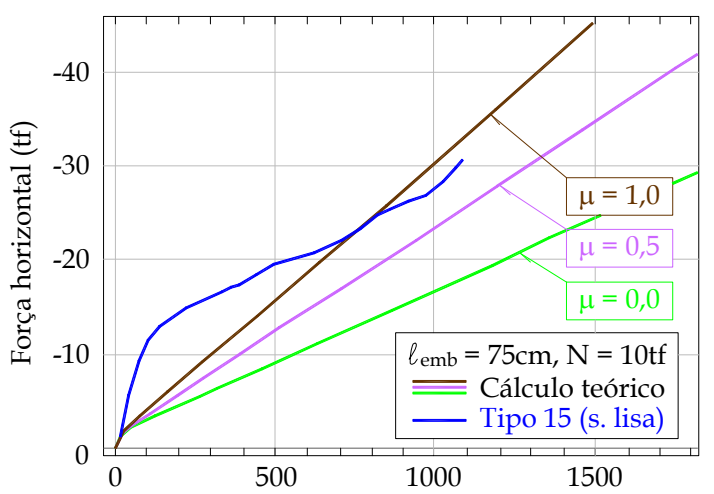

Deformação da armadura horizontal superior $(\mu \varepsilon)$

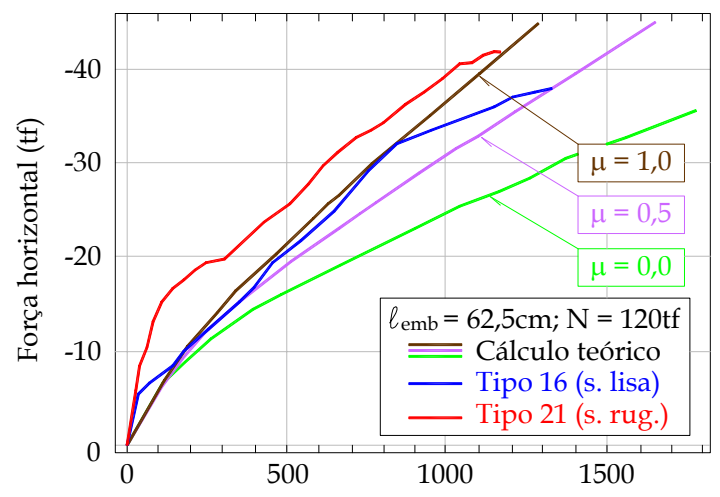

Deformação da armadura horizontal superior $(\mu \varepsilon)$

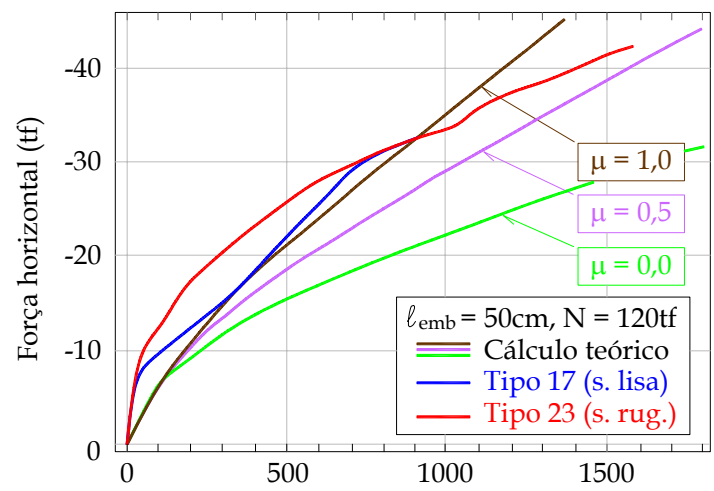

Deformação da armadura horizontal superior $(\mu \varepsilon)$

Figura 2.29 - Resultados teóricos e experimentais: curva força horizontal versus deformação na armadura horizontal do cálice - OSANAI et al. (1996) adaptado por CANHA (2004)

\subsubsection{MODELO E RECOMENDAÇOES DE PROJETO SEGUNDO A CNR 10025 (1998)}

\subsubsection{Propriedades geométricas e resultantes de forças no cálice}

No que diz respeito ao comprimento de embutimento, a CNR 10025 (1998) não diferencia o cálice liso e o rugoso, recomendando:

- $\ell_{e m b} \geq 1,2 h \quad$ para $\quad M_{d} / N_{d} \leq 0,15 h$

- $\ell_{e m b} \geq 2,0 h \quad$ para $M_{d} / N_{d} \geq 2,00 h$

O valor mínimo do comprimento de embutimento $\ell_{e m b}$ recomendado pela CNR 
10025 é de $30 \mathrm{~cm}$. Quanto a espessura do colarinho $h_{c}$, o valor é semelhante ao modelo de LEONHARDT \& MÖNNIG (1977), ou seja, deve ser maior ou igual a $1 / 3$ da menor distância interna entre as paredes do colarinho $\left(h_{\text {int }}\right.$ ou $\left.b_{\text {int }}\right)$, e no mínimo igual a $100 \mathrm{~mm}$.

Os esforços atuantes no cálice e seus respectivos pontos de aplicação estão ilustrados na Figura 2.30.
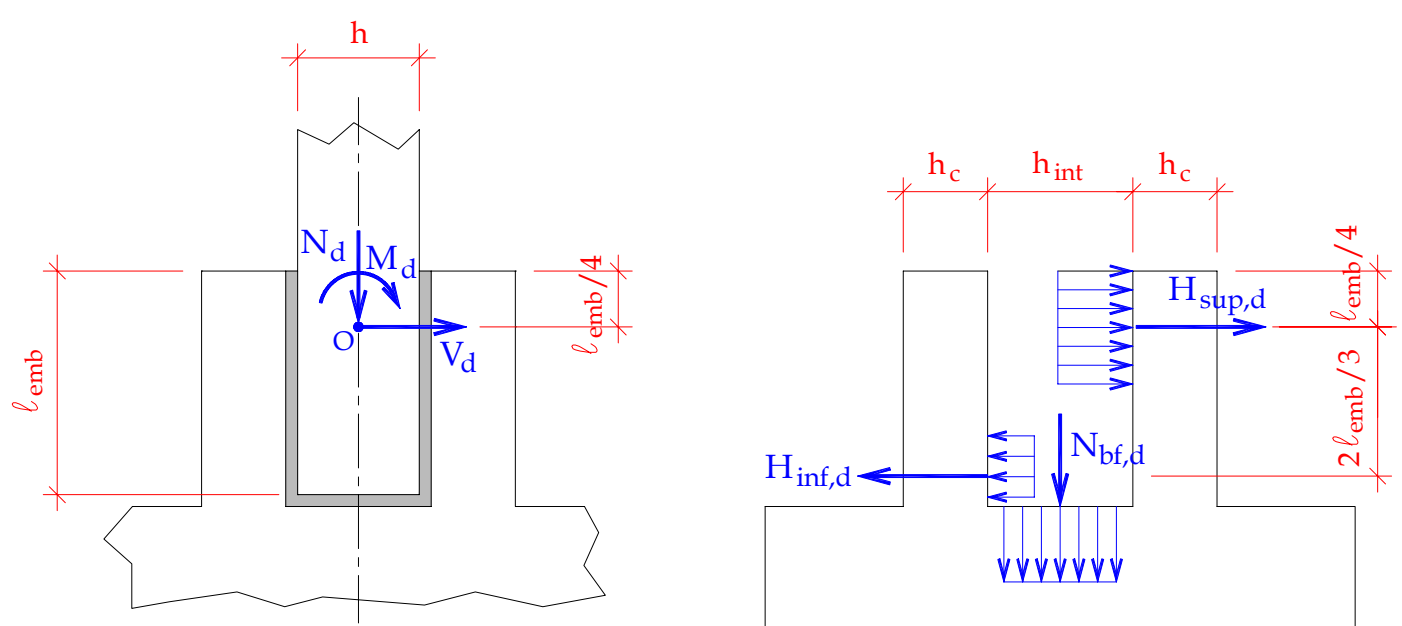

Figura 2.30 - Transferência de forças no cálice - CNR10025 (1998)

Neste modelo são desprezadas as forças de atrito, ocorrendo apenas as solicitações de compressão calculadas conforme as seguintes expressões:

$$
\begin{aligned}
& H_{s u p, d}=V_{d}+\frac{3}{2} \frac{M_{d}}{\ell_{e m b}} \\
& H_{i n f, d}=\frac{3}{2} \frac{M_{d}}{\ell_{e m b}} \\
& N_{b f, d}=N_{d}
\end{aligned}
$$

As ações $M_{d}, N_{d}$ e $V_{d}$ estão aplicadas em um ponto $O$ situado a $\ell_{e m b} / 4$ do topo do cálice.

\subsubsection{Comportamento e dimensionamento das paredes do cálice}

A CNR 10025 (1998) aborda de uma maneira diferente a questão referente ao dimensionamento das paredes do colarinho, comparando-se aos modelos propostos 
anteriormente. Ao contrário do cálculo direto das armaduras, são feitas verificações quanto aos esforços atuantes. Essas verificações são divididas em três etapas: verificação do bordo frontal, verificação do bordo lateral e verificação da parede lateral. Entende-se como bordo a parte superior da parede, ou seja, a facha da parede necessária para resistir à força $H_{\text {sup,d }}$. Serão mostradas a seguir as expressões de cálculo para cada uma destas etapas.

A primeira etapa consiste em verificar a resistência das paredes transversais do colarinho. Esta verificação é feita a partir do modelo de bielas e tirantes, como é ilustrado na Figura 2.31.

A área de armadura necessária para suportar a força $H_{\text {sup,d }}$ atuando na parede transversal $l$ é dada por:

$$
\frac{2 A_{s, h f t e}\left(1+\alpha_{s, f t}\right) f_{y d}}{\lambda_{f t}}>H_{s u p, d}
$$

Neste modelo, a força externa é dividida em duas parcelas, $R_{f t, d}$ e $R_{f t, d}^{\prime}$, solicitando a armadura $A_{s, h f t e}$ e a outra a $A_{s, h f i}$ respectivamente, sendo a soma delas igual a $H_{\text {sup }, d} / 2$ (Figura 2.31).
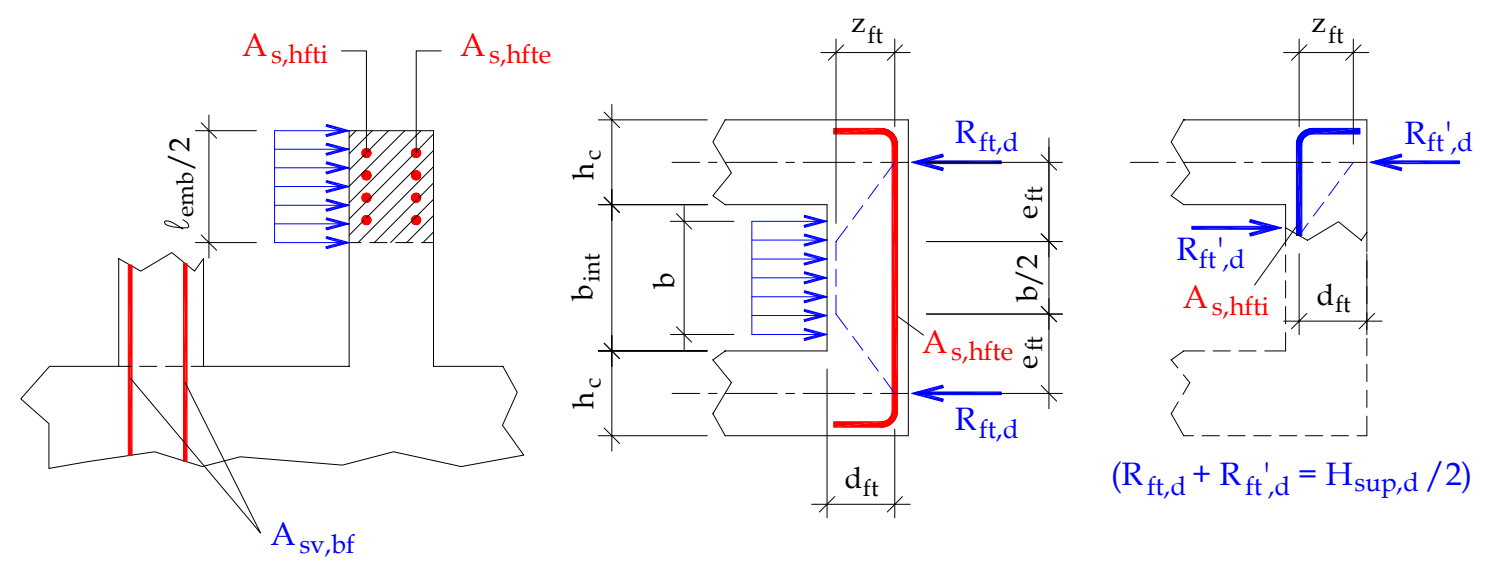

Figura 2.31 - Forças nas paredes transversais - CNR 10025 (1998)

A verificação da resistência do concreto por meio da biela comprimida é dada por: 


$$
\frac{2.0,4 d_{f t}\left(\ell_{e m b} / 2\right) \sigma_{c d}}{1+\lambda_{f t}{ }^{2}}>H_{s u p, d}
$$

Quanto a verificação da região inferior da parede transversal 2 tem-se:

$$
\left[h_{c}\left(b+h_{c}\right)+\alpha_{e} A_{s v, b f}\right] f_{c t d}>H_{\text {sup }, d}
$$

onde:

$$
\alpha_{s, f t}=\frac{A_{s, h f t e}}{A_{s, h f t i}}, \quad \alpha_{e}=\frac{E_{s}}{E_{c}}, \quad \lambda_{f t}=\frac{e_{f t}}{z_{f t}}, \quad z_{f t}=0,9 d_{f t}, \quad e_{f t}=\frac{b_{i n t}+h_{c}}{2}-\frac{b}{4}
$$

A segunda etapa referente a verificação dos bordos longitudinais é efetuada segundo o modelo de consolo, com uma diferença apenas no cálculo da armadura horizontal como está ilustrado na Figura 2.32.


Figura 2.32 - Forças nas paredes longitudinais - CNR 10025 (1998) adaptado por CANHA (2004)

O bordo longitudinal é solicitado a flexo-tração e a armadura necessária para resistir a esses esforços é calculada conforme as Equações (2.69) e (2.70).

$$
\begin{aligned}
& \frac{2 A_{s, h p e} \cdot f_{y d}}{1-\left(\alpha_{s, f t} \cdot e_{f t}\right) / z_{h s u p}}>H_{s u p, d} \\
& \frac{2 A_{s, h p i} \cdot f_{y d}}{1+\left(\alpha_{s, f t} \cdot e_{f t}\right) / z_{h s u p}}>H_{s u p, d}
\end{aligned}
$$

A terceira e última etapa referente ao dimensionamento das paredes do colarinho é a da parede longitudinal, com as verificações quanto a biela de concreto comprimida e a armadura vertical principal (Figura 2.32), conforme as seguintes equações: 


$$
\begin{aligned}
& \frac{2 A_{s, v p} \cdot f_{y d}}{\lambda_{c}}>H_{s u p, d} \\
& \frac{2.0,4 d_{c} \cdot h_{c} \sigma_{c d}}{1+\lambda^{2}{ }_{c}}>H_{s u p, d}
\end{aligned}
$$

onde:

$$
\begin{aligned}
& \lambda_{c}=\frac{\ell_{o}}{d_{c}}, \\
& \lambda_{c}=\frac{\ell_{c}-\ell_{e m b}}{4+h_{b i e}{ }^{\prime} / 2}, \\
& \lambda_{c}=h_{e x t}-\frac{h_{c}}{2}, \\
& h_{b i e}{ }^{\prime} 2 \text { é o valor mínimo entre } 0,2 d_{c} \text { e } \frac{\ell_{b f}}{2} .
\end{aligned}
$$

Para interface rugosa, considera-se a ligação como sendo monolítica e, portanto, para as verificações de resistência, estabilidade e punção, são consideradas as dimensões externas do colarinho para efeito de projeto.

A transmissão da força de tração do pilar para a fundação, se dá por um comprimento de traspasse igual à soma da parcela referente à aderência aço-concreto com o espaçamento entre as armaduras, conforme Figura 2.33. Deve-se dispor de estribos horizontais para a união dessas armaduras no trecho de ancoragem.

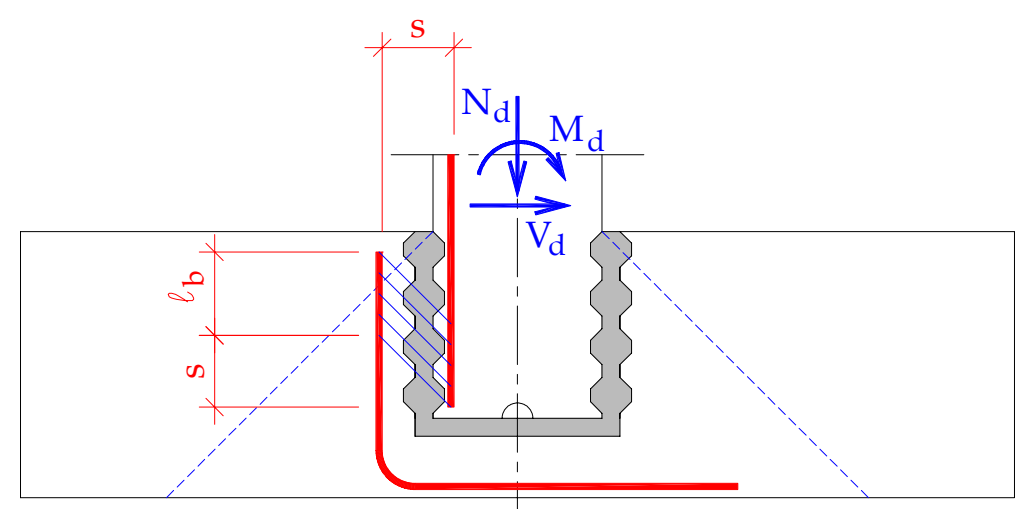

Figura 2.33 - Ancoragem das armaduras do pilar e da fundação - CNR 10025 (1998) adaptado por CANHA (2004) 


\subsubsection{RECOMENDAÇOES PARA PROJETO SEGUNDO CERIB (2001)}

Conforme CERIB (2001), considera-se que a transmissão de ações do pilar para o cálice de fundação, levando em consideração a conformidade entre as paredes do pilar e do colarinho, pode ser feita de duas maneiras: por ação e reação, no caso de interface lisa ou levemente rugosa ou por intermédio de chaves de cisalhamento (interface rugosa), no caso de paredes nervuradas.

Considera-se como superfície levemente rugosa, a superfície com relevos menores que $3 \mathrm{~mm}$ de profundidade e espaçados cerca de $40 \mathrm{~mm}$, ou a utilização de qualquer tipo de procedimento que chegue a um resultado equivalente. Já a ligação com paredes nervuradas, pode se considerar que se comporte como monolítica, portanto, dimensionada como tal.

São consideradas como nervuras as superfícies cuja configuração geométrica está ilustrada na Figura 2.34, conforme o EUROCODE (2001).

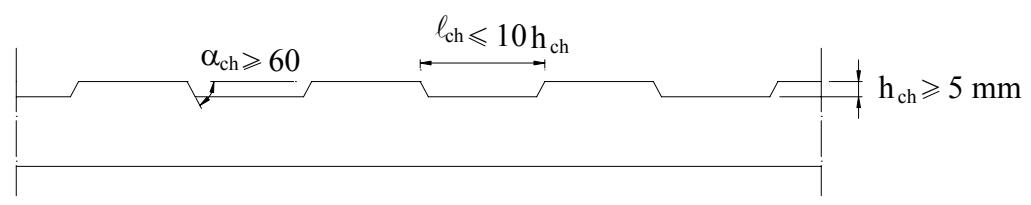

Figura 2.34 - Dimensões das chaves de cisalhamento - EUROCODE (2001)

Levando em consideração as definições comentadas acima, serão mostradas a seguir as recomendações de projeto descritas no CERIB (2001).

\subsubsection{Propriedades geométricas e resultantes de forças no cálice}

Na Figura 2.35 está ilustrado o esquema de forças atuantes no cálice de fundação tanto para ligações com interface lisa quanto interface levemente rugosa.

Recomenda-se que o espaçamento entre o pilar e o colarinho $h_{j}$ seja compatível com as tolerâncias de execução, ou seja, deve-se levar em conta a dimensão do equipamento que será utilizado para vibração do concreto de preenchimento. $\mathrm{O}$ valor recomendado é de $\ell_{\text {emb }} / 10$ com um valor mínimo de $50 \mathrm{~mm}$, entretanto sem exceder a $200 \mathrm{~mm}$ quando não for utilizado argamassa não retrátil. A resistência do concreto da junta (preenchimento) não deve ser inferior a $25 \mathrm{MPa}$ e sua granulometria deve ser 
adaptada em função do espaçamento $h_{j}$.

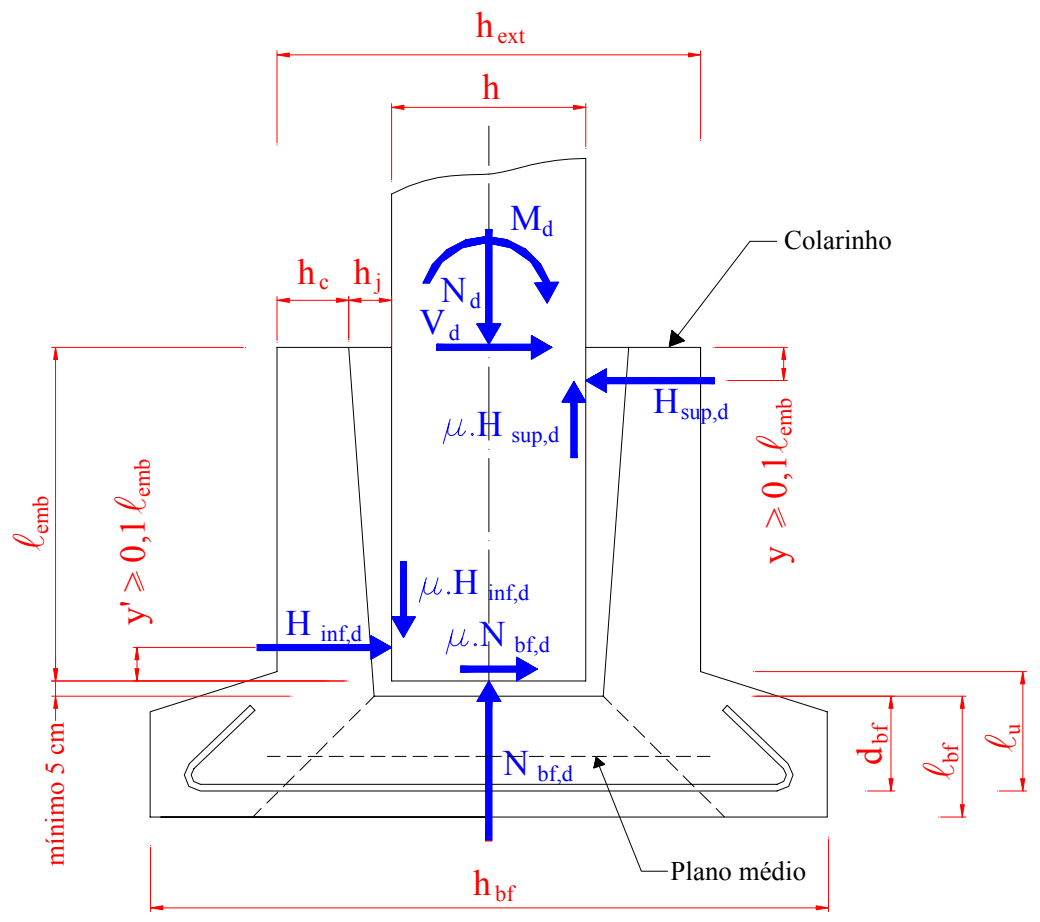

Figura 2.35 - Características geométricas e resultantes de forças na ligação pilar-fundação por meio de cálice - CERIB (2001)

Com relação à espessura no topo da parede do colarinho $h_{c}$, os autores recomendam que seja maior que $15 \mathrm{~cm}$, contanto que as dimensões transversais do pilar não sejam superiores a $60 \mathrm{~cm}$. Além disso, no caso de interface rugosa (com chaves de cisalhamento), é necessário aumentar a espessura da parede do colarinho em direção à base, pois é preciso garantir a rigidez frente ao monolitismo deste tipo de ligação.

O comprimento de embutimento $\ell_{e m b}$ é determinado de acordo com a seguinte relação:

$$
\ell_{e m b} \geq 1,2 h
$$

No caso de paredes nervuradas o comprimento deve ainda ser compatível com o comprimento de ancoragem das armaduras longitudinais do pilar como mostra a Figura 2.36. Esta ancoragem é feita por traspasse, com comprimento igual à parcela referente à aderência aço-concreto $\ell_{b}$ mais o espaçamento entre as armaduras $s$. 


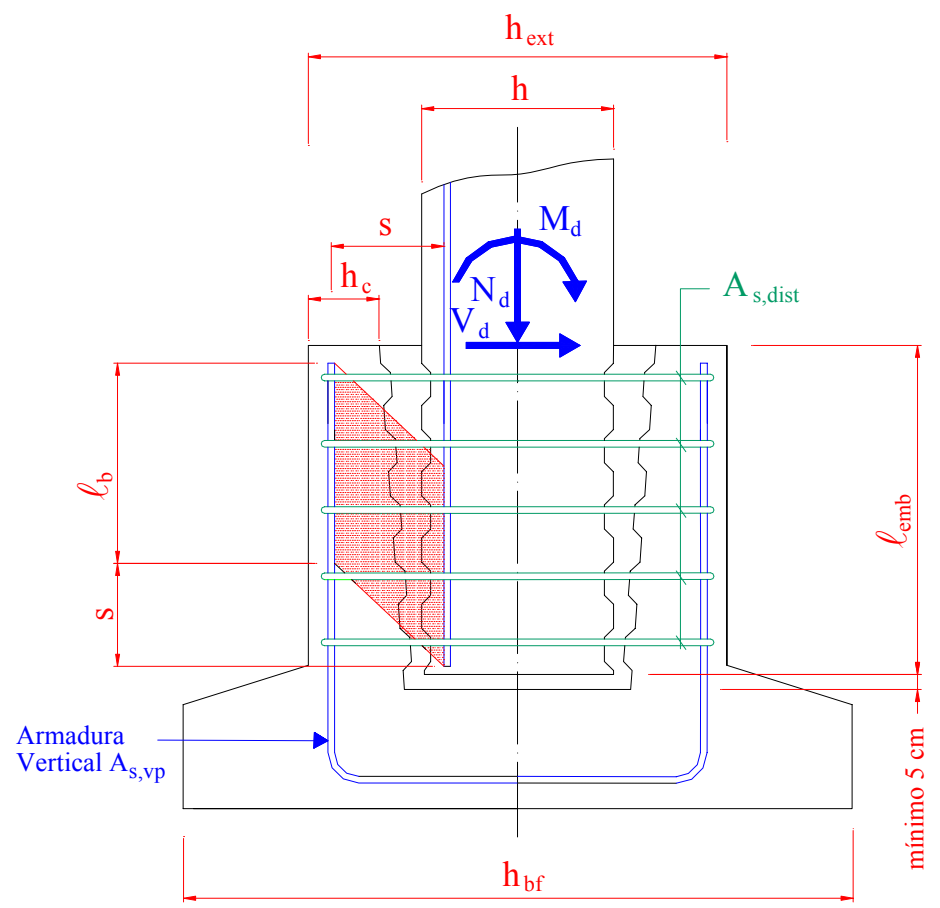

Figura 2.36 - Ancoragem das armaduras do pilar e da fundação - CERIB (2001)

Os esforços atuantes no cálice de fundação, no caso de interface lisa e levemente rugosa, podem ser determinados de acordo com as condições de equilíbrio do modelo apresentado na Figura 2.35:

- Equilíbrio de momentos:

$$
M_{d}=\left[\frac{\mu \cdot h}{2}-y\right] \cdot H_{s u p, d}+\left[\frac{\mu \cdot h}{2}+\ell_{e m b}-y^{\prime}\right] \cdot H_{i n f, d}+\left[\mu \cdot \ell_{e m b}\right] \cdot N_{b f, d}
$$

- Equilíbrio de forças verticais:

$$
N_{d}=\mu . H_{s u b, d}-\mu . H_{i n f, d}+N_{b f, d}
$$

- Equilíbrio de forças horizontais:

$$
V_{d}=H_{s u b, d}-H_{i n f, d}-\mu \cdot N_{b f, d}
$$

Conforme o EUROCODE (2001), o valor do coeficiente de atrito $\mu$, especificado para interface lisa, é zero e para a levemente rugosa, é 0,3 .

Levando em conta esses valores, têm-se as seguintes equações:

- Superfície lisa: 


$$
\begin{aligned}
& H_{s u p, d}=\frac{5}{4} \frac{M_{d}}{\ell_{e m b}}+\frac{9}{8} V_{d} \\
& H_{i n f, d}=\frac{5}{4} \frac{M_{d}}{\ell_{e m b}}+\frac{1}{8} V_{d} \\
& N_{b f, d}=N_{d}
\end{aligned}
$$

- Superfície levemente rugosa:

$$
\begin{aligned}
& H_{\text {sup }, d}=\frac{1,09 \cdot M_{d}-\left(0,03 \cdot \ell_{e m b}-0,045 \cdot h\right) \cdot N_{d}+\left(0,99 \cdot \ell_{e m b}+0,15 \cdot h\right) \cdot V_{d}}{1,09 \cdot\left(0,8 \cdot \ell_{e m b}+0,3 \cdot h\right)} \\
& H_{\text {inf,d }}=\frac{1,09 \cdot M_{d}-\left(0,27 \cdot \ell_{e m b}-0,045 \cdot h\right) \cdot N_{d}+\left(0,19 \cdot \ell_{e m b}+0,15 \cdot h\right) \cdot V_{d}}{1,09 \cdot\left(0,8 \cdot \ell_{e m b}+0,3 \cdot h\right)} \\
& N_{b f, d}=\frac{0,3 \cdot V_{d}-N_{d}}{1,09}
\end{aligned}
$$

Substituindo a Equação (2.73) nas equações acima tem-se:

$$
\begin{aligned}
& H_{\text {sup, } d}=0,95 \frac{M_{d}}{\ell_{e m b}}+0,97 \cdot V_{d}+0,01 \cdot N_{d} \\
& H_{i n f, d}=0,95 \frac{M_{d}}{\ell_{e m b}}+0,27 \cdot V_{d}-0,2 \cdot N_{d} \\
& N_{b f, d}=0,27 \cdot V_{d}-0,92 \cdot N_{d}
\end{aligned}
$$

\subsubsection{Comportamento e dimensionamento das paredes do cálice}

A transmissão dos esforços atuantes nas paredes do cálice para a base da fundação se faz por meio de bielas e tirantes seguindo o modelo da Figura 2.37.

A força $H_{s u p, d}$ é absorvida pela armadura horizontal principal longitudinal $A_{s, h p}$ disposta em uma altura igual a $2 y$, ou seja, as armaduras são calculadas para resistir as forças de tração conforme o modelo de bielas e tirantes representado pela Figura 2.37, permitindo assim a transferência adequada das forças para base da fundação. 


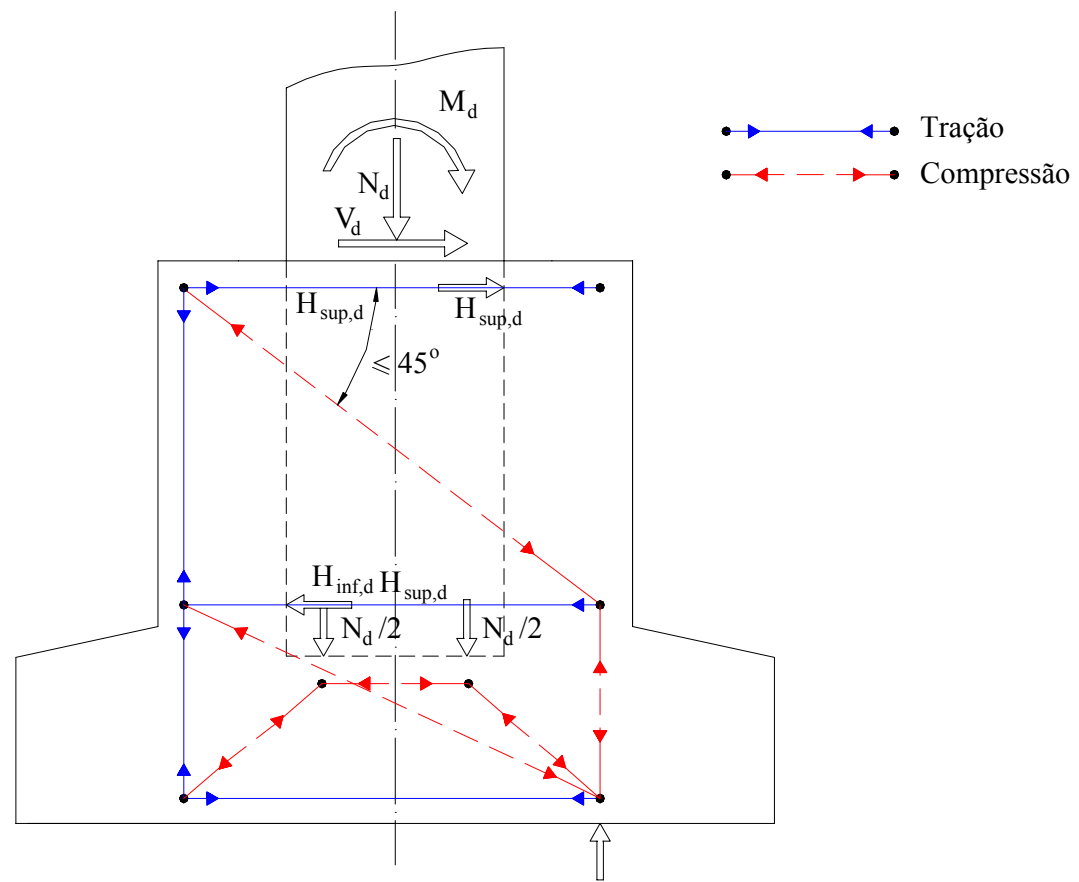

Figura 2.37 - Modelo de bielas e tirantes para transferência de esforços na ligação pilar fundação por meio de cálice - CERIB (2001)

No caso da ligação com paredes nervuradas (chaves de cisalhamento), a ligação é dimensionada com se fosse monolítica, ou seja, como se todos os esforços atuantes no pilar fossem perfeitamente transferidos para o cálice de fundação. Para isso, as armaduras longitudinais do pilar (Figura 2.36) devem assegurar a absorção dos esforços solicitantes que geram flexão composta transmitidos pelo pilar por meio das interfaces pilar - concreto de enchimento - colarinho. Portanto, essa armadura é dimensionada para resistir um esforço igual a:

$$
R_{s l, d}=\frac{M_{d}}{z}
$$

onde: $z$ é igual ao braço de alavanca das armaduras $A_{s, v p}$ do cálice.

Deve-se ainda no caso de paredes nervuradas, dispor de estribos horizontais $A_{s, d i s t}$ (Figura 2.36) com o objetivo de resistir as forças transversais de tração que surgem ao longo do comprimento de embutimento. Conforme descrito no EUROCODE (2001), essa armadura é tal que:

$$
\sum A_{s, d i s t} \geq A_{s, v p}
$$

De acordo com os autores, deve ser feita a verificação quanto às tensões 
cisalhantes na interface pilar-colarinho com interface rugosa. A capacidade resistente da ligação é determinada considerando a área $S_{r}$ ilustrada na Figura 2.38, cujo valor é definido pela seguinte relação:

$$
S_{r}=\left(b+\frac{h}{4}\right) \cdot \ell_{r}
$$

onde $\ell_{r}=\ell_{e m b}-s$

Com isso, a capacidade resistente da interface relativo ao cisalhamento é determinada a partir da força última conforme a seguinte relação, segundo EUROCODE (2001):

$$
F_{u}=C \cdot f_{c k}{ }^{2 / 3} \cdot S_{r}+\mu \cdot A_{h} \cdot \frac{f_{y d}}{\gamma_{s}} \leq 0,3 \cdot \frac{\left(1-f_{c k} / 250\right) \cdot f_{c k}}{\gamma_{c}} \cdot S_{r}
$$

onde:

$C$ e $\mu$ (Tabela 2.2): são coeficientes que depende da rugosidade da interface, considerando a superfície menos rugosa entre $R_{1}$ (rugosidade do pilar) e $R_{2}$ (rugosidade do colarinho)

$f_{c k}$ : é a resistência característica à compressão do concreto de menor resistência

$\gamma_{s}$ e $\gamma_{c}$ : são coeficientes de minoração da resistência do aço e do concreto respectivamente

$$
F_{u} \text { : é a força ultima na interface da ligação }
$$

Portanto, se a força $R_{s l, d}$ for maior que $F_{u}$, é conveniente reavaliar os parâmetros da ligação tais como: as características da rugosidade, a resistência do concreto, as armaduras horizontais e o comprimento de embutimento, procurando aumentar a capacidade resistente ao cisalhamento da ligação.

Tabela 2.2 - Coeficientes relativos a qualidade da interface - EUROCODE (2001)

\begin{tabular}{|c|c|c|}
\hline Tipo de superfície & $C$ & $\mu$ \\
\hline Nervurada & 0,07 & 0,9 \\
\hline Rugosa & 0,063 & 0,7 \\
\hline
\end{tabular}




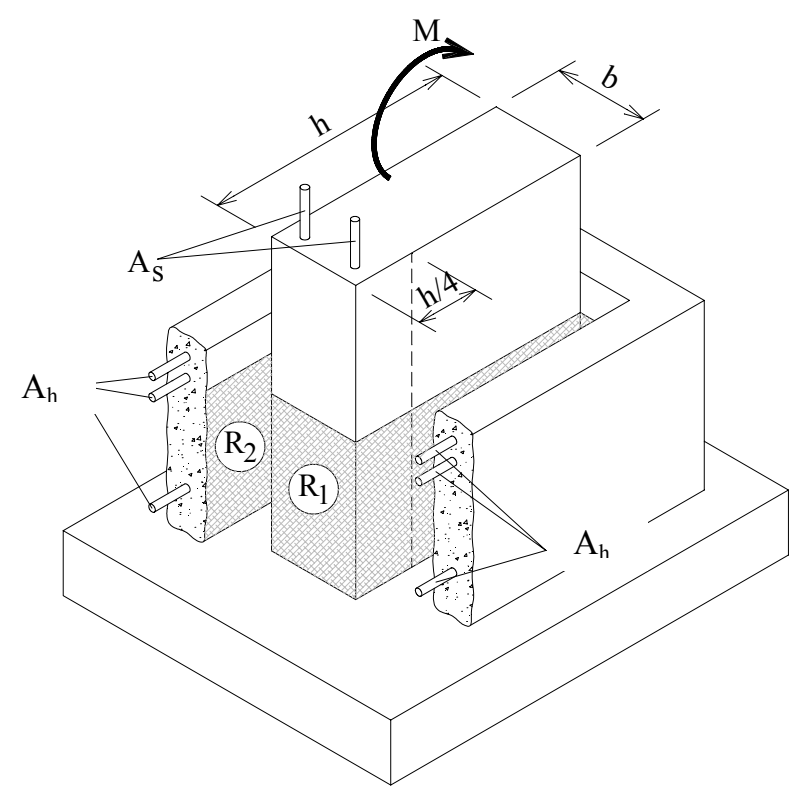

Figura 2.38 - Verificação das tenções de cisalhamento na interface pilar-colarinho com com interface rugosa - CERIB (2001)

\subsubsection{MODELO E RECOMENDAÇOES DE PROJETO DA EMPRESA MUNTE APRESENTADOS EM MELO (2004)}

O Manual Munte de Projetos em Pré-Fabricados de Concreto, organizado por MELO (2004), apresenta um modelo de projeto simples, prático e realista.

Deve-se obrigatoriamente utilizar ranhuras nas interfaces do colarinho e pilar, para um melhor comportamento da ligação. Dito isso, serão apresentados as principais recomendações de projeto referentes ao dimensionamento do colarinho, tais como a determinação dos esforços e o cálculo das armaduras.

\subsubsection{Resultantes de forças no cálice}

Na Figura 2.39 está apresentado o modelo teórico para o cálice com interface rugosa.

Para o comprimento de embutimento, MELO (2004) recomenda os seguintes valores, semelhantes aos apresentados na NBR 9062: (1985):

$$
\begin{aligned}
& \ell_{e m b} \geq 1,2 \mathrm{~h} \text { para } M_{d} / N_{d} \leq 0,15 h \\
& \ell_{e m b} \geq 1,6 h \text { para } M_{d} / N_{d} \geq 2,00 h
\end{aligned}
$$


com um valor mínimo de $40 \mathrm{~cm}$.

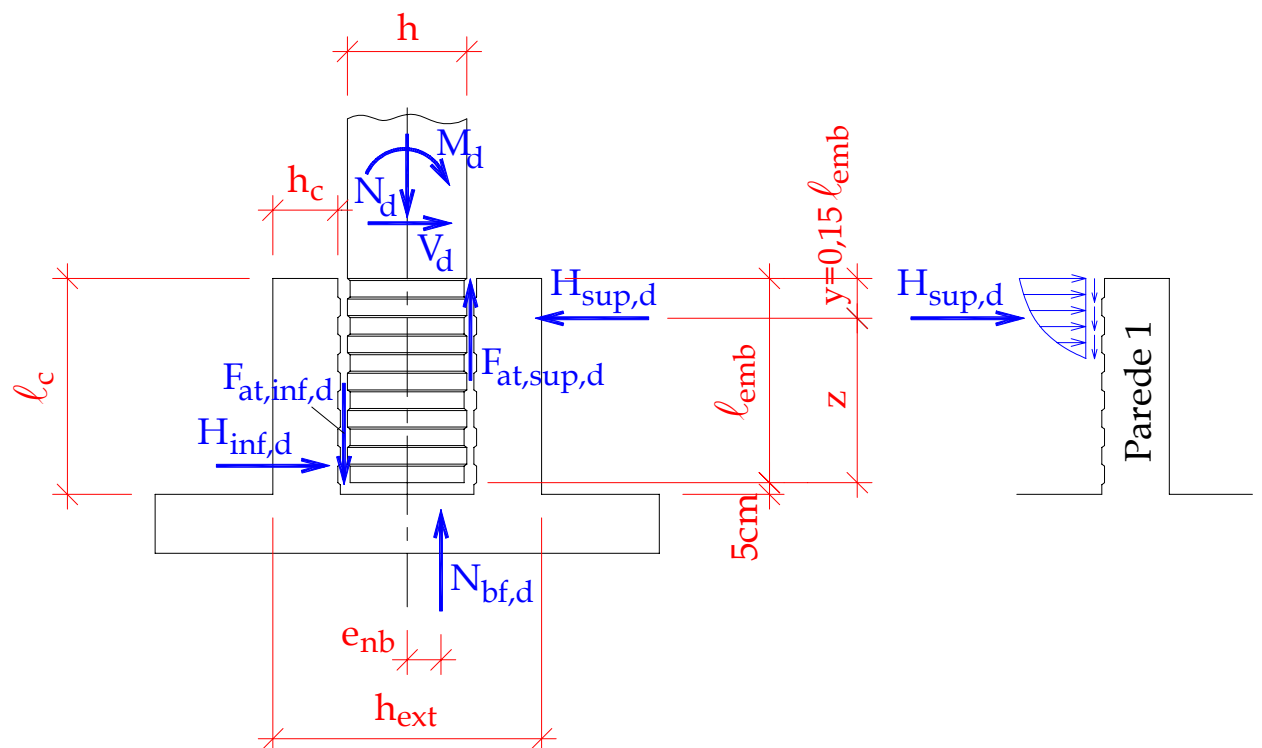

Figura 2.39 - Modelo teórico da Empresa Munte para cálice com interface rugosa-MELO (2004) adaptado por CANHA (2004)

Com o objetivo de uniformizar as medidas e níveis, o autor recomenda que, de maneira geral, se utilize o valor a favor da segurança de $\ell_{e m b} \geq 1,6 h$, pois não há um aumento no custo global da fundação em virtude do cálice apresentar menos armadura em função do binário resistente.

Levando em consideração as equações de equilíbrio da Figura 2.39, tem-se:

$$
\begin{aligned}
& M_{d}=F_{a t l, d} \cdot h+H_{s u p, d} \cdot z+N_{b f, d} \cdot e_{n b} \\
& N_{d}=N_{b f, d}+F_{a t, s u p, d}-F_{a t, i n f, d} \\
& V_{d}=H_{s u p, d}-H_{i n f, d}
\end{aligned}
$$

Os esforços atuantes no colarinho são divididos num esquema de parcelas resistentes ao momento solicitante, onde cada uma possui uma parte percentual resistente cuja soma é maior que $100 \%$ do esforço solicitante. Isto se deve pelo fato de não haver conhecimento do valor exato de cada parcela, portanto os coeficientes de segurança já se encontram embutido na equação. Com isso, a partir da Equação (2.90) definem-se as Equações (2.93), (2.94) e (2.95): 


$$
\begin{aligned}
& F_{a t l, d} \cdot h=0,45 M_{d} \\
& H_{s u p, d} \cdot z=0,85 M_{d}+1,2 V_{d} \cdot z \\
& N_{b f, d} \cdot e_{n b}=0,1 M_{d}
\end{aligned}
$$

O sistema se solucionará com a resolução de 8 equações e 8 incógnitas, portanto as últimas três equações são:

$$
\begin{aligned}
& N_{b f, d}=0,1 N_{d} \\
& F_{a t, i n f, d}=F_{a t 1, d}-F_{a t 2, d} \\
& F_{a t 2, d}=\frac{\left(N_{d}-N_{b f, d}\right)}{2}
\end{aligned}
$$

onde a Equação (2.96) é obtida levando em consideração que a força normal na base da fundação vale $10 \%$ da força total atuante.

A partir da Equação (2.96), obtém-se $N_{b f, d}$, que substituindo na Equação (2.95), encontra-se o valor da excentricidade $e_{n b}$ da reação normal na base da fundação. Caso esse valor seja maior que $h / 2$, deve-se adotar $e_{n b}=h / 2$, e conseqüentemente redefinir um novo percentual para a Equação (2.95). Posteriormente, deve-se ajustar as Equações (2.93) e (2.94) para que a soma dos três percentuais seja mantido em $1,4 M_{d}$. Da Equação (2.93) e (2.98), obtém-se o valor de $F_{a t l, d}$ e $F_{a t 2, d}$ respectivamente, que substituindo em (2.97), chega-se ao valor da força de atrito inferior $F_{a t, i n f, d}$, em que se esse valor for positivo, é de tração; e negativo, se for de compressão. Finalmente, com as Equações (2.91), (2.94) e (2.92), determinam-se as forças $F_{a t, i n f, d}, H_{s u p, d}$ e $H_{i n f, d}$ respectivamente e com isso definindo todas as forças atuantes no colarinho para o posterior cálculo das armaduras.

\subsubsection{Comportamento e dimensionamento das paredes do cálice}

A transferência das forças atuantes no pilar para as paredes transversais 1 e 2 do cálice, se dá basicamente por meio das resultantes de pressões $H_{s u p, d}, H_{i n f, d}, F_{a t, i n f, d} \mathrm{e}$ 
$F_{a t, s u p, d}$ conforme esquema apresentado na Figura 2.39.

A força $H_{\text {sup,d }}$ gera tensões de compressão na parede transversal 1 , onde são transferidas por flexão para as paredes longitudinais 3 e 4, que são dimensionadas como consolos engastados na fundação, transferindo os esforços diretamente para a base, com a armadura horizontal principal $A_{s, h p}$ e a armadura vertical principal $A_{s, v p}$ determinadas semelhantes ao disposto em LEONHARDT \& MÖNNIG (1977), dados por:

$$
\begin{aligned}
& A_{s, h p}=\frac{H_{s u p, d}}{2 \cdot f_{y d}} \\
& A_{s, v p}=\frac{F_{t i r, d}}{f_{y d}}
\end{aligned}
$$

com $F_{t i r, d}$ igual a força oriunda do consolo mais uma parcela da força de atrito inferior transmitida para a parede transversal 2, se seu sentido estiver para cima na interface colarinho-junta de acordo com a Figura 2.40:

$$
F_{t i r, d}=\frac{\left(H_{s u p, d} / 2\right) \cdot\left(\ell_{c}-y\right)}{\left(0,85 h_{e x t}-h_{c} / 2\right)}+0,75 F_{a t, i n f, d}
$$

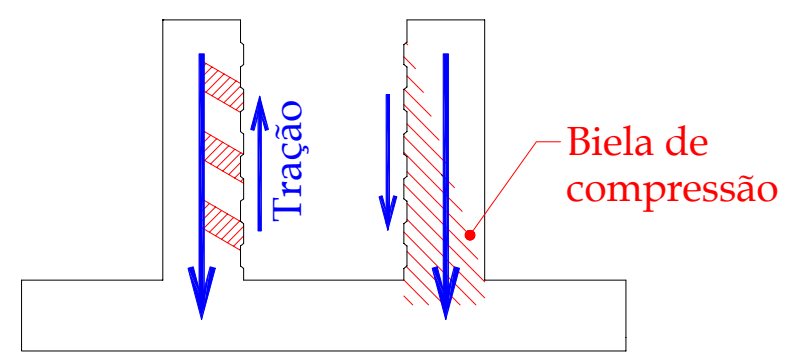

Figura 2.40 - Transmissão das forças de atrito $F_{a t, s u p, d}$ e $F_{a t, i n f, d}$ para o centro das paredes transversais 1 e 2 do colarinho, respectivamente - MELO (2004) adaptado por CANHA (2004)

$\mathrm{O}$ autor recomenda que se utilize $f_{y d}=420 \mathrm{MPa}$ e uma área mínima para $A_{s, v p}$ de $0,15 \% h_{c} \cdot\left(h_{i n t}+h_{c}\right)$.

Pelo fato das armaduras $A_{s, h p}$ e $A_{s, h f t}$ estarem na mesma posição, deve-se adotar a maior armadura entre elas. 
As áreas das armaduras secundárias verticais e horizontais $\left(A_{s, v s}\right.$ e $\left.A_{s, h s}\right)$, tanto na direção longitudinal como na transversal, devem ter o maior entre os valores abaixo:

$$
A_{s, v s}=A_{s, h s} \geq\left\{\begin{array}{l}
0,7 F_{a t, i n f, d} / f_{y d} \\
0,25 \cdot A_{s, v p}
\end{array}\right.
$$

\subsubsection{MODELO DE PROJETO PROPOSTO POR CANHA (2004)}

Este sem dúvida é o trabalho mais completo e recente sobre a ligação pilarfundação por meio de cálice em estruturas de concreto pré-moldado com ênfase no colarinho.

Na parte experimental, foram ensaiados cinco modelos em escala 1:1 sob força normal com grande excentricidade, variando-se o tipo e condição de interface, sendo três com interface lisa, onde em dois modelos procurou-se eliminar a adesão aplicando desmoldante entre a junta e os elementos para representar a situação mais adequada de projeto; e dois com interface rugosa, onde também aplicou-se desmoldante na interface da ligação, com diferentes configurações de chaves de cisalhamento.

Após as análises dos resultados dos protótipos ensaiados, a autora propôs um modelo de projeto para o cálice liso, considerando o atrito entre as interfaces e o cálculo das paredes longitudinais como consolos; e para o cálice rugoso, pelo fato de ter atingido uma resistência experimental próxima ao de uma ligação monolítica, recomendou o dimensionamento de suas armaduras verticais admitindo a transferência total dos esforços, e das armaduras superiores também com o funcionamento das paredes longitudinais como consolos.

Será apresentado neste item apenas o modelo de projeto proposto por CANHA (2004), já que os resultados referentes aos modelos físicos serão mostrados juntamente com os obtidos neste trabalho no Capítulo 5.

\subsubsection{Propriedades geométricas e resultantes de forças no cálice}

Quanto as dimensões geométricas do cálice, a autora recomenda que se utilize as encontradas em LEONHARDT \& MÖNNIG (1977) e na NBR 9062: (1985), ou seja:

- O comprimento de embutimento $\ell_{e m b}$ recomendado pela NBR 9062: (1985); 
- A espessura da parede do colarinho $h_{c}$ de no mínimo $10 \mathrm{~cm}$ e maior ou igual a $1 / 3$ da menor distância interna entre as paredes do colarinho $\left(h_{\text {int }}\right.$ ou $\left.b_{\text {int }}\right)$;

- A espessura da junta $h_{j}$ de no mínimo $5 \mathrm{~cm}$ e que possibilite a entrada do vibrador, no caso de concreto de granulometria fina confeccionado no local;

- As dimensões da base da fundação conforme o tipo de fundação adotada. No caso de sapata, recomenda-se um altura mínima $\ell_{b f}$ de $20 \mathrm{~cm}$, podendo-se reduzi-la com a utilização de armadura de suspensão e a verificação da punção na base.

Baseados nos resultados teóricos e experimentais, CANHA (2004) propôs um modelo de projeto para o cálice com interface lisa que considera a contribuição das forças de atrito $F_{a t, s u p}, F_{a t, i n f}$ e $F_{a t, b f}$ e a excentricidade $e_{n b}$ da reação normal na base do pilar $N_{b f}$. O esquema da atuação das forças no cálice está ilustrado na Figura 2.41.

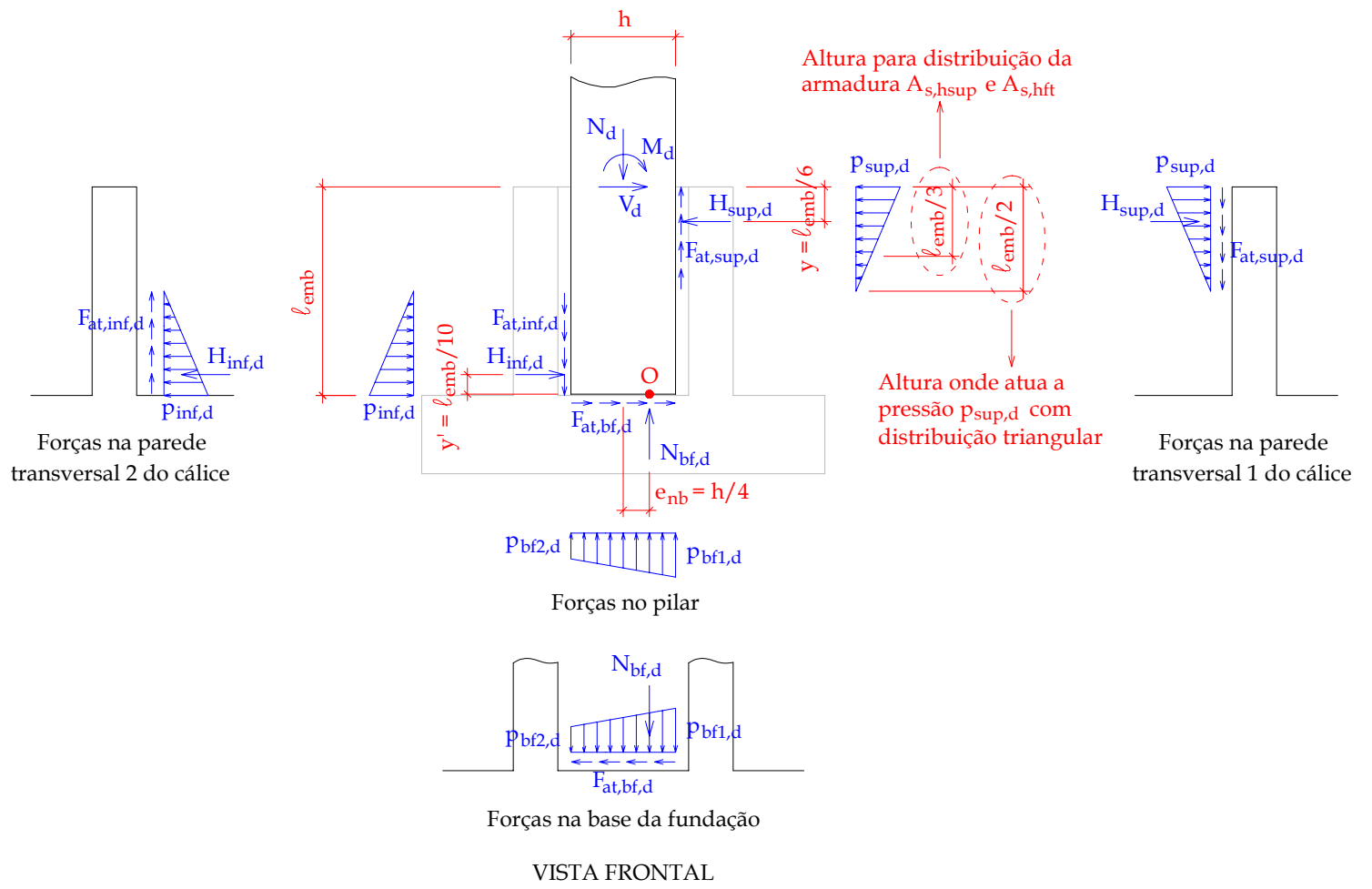

Figura 2.41 - Esquema de forças atuantes do modelo de projeto proposto para cálice com interface lisa - CANHA (2004)

As forças de atrito atuantes na ligação são definidas conforme as equações abaixo: 


$$
\begin{aligned}
& F_{a t, s u p, d}=\mu \cdot H_{s u p, d} \\
& F_{a t, i n f, d}=\mu \cdot H_{i n f, d} \\
& F_{a t, b f, d}=\mu . H_{b f, d}
\end{aligned}
$$

Das condições de equilíbrio, resultam as seguintes equações:

Equilíbrio de forças verticais:

$$
N_{d}-N_{b f, d}-F_{a t, s u p, d}+F_{a t, i n f, d}=0
$$

Equilíbrio de forças horizontais:

$$
V_{d}+F_{a t, b f, d}-H_{s u p, d}+H_{i n f, d}=0
$$

Equilíbrio de momentos no ponto $O$ :

$$
\begin{aligned}
& M_{d}-N_{d} \cdot e_{n b}+V_{d} \cdot \ell_{e m b}-H_{\text {sup }, d} \cdot\left(\ell_{e m b}-y\right)+H_{\text {inf }, d} \cdot y^{\prime}-F_{a t, \text { sup }, d} \cdot\left(0,5 h-e_{n b}\right)+ \\
& -F_{a t, \text { inf }, d} \cdot\left(0,5 h+e_{n b}\right)=0
\end{aligned}
$$

Fazendo as pertinentes substituições, tem-se:

$$
\begin{aligned}
& F_{a t, b f, d}=\frac{\mu \cdot N_{d}-\mu^{2} \cdot V_{d}}{1+\mu^{2}} \\
& N_{d}-N_{b f, d}-F_{a t, s u p, d}+F_{a t, i n f, d}=0
\end{aligned}
$$

Esses valores são então substituídos na Equação (2.108), resultando na Expressão (2.111).

$$
H_{\text {sup }, d}=\frac{M_{d}-N_{d} \cdot\left(e_{n b}+\frac{\mu \cdot y^{\prime}-\mu^{2} \cdot\left(0,5 h+e_{n b}\right)}{1+\mu^{2}}\right)+V_{d} \cdot\left(\ell_{e m b}-\frac{y^{\prime}-\mu \cdot\left(0,5 h+e_{n b}\right)}{1+\mu^{2}}\right)}{\ell_{e m b}-y-y^{\prime}+\mu \cdot h}
$$

No caso dos modelos ensaiados onde a força cortante horizontal é nula e $M_{d}=N_{d} . e$, a Equação (2.111) se resume em: 


$$
H_{\mathrm{sup}, d}=\frac{N_{d} \cdot\left(e-e_{n b}-\frac{\mu \cdot y^{\prime}-\mu^{2} \cdot\left(0,5 h+e_{n b}\right)}{1+\mu^{2}}\right)}{\ell_{e m b}-y-y^{\prime}+\mu \cdot h}
$$

Com o objetivo de calibrar a equação acima com a força ultima experimental, variou-se os seguintes parâmetros: $e_{n b}, y^{\prime}$ e $y$ e utilizou-se o coeficiente de atrito $\mu$ usual de 0,6 para interface lisa. Assim, com base nesses resultados, a autora recomenda para o projeto do cálice com interface lisa as Expressões (2.111) e (2.112), conforme o tipo de solicitação, com os parâmetros $\mu=0,6, e_{n b}=h / 4, y=\ell_{e m b} / 6$ e $y^{\prime}=\ell_{e m b} / 10$.

O valor de $e_{n b}=h / 4$ é referente, levando em conta o modelo de OSANAI et al. (1996) onde $e_{n b}$ é definida com a excentricidade da força de compressão $R_{c d}$ na base do pilar, ao limite do domínio 3 e 4, pois conforme CANHA (2004) este é o dimensionamento usual e mais econômico.

Quanto ao valor recomendado para $y$, a autora considera que as tensões de compressão na parede transversal 1 estejam distribuídas triangularmente $\left(y=\ell_{e m b} / 6\right)$, pois, adotando-se uma distribuição parabólica $\left(y=3 \ell_{\text {emb }} / 16\right)$, a resistência teórica se distanciou dos resultados experimentais, e portanto, manteve-se o valor de $y=\ell_{\text {emb }} / 6$, embora a armadura $A_{s, h p}$ continua sendo distribuída uniformemente ao longo do trecho superior de altura igual a $\ell_{e m b} / 3$, onde ocorre a maior concentrações de tensões.

O valor de $y^{\prime}=\ell_{e m b} / 10$ é o mesmo indicado por OLIN et al. (1985), e segundo CANHA (2004), apesar da força de compressão inferior $H_{i n f, d}$ ser absorvida diretamente pela base da fundação devido à sua pequena altura em ralação à base, é prudente considerar um valor diferente de zero de forma a abranger todo intervalo de grande excentricidade $(e \geq 2 h)$.

Este modelo deve ser aplicado aos casos de grandes excentricidades, em que a ação do momento predominante sobre a força normal tende a gerar a força de atrito $F_{a t, b f, d}$ na base da fundação com o mesmo sentido de $H_{i n f, d}$ e a força de atrito $F_{a t, i n f, d}$ na parede transversal 2 com o sentido para cima e no pilar com o sentido para baixo, como indicado na Figura 2.41.

Quanto ao dimensionamento da armadura de flexão disposta transversalmente na 
parede $1\left(A_{s, h f t}\right)$, CANHA (2004) apresenta uma idéia da distribuição de pressões nessa parede, no caso do cálice liso, com o objetivo de apresentar um modelo de projeto menos conservador comparado com os apresentados em EL DEBS (2000) e CNR10025 (1998) para o cálculo dessa armadura, que foi calibrado aos resultados adquiridos nas análises dos protótipos ensaiados. Será mostrado neste trabalho apenas a idealização das pressões na parede transversal 1 e o modelo de cálculo sugerido, não entrando em detalhes nos resultados da calibração desse modelo de projeto.

Conforme os resultados experimentais, percebeu-se que em todos os protótipos a armadura $A_{s, h f t}$ foi submetida à flexo-tração, ou seja, parte da pressão oriunda do pilar foi transferida diretamente para os apoios com diferentes inclinações, por motivo da constatação de fissuras com inclinações variáveis nessa região. Também foi observada uma fissura entre a junta e a parede transversal 1 , indicando o deslocamento no trecho central e que as pressões são nulas nessa região, portanto, a outra parcela da pressão oriunda do pilar está mais concentrada na região próxima aos apoios, ocasionando a flexão da parede. Segundo a autora, além dessas pressões, existe a força de atrito resultante da pressão de contato do pilar e a junta no cálice que não é direcionada para os apoios, no entanto, essa força de atrito não será considerada nos cálculos. A distribuição idealizada de pressões juntamente com as outras forças na parede transversal 1 e a correspondente modelagem do seu comportamento, são ilustrados na Figura 2.42 e Figura 2.43 respectivamente.

Calibrando o modelo com as deformações nas armaduras dos protótipos ensaiados, a autora chegou aos seguintes valores: $H_{\text {sup } 1, d} / H_{\text {sup }, d}=0,35$, $H_{\text {sup } 2, d} / H_{\text {sup }, d}=0,65$ e $n_{l}=5$, indicando que a maior parcela de $H_{\text {sup }, d}$ é direcionada para os apoios. A força de atrito $F_{a t, h f t, d}$ não foi considerada nos cálculos e adotou-se o ângulo $\theta$ igual a $45^{\circ}$, pois as dimensões dos modelos analisados são iguais nas duas direções.

Analisando o comportamento dos modelos rugosos, CANHA (2004) chegou a conclusão que realmente a resistência desses modelos se aproximou bastante ao da capacidade resistente de uma ligação monolítica, e que poderiam então ser dimensionados pela teoria da flexão, ou seja, considerando a transferência total do momento fletor e da força normal do pilar para o cálice de fundação. Tendo isso, a capacidade da ligação é determinada para a seção de concreto flexo-comprimida com 
área equivalente às dimensões externas do colarinho e com todas as armaduras verticais principais tracionadas do colarinho contribuindo, inclusive as secundárias, conforme o esquema ilustrado na Figura 2.44 (Modelo1).

A resultante $R_{c d}$ é determinada, considerando-se o valor da resistência média a compressão $f_{c m}$ do concreto do cálice e a distribuição de tensões parabólica-retangular. A linha neutra fica situada no domínio $2 a$ de deformação conforme a NBR 6118: (2003) e as armaduras comprimidas não são levadas em conta.

Tendo em vista a facilidade de cálculo e por apresentar resultados próximos aos modelos ensaiados, sugere-se adotar apenas as armaduras da parede transversal 2 $\left(2 A_{s, v p}+A_{s, v s}\right)$ contribuindo para a resistência do cálice e a distribuição de tensões retangular, conforme ilustrado na Figura 2.44 (Modelo 2). No entanto, segundo CANHA (2004), esse procedimento deve ser utilizado somente quando a armadura de costura for determinada segundo a NBR 9062: (1985), de acordo com o percentual da armadura do tirante conforme a classificação de consolo referente as paredes longitudinais 3 e 4 .
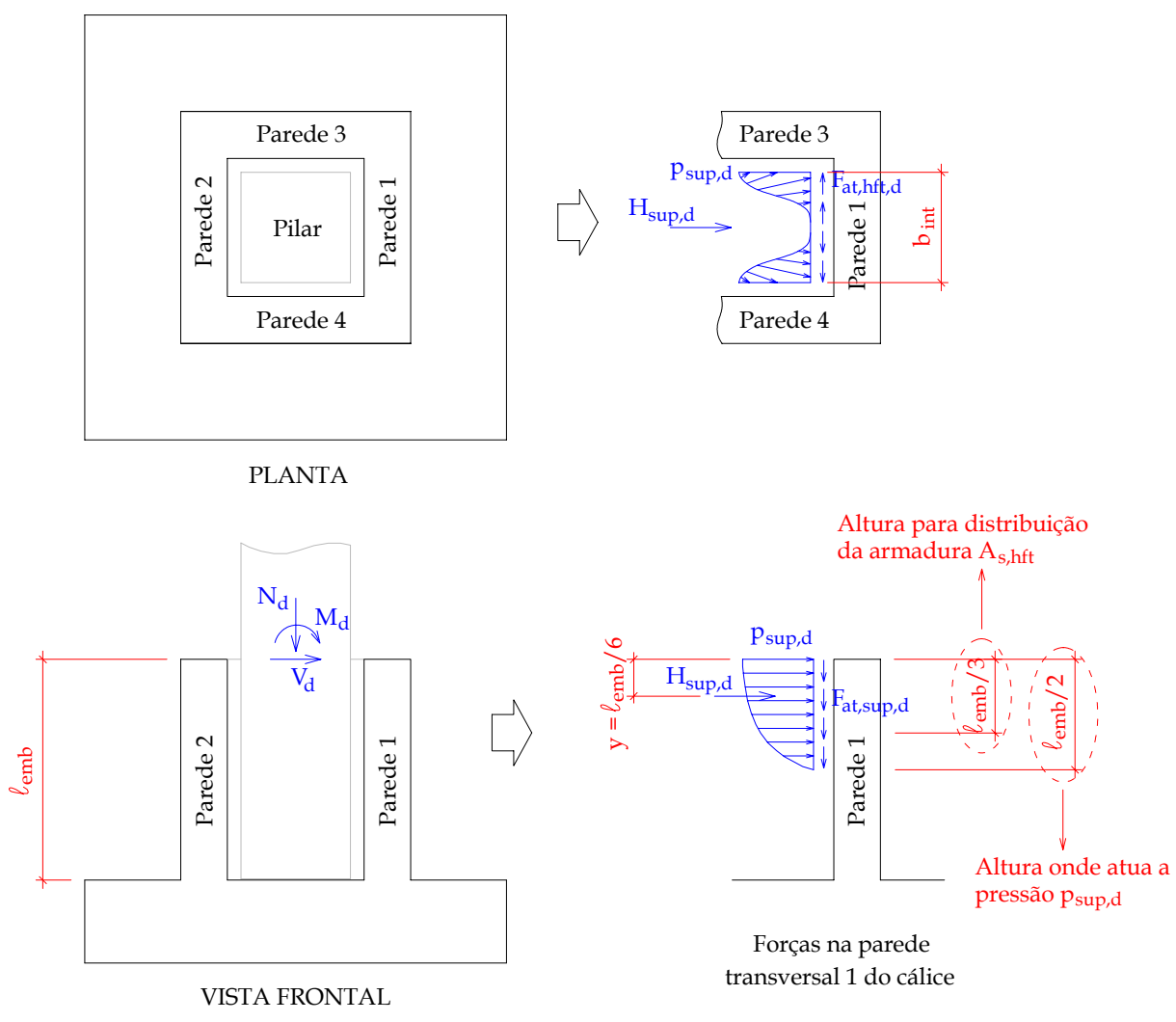

Figura 2.42 - Idealização da distribuição de pressões na parede transversal 1 do cálice com interface lisa - CANHA (2004) 


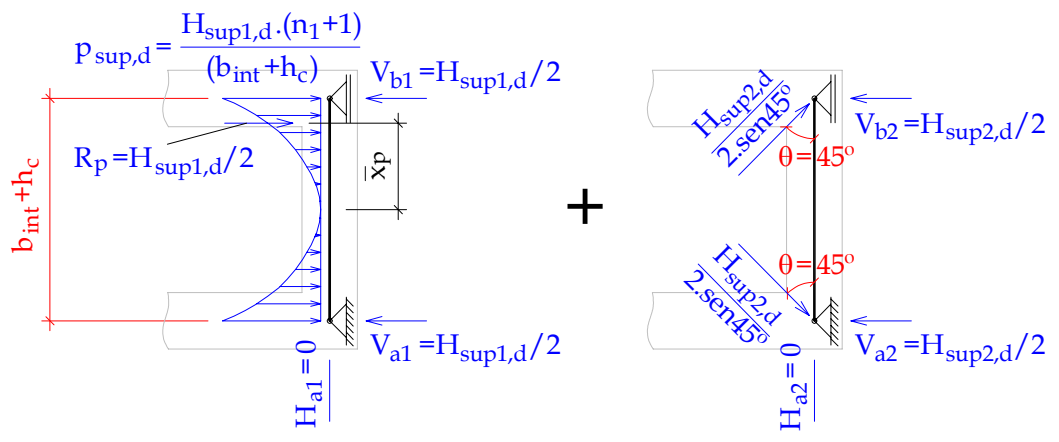

PLANTA

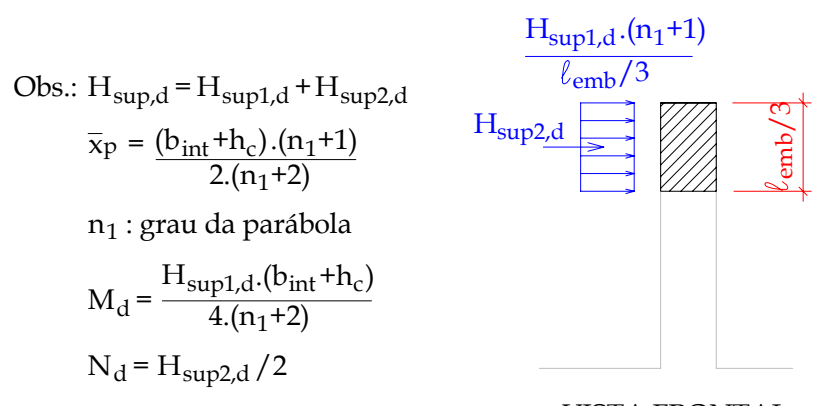

VISTA FRONTAL

Figura 2.43 -Modelo do comportamento da parede transversal 1 do cálice com interface lisa CANHA (2004)



Figura 2.44 - Dimensionamento das armaduras para cálice com interface rugosa

Caso contrario, deve-se utilizar o caso mais preciso, ou seja, em que são consideradas as armaduras verticais com suas respectivas alturas úteis. 
A autora ainda apresenta para fins de comparação com a capacidade da ligação determinada pelo escoamento das armaduras verticais, a aplicação do modelo de projeto para cálice liso (Equação (2.111)) com os seguintes parâmetros adaptados para o cálice rugoso: $\mu=1,0, e_{n b}=h / 4, y=3 \ell_{e m b} / 20$ e $y^{\prime}=\ell_{e m b} / 10$. Este modelo será chamado de agora em diante de modelo de CANHA (2004) com parâmetros alterados, para diferenciar do modelo para o cálice liso.

\subsubsection{Critérios para o dimensionamento das armaduras}

Para o cálice com interface lisa, conhecidos as forças externas atuantes no pilar, efetua-se o dimensionamento da armadura $A_{s, h p}$ para transmitir a força $H_{s u p, d}$ determinada pela Equação (2.111) com os parâmetros $\mu=0,6, e_{n b}=h / 4, y=\ell_{e m b} / 6$ e $y^{\prime}=\ell_{e m b} / 10$ indicados no item anterior.

No que diz respeito ao dimensionamento da armadura vertical principal (tirante do consolo) $A_{s, v p}$ e a verificação da resistência à compressão do concreto devem ser feitos conforme o modelo LEONHARDT \& MÖNNIG (1977), ou seja, considerando as paredes longitudinais 3 e 4 como consolos engastados na fundação. Quanto as armaduras verticais e horizontais secundárias $\left(A_{s, v s}\right.$ e $\left.A_{s, h s}\right)$, devem ser calculadas conforme as recomendações para consolos da NBR 9062: (1985).

Para o dimensionamento da armadura vertical do cálice rugoso, sugere adotar o Modelo 2 da Figura 2.44, ou seja, efetuar o cálculo da ligação monolítica pela teoria de flexão com a contribuição das armaduras da parede transversal $2\left(2 A_{s, v p}+A_{s, v s}\right)$. No entanto, conforme mencionado anteriormente, deve-se adotar para armadura vertical secundária $A_{s, v s}$ um percentual da armadura $A_{s, v p}$ conforme o tipo de consolo em que a parede longitudinal se classifica segundo as recomendações da NBR 9062: (1985). Segundo CANHA (2004), embora o dimensionamento da armadura $A_{s, h p}$ pelo modelo de LEONHARDT \& MÖNNIG (1977) tenha sido conservador para o modelo rugoso conforme foi constatado nos resultados experimentais, recomenda-se após o cálculo da armadura vertical principal $A_{s, v p}$, efetuar o dimensionamento de $A_{s, h p}$ com o procedimento de biela e tirante para consolo, pois ainda não foi possível chegar a um modelo de projeto mais consistente. 


\subsection{RESUMO DOS PRINCIPAIS PARÂMETROS DOS MODELOS DE PROJETO}

Com a finalidade de melhor visualizar os principais parâmetros sugeridos pelos autores apresentados neste capítulo, mostra-se na Tabela 2.3 um resumo contendo todos os modelos de projeto analisados neste trabalho e suas respectivas recomendações.

As letras encontradas na coluna referente a interface significam:

L: Lisa;

R: Rugosa;

LR: Levemente rugosa;

$\mathrm{N}$ : Nervurada

LPA: Lisa com parâmetros alterados.

Vale lembrar que em alguns modelos de projeto nada se comenta sobre cálice rugoso, portanto neste caso apresentam-se apenas as recomendações sobre a ligação com interface lisa.

Os comprimentos de embutimento mínimos apresentados são referentes, quando o modelo faz esta distinção, aos carregamentos com grande excentricidade, pois os protótipos aqui ensaiados estão submetidos a uma força normal com excentricidade igual a $3 h$, ou seja, maior que $2 h$ definido nos modelos de projeto como limite.

A palavra ancoragem (Anc.) encontrada na coluna referente ao comprimento de embutimento significa que o modelo, no caso de interface rugosa, não faz referência a um determinado valor e sim recomenda que o valor de $\ell_{e m b}$ tenha que ser no mínimo igual ao comprimento de ancoragem, ou seja, o comprimento de traspasse entre a armadura vertical principal do colarinho e a armadura longitudinal do pilar, conforme a Figura 2.33 e Figura 2.36 .

Quanto ao coeficiente de atrito $\mu$, são apresentados os valores recomendados por cada autor e para cada tipo de interface, obviamente quando o modelo em questão levar em consideração a força de atrito no dimensionamento do cálice.

Alguns modelos de projeto apresentados neste capítulo leva em consideração a excentricidade da reação da base do pilar $e_{n b}$ causada pelo momento resultante que atua na região de embutimento no Estado Limite Último, e por isso são apresentados na 
tabela adiante.

O braço de alavanca $z$ é a distância entres as resultantes de pressão $H_{\text {sup,d }} \mathrm{e}$ $H_{i n f, d}$ ou em alguns modelos entre $H_{\text {sup,d }}$ e $R_{i n f, d}$.

Algumas observações tiveram que ser feitas e por isso foram marcadas com asterisco na Tabela 2.3, tais como:

(*) Quando houver apenas força normal excêntrica (Figura 2.21 (a)):

(**) Quando houver força normal excêntrica e força cortante horizontal (Figura $2.21(b))$, onde:

$$
\begin{aligned}
& \ell_{v}=\frac{V_{d}}{0,4 f_{c d} \cdot . b} \\
& \ell_{h}{ }^{2}-\left(\mu \cdot h+0,9 \ell_{e m b}-\ell_{v}\right) \cdot \ell_{h}+\frac{M_{d}+V_{d} \cdot\left(0,1 \ell_{e m b}+0,5 \ell_{v}\right)}{0,4 f_{c d} \cdot . b}=0 \\
& \ell_{v}+2 \ell_{h}<0,9 \cdot\left(0,9 \ell_{e m b}\right)
\end{aligned}
$$

(***) O braço de alavanca $z$ quando houver apenas força normal excêntrica é igual a $0,45 \ell_{e m b}$. Quando atuar também a força horizontal, o valor de $z$ deve ser determinado após o calculo dos valores de $\ell_{v}$ e $\ell_{h}$ conforme a Figura 2.21 (b).

(****) O valor da excentricidade $e_{n b}$ da reação normal na base da fundação é igual a $\frac{M_{d}}{N_{d}}$ e, caso esse valor seja maior que $h / 2$, deve-se adotar $e_{n b}=h / 2 \mathrm{e}$ consequentemente redefinir um novo percentual para a Equação (2.95), conforme foi comentado no item 2.4.8.1. 
Tabela 2.3 - Resumo dos principais parâmetros dos modelos de projeto

\begin{tabular}{|c|c|c|c|c|c|c|}
\hline & Int. & $\ell_{e m b}$ & $\mu$ & Resultante de pressão superior & $e_{n b}$ & $z$ \\
\hline \multirow{2}{*}{$\begin{array}{l}\text { LEONHARDT } \\
\text { \& MÖNNIG e } \\
\text { NBR: } 9062\end{array}$} & $\mathrm{~L}$ & $2,00 h$ & \multirow{2}{*}{ - } & $H_{\text {sup }, d}=\frac{3 M_{d}}{2 \ell_{e m b}}+\frac{5}{4} V_{d}$ & \multirow{2}{*}{ - } & $0,67 \ell_{e m b}$ \\
\hline & $\mathrm{R}$ & $1,60 h$ & & $H_{s u p, d}=\frac{6 M_{d}}{5 \ell_{e m b}}+\frac{6}{5} V_{d}$ & & $0,84 \ell_{e m b}$ \\
\hline $\begin{array}{c}\text { WILLERT \& } \\
\text { KESSER }\end{array}$ & $\mathrm{L}$ & $1,5 h$ & 0,67 & $H_{s u p, d}=\frac{6 \cdot M_{d}+\left[\ell_{e m b} \cdot\left(6-\beta_{z}\right)+3 \cdot \mu \cdot h\left(1+\beta_{z}\right)\right] \cdot V_{d}}{\ell_{e m b} \cdot\left(5-\beta_{z}\right)+3 \cdot \mu \cdot\left(1+\beta_{z}\right)}$ & - & $\begin{array}{l}0,17 \ell_{e m b} . \\
\left(5-\beta_{z}\right)\end{array}$ \\
\hline \multirow{2}{*}{ OLIN et al. } & $\mathrm{L}$ & \multirow{2}{*}{$1,30 h$} & 0,3 & $H_{\text {sup,d }}=\frac{M_{d}-e_{n b} \cdot h \cdot N_{d}+0,9 \cdot \ell_{e m b} \cdot V_{d}}{0,8 \cdot \ell_{e m b}+0,33 \cdot \mu \cdot h}$ & \multirow{2}{*}{$\frac{h}{6}$} & \multirow{2}{*}{$0,8 \ell_{e m b}$} \\
\hline & $\mathrm{R}$ & & 0,6 & $H_{s u p, d}=\frac{M_{d}-e_{n b} \cdot h \cdot N_{d}+0,9 \cdot \ell_{e m b} \cdot V_{d}-0,012 \cdot h^{2} \cdot f_{c t d} \cdot \ell_{e m b}}{0,8 \cdot \ell_{e m b}+0,33 \cdot \mu \cdot h}$ & & \\
\hline ELLIOTT & $\mathrm{L}$ & $1,50 h$ & 0,7 & $H_{s u p, d}=\frac{M_{d}}{0,45 \ell_{e m b}+\mu . h}(*) \quad$ e $\quad R_{s u p, d}=H_{s u p}+V_{d}=0,4 f_{c d}^{\prime} \cdot b \cdot\left(\ell_{v}+\ell_{h}\right)(* *)$ & - & $(* * *)$ \\
\hline \multirow[t]{2}{*}{ OSANAI et al. } & $\mathrm{L}$ & $1,50 h$ & 1,0 & $M_{d}-\left[e_{n b}-\frac{\mu^{2}\left(0,5 h+e_{n b}\right)}{1+\mu^{2}}\right] \cdot N_{d}+\left[0,78 \ell_{e m b}+\frac{\mu\left(0,5 h+e_{n b}\right)}{1+\mu^{2}}\right] . V_{d}$ & \multirow[t]{2}{*}{$\begin{array}{l}0,5 \ell_{e m b} \\
-\xi^{\prime} \cdot x\end{array}$} & \multirow[t]{2}{*}{$0,73 \ell_{e m b}$} \\
\hline & $\mathrm{R}$ & $1,00 h$ & 0,5 & & & \\
\hline
\end{tabular}









\section{INVESTIGAÇÃO EXPERIMENTAL}

\subsection{DEFINIÇÃO DAS VARIÁVEIS}

A investigação experimental realizada neste trabalho só foi viável, levando em conta o tempo previsto para o mestrado, em virtude dos dispositivos metálicos (estrutura de reação) já terem sido dimensionados e construídos anteriormente nos ensaios de ligação pilar-fundação por meio de chapa de base durante a prestação de serviços externos do Laboratório de Estruturas.

Quanto aos ensaios realizados por CANHA (2004), no qual tive a oportunidade de acompanhar e que foi de grande valia para realização desta pesquisa, essa estrutura de reação foi adaptada para ligação com cálice de fundação, e como os modelos físicos estudados neste trabalho possuem as mesmas características geométricas do que os ensaiados na pesquisa anterior, utilizou-se a mesma estrutura, conforme ilustrado na Figura 3.1.

O modelo foi fixado por chumbadores ao dispositivo de transição onde este foi acoplado na base metálica de reação. Na parte superior do pilar foi conectado uma viga metálica para aplicação da força normal excêntrica por meio de um atuador hidráulico. Este por sua vez foi fixado por um dispositivo na base metálica de reação, com o deslocamento do pistão para baixo, ou seja, tracionando o conjunto de rotulas e viga metálica disposta entre a viga superior e o atuador servo-hidráulico. Com isso, criou-se um circuito fechado de peças formando um sistema auto-equilibrado de ensaio.

$\mathrm{Na}$ pesquisa realizada por CANHA (2004), foram ensaiados 5 modelos sob flexão normal composta com grande excentricidade $(3,0 h$ e 4,6h), onde três tinham interface pilar-colarinho lisa (IL1, IL2, IL3) e dois interface rugosa (IR1, IR2) e as propriedades geométricas desses modelos determinadas segundo as recomendações de LEONHARDT \& MÖNNIG (1977) e NBR 9062: (1985).

Os valores de comprimento de embutimento utilizados pela autora $\left(\ell_{e m b}=2,0 . h\right.$ 
para interface lisa e $\ell_{e m b}=1,6 . h$ para interface rugosa) correspondem as recomendações da NBR 9062: (1985).

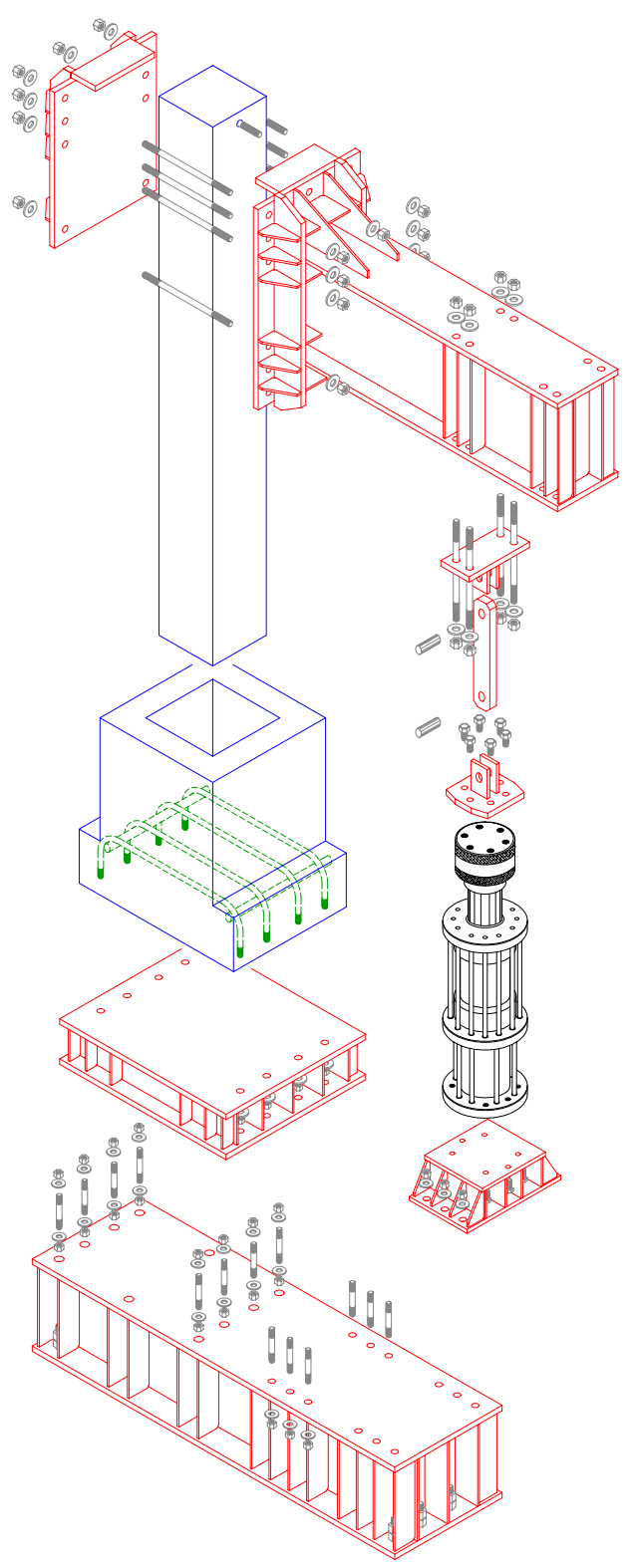

(a) Peças explodidas
Modelo

Chumbadores de fixação do cálice

Dispositivos metálicos

Atuador (INSTRON)

Parafusos, barras rosqueadas e pinos para ligação das peças

Figura 3.1-Esquema de ensaio dos modelos físicos - CANHA (2004)

Com o intuito de dar continuidade a essa pesquisa de doutorado, resolveu-se neste trabalho ensaiar mais dois modelos físicos com as mesmas propriedades e submetidos aos mesmos esforços, mas adotando comprimentos de embutimento menores, podendo com isso avaliar o comportamento de transferência das ações do pilar para as paredes do cálice utilizando comprimentos inferiores aos recomendados pela NBR 9062: (1985), e portanto analisar a possibilidade de adotar esses modelos para 
projetos.

Optou-se então por construir um protótipo com interface lisa (IL4) com profundidade de embutimento igual a $1,6 . h$ e o outro com interface rugosa (IR3) e profundidade de embutimento igual a 1,2.h, ou seja, todos os valores menores que os recomendados pela norma brasileira.

A Figura 3.2 e a Tabela 3.1 apresenta a nomenclatura e o resumo das dimensões dos modelos físicos ensaiados, respectivamente, inclusive os analisados por CANHA (2004). Os protótipos analisados neste trabalho estão destacados em vermelho na Tabela 3.1 (IL4 e IR3).

Todos os modelos tiveram sua geometria definida a partir de um pilar de seção quadrada $40 \mathrm{~cm} \times 40 \mathrm{~cm}$, no qual é bastante comum em edifícios de concreto prémoldado e foi adotado para espessura da parede do colarinho um valor igual a $h_{c}=h_{\text {int }} / 3$ recomendado por LEONHARDT \& MÖNNIG (1977).

Com exceção do Modelo IL1, o qual foi feito com concretagem normal da junta de forma a verificar se ocorria a transferência total do momento e força normal do pilar para o cálice, em todos os outros modelos analisados por CANHA(2004) tentou-se retirar a adesão das interfaces, aplicando desmoldante entre os elementos e a junta, pretendendo com isso simular uma situação mais adequada para projeto. Isto e justificável, pois não se garante um perfeito contato entre as interfaces, e no mais, durante a cura do concreto da junta, existe o fenômeno da retração que ocasiona um descolamento dos elementos. Portanto, retirando-se a adesão na interface da ligação, apenas a parcela referente ao atrito é mobilizada e com isso o comportamento da ligação se torna mais racional e a favor da segurança. Seguindo o mesmo raciocínio, nos Modelos IL4 e IR3 adotou-se o mesmo procedimento.

Quanto as excentricidades da força normal, nos primeiros modelos ensaiados por CANHA (2004) (IL1 e IL2), com o objetivo de garantir a ruptura do cálice de fundação e por causa da limitação da capacidade de força do atuador, utilizou-se uma excentricidade da força normal igual $1,85 \mathrm{~m}(4,6 h)$. Conhecida a capacidade experimental do Modelo IL2, reduziu-se para 1,2 $m(3 h)$ para o restante dos modelos, no qual é um valor mais próximo da realidade referente aos esforços nas estruturas em concreto pré-moldado. Portanto, nos modelos IL4 e IR3 resolveu-se utilizar essa mesma excentricidade para efeito de comparação. 

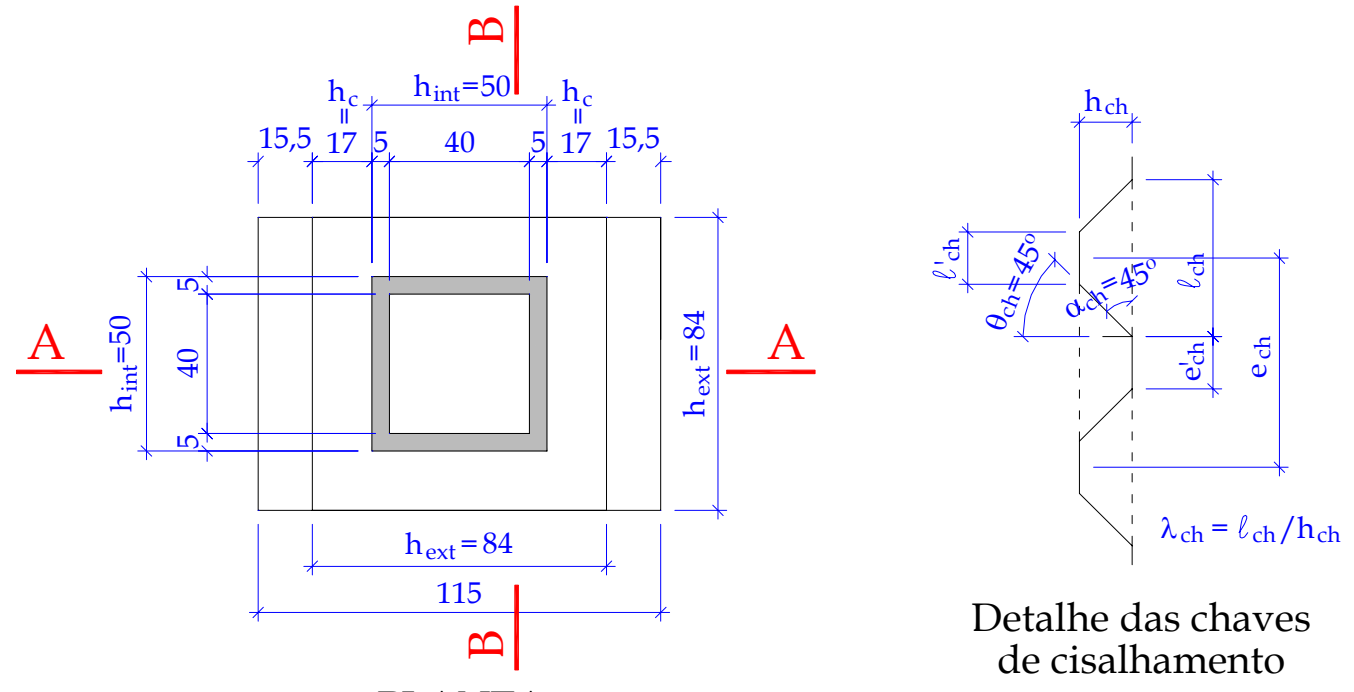

Detalhe das chaves

PLANTA
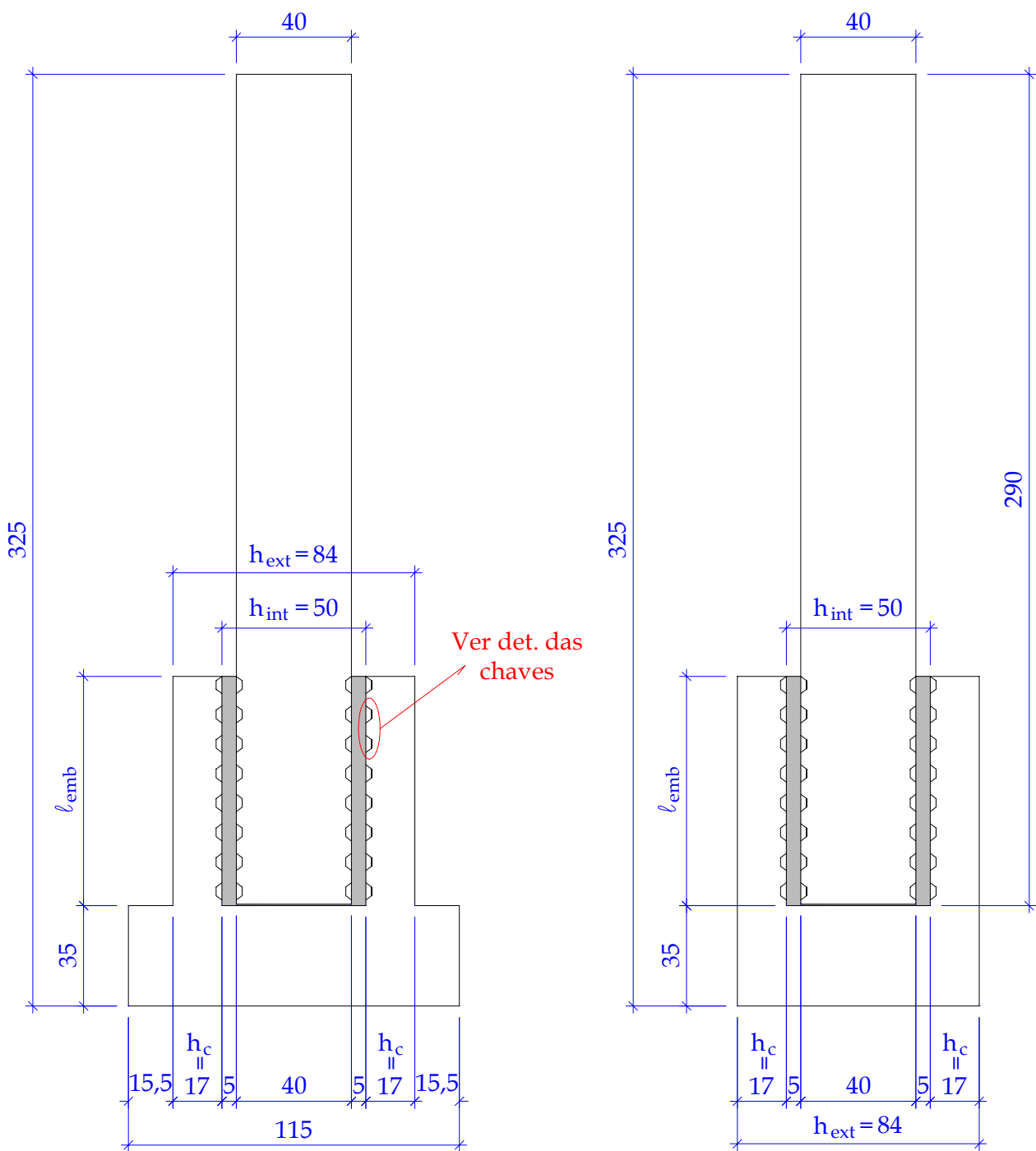

CORTE A-A

Ver det. das chaves

CORTE B-B

Obs.: dimensões em cm

Figura 3.2 - Nomenclatura das dimensões adotada para os modelos físicos - CANHA (2004) 
Tabela 3.1 - Resumo das propriedades geométricas dos modelos físicos ensaiados

\begin{tabular}{|c|c|c|c|c|c|c|c|c|c|}
\hline Série & Modelo & Interface & $\begin{array}{c}e \\
(\mathrm{~cm})\end{array}$ & $\begin{array}{l}\ell_{e m b} \\
(\mathrm{~cm})\end{array}$ & $\begin{array}{c}h_{c} \\
(\mathrm{~cm})\end{array}$ & $\alpha_{c h}$ & $\begin{array}{c}h_{c h} \\
(\mathrm{~cm})\end{array}$ & $\begin{array}{c}\ell_{c h} \\
(\mathrm{~cm})\end{array}$ & $\begin{array}{c}e_{c h}^{\prime} \\
(\mathrm{cm})\end{array}$ \\
\hline \multirow{4}{*}{ IL } & IL1 & Lisa & 185 & $80(2,0 h)$ & \multirow{4}{*}{17} & \multirow{4}{*}{-} & \multirow{4}{*}{ - } & \multirow{4}{*}{ - } & \multirow[t]{4}{*}{1} \\
\hline & IL2 & Lisa & 185 & $80(2,0 h)$ & & & & & \\
\hline & IL3 & Lisa & 120 & $80(2,0 h)$ & & & & & \\
\hline & IL4 & Lisa & 120 & $64(1,6 h)$ & & & & & \\
\hline \multirow{3}{*}{ IR } & IR1 & Rugosa & 120 & $64(1,6 h)$ & \multirow{3}{*}{17} & $45^{\circ}$ & 1 & 6 & 4 \\
\hline & IR2 & Rugosa & 120 & $64(1,6 h)$ & & $45^{\circ}$ & 1 & 3 & 1 \\
\hline & IR3 & Rugosa & 120 & $48(1,2 h)$ & & $45^{\circ}$ & 1 & 6 & 4 \\
\hline
\end{tabular}

\subsection{PROPRIEDADES DOS MODELOS FÍSICOS}

\subsubsection{DIMENSIONAMENTO E DETALHAMENTO DAS ARMADURAS}

O dimensionamento das armaduras do colarinho obedeceu ao modelo de LEONHARDT \& MÖNNIG (1977), juntamente com as recomendações da NBR-9062 (1985) e EL DEBS (2000) para o dimensionamento de consolo curto.

Como o objetivo da pesquisa é que a ruptura do modelo seja determinada pela ruptura do cálice, utilizou-se o processo inverso de dimensionamento das armaduras. Primeiramente adotou-se a armadura vertical principal e com isso calcularam-se as armaduras secundárias horizontais e verticais. Por último, foi determinada a armadura horizontal principal conforme o modelo de consolo curto. Esse procedimento de cálculo foi o mesmo utilizado por CANHA (2004), inclusive o valor da armadura vertical principal, ou seja, a única diferença entre os protótipos é a quantidade de armadura horizontal principal para transmitir $H_{\text {sup }}$, que depende exclusivamente da altura do colarinho, considerando que todos os protótipos resultaram em consolo curto. Na Figura 3.3 e Figura 3.4 são mostrados o posicionamento e o detalhamento dessas armaduras para o Modelo IL4, respectivamente.

Visando a facilidade de montagem das armaduras horizontais do cálice, ao invés de se utilizar estribos, já que se percebeu uma certa dificuldade de posicionamento dessas armaduras nos modelos realizados anteriormente, adotou-se um esquema diferente para representar-las. Resolveu-se fazer um quadro fechado que é disposto ao longo do perímetro das paredes do colarinho como se fosse o ramo externo do estribo. Para representar o ramo interno, foram feitos quatro elementos em forma de U que são posicionados na parte interna das quatro paredes do cálice consolidando a configuração 
final, conforme ilustrado na Figura 3.5.

Já que no trabalho de doutorado realizado anteriormente, as armaduras longitudinais do pilar e também os estribos tanto na região de embutimento quanto na parte superior do pilar foram determinadas para suportar uma flexo-compressão considerando a capacidade máxima do atuador e a uma excentricidade de $1,85 \mathrm{~m} .(4,6 \mathrm{~h})$, resolveu-se manter a mesma armadura, garantindo assim que a ruptura dos protótipos se dê pelo cálice. O detalhamento e o posicionamento das armaduras do pilar para o Modelo IL4, estão ilustrados na Figura 3.6 e Figura 3.7, respectivamente.

Pelo mesmo motivo já mencionado, no Modelo IR3 utilizou-se a mesma quantidade de armadura vertical principal e armadura vertical e horizontal secundária, com diferença apenas na quantidade de armadura horizontal principal, que com um comprimento de embutimento inferior foi necessário aumentar o diâmetro da armadura de 8 para $10 \mathrm{~mm}$ dispostas em 3 camadas, conforme ilustrado na Figura 3.8 e Figura 3.9.

No que diz respeito à armação do pilar, apenas foi alterado a quantidade de estribos disposto na região inferior (comprimento de embutimento), como mostra a Figura 3.10 e Figura 3.11 


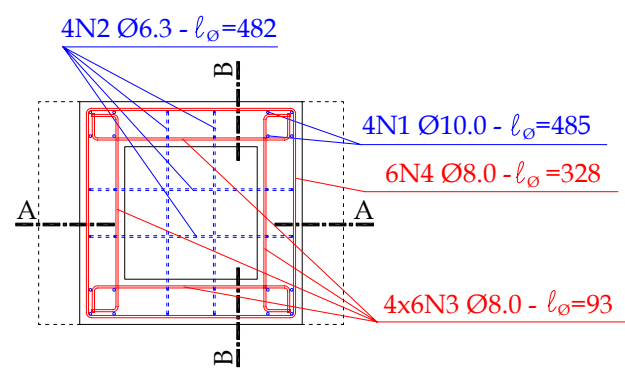

PLANTA BAIXA DAS

ARMADURAS PRINCIPAIS

DO COLARINHO

3X3N7 Ø6.3 c/7.5 - $\varnothing=193$

4 X3N6 Ø6.3 $\mathrm{c} / 7.5-\ell_{\varnothing}=255$

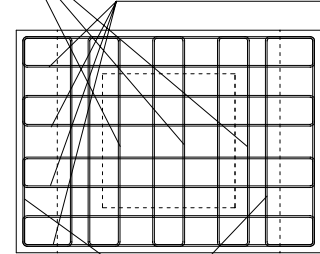

2X3N5 Ø6.3c/7.5 - $\varnothing \varnothing=207$

PLANTA BAIXA DA

ARMADURA DE DISTRIBUIÇÃO

DA BASE DA FUNDAÇÃO

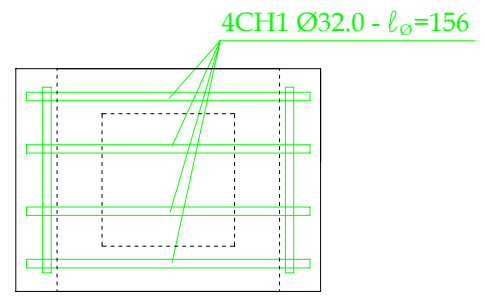

PLANTA BAIXA DA POSIÇÃO DOS CHUMBADORES

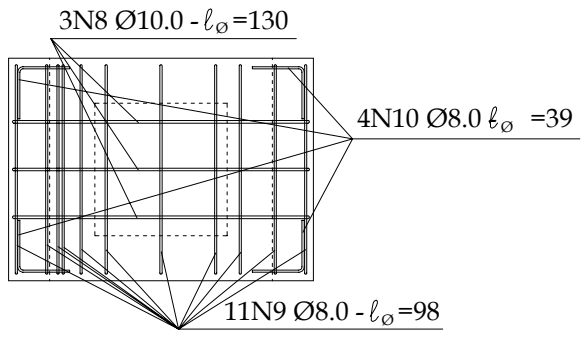

PLANTA BAIXA DA ARMADURA INFERIOR DA BASE DA FUNDAÇÃO


CORTE B-B

Obs: Comprimentos e espaçamentos em $\mathrm{cm}$ e diâmetros das armaduras em $\mathrm{mm}$.

Figura 3.3 -Posicionamento das armaduras do cálice de fundação do Modelo IL4 


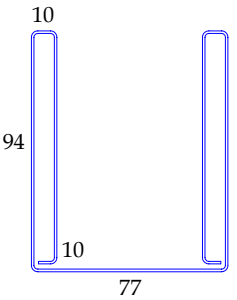

$4 \mathrm{~N} 1 \varnothing 10.0-\ell_{\varnothing}=485$ ARMADURA VERTICAL PRINCIPAL

10



$24 \mathrm{~N} 3 \varnothing 8.0-\ell_{\varnothing}=93$

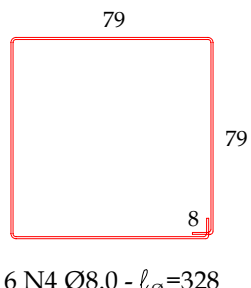

ARMADURA HORIZONTAL PRINCIPAL E SECUNDÁRIA

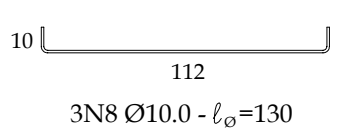

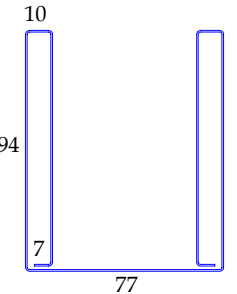

$4 \mathrm{~N} 2 \varnothing 6.3-\ell_{\varnothing}=482$ ARMADURA VERTICAL SECUNDÁRIA

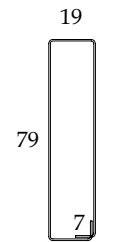

12

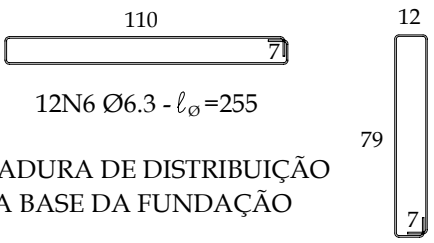

$6 \mathrm{~N} 5 \varnothing 6.3-\ell_{\varnothing}=207$

9N7Ø6.3 - $\ell_{\varnothing}=193$

ARMADURA INFERIOR
DA BASE DA FUNDAÇÃO

107,2

38,2

4CH1 Ø32.0 - $\ell_{\varnothing}=156$

CHUMBADORES DE LIGAÇÃO

DA BASE DA FUNDAÇÃO AO

DISPOSITIVO DE TRANSIÇÃO

Obs: Comprimentos e espaçamentos em $\mathrm{cm}$ e diâmetros das armaduras em $\mathrm{mm}$.

Figura 3.4 -Detalhamento das armaduras do cálice de fundação do Modelo IL4

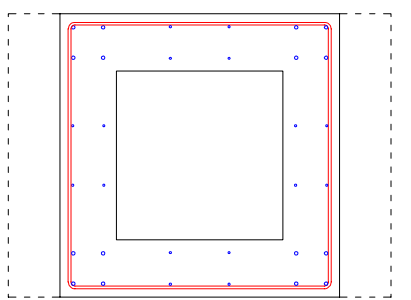

Quadro externo

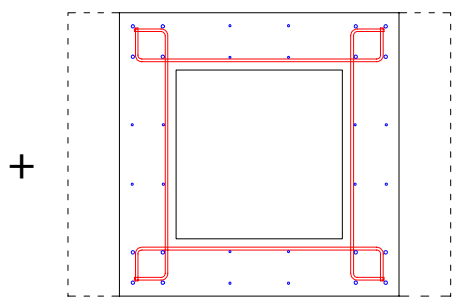

Elementos em forma de U

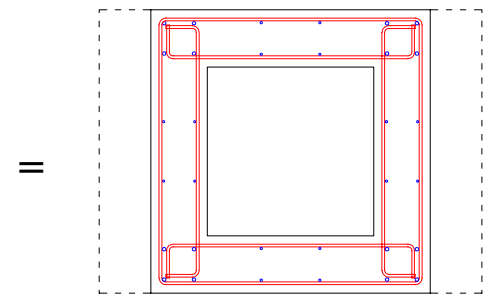

Composição final

Figura 3.5 -Detalhe da armadura horizontal dos Modelos IL4 e IR3 


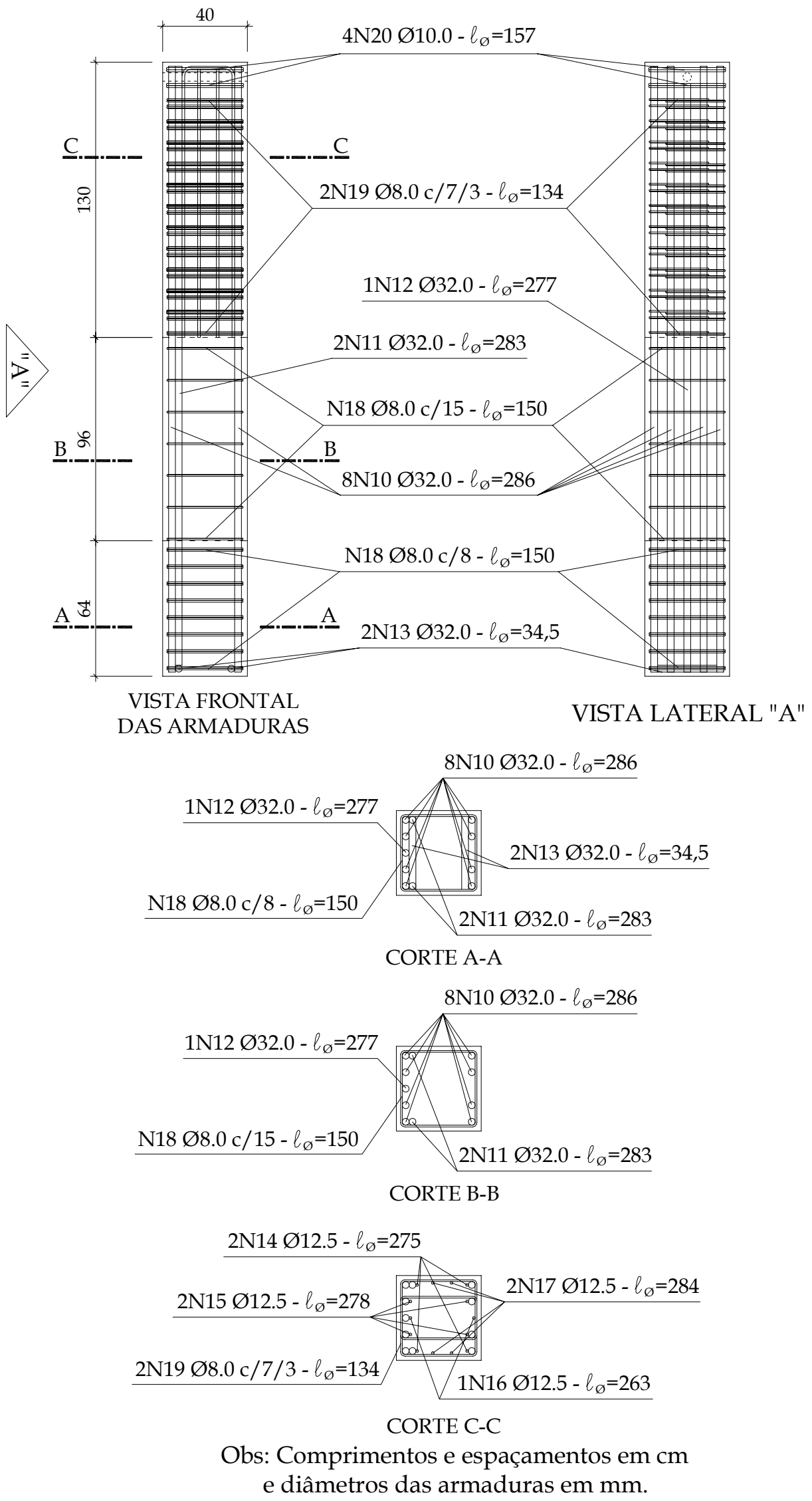

Figura 3.6 - Posicionamento das armaduras do pilar do Modelo IL4 


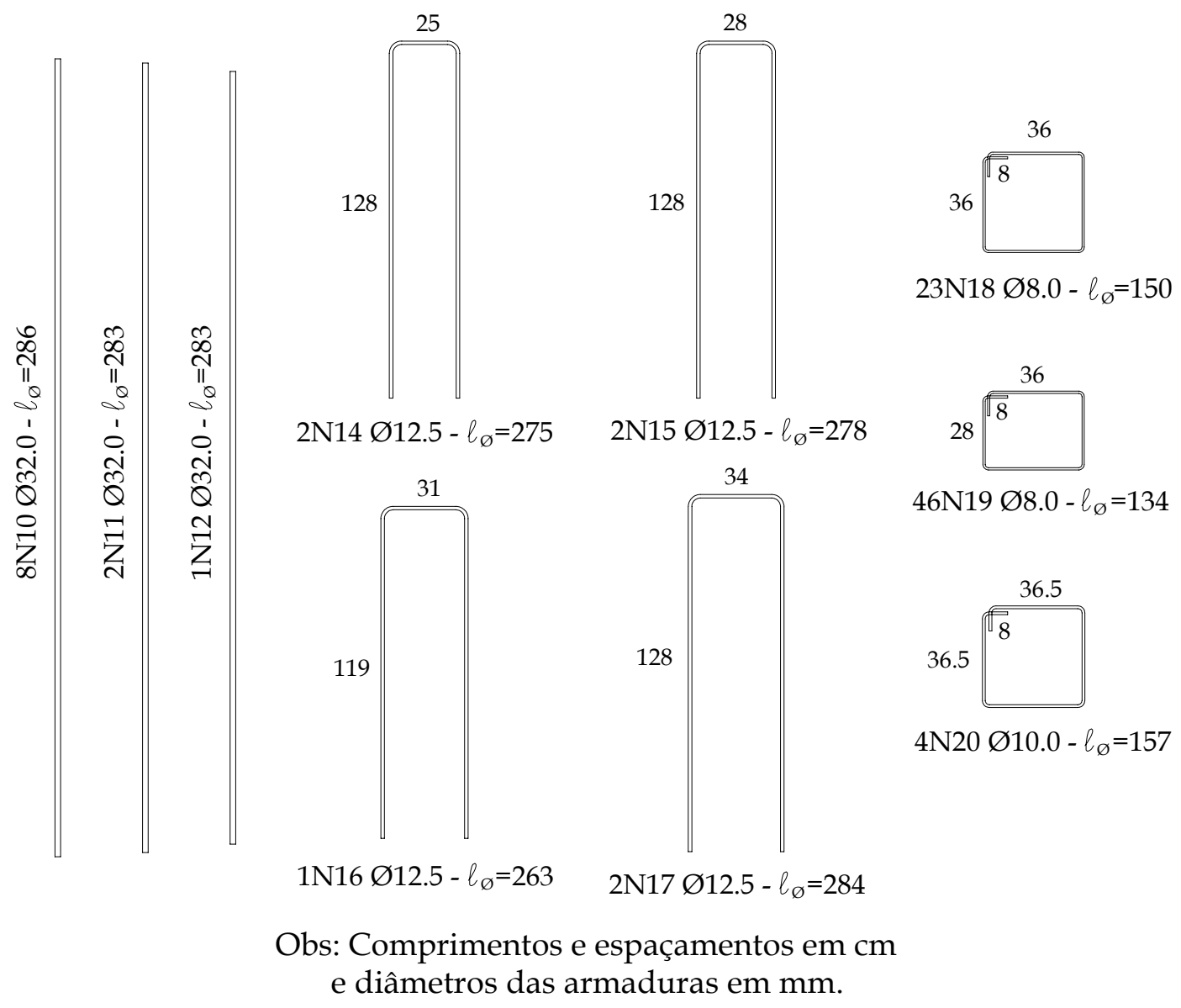

Figura 3.7 - Detalhe das armaduras do pilar do Modelo IL4 


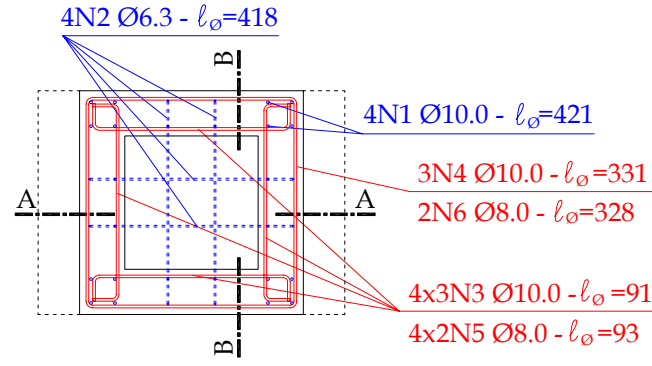

PLANTA BAIXA DAS ARMADURAS PRINCIPAIS DO COLARINHO

3X3N9 Ø6.3 $\mathrm{c} / 7.5-\ell_{\varnothing}=193$

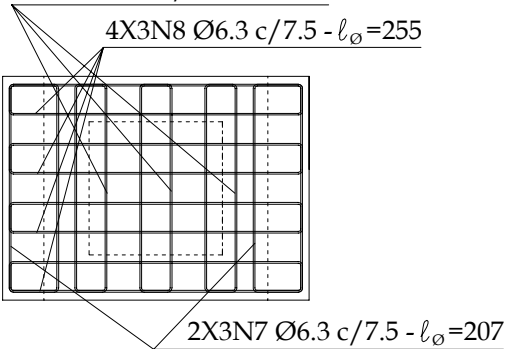

PLANTA BAIXA DA

ARMADURA DE DISTRIBUIÇÃO

DA BASE DA FUNDAÇÃO

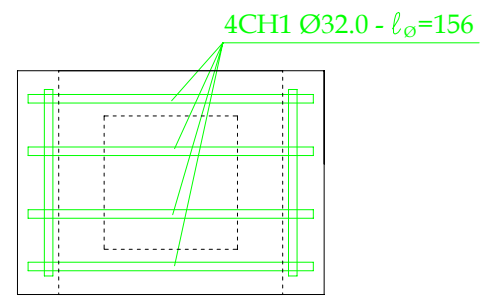

PLANTA BAIXA DA POSIÇÃO DOS CHUMBADORES



PLANTA BAIXA DA ARMADURA INFERIOR DA BASE DA FUNDAÇÃO
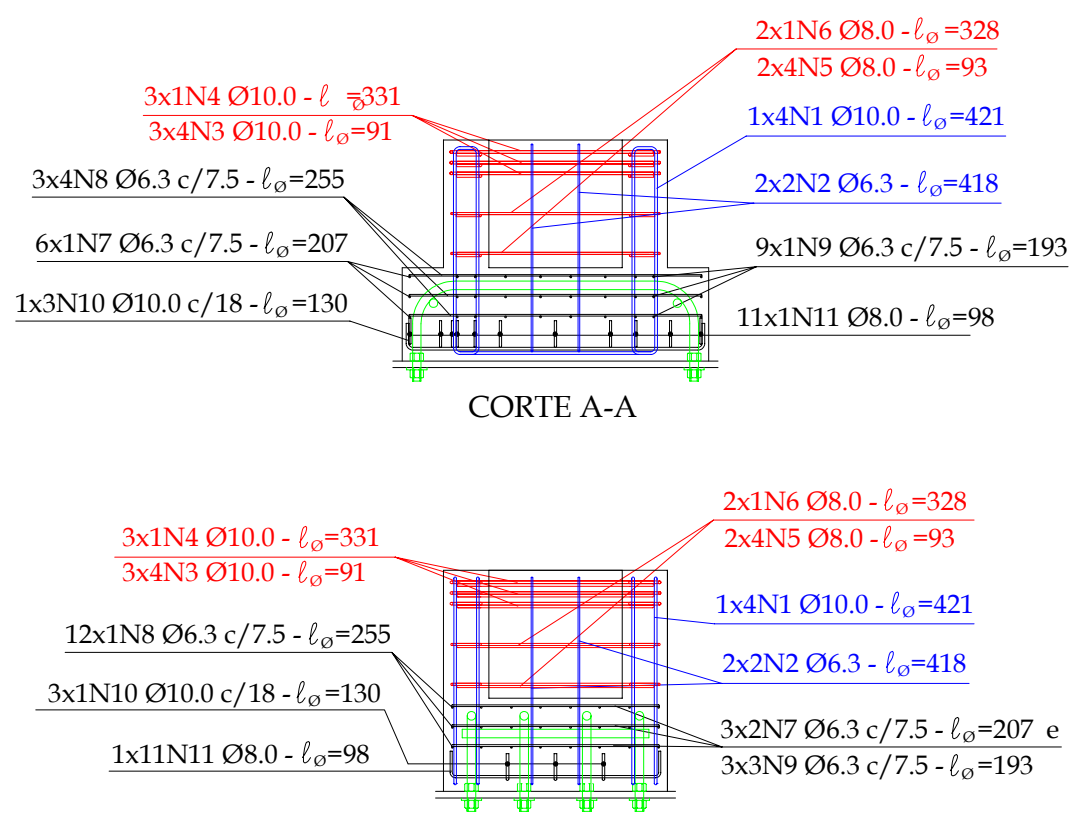

CORTE B-B

Obs: Comprimentos e espaçamentos em $\mathrm{cm}$ e diâmetros das armaduras em mm.

Figura 3.8 -Posicionamento das armaduras do cálice de fundação do Modelo IR3 


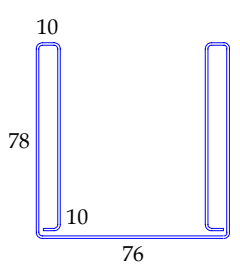

$4 \mathrm{~N} 1 \varnothing 10.0-\ell_{\varnothing}=421$

ARMADURA VERTICAL PRINCIPAL

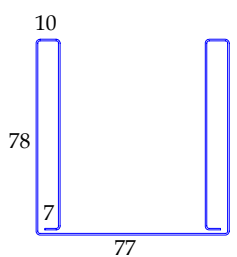

$4 \mathrm{~N} 2 \varnothing 6.3-\ell_{\varnothing}=418$

ARMADURA VERTIVAL SECUNDÁRIA
10

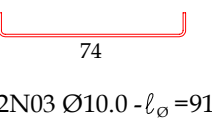

ARMADURA HORIZONTAL PRINCIPAL
79

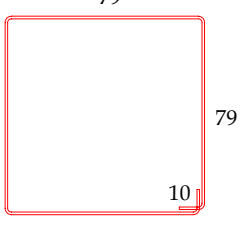

$3 \mathrm{~N} 4 \varnothing 10.0-\ell_{\varnothing}=331$
10

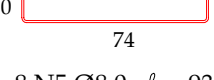

$8 \mathrm{~N} 5 \varnothing 8.0-\ell_{\varnothing}=93$
79

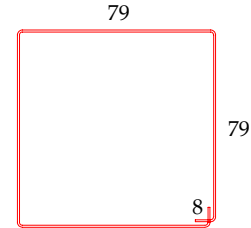

$2 \mathrm{~N} 6 \varnothing 8.0-\ell_{\varnothing}=328$

ARMADURA HORIZONTAL

SECUNDÁRIA

10



12

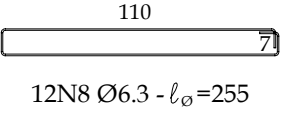

79

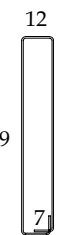

$6 \mathrm{~N} 7 \varnothing 6.3-\ell_{\varnothing}=207$

$9 \mathrm{~N} 9 \varnothing 6.3-\ell_{\emptyset}=193$

10

$$
3 \mathrm{~N} 10 \varnothing 10.0-\ell_{\varnothing}=130
$$

ARMADURA DE DISTRIBUIÇÃO

DA BASE DA FUNDAÇÃO
$20 \stackrel{\frac{20}{20}}{\stackrel{2}{2}} 20$

$4 \mathrm{~N} 12 \varnothing 8.0-\ell_{\varnothing}=39$

ARMADURA INFERIOR

DA BASE DA FUNDAÇÃO

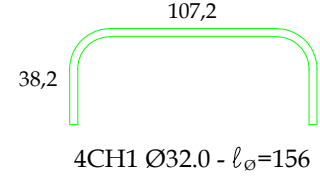

CHUMBADORES DE LIGAÇ̃̃O

DA BASE DA FUNDAÇÃO AO

DISPOSITIVO DE TRANSIÇÃO

Obs: Comprimentos e espaçamentos em $\mathrm{cm}$ e diâmetros das armaduras em $\mathrm{mm}$.

Figura 3.9 -Detalhamento das armaduras do cálice de fundação do Modelo IR3 


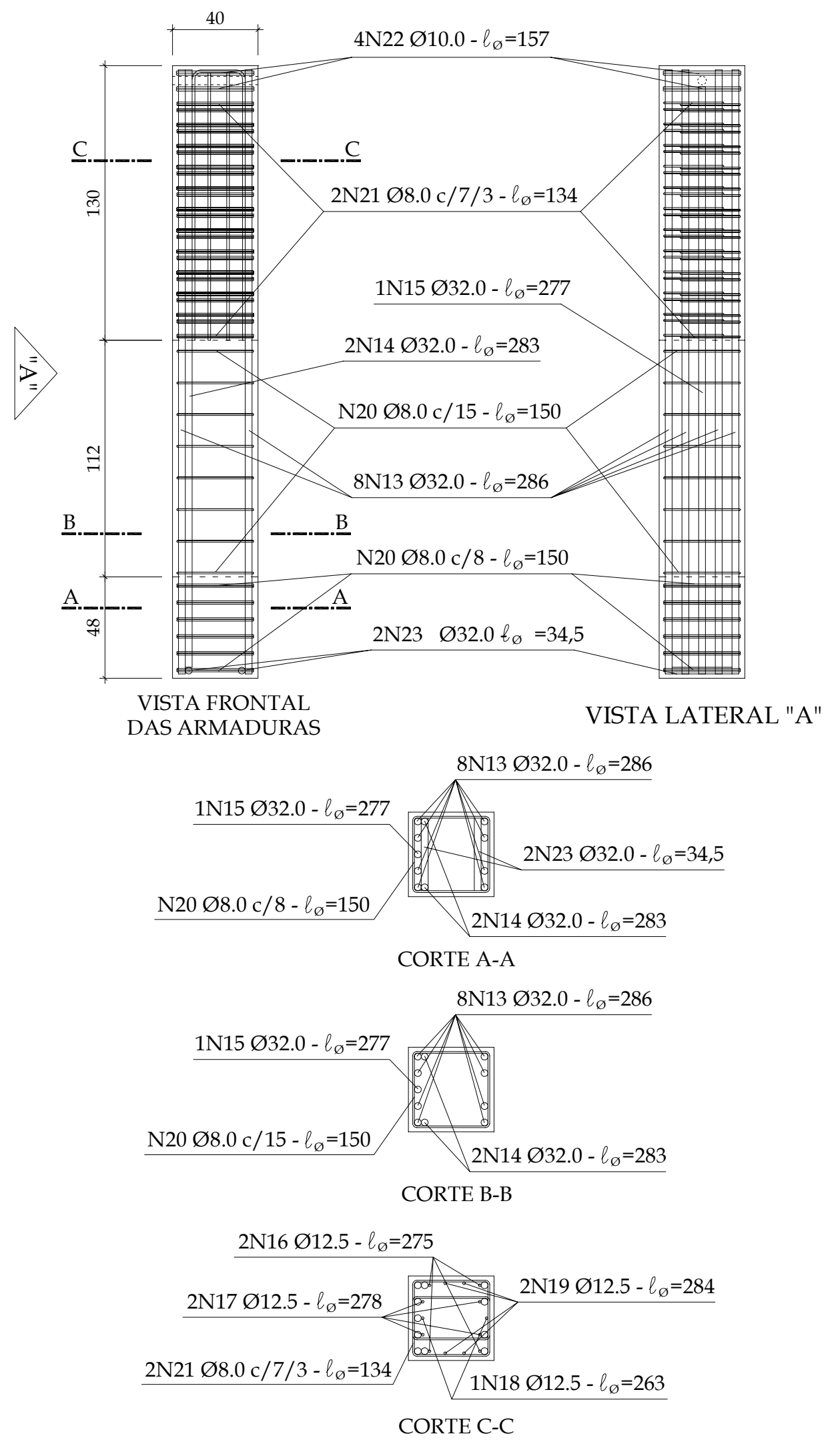

Obs: Comprimentos e espaçamentos em $\mathrm{cm}$ e diâmetros das armaduras em mm.

Figura 3.10 - Posicionamento das armaduras do pilar do Modelo IR3 


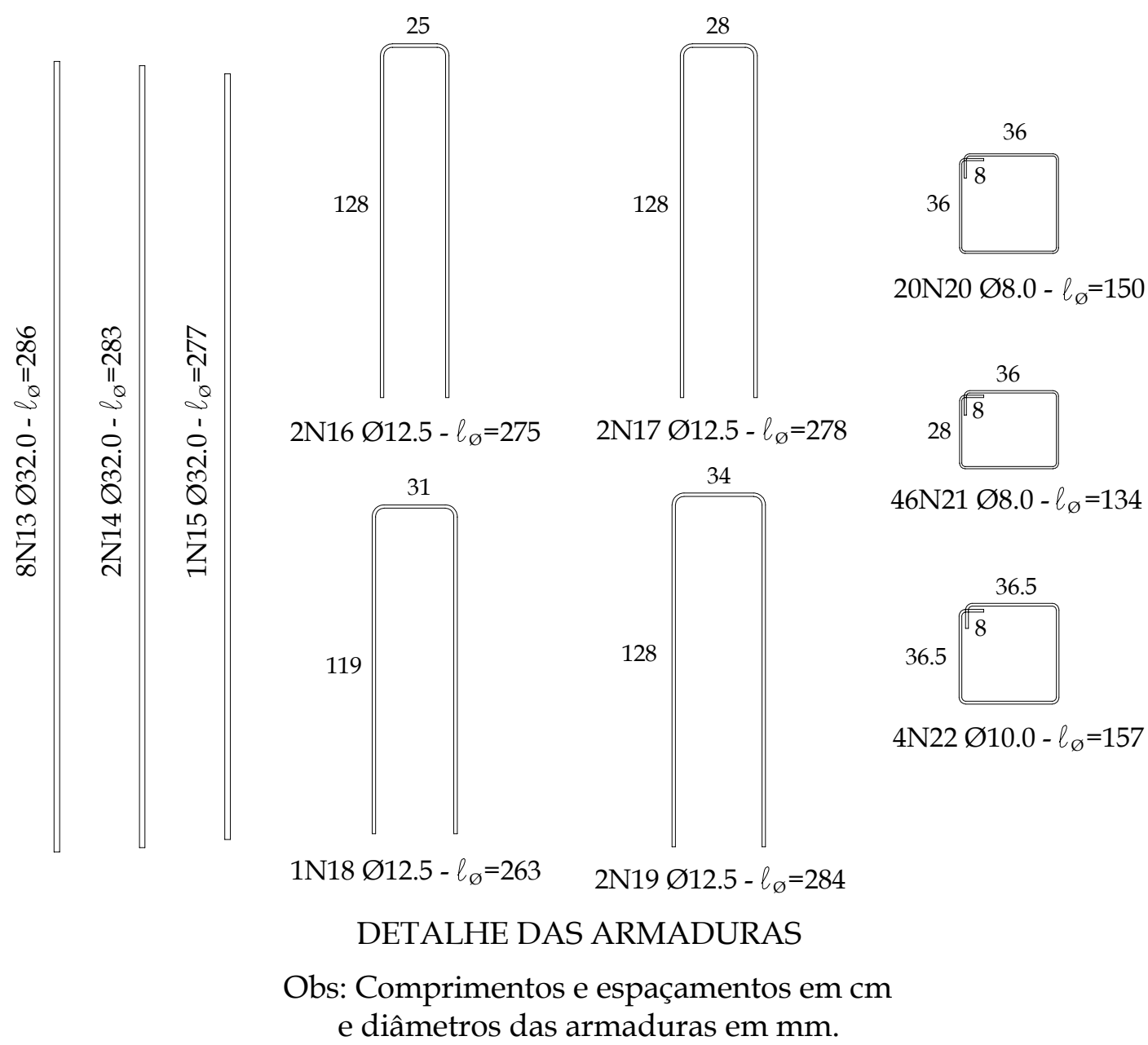

Figura 3.11 - Detalhe das armaduras do pilar do Modelo IR3

\subsection{PROGRAMA EXPERIMENTAL}

Seguiram-se as seguintes etapas para realização do programa experimental:

a) Execução das fôrmas de madeira dos cálices e dos pilares;

b) Montagem das armaduras dos pilares e instrumentação das armaduras dos cálices;

c) Concretagem dos pilares, envolvendo lançamento, adensamento e cura do concreto;

d) Montagem das armaduras dos cálices;

e) Concretagem dos cálices, envolvendo lançamento, adensamento e cura do concreto;

f) Içamento do cálice para o dispositivo de transição; 
g) Aplicação de desmoldante no cálice e no pilar;

h) Içamento e fixação temporária do pilar no cálice;

i) Içamento do modelo para a base metálica de reação;

j) Travamento do pilar;

k) Concretagem da junta de ligação dos elementos, envolvendo lançamento, adensamento e cura do concreto;

l) Montagem dos outros dispositivos metálicos;

m)Posicionamento dos transdutores de deslocamentos;

n) Execução do ensaio;

o) Ensaio à compressão axial de corpos-de-prova cilíndricos de $15 \mathrm{~cm}$ x $30 \mathrm{~cm}$ para obter a resistência à compressão e o módulo de elasticidade do concreto no dia de ensaio;

p) Ensaio à tração diametral de corpos-de-prova cilíndricos de $15 \mathrm{~cm} \times 30 \mathrm{~cm}$ para obter a resistência à tração do concreto no dia de ensaio;

q) Ensaio de tração de corpos-de-prova de $80 \mathrm{~cm}$ de comprimento para obter a tensão de escoamento, o módulo de elasticidade e a tensão última das armaduras;

r) A partir do sistema de aquisição de dados, elaboração das planilhas e, em seguida, os diagramas necessários para a realização das análises.

\subsubsection{INSTRUMENTAÇÃO}

Como o objetivo dessa pesquisa é analisar o comportamento do cálice de fundação, foram colocados extensômetros de modo a avaliar as deformações apenas nas principais armaduras situadas nas paredes do colarinho, tais como: armadura horizontal principal $\left(A_{s, h p}\right)$, armadura vertical principal $\left(A_{s, v p}\right)$ e armadura vertical secundária $\left(A_{s, v s}\right)$.

Na Figura 3.12 e Figura 3.13, indica-se o posicionamento dos extensômetros nas armaduras dos Modelos IL4 e IR3, respectivamente.

No que se refere às armaduras horizontais, foram instrumentadas tanto na direção transversal ao plano de atuação do momento fletor para verificar a flexão do topo da parede transversal 1 e 2, quanto na direção longitudinal para obtenção da força máxima transmitida por essa armadura. O posicionamento desses extensômetros se deu em função do tipo de solicitação prevista para cada armadura. 

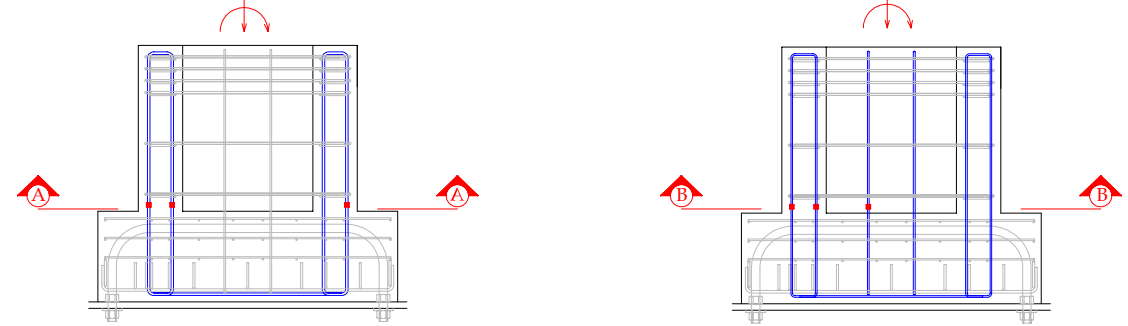

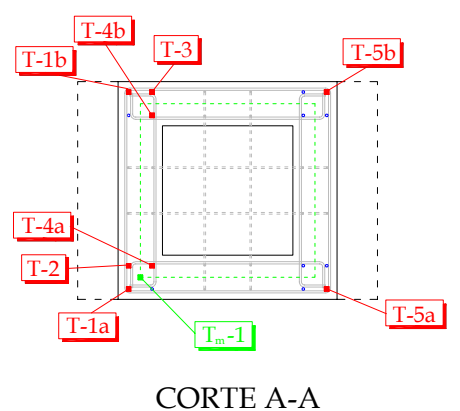

Total $=8$ extensômetros

INSTRUMENTAÇÃO DA ARMADURA VERTICAL PRINCIPAL



Total $=8$ extensômetros

INSTRUMENTAÇÃO DA ARMADURA VERTICAL SECUNDÁRIA

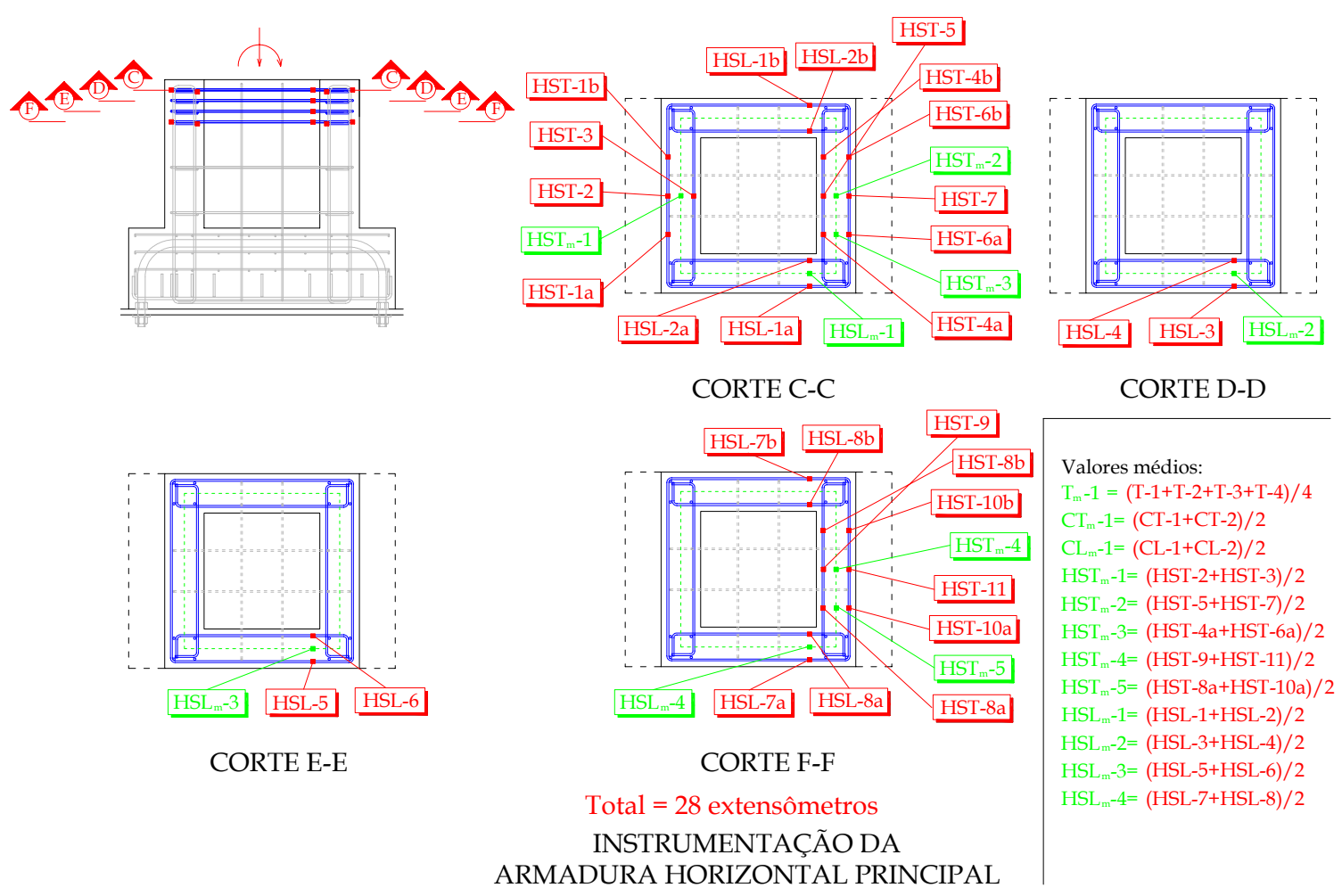

Figura 3.12 - Instrumentação das armaduras do cálice do Modelo IL4 



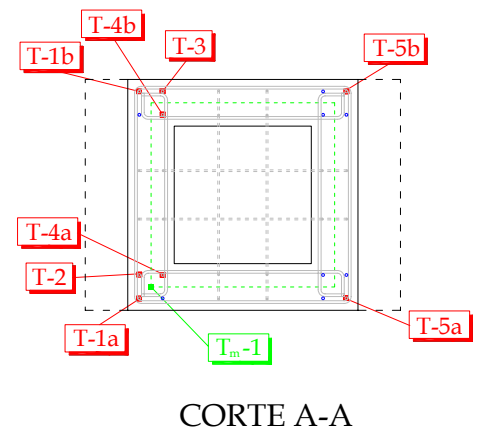

Total $=8$ extensômetros

INSTRUMENTAÇÃO DA ARMADURA VERTICAL PRINCIPAL

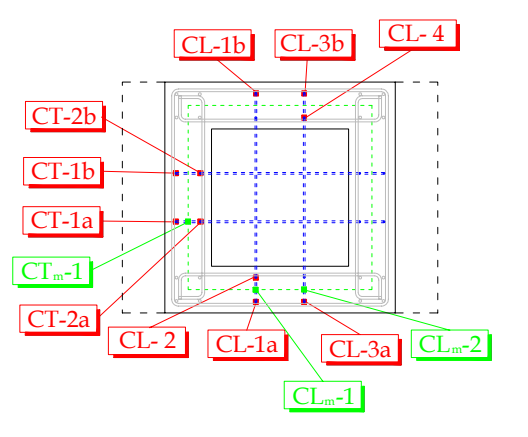

\section{CORTE B-B}

Total $=10$ extensômetros INSTRUMENTAÇÃO DA ARMADURA VERTICAL SECUNDÁRIA
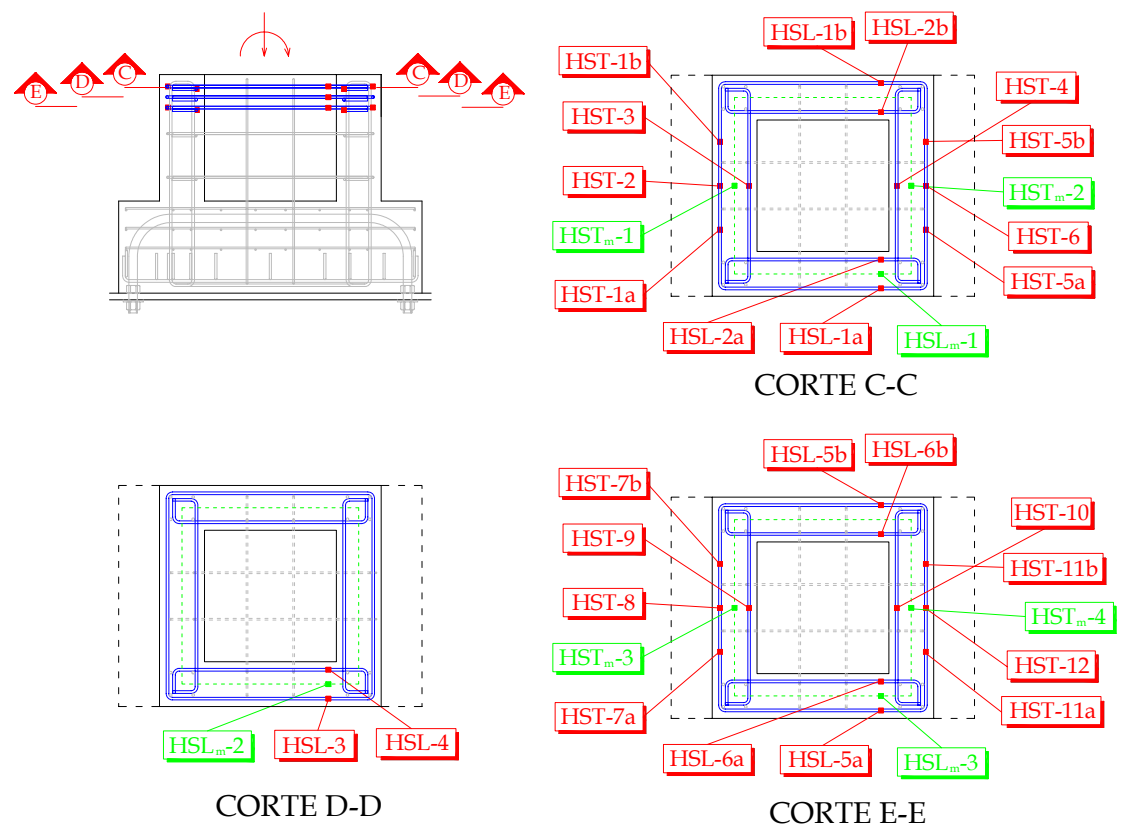

Valores médios:

$\mathrm{T}_{\mathrm{m}}-1=(\mathrm{T}-1+\mathrm{T}-2+\mathrm{T}-3+\mathrm{T}-4) / 4$

$\mathrm{CT}_{\mathrm{m}}-1=(\mathrm{CT}-1+\mathrm{CT}-2) / 2$

$\mathrm{CL}_{\mathrm{m}}-1=(\mathrm{CL}-1+\mathrm{CL}-2) / 2$

$\mathrm{CL}_{\mathrm{m}}-2=(\mathrm{CL}-3+\mathrm{CL}-4) / 2$

$\mathrm{HST}_{\mathrm{m}}-1=(\mathrm{HST}-2+\mathrm{HST}-3) / 2$

$\mathrm{HST}_{\mathrm{m}}-2=($ HST $-4+\mathrm{HST}-6) / 2$

$\mathrm{HST}_{\mathrm{m}}-3=($ HST $-8+$ HST-9) $/ 2$

$\mathrm{HST}_{\mathrm{m}}-4=($ HST $-10+\mathrm{HST}-12) / 2$

$\mathrm{HSL}_{\mathrm{m}}-1=($ HSL $-1+\mathrm{HSL}-2) / 2$

HSL $_{\mathrm{m}}-2=($ HSL $-3+\mathrm{HSL}-4) / 2$

HSL $_{m}-3=($ HSL-5+HSL-6) $/ 2$

Total $=26$ extensômetros

INSTRUMENTAÇÃO DA

ARMADURA HORIZONTAL PRINCIPAL

Figura 3.13 - Instrumentação das armaduras do cálice do Modelo IR3 
Nos protótipos analisados por CANHA (2004), observou-se que em todos os modelos ocorreram esforços por flexo-tração na parede transversal 1 , o que resultou na tração dos ramos externos e internos da armadura. Portanto resolveu-se aumentar o número de pontos de instrumentação nessa armadura para o Modelo IL4, no qual a solicitação de flexo-tração é mais significativa do que no Modelo rugoso IR3.

Percebeu-se também na pesquisa anterior, que na região superior da parede transversal 2 ocorreram fissuras que indicaram uma possível flexão dessa parede. Como a armadura horizontal principal localizada no topo dessa parede não foi instrumentada, resolveu-se nesta pesquisa colocar extensômetros na primeira camada dessa armadura do Modelo IL4 e na primeira e última camada do Modelo IR3, pois esse comportamento foi mais perceptível nos modelos rugosos.

No caso das armaduras verticais, os extensômetros foram colocados na posição referente à ligação colarinho-base da fundação para se avaliar a contribuição dessas armaduras. Devido a limitação de canais do sistema de aquisição de dados (75 canais) e com o aumento de pontos instrumentados nas armaduras horizontais, na armadura vertical secundária do Modelo IL4, situada nas paredes longitudinais 3 e 4, foram colocados extensômetros apenas na região mais tracionada (CL-1 e CL-2), pois para os modelos lisos analisados por CANHA (2004), as outras armaduras foram pouco solicitadas.

Para medir a deformabilidade do modelo, foram utilizados transdutores de deslocamento em pontos específicos do cálice. Na Figura 3.14 e Figura 3.15 estão mostrados os transdutores dos Modelos IL4 e IR3, respectivamente.

Esses transdutores foram posicionados de forma a medir a deformabilidade do modelo como um todo. Em relação aos modelos analisados na pesquisa anterior, houve um acréscimo na quantidade de transdutores nos dois protótipos, com o objetivo de medir também os deslocamentos causados pelos esforços de flexão no topo da parede transversal 2, pois como foi comentado anteriormente, nessa região observou-se fissuras caracterizando esses esforços. 

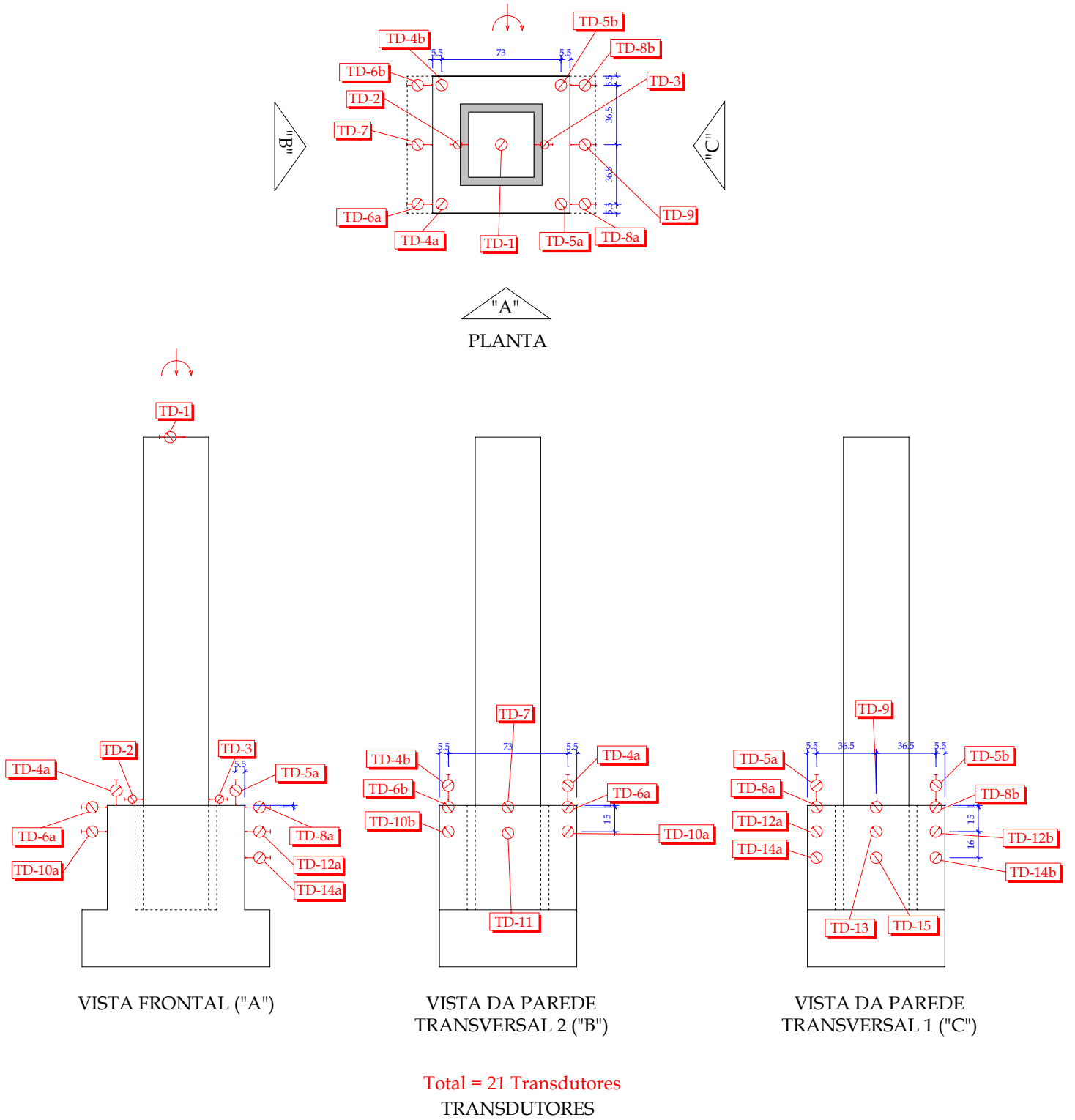

Figura 3.14 - Transdutores de deslocamento do Modelo IL4 


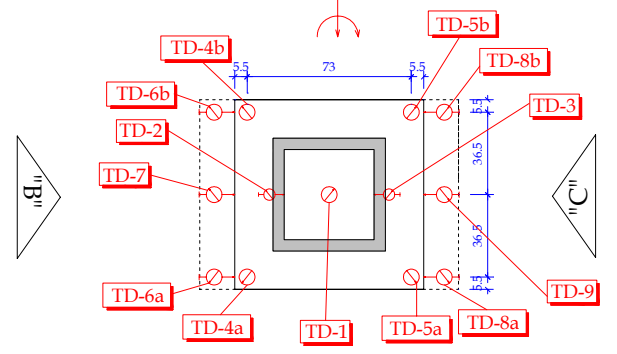

$$
\frac{\text { "A" }}{\text { PLANTA }}
$$

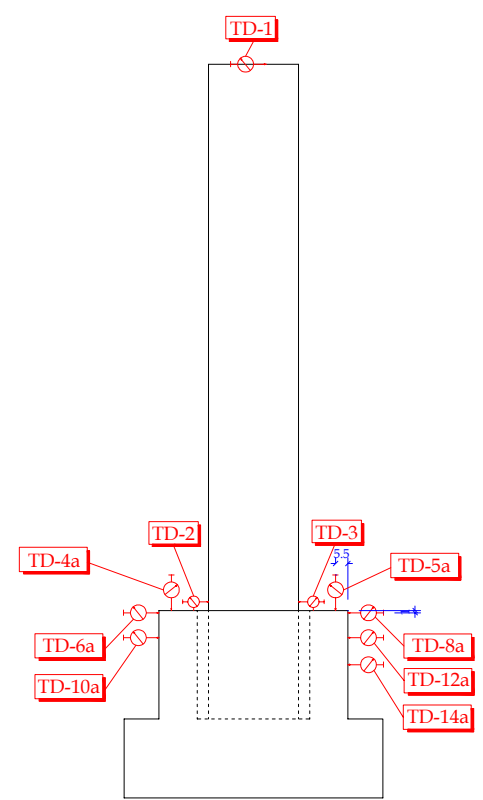

VISTA FRONTAL ("A")

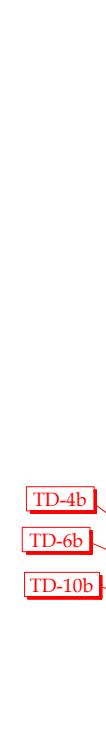

VISTA DA PAREDE TRANSVERSAL 2 ("B")

Total $=21$ Transdutores TRANSDUTORES

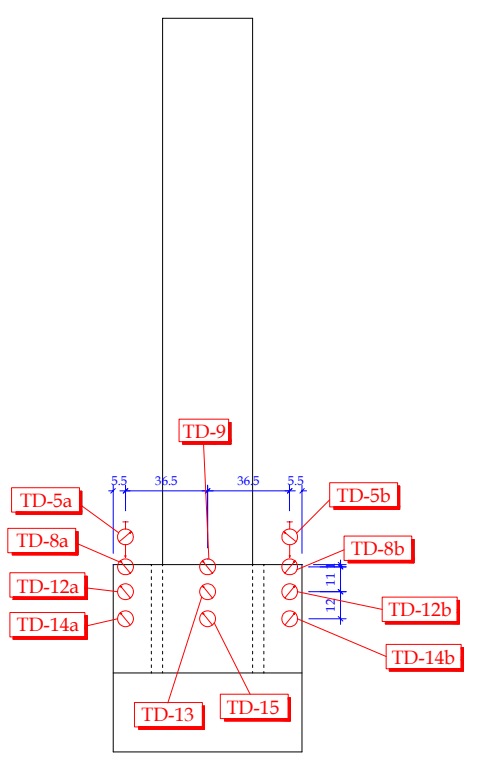

VISTA DA PAREDE TRANSVERSAL 1 ("C")

Figura 3.15 - Transdutores de deslocamento do Modelo IR3

\subsubsection{CONSTRUÇÃO DOS ELEMENTOS E MONTAGEM DOS PROTÓTIPOS}

\subsubsection{Pilar}

Em relação a seqüência de execução dos protótipos, primeiramente confeccionou-se os pilares enquanto as armaduras do cálice estavam sendo instrumentadas, já que o pilar não possuía pontos de instrumentação.

Na Figura 3.16 está ilustrada as principais etapas da montagem e moldagem dos pilares dos Modelos IL4 e IR3. 


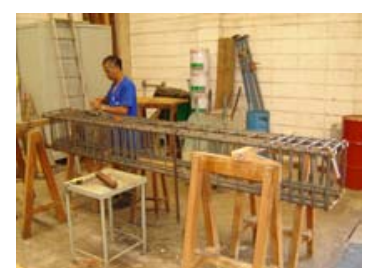

$\left.1^{\circ}\right)$ Montagem da armadura do pilar

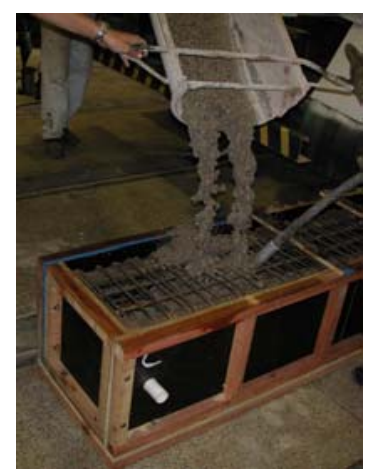

$3^{\circ}$ ) Concretagem do pilar

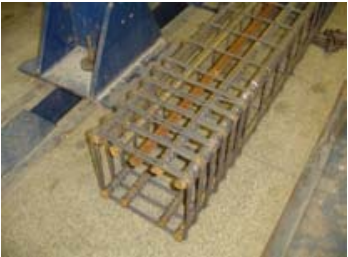

Armadura do trecho de embutimento

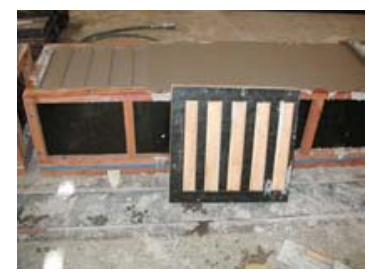

Chaves de madeira coladas na fôrma do pilar (detalhe da estrutura removível)Modelo IR3

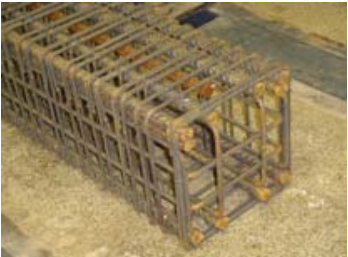

Armadura da "cabeça do pilar"

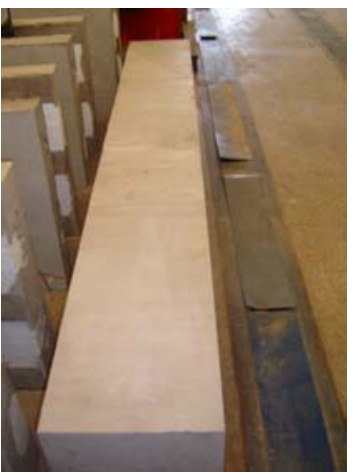

Pilar do Modelo IL4

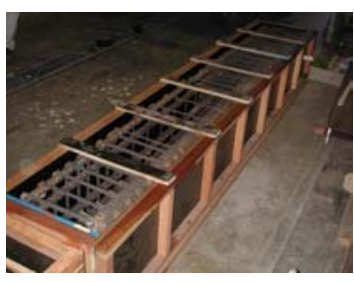

$2^{\circ}$ ) Armadura disposta na fôrma de madeira

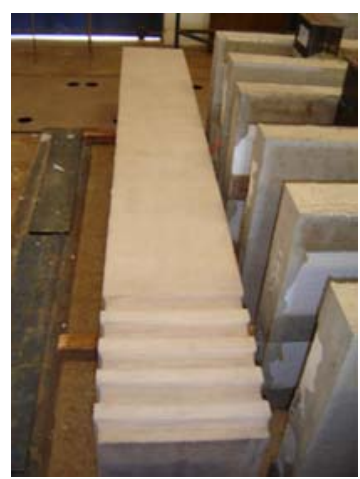

Pilar do Modelo IR3

Figura 3.16 - Confecção dos pilares dos Modelos IL4 e IR3

As fôrmas foram executadas em madeira compensada de $18 \mathrm{~mm}$ de espessura e reforçadas lateralmente por meio de caibros. A concretagem dos pilares foi realizada na posição horizontal e as chaves de cisalhamento, no caso do Modelo IR3, foram feitas por meio de chapas de madeira no formato das chaves e posteriormente fixadas na fôrma. Estas chapas foram dispostas nos três lados da caixa, sendo que no lado livre foram coladas em uma estrutura removível para completar o perímetro da região de embutimento.

\subsubsection{Cálice}

Após a construção dos pilares, iniciou-se o processo de confecção dos cálices, no qual é ilustrada pela seqüência de fotos da Figura 3.17.

Com os chumbadores previamente posicionados no gabarito metálico, as armaduras dos cálices foram montadas. As fôrmas, igualmente as dos pilares, foram executadas em madeira compensada de $18 \mathrm{~mm}$ de espessura e compostas por duas partes: uma parte externa maior cobrindo toda a superfície lateral do cálice como a base e o contorno externo do colarinho; e a parte interna menor, delimitando a parte referente à superfície interna das paredes do colarinho. 


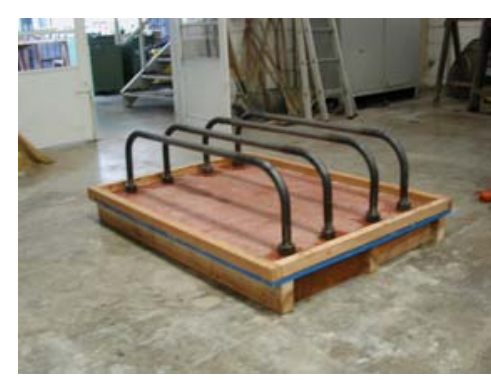

$1^{\circ}$ ) Chumbadores posicionados

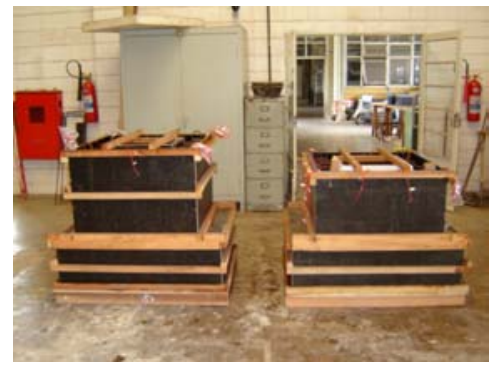

$4^{\circ}$ ) Armadura na fôrma

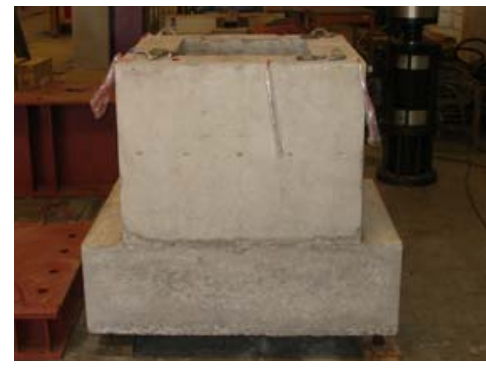

Cálice do Modelo IL4

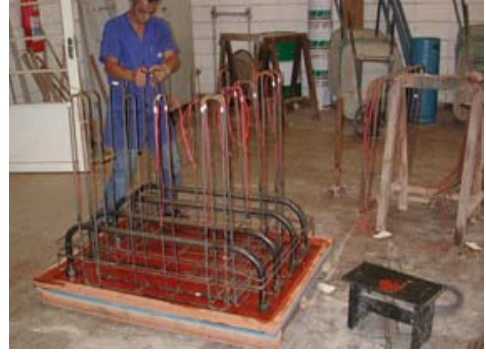

$2^{\circ}$ ) Montagem da armadura

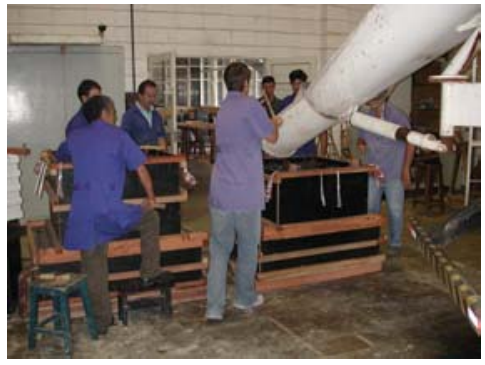

$5^{\circ}$ ) Concretagem

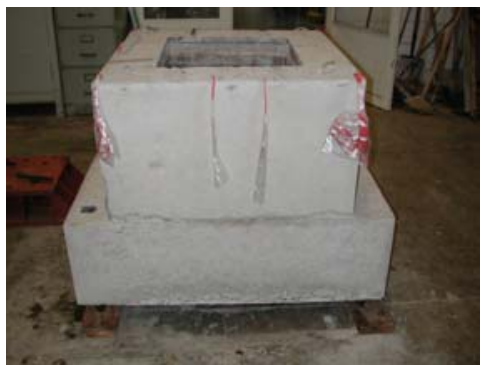

Cálice do Modelo IR3

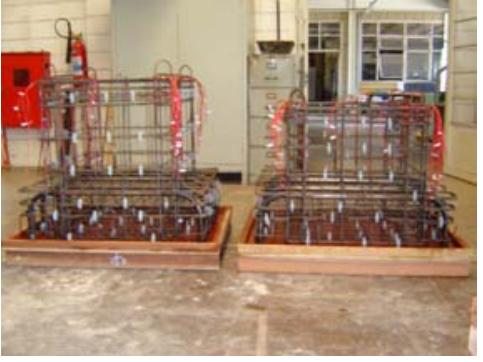

$3^{\circ}$ ) Armadura montada

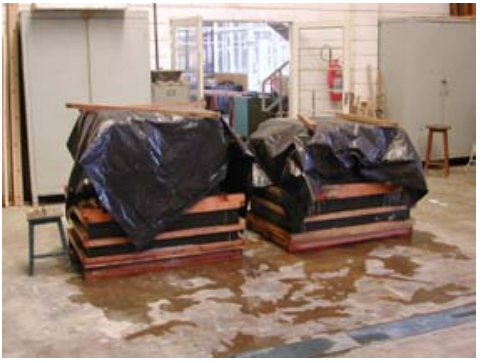

$6^{\circ}$ ) Cura



Detalhe das chaves de cisalhamento do Modelo IR3

Figura 3.17 - Confecção dos cálices dos Modelos IL4 e IR3

No caso do Modelo IR3, a parte interna da fôrma foi revestida de poliestireno expandido com o formato das chaves de cisalhamento. A Figura 3.18 e Figura 3.19 mostram com maiores detalhes as armaduras e as fôrmas dos cálices respectivamente.

Depois de posicionar as armaduras nas fôrmas, iniciou-se a concretagem. Primeiramente o concreto foi lançado e adensado na base da fundação. Posteriormente, colocou-se a parte interna da fôrma e por final concretou-se o colarinho, conforme Figura 3.20.

No processo de cura do concreto, os cálices foram cobertos com lona plástica para evitar a rápida evaporação da água de amassamento e com isso evitando fissuras de retração na superfície superior das paredes do colarinho. 


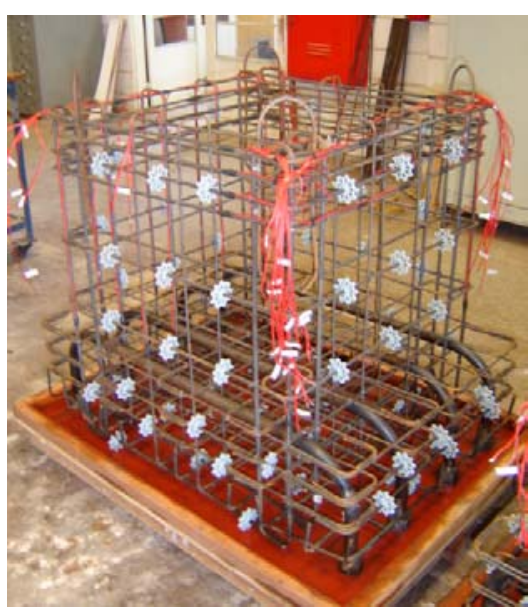

Modelo IL4

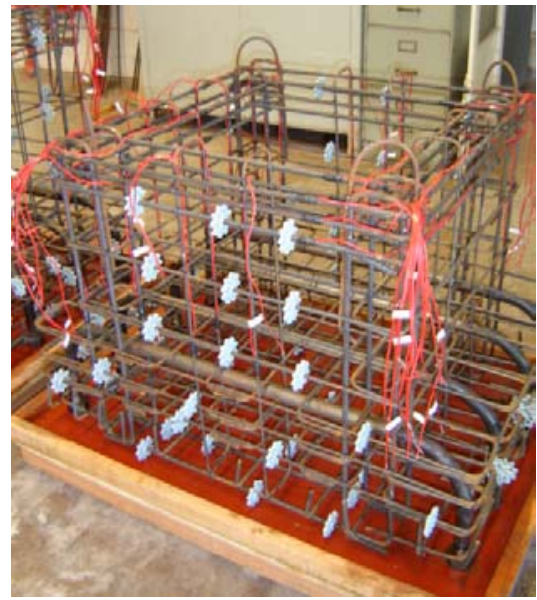

Modelo IR3

Figura 3.18 - Perspectiva da armadura do cálice dos Modelos IL4 e IR3



Modelo IL4

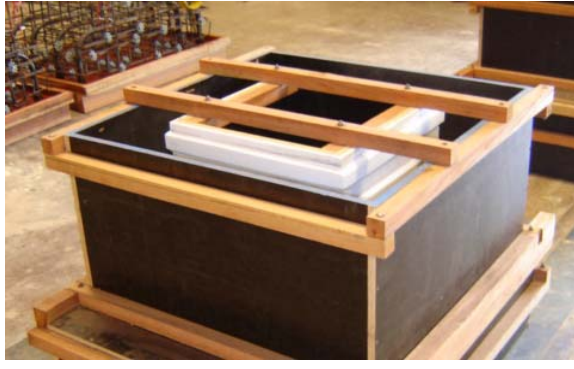

Modelo IR3

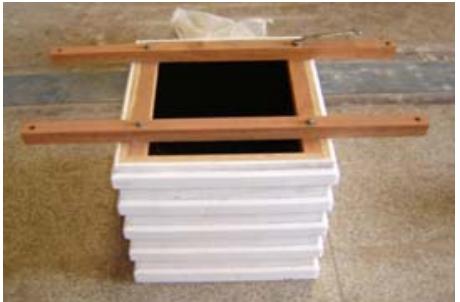

Parte interna da fôrma

Figura 3.19 - Fôrmas do cálice dos Modelos IL4 e IR3



$1^{\circ}$ ) Concretagem da base da fundação



$2^{\circ}$ ) Colocação da parte interna da fôrma

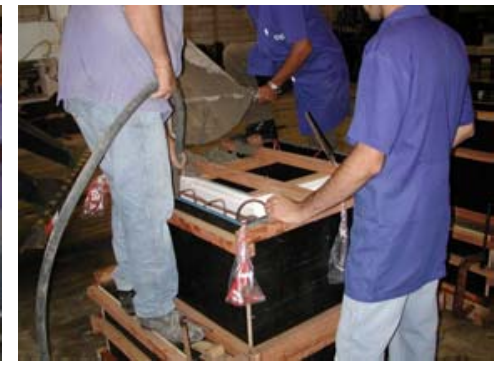

$3^{\circ}$ ) Concretagem do colarinho

Figura 3.20 - Procedimento de concretagem dos cálices

No caso do modelo rugoso, a desfôrma da parte interna do cálice foi feita 
dissolvendo-se com solvente o poliestireno expandido e sacando-a com o auxílio da ponte rolante, pois manualmente seria impossível em virtude da pressão muito alta exercida nas faces que compõe a caixa interna provocada pela expansão do concreto no seu processo de endurecimento. A mistura de solvente e o poliestireno expandido formou uma espécie de cola impregnando a região interna do cálice. Portanto, teve-se que retirar toda essa mistura e por final a superfície de concreto das chaves foi lixada para evitar uma eventual aspereza oriunda do poliestireno expandido. Esse procedimento está ilustrado na Figura 3.21.

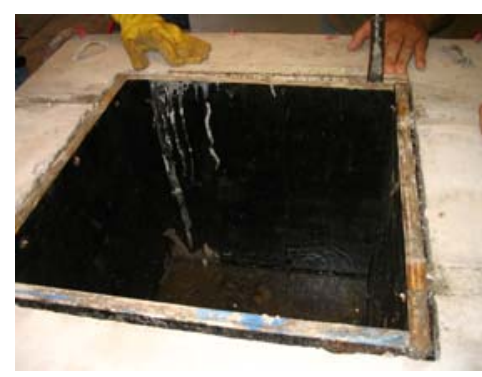

$\left.1^{\circ}\right)$ Dissolução do poliestireno expandido com solvente

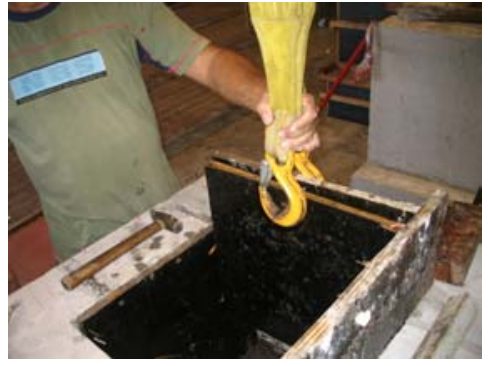

$2^{\circ}$ ) Retirada da parte interna da fôrma com auxílio da ponte rolante

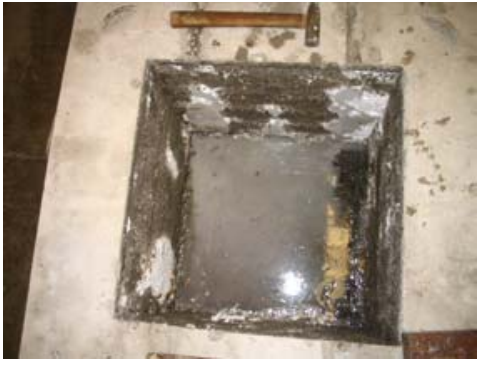

$3^{\circ}$ ) Poliestireno expandido impregnado na região interna do cálice

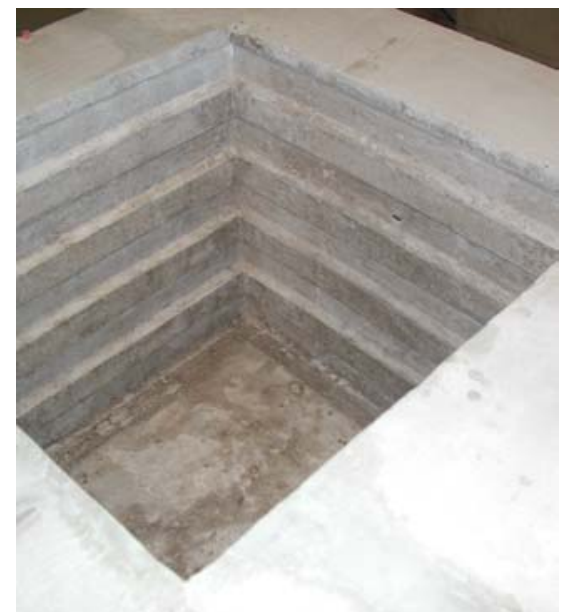

$\left.4^{\circ}\right)$ Região interna do cálice depois do acabamento final feito com lixa

Figura 3.21 - Procedimento de dês-fôrma do cálice do Modelo IR3

\subsubsection{Montagem dos protótipos}

Com a confecção dos elementos pré-moldados (pilar e cálice de fundação), iniciou-se o processo de união desses elementos, conforme a seqüência apresentada na Figura 3.22. Foi montado e ensaiado um protótipo de cada vez, ou seja, a seqüência apresentada foi feita separadamente para cada protótipo. 

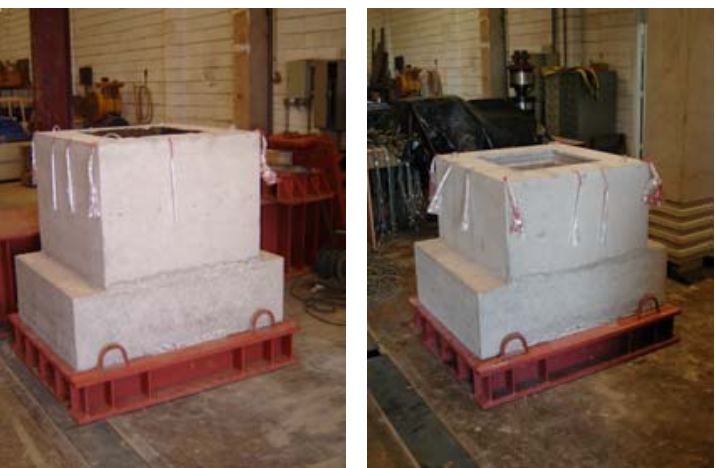

$1^{\circ}$ ) Modelos IL4 e IR3 posicionados no dispositivo de transição

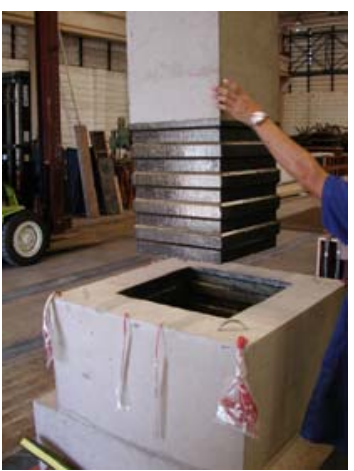

$3^{\circ}$ ) Içamento do pilar para o cálice
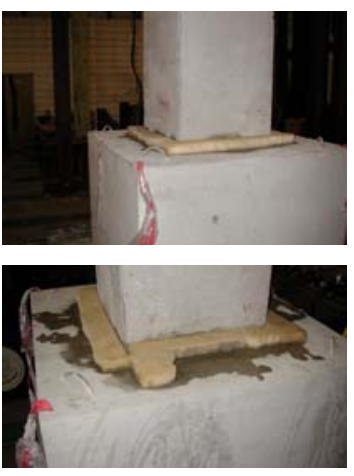

$\left.7^{\circ}\right)$ Cura do concreto da junta

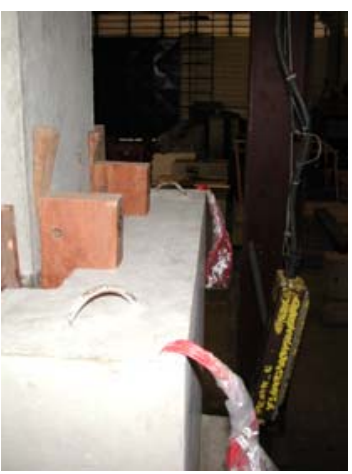

$\left.4^{\circ}\right)$ Travamento do pilar

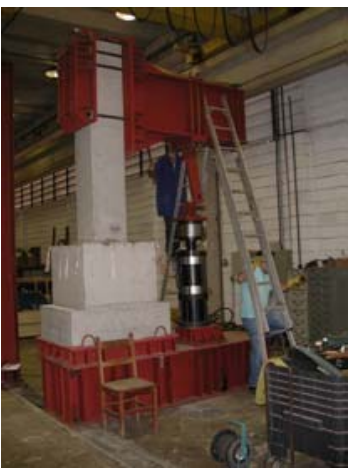

$8^{\circ}$ ) Montagem dos dispositivos restantes
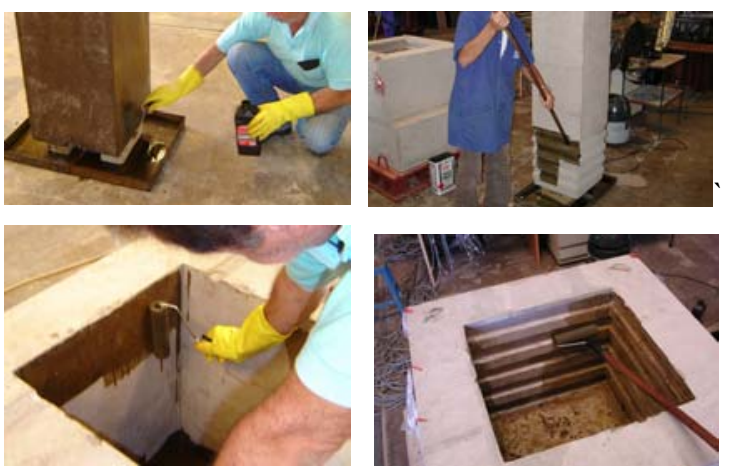

$2^{\circ}$ ) Aplicação de desmoldante no pilar e no cálice dos Modelos IL4 e IR3

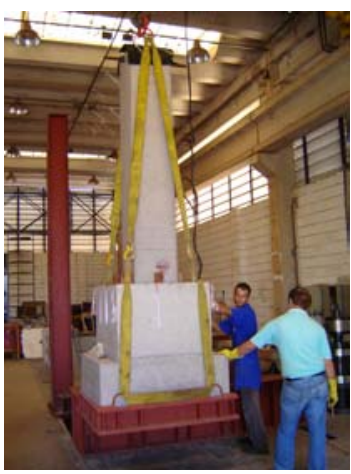

$5^{\circ}$ ) Içamento do modelo para a base metálica de reação

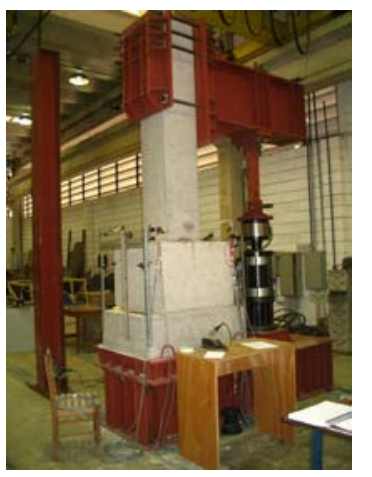

$9^{\circ}$ ) Modelos IL4 e IR3 prontos para serem ensaiados

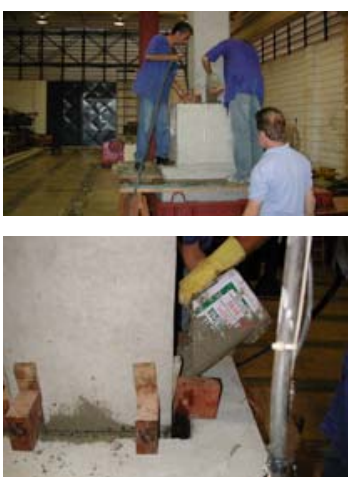

$\left.6^{\circ}\right)$ Concretagem da junta

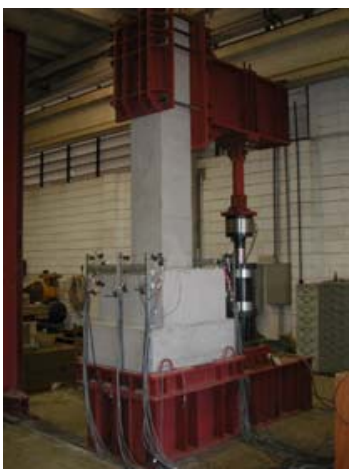

$$
\text { dos }
$$

Figura 3.22 - Montagem dos Protótipos IL4 e IR3

Como foi comentado anteriormente, procurou-se eliminar a adesão entre os elementos aplicando desmoldante na superfície do pilar e do cálice na região de embutimento. Depois o pilar foi encaixado e travado no cálice por meio de cunhas de madeira. Feito isso, o protótipo foi içado para base metálica de reação onde foi posicionado para a posterior concretagem da junta. Após a moldagem e a cura desse concreto, por aproximadamente três dias, com espuma úmida colocada na sua superfície 
externa, montaram-se os dispositivos metálicos restantes e posicionaram-se os transdutores de deslocamento no cálice.

Por final, conectaram-se os extensômetros e transdutores no sistema de aquisição de dados e o protótipo ficou pronto para ser ensaiado.

\subsubsection{CARACTERIZAÇÃO DOS MATERIAIS}

\subsubsection{Concreto}

Utilizou-se como resistência de projeto para os três concretos os valores de: $25 \mathrm{MPa}$ para resistência do cálice de fundação; $35 \mathrm{MPa}$ para o pilar; e para o concreto de enchimento a mesma resistência do pilar. O concreto utilizado para construção do pilar e do cálice de fundação foi usinado em central e o concreto de preenchimento da junta no Laboratório de Estruturas da EESC-USP. Como na pesquisa realizada anteriormente sobre o mesmo tema foi feito um estudo de traço para o concreto de preenchimento da junta, com uma razoável consistência e proporcionando uma resistência equivalente à prevista para o pilar, utilizou-se para esta pesquisa o mesmo traço, já que se dispunha dos mesmos materiais utilizados na elaboração desse concreto.

A caracterização do concreto á compressão, tração e a obtenção do módulo de elasticidade longitudinal foram feitos na máquina ELE e no mesmo dia do ensaio, moldando-se três corpos-de-prova de $15 \mathrm{~cm}$ x $30 \mathrm{~cm}$ para cada tipo de ensaio realizado, conforme Figura 3.23.

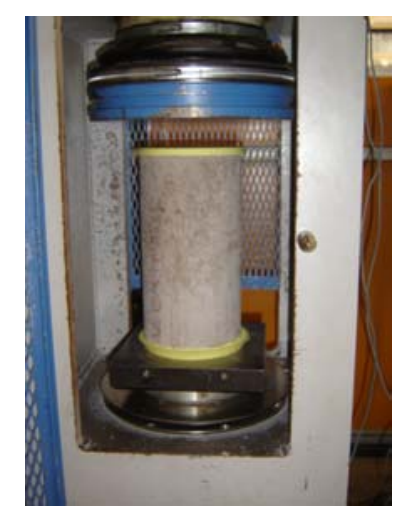

Ensaio a compressão do concreto

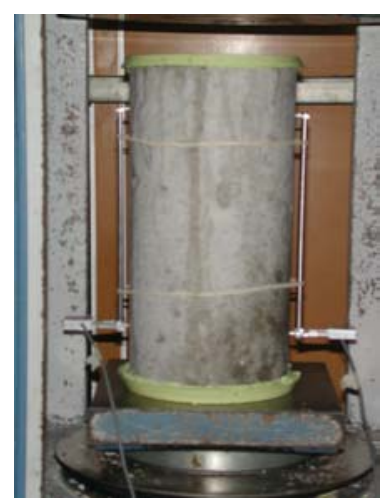

Obtenção do módulo de elasticidade longitudinal do concreto

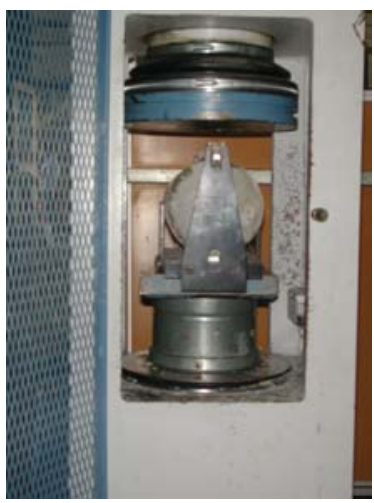

Ensaio à tração do concreto por compressão diametral

Figura 3.23 - Caracterização do concreto na máquina ELE

Nas Tabelas 3.2 a 3.4 estão apresentados os resultados dos ensaios em corpos- 
de-prova dos três concretos utilizados, onde:

$f_{c m}:$ Resistência média à compressão;

$f_{c t m, s p}$ : Resistência média a tração por compressão diametral;

$E_{c m}$ : Valor médio do módulo de elasticidade longitudinal tangente do concreto

Idade: Número de dias entre a moldagem do concreto e o ensaio do modelo

Tabela 3.2 - Propriedades mecânicas do concreto do cálice

\begin{tabular}{|c|c|c|c|c|c|}
\hline Modelo & $\begin{array}{c}\text { Idade } \\
(\text { dias })\end{array}$ & $\begin{array}{c}f_{c m} \\
(\mathrm{MPa})\end{array}$ & $\begin{array}{c}f_{c t m, s p} \\
(\mathrm{MPa})\end{array}$ & $\begin{array}{c}E_{c m} \\
(\mathrm{GPa})\end{array}$ & $\begin{array}{c}\text { Slump } \\
(\mathrm{cm})\end{array}$ \\
\hline IL4 & 23 & 25,60 & 1,67 & 28,9 & 8 \\
\hline IR3 & 43 & 26,50 & 1,71 & 29,8 & 8 \\
\hline
\end{tabular}

Tabela 3.3 - Propriedades mecânicas do concreto do pilar

\begin{tabular}{|c|c|c|c|c|c|}
\hline Modelo & $\begin{array}{c}\text { Idade } \\
(\text { dias })\end{array}$ & $\begin{array}{c}f_{c m} \\
(\mathrm{MPa})\end{array}$ & $\begin{array}{c}f_{c t m, s p} \\
(\mathrm{MPa})\end{array}$ & $\begin{array}{c}E_{c m} \\
(\mathrm{GPa})\end{array}$ & $\begin{array}{c}\text { Slump } \\
(\mathrm{cm})\end{array}$ \\
\hline IL4 & 40 & 39,50 & 3,08 & 34,5 & 18 \\
\hline IR3 & 61 & 41,20 & 3,11 & 34,8 & 18 \\
\hline
\end{tabular}

Tabela 3.4 - Propriedades mecânicas do concreto da junta

\begin{tabular}{|c|c|c|c|c|c|}
\hline Modelo & $\begin{array}{c}\text { Idade } \\
(\text { dias })\end{array}$ & $\begin{array}{c}f_{c m} \\
(\mathrm{MPa})\end{array}$ & $\begin{array}{c}f_{c t m, s p} \\
(\mathrm{MPa})\end{array}$ & $\begin{array}{c}E_{c m} \\
(\mathrm{GPa})\end{array}$ & $\begin{array}{c}\text { Slump } \\
(\mathrm{cm})\end{array}$ \\
\hline IL4 & 12 & 43,34 & 1,69 & 32,3 & 4 \\
\hline IR3 & 12 & 44,28 & 2,87 & 34,2 & 5 \\
\hline
\end{tabular}

\subsubsection{Armaduras}

Das armaduras utilizadas na construção dos protótipos, foram ensaiadas apenas aquelas utilizadas no cálice de fundação.

Para cada diâmetro de armadura, utilizaram-se três corpos-de-prova para realizar o ensaio de tração na máquina INSTRON, conforme ilustrado na Figura 3.24.

Na Tabela 3.5 são apresentadas as propriedades mecânicas das armaduras obtidas dos ensaios, onde:

$A_{s(n o m)}$ : Área nominal da seção transversal da armadura;

$f_{y m}:$ Resistência média ao escoamento;

$\varepsilon_{y m}$ : Deformação específica de início de escoamento;

$f_{\text {stm: }}$ Resistência média à tração; 
$E_{s m}$ : Valor médio do módulo de elasticidade.

Tabela 3.5 - Propriedades mecânicas das armaduras

\begin{tabular}{|c|c|c|c|c|c|}
\hline$\Phi(\mathrm{mm})$ & $\begin{array}{c}A_{s(\text { nominal })} \\
\left(\mathrm{cm}^{2}\right)\end{array}$ & $\begin{array}{c}f_{y m} \\
(\mathrm{MPa})\end{array}$ & $\begin{array}{c}\varepsilon_{y m} \\
(\mathrm{MPa})\end{array}$ & $\begin{array}{c}f_{s t m} \\
(\mathrm{MPa})\end{array}$ & $\begin{array}{c}E_{s m} \\
(\mathrm{GPa})\end{array}$ \\
\hline 6,3 & 0,308 & 603 & 2,90 & 706 & 210 \\
\hline 8 & 0,496 & 640 & 3,00 & 732 & 220 \\
\hline 10 & 0,776 & 602 & 2,70 & 717 & 230 \\
\hline
\end{tabular}


Figura 3.24 - Ensaio a tração da armadura

\subsubsection{PROCEDIMENTOS DE ENSAIO}

Quanto a ordem dos ensaios dos protótipos, ensaiou-se primeiro o Modelo IL4 e depois o Modelo IR3.

O carregamento foi aplicado de cima para baixo pelo atuador servo-hidráulico com controle de deslocamento do pistão, conforme o esquema apresentado na Figura 3.25 .

Será descrito em seguida o procedimento de ensaio e alguns aspectos inerentes a cada um dos modelos. 

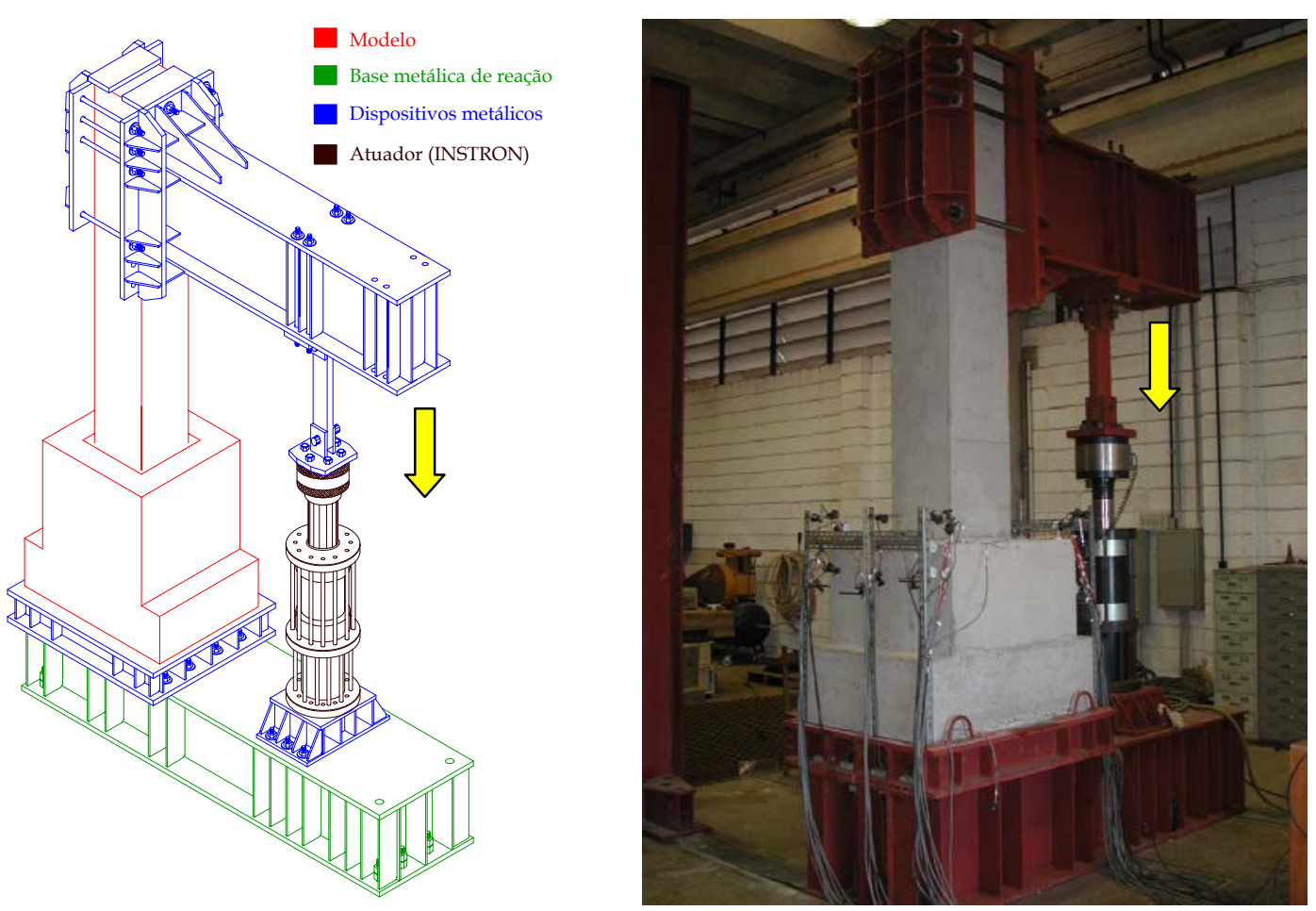

Figura 3.25 - Esquema de ensaio

\section{Modelo IL4}

Antes da realização do ensaio, fez-se o "escorvamento" do Modelo IL4 aplicando uma força de aproximadamente $25 \mathrm{kN}$. Entende-se por "escorvamento", a força inicial aplicada com a finalidade de se verificar o funcionamento dos instrumentos e eliminar acomodações do modelo durante o início do ensaio.

Tendo em vista os modelos analisados por CANHA (2004), onde foram aplicados intencionalmente 3 ciclos de pré-carregamento com pequena intensidade de força para provocar o descolamento da junta com os elementos, tentando com isso retirar a adesão entre os três "concretos", resolveu-se aumentar a quantidade para 20 ciclos com o objetivo de avaliar a eficiência desse procedimento. Observando-se os valores das forças alcançadas nos ciclos da pesquisa anterior, optou-se por aplicar uma força máxima de $65 \mathrm{kN}$ para os 20 ciclos.

Feito isso, iniciou-se o ensaio do Modelo IL4. Próximo ao final do ensaio observou-se uma excentricidade relativamente grande no sistema de rótulas situadas entre a viga metálica e o atuador e consequentemente o surgimento de uma componente horizontal de força atuando no pistão podendo com isso danificá-lo. Portanto, resolveuse encerrar o ensaio antes mesmo do modelo atingir sua capacidade resistente, embora a bomba hidráulica não estivesse mais conseguindo aplicar um valor significativo de 
força, ou seja, o modelo estava próximo de sua capacidade limite.

Na Figura 3.26 está ilustrado o deslocamento do sistema de rótulas no final do ensaio do Modelo IL4.


Figura 3.26 - Excentricidade do sistema de rotulas no final do ensaio do Modelo IL4

\section{Modelo IR3}

Neste modelo, o valor da força de "escorvamento" foi de $30 \mathrm{kN}$. Aplicou-se também 20 ciclos de pré-carregamento com uma força máxima de $75 \mathrm{kN}$, tentando eliminar a adesão entre os elementos e o concreto da junta.

Com o objetivo de evitar o problema ocorrido no ensaio do Modelo IL4, no qual se parou o ensaio por causa da elevada excentricidade do sistema de rótulas entre a viga metálica e o atuador hidráulico, foram colocadas algumas chapas entre o dispositivo de transição, onde está fixado o modelo, e a base metálica da estrutura de reação para levantar todo conjunto ocasionando com isso uma excentricidade na direção oposta à deformação do modelo durante o ensaio. O posicionamento dessas chapas está ilustrado na Figura 3.27.

Durante o ensaio deste protótipo, a bomba hidráulica desligou por motivo de superaquecimento, por conseqüência da alta temperatura ambiente no dia em questão e somado ao longo tempo de duração do ensaio, de aproximadamente três horas. Resolveu-se então reiniciar o ensaio no dia seguinte aplicando força até sua capacidade resistente, ou seja, quando a bomba hidráulica não conseguiu aplicar mais carregamento. $\mathrm{Na}$ análise dos resultados foi computada a deformação residual das 
armaduras no primeiro ensaio.
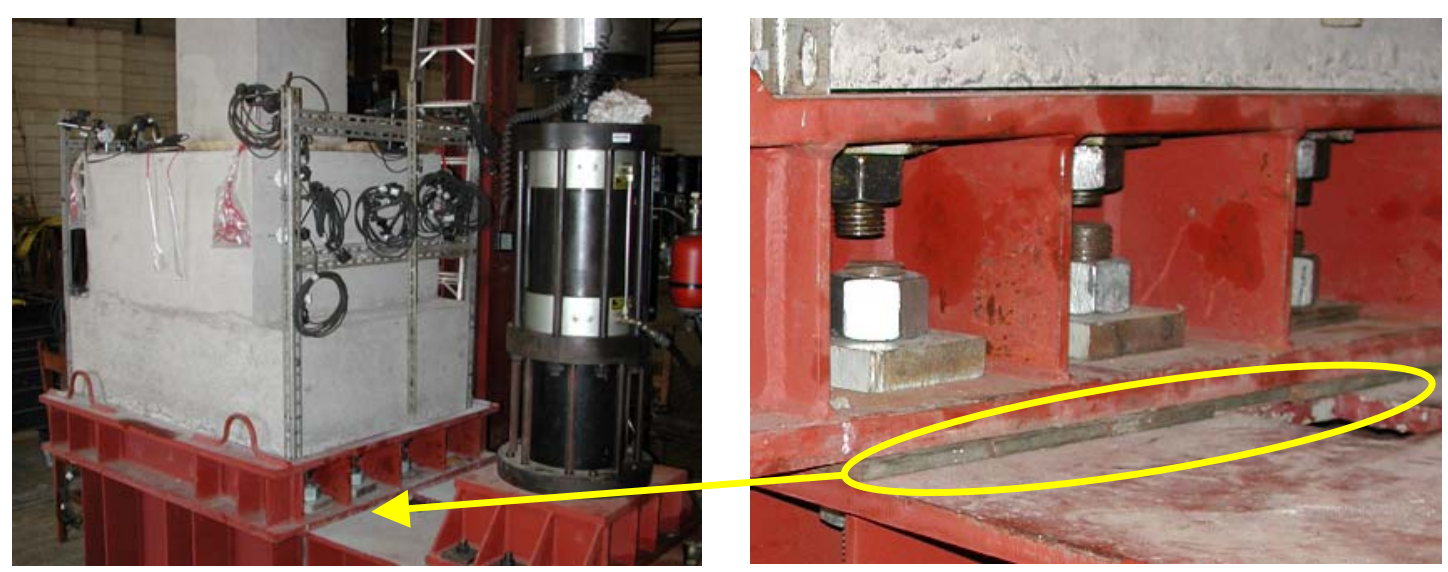

Figura 3.27 - Chapas metálicas entre o dispositivo de transição e a base de reação

\subsubsection{DISPOSITIVOS, INSTRUMENTOS E EQUIPAMENTOS UTILIZADOS NOS ENSAIOS}

Na Figura 3.28 está ilustrado o projeto do esquema de ensaio dos modelos físicos e o atuador hidráulico INSTRON utilizado para aplicação da força normal excêntrica nos modelos.

As características dos principais equipamentos e instrumentos utilizados nos ensaios estão descritos na Tabela 3.6. 

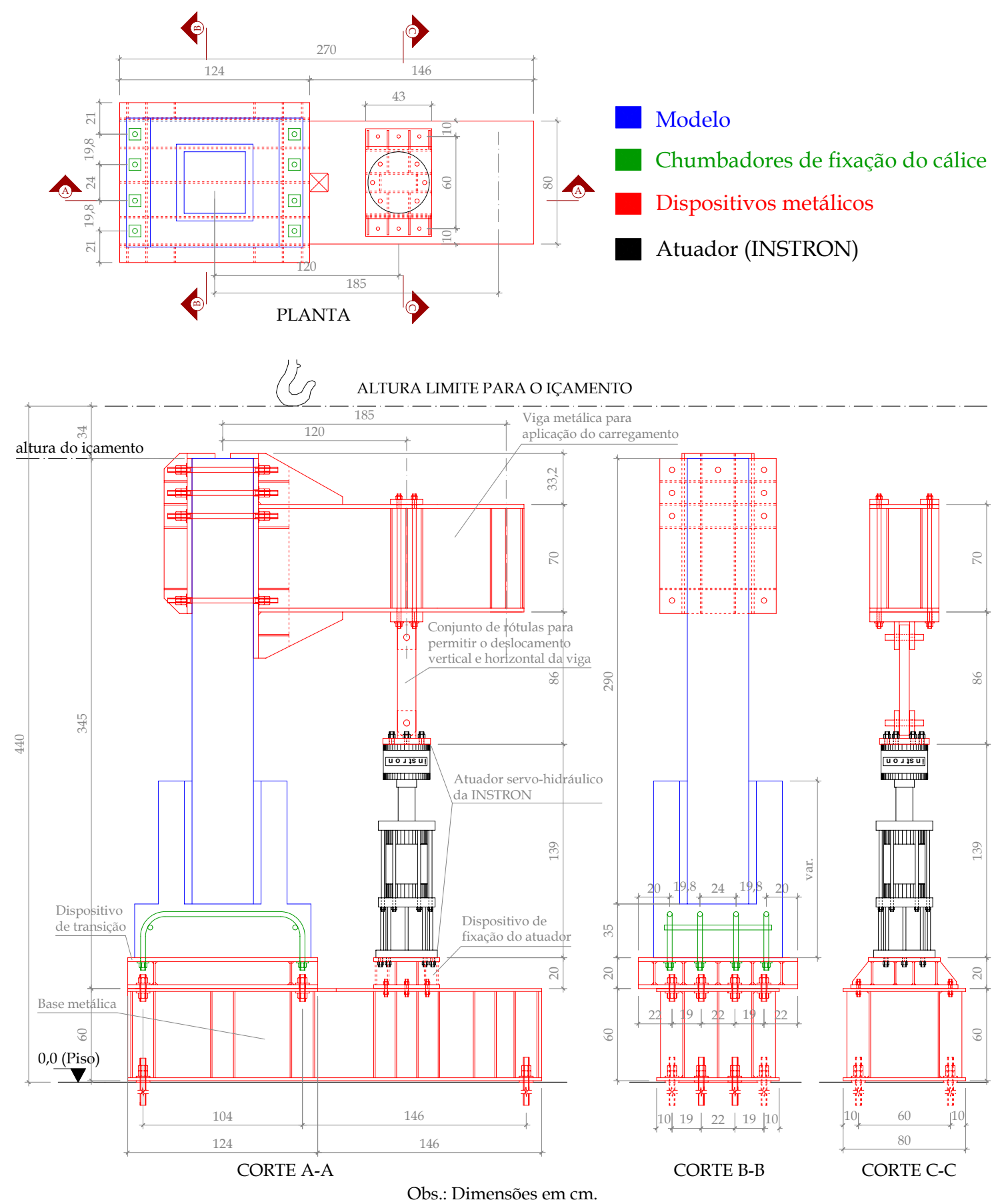

Figura 3.28-Esquema de ensaio dos modelos físicos - CANHA (2004) 
Tabela 3.6 - Equipamentos e instrumentos utilizados na investigação esperimental

\begin{tabular}{|c|c|c|c|c|c|}
\hline $\begin{array}{l}\text { Equipamento/ } \\
\text { Instrumento }\end{array}$ & Marca & Modelo & \multicolumn{2}{|c|}{ Características } & Finalidade \\
\hline $\begin{array}{c}\text { Sistema de } \\
\text { aquisição de } \\
\text { dados de } \\
\text { extensometria }\end{array}$ & $\begin{array}{c}\text { Vishay } \\
\text { Measurements } \\
\text { Group, Inc. }\end{array}$ & $\begin{array}{l}\text { SYSTEM } \\
5000\end{array}$ & \multicolumn{2}{|r|}{ - } & $\begin{array}{c}\text { cquisição } \\
\text { automática de } \\
\text { dados }\end{array}$ \\
\hline $\begin{array}{l}\text { Atuador servo- } \\
\text { hidráulico }\end{array}$ & INSTRON & $\begin{array}{l}\text { A1891Y- } \\
101\end{array}$ & \multicolumn{2}{|c|}{$\begin{array}{c}\text { controle de } \\
\text { deslocamento do } \\
\text { pistão }\end{array}$} & $\begin{array}{l}\text { aplicação do } \\
\text { carregamento } \\
\text { nos modelos }\end{array}$ \\
\hline $\begin{array}{l}\text { Máquina de } \\
\text { ensaio servo- } \\
\text { hidráulica }\end{array}$ & INSTRON & 8506 & \multicolumn{2}{|c|}{$\begin{array}{c}\text { Controle de } \\
\text { deslocamento do } \\
\text { pistão }\end{array}$} & $\begin{array}{l}\text { Caracterização } \\
\text { das armaduras }\end{array}$ \\
\hline $\begin{array}{l}\text { Máquina } \\
\text { hidráulica } \\
\text { automática }\end{array}$ & ELE & $\begin{array}{l}\text { Autotest } \\
2000\end{array}$ & \multicolumn{2}{|c|}{ Controle de força } & $\begin{array}{c}\text { Caracterização } \\
\text { do concreto à } \\
\text { compressão e } \\
\text { à traçao por } \\
\text { comp. } \\
\text { Diametral }\end{array}$ \\
\hline $\begin{array}{l}\text { Extensômetros } \\
\text { elétricos de } \\
\text { resistência }\end{array}$ & KYOWA & $\begin{array}{c}\text { KGF-5- } \\
120-C 1- \\
11\end{array}$ & \multicolumn{2}{|c|}{$\mathrm{GF}=2,12$} & $\begin{array}{l}\text { Medição das } \\
\text { deformações } \\
\text { do aço }\end{array}$ \\
\hline $\begin{array}{l}\text { Extensômetro } \\
\text { removível }\end{array}$ & MSI & - & \multicolumn{2}{|c|}{$\begin{array}{l}\text { Base de medida }= \\
20 \mathrm{~cm}\end{array}$} & $\begin{array}{c}\text { Medição de } \\
\text { deslocamento } \\
\text { no concreto } \\
\text { para } \\
\text { determinar o } \\
\text { modulo Eci } \\
\end{array}$ \\
\hline \multirow{4}{*}{$\begin{array}{c}\text { Transdutores de } \\
\text { deslocamento }\end{array}$} & \multirow{4}{*}{ KYOWA } & Tipo & $\begin{array}{l}\text { Base } \\
(\mathrm{cm})\end{array}$ & $\begin{array}{l}\text { Resolução } \\
\text { (mm) }\end{array}$ & \multirow{4}{*}{$\begin{array}{c}\text { Medição de } \\
\text { deslocamentos } \\
\text { dos modelos }\end{array}$} \\
\hline & & DT-10D & 10 & 0,003 & \\
\hline & & DT-20D & 20 & 0,005 & \\
\hline & & DT-100A & 100 & 0,02 & \\
\hline
\end{tabular}




\section{RESULTADOS E ANÁLISES}

\subsection{CICLOS DE PRÉ-CARREGAMENTO E ENVOLTÓRIAS}

Como foi mencionado anteriormente, antes do ensaio propriamente dito, aplicou-se 20 ciclos de pré-carregamento de pequena intensidade nos Protótipos IL4 e IR3. Como houve pouca alteração na rigidez no re-carregamento e as deformações residuais das armaduras mais solicitadas (armaduras verticais da parede transversal 2) foram pequenas, esses ciclos não interferiram na resistência da ligação. Deve-se também lembrar que durante o ensaio do Modelo IR3, a bomba hidráulica desligou por atingir temperatura elevada, reiniciando-se o ensaio no dia seguinte. Neste caso também não houve grande mudança na rigidez e as armaduras verticais não chegaram a escoar, mesmo com o carregamento atingindo $228 \mathrm{kN}, 63 \%$ da capacidade resistente do protótipo. Portanto, nas análises que serão feitas do comportamento de ambos os protótipos, considerar-se-á a envoltória.

$\mathrm{Na}$ Figura 4.1 e Figura 4.2, estão ilustrados o comportamento ao longo dos ciclos e a envoltória do Modelo IL4 e o comportamento ao longo dos ciclos, do $1^{\circ}$ ensaio, $2^{\circ}$ ensaio e envoltória do Modelo IR3, respectivamente. 


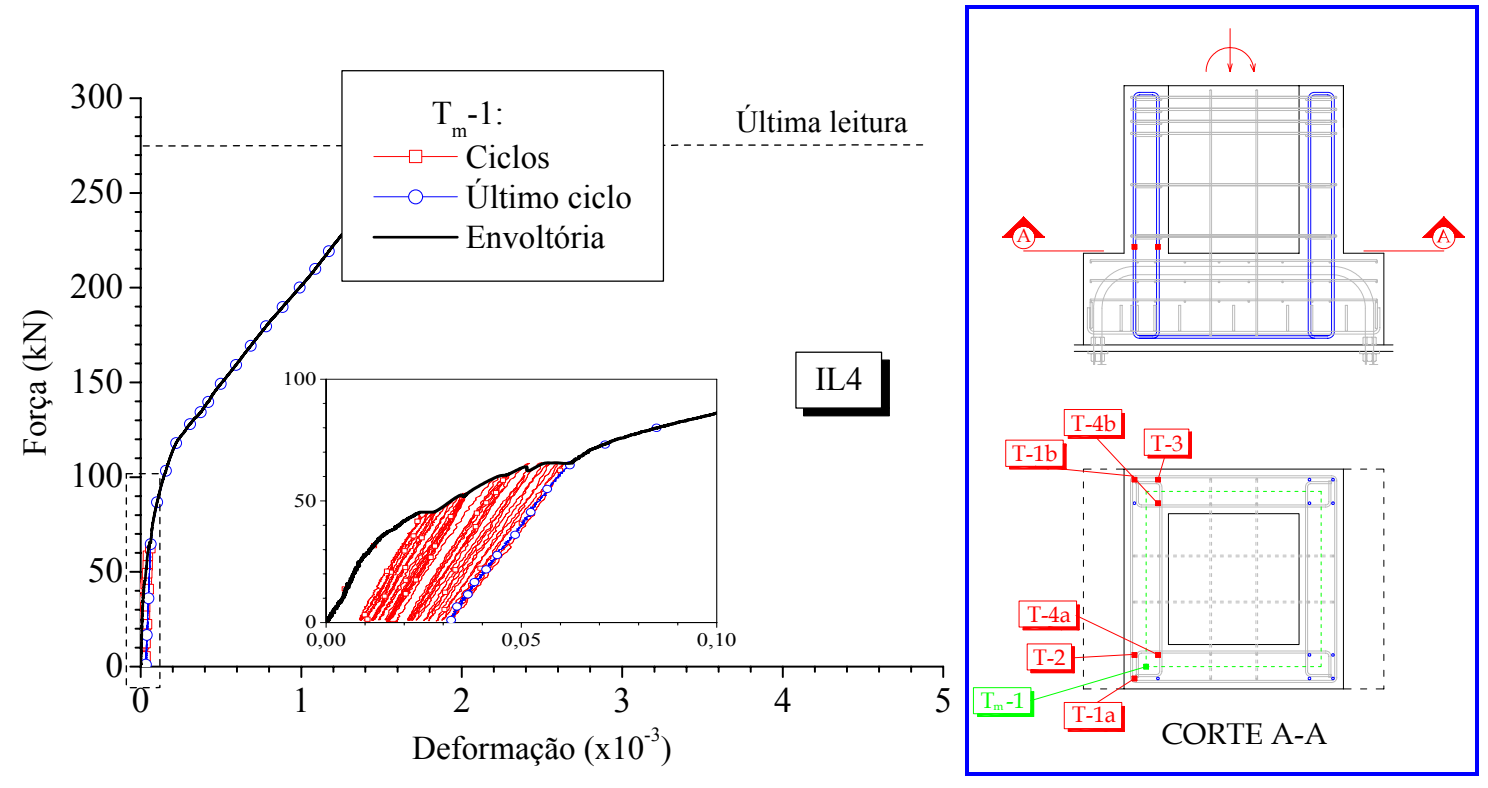

Figura 4.1 - Ciclos e envoltória da curva força aplicada versus deformação média na armadura vertical principal - Modelo IL4
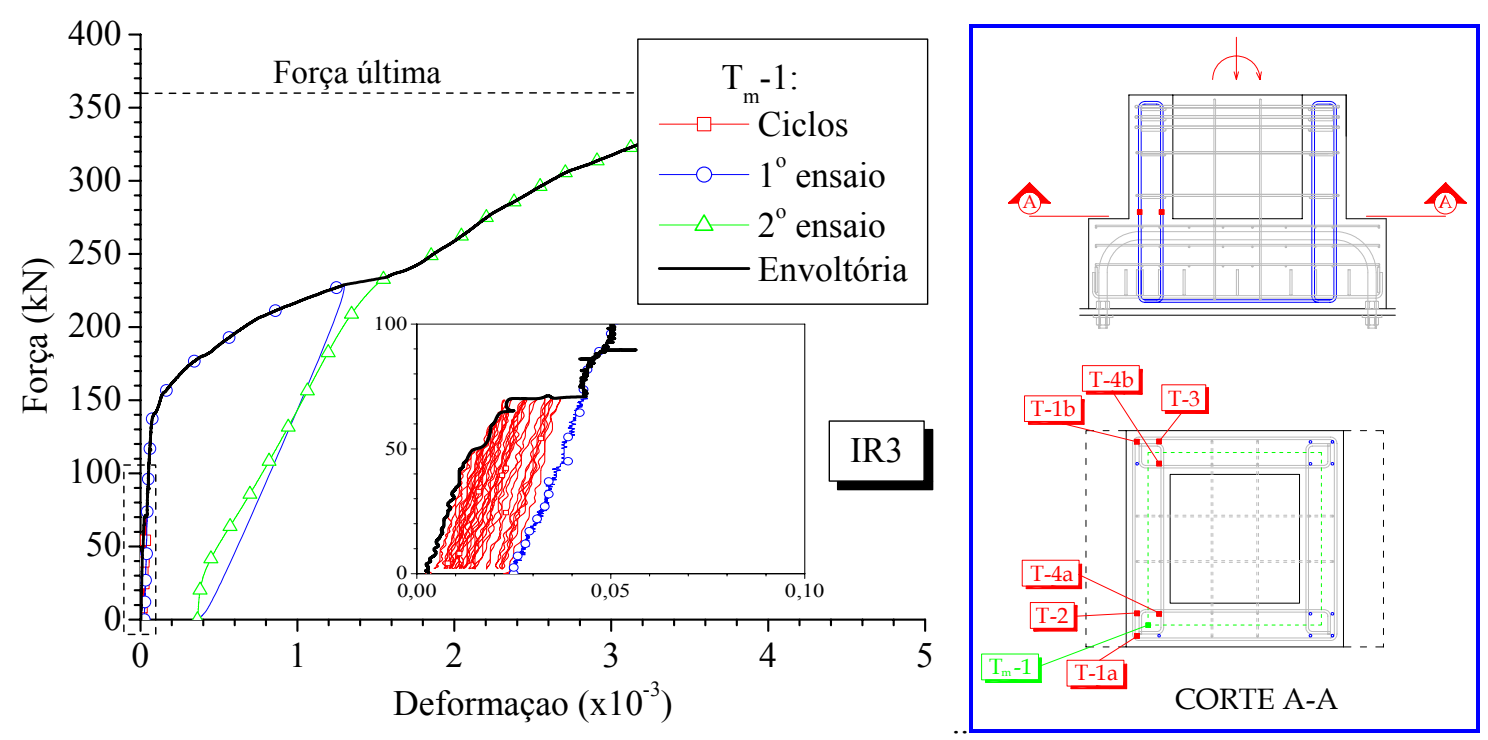

Figura 4.2 - Ciclos, $1^{\circ}$ ensaio, $2^{\circ}$ ensaio e envoltória da curva força aplicada versus deformação média na armadura vertical principal - Modelo IR3

\subsection{RESISTÊNCIA DOS MODELOS E DESCOLAMETO ENTRE A JUNTA E OS ELEMENTOS DO MODELO IL4}

Na Tabela 2.3, são apresentados os resultados experimentais da força normal última e o momento último dos modelos ensaiados. Como era de se esperar, mesmo com uma profundidade de embutimento inferior, o modelo rugoso teve uma maior capacidade resistente em relação ao liso. 
Tabela 4.1 - Resistência experimental dos modelos ensaiados

\begin{tabular}{|c|c|c|c|}
\hline Modelo & $\begin{array}{c}\text { Excentricidade } \\
e(\mathrm{~m})\end{array}$ & $\begin{array}{c}\text { Força normal última } \\
N u(\mathrm{kN})\end{array}$ & $\begin{array}{c}\text { Momento último } \\
M u(\mathrm{kN} . \mathrm{m})\end{array}$ \\
\hline IL4 & 1,20 & 275 & 330 \\
\hline IR3 & 1,20 & 360 & 432 \\
\hline
\end{tabular}

Como já foi mencionado, o pilar foi dimensionado para resistir à capacidade máxima do atuador já que esse trabalho objetiva avaliar a resistência do cálice e a ruptura da ligação. Sendo assim, a resistência do Modelo IR3 foi determinada pela força última absorvida pelo cálice de fundação, com o escoamento das armaduras verticais situadas na parede transversal 2 e a vertical secundária mais solicitada das paredes longitudinais 3 e 4 , como será mostrado mais adiante.

No caso do Modelo IL4, como já foi comentado no item anterior, próximo a capacidade resistente da ligação houve a necessidade de parar o ensaio para preservar o atuador hidráulico, mas nesse instante já havia escoado a armadura vertical secundária da parede transversal 2 e com a armadura vertical e horizontal principal próximas a entrarem em regime de escoamento. Com isso, a capacidade última do cálice não foi alcançada, mas ficando próximo a ela, pois o atuador já não conseguia aplicar uma força significativa quando o ensaio foi interrompido. Portanto, a força ultima referente ao Modelo IL4, apresentado na Tabela 4.1, fica mais bem definida como força da última leitura do ensaio.

Constatou-se, nos dois protótipos, a separação e deslizamento entre a junta e os elementos na região de embutimento no decorrer do ensaio. No entanto, observou-se que no Modelo IL4, essa abertura só veio tornar-se significativa após $70 \%$ da última leitura do carregamento desse modelo, ao contrário do que se esperava, pois com a colocação de óleo entre a junta e os elementos e com os ciclos de carga aplicada no modelo, essa separação deveria ocorrer desde o inicio do carregamento, semelhante aos modelos lisos IL2 e IL3 ensaiados por CANHA (2004). Vale lembrar que esse procedimento foi feito com a intenção de obter valores mais adequados de projeto, já que não se garante um perfeito contato entre as interfaces, e além do que a retração desse concreto pode ocasionar um descolamento dos elementos.

Já no Modelo IR3, essa separação foi mais significativa desde o início do ensaio. Isso pode se explicado levando em conta que o pilar, a junta e o cálice nos lados comprimidos e longitudinais trabalharam em conjunto ao longo do carregamento, por 
causa do travamento das chaves, e, consequentemente, a região superior dessa parede foi solicitada a flexo-tração em alguns trechos e principalmente a flexão, surgindo então fissuras na interface da junta e dos elementos no topo da parede transversal 2.

Objetivando avaliar o comportamento dessa separação, foi disposto um transdutor no lado tracionado do pilar próximo ao embutimento em cada modelo, fixados na parede transversal 2. Para efeito de comparação entre o deslocamento do pilar nessa região no Modelo IL4 e o ocorrido no Modelo IL3 analisado por CANHA (2004), na Figura 4.3 estão ilustradas as curvas força aplicada versus deslocamento do pilar na região tracionada próximo ao embutimento medido por esses transdutores. Escolheu-se o Protótipo IL3 por ter a mesma excentricidade de carregamento do Modelo IL4.
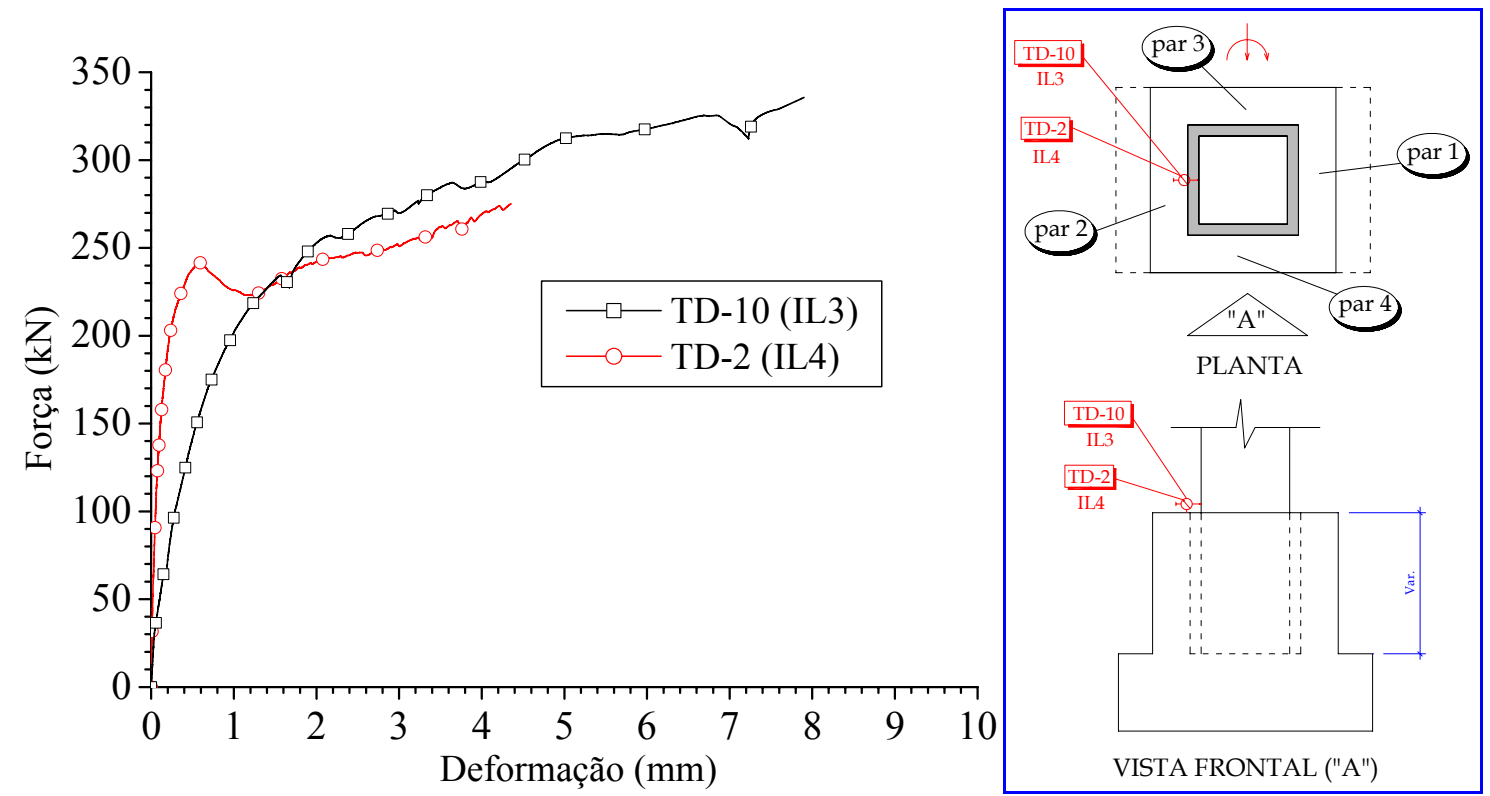

Figura 4.3 - Curva força aplicada versus abertura da junta na região superior da parede transversal 2 - Comparação entra Modelo IL3 e IL4

Nota-se que no decorrer do ensaio do Modelo IL4, o deslocamento relativo do pilar em relação à parede transversal 2, ou seja, a separação entre a junta e os elementos, foi muito pequeno até uma força de aproximadamente $240 \mathrm{kN}(87 \%$ da última leitura do ensaio). A partir daí, houve uma queda no carregamento e uma posterior retomada de força com uma rigidez inferior representada pela curva força aplicada versus abertura da junta, diferentemente do Modelo IL3, cuja rigidez diminuiu gradativamente desde o início do ensaio. Esse fenômeno pode ser explicado levando em conta que no início do carregamento do Modelo IL4, não houve um descolamento efetivo entre os elementos e 
a junta, talvez pelo fato da adesão inicial não ter sido totalmente eliminada, ou também por esse modelo possuir uma profundidade de embutimento menor, podendo ter influenciado para esse comportamento.

Quando o carregamento do protótipo atingiu uma força de $240 \mathrm{kN}$, houve um descolamento completo e repentino da interface da ligação causada pela ruptura total da adesão e consequentemente um deslizamento do pilar na região de embutimento, causando um decréscimo da força, já que o ensaio era controlado pelo deslocamento do pistão do atuador hidráulico. O modelo então sofreu um processo de redistribuição dos esforços e posteriormente voltou a absorver força.

Esse fenômeno, como será visto a seguir, influenciou no comportamento geral do Modelo IL4, pois as armaduras horizontais principais só foram realmente solicitadas quando houve o deslizamento do pilar, podendo considerar como uma ruptura repentina da adesão entre a junta e os elementos.

Na Figura 4.4, estão apresentadas as fissuras dos modelos que caracterizam a abertura entre a junta e os elementos na parte tracionada da ligação, ou seja, no topo da parede transversal 2 .

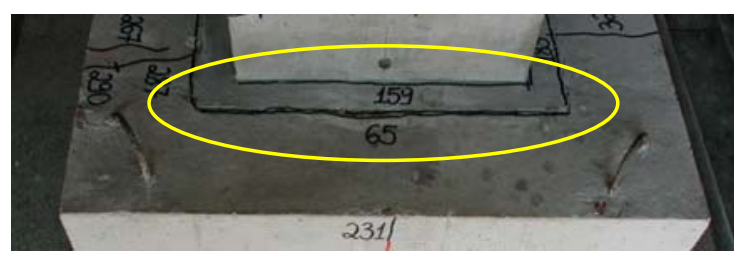

Modelo IL3

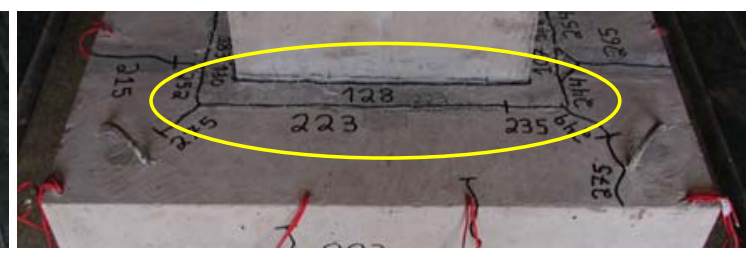

Modelo IL4

Figura 4.4 - Fissuras características da abertura entre a junta e os elementos no topo da parede transversal 2

Analisando o valor da força anotada no instante que ocorreu a fissura durante o ensaio, nota-se que no Modelo IL3, essa fissura surgiu primeiramente entre a junta e a parede transversal 2, indicando a separação entre eles. Com o andamento do ensaio, ocorreu então a segunda fissura localizada entre a junta e o pilar. Já no Modelo IL4 ocorreu o contrário, a primeira separação visual foi entre o pilar e a junta e posteriormente entre a junta e a parede transversal 2.

Comparando a fissuração entre os Modelos IL3 e IL4 com relação ao valor da força marcada no modelo, desde o início do carregamento já se evidenciou a separação e o deslizamento entre a junta e os elementos no Modelo IL3, e que, no Modelo IL4, 
esse fenômeno só aconteceu depois que este atingiu um carregamento mais elevado.

\subsection{COMPORTAMENTO DA REGIÃO SUPERIOR DA PAREDE TRANSVERSAL 1}

\subsubsection{DEFORMAÇÃO NA ARMADURA HORIZONTAL PRINCIPAL}

Na Figura 4.5, está apresentada a curva força aplicada versus deformação nas armaduras horizontais principais dispostas na parede transversal 1 do Modelo IL4.

Com foi mencionado anteriormente, as armaduras horizontais desse modelo foram diretamente governadas pelo rompimento total da adesão na interface da ligação, ou seja, essas armaduras só foram realmente solicitadas quando houve o deslizamento do pilar na região de embutimento, onde então se passou a atuar efetivamente a resultante de pressão $H_{\text {sup }}$ na parede transversal 1. Após esse fenômeno, os dois ramos dessa armadura foram tracionados, ou seja, a parede transversal 1 foi submetida a flexotração, comprovando o descrito em CANHA (2004), cujos protótipos ensaiados apresentaram o mesmo comportamento. Nota-se também que o ramo externo da armadura mais solicitada chegou próximo ao escoamento, enquanto o interno foi pouco solicitado, apontando um modelo de projeto que leve em consideração essa flexo-tração.

Vale lembrar que esse protótipo não foi levado até sua capacidade máxima por causa da elevada excentricidade do sistema de rótulas comentado anteriormente, ou seja, percebe-se pela curva força aplicada versus deformação na armadura horizontal principal da parede transversal $l$ que há uma tendência dessas armaduras a continuarem se deformando se o ensaio não tivesse sido interrompido, podendo até chegar ao escoamento dos ramos externos, mas, como já foi mencionado, o atuador hidráulico já não mais conseguia aplicar uma força significativa nesse modelo.

As deformações nos níveis superior e inferior dessa armadura não variaram significativamente, indicando que considerar, no dimensionamento e na distribuição da armadura $A_{s, h f t}$, a base dessa parede equivalente a $\ell_{e m b} / 3$ está razoável com os resultados experimentais, mesmo nesse caso, quando a relação $\ell_{e m b}$ e $h$ não segue as recomendações da NBR 9062: (1985), pois o comprimento de embutimento utilizado nesse modelo é inferior ao recomendado pela norma brasileira.

Não foi possível obter os valores referentes à leitura do extensômetro HST-5, 
pois houve um defeito interno no próprio extensômetro ou na sua conexão com o fio que serve de ligação com o sistema de aquisição.
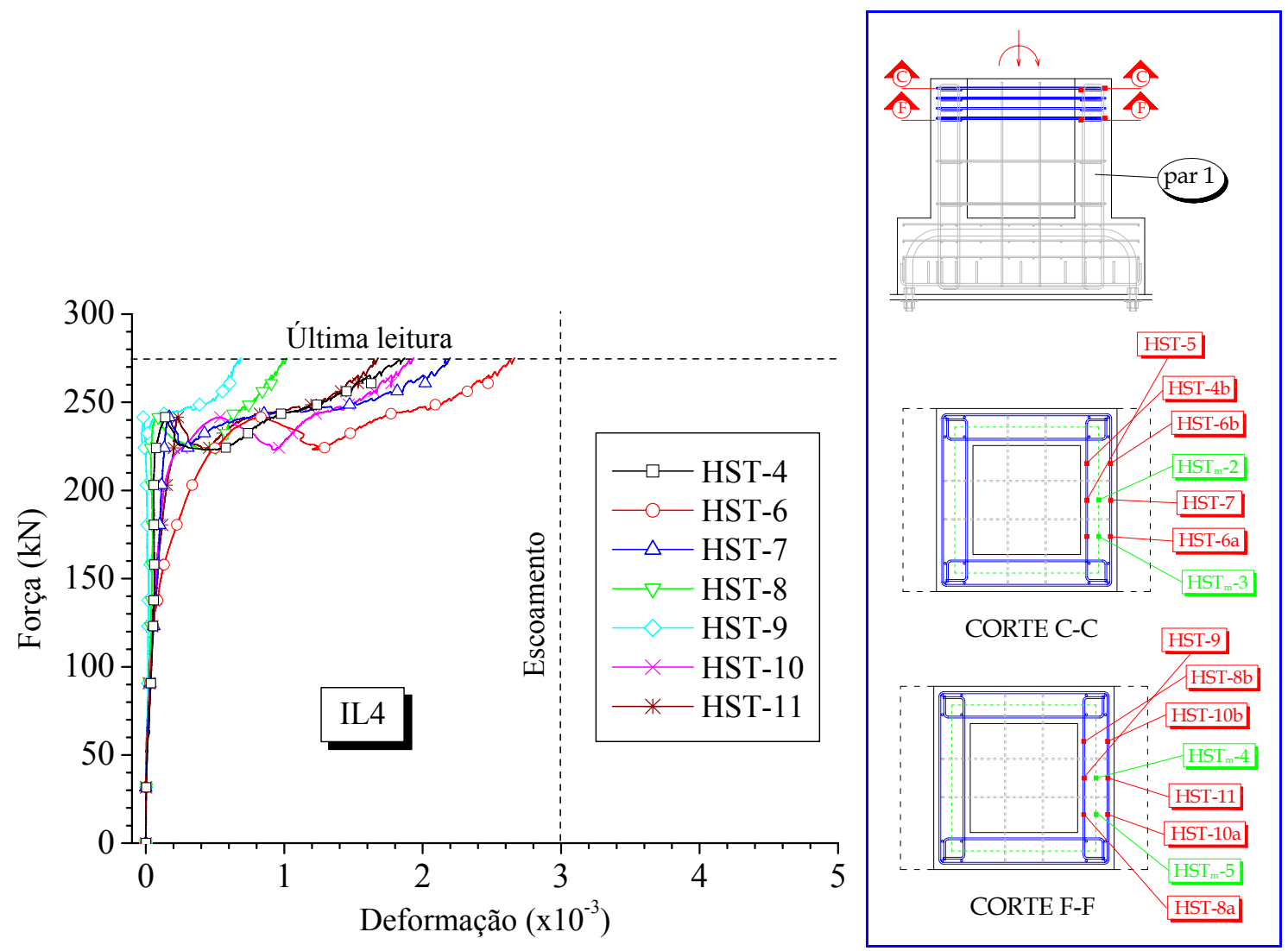

Figura 4.5 - Curva força aplicada versus deformação na armadura horizontal principal disposta no topo da parede transversal 1 - Modelo IL4

$\mathrm{Na}$ Figura 4.6, ilustra-se a curva força aplicada versus deformação nas armaduras horizontais principais dispostas transversalmente na parede 1 do Modelo IR3. Como era de se esperar, nos cálices com chaves de cisalhamento essas armaduras não foram muito solicitadas, pois esse protótipo apresentou um comportamento próximo ao de uma ligação monolítica e, portanto, os esforços por flexo-tração na parede transversal 1 foram bastante reduzidos.

Nota-se que houve um problema na leitura do extensômetro HST-12, provavelmente pelo mau contato no canal de leitura, mas, próximo ao final do ensaio, retornou a registrar normalmente as deformações.

$\mathrm{Na}$ Figura 4.7, apresenta-se um análise comparativa do resultado médio $\mathrm{HST}_{\mathrm{m}}-2$ entre os Modelos IL4 e IR3. 

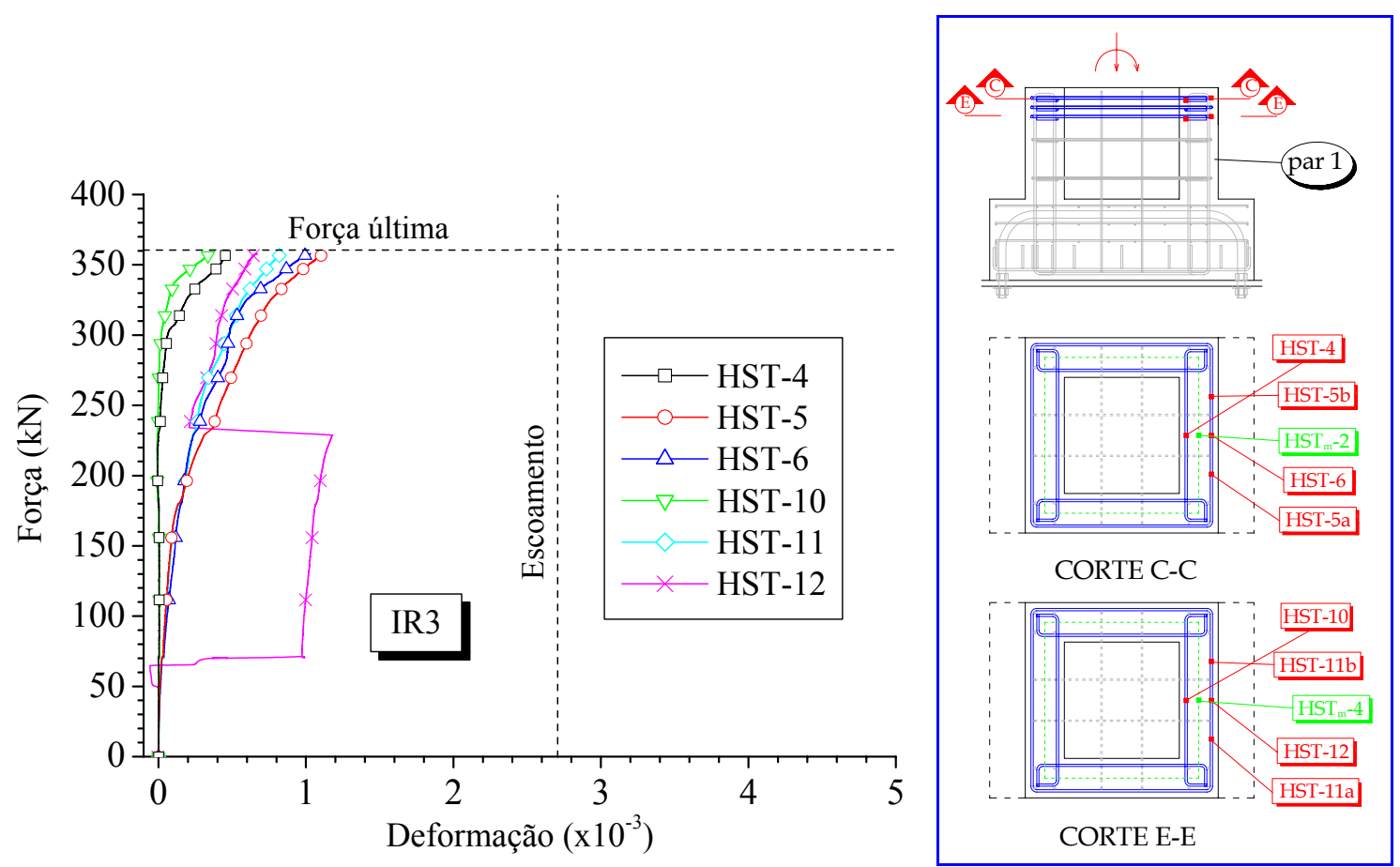

Figura 4.6 - Curva força aplicada versus deformação na armadura horizontal principal disposta no topo da parede transversal 1 - Modelo IR3

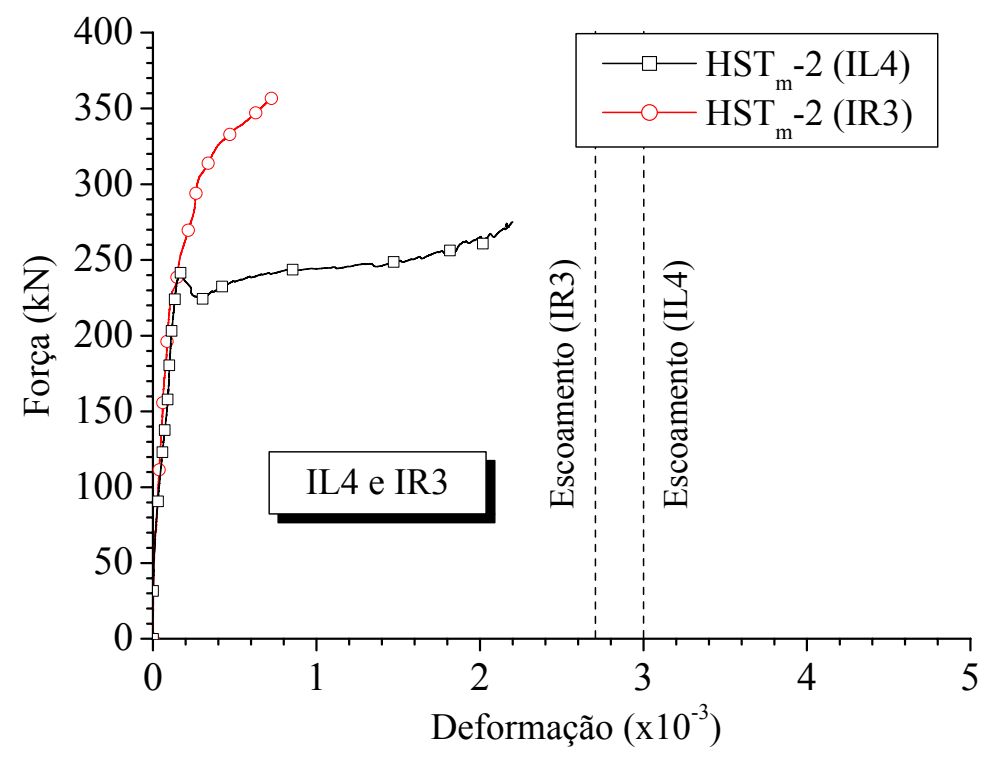

Figura 4.7 - Curva força aplicada versus deformação média na armadura horizontal principal disposta no topo da parede transversal 1 - Comparação entre os Modelos IL4 e IR3

Percebe-se, que até o carregamento que gerou o deslizamento do pilar no Modelo IL4 e consequentemente a redistribuição dos esforços na ligação, as deformações dessas armaduras tiveram praticamente o mesmo comportamento, mostrando que até o ensaio atingir esse carregamento, o Modelo IL4 se comportou de modo semelhantemente ao Modelo IR3 no que diz respeito às armaduras horizontais da 
parede 1 . No entanto, após a parede transversal 1 do modelo liso ser efetivamente solicitada, essa armadura se deformou muito em relação a do Modelo IR3, ou seja, houve uma brusca queda de rigidez permanecendo assim até a ultima leitura da força.

\subsubsection{DESLOCAMENTO}

Na Figura 4.8, mostram-se os deslocamentos medidos na primeira metade da parede transversal 1 ao longo do carregamento do Modelo IL4. Esses deslocamentos, após a ocorrência do rompimento repentino da adesão na interface desse modelo, foram relativamente grandes na parte superior da parede e diminuíram gradativamente conforme o afastamento em direção a base da fundação, comprovando o comportamento analisado nas armaduras horizontais principais dispostas na região superior dessa parede.
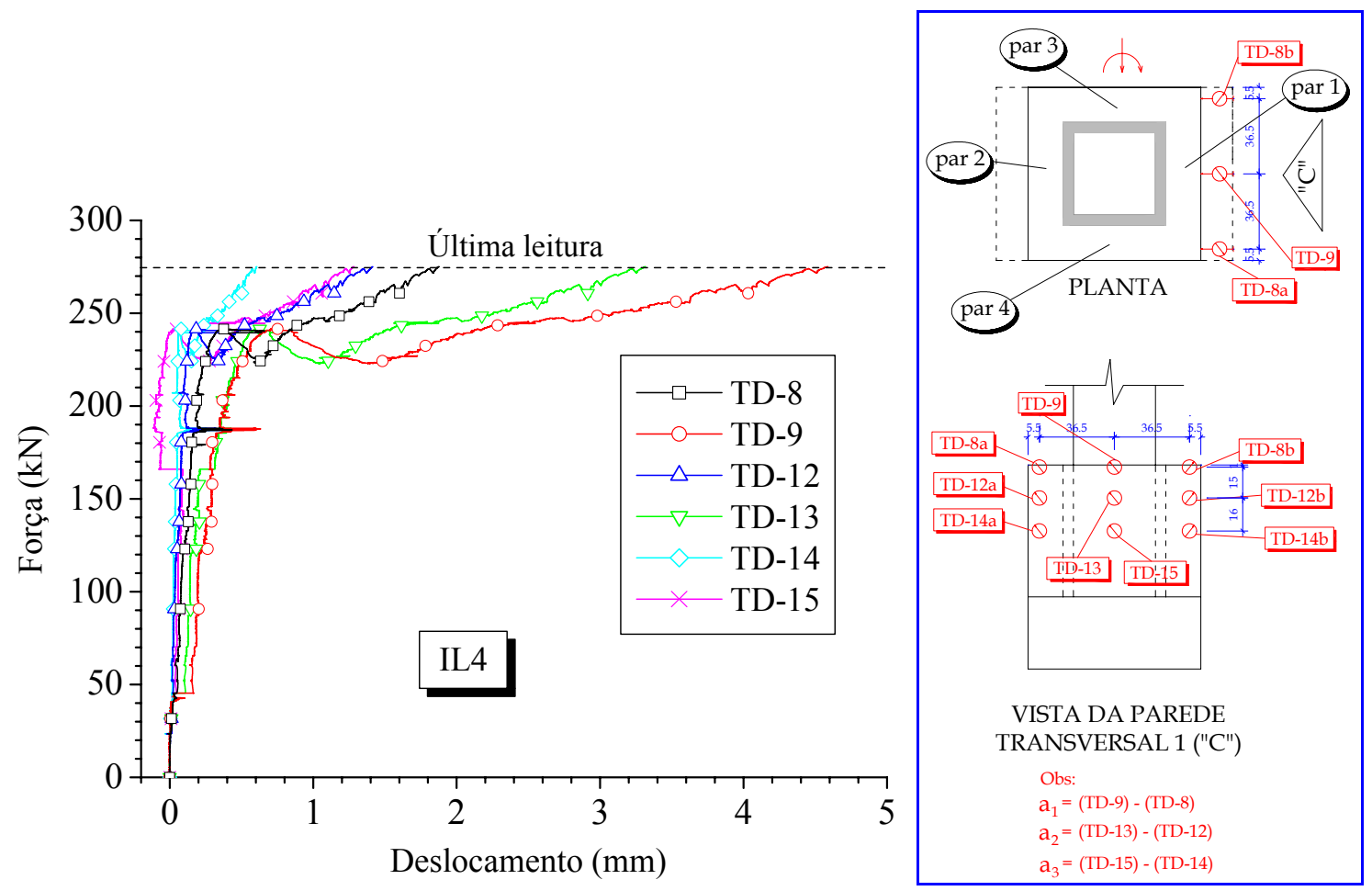

Figura 4.8 - Curva força aplicada versus deslocamento na parede transversal 1 - Modelo IL4

Constata-se também, que a consideração do trecho da parede transversal 1 de altura equivalente a $\ell_{e m b} / 3$ para o dimensionamento e distribuição da armadura horizontal principal dessa parede $\left(A_{s, h f t}\right)$ no cálice liso indicou uma coerência com os resultados desses deslocamentos, confirmando o que já foi descrito anteriormente.

Já as deformações medidas na parede transversal 1 do Modelo IR3 foram 
reduzidas, conforme mostra a Figura 4.9, por conseqüência do travamento ocasionado pelas chaves, entre a junta e os elementos.
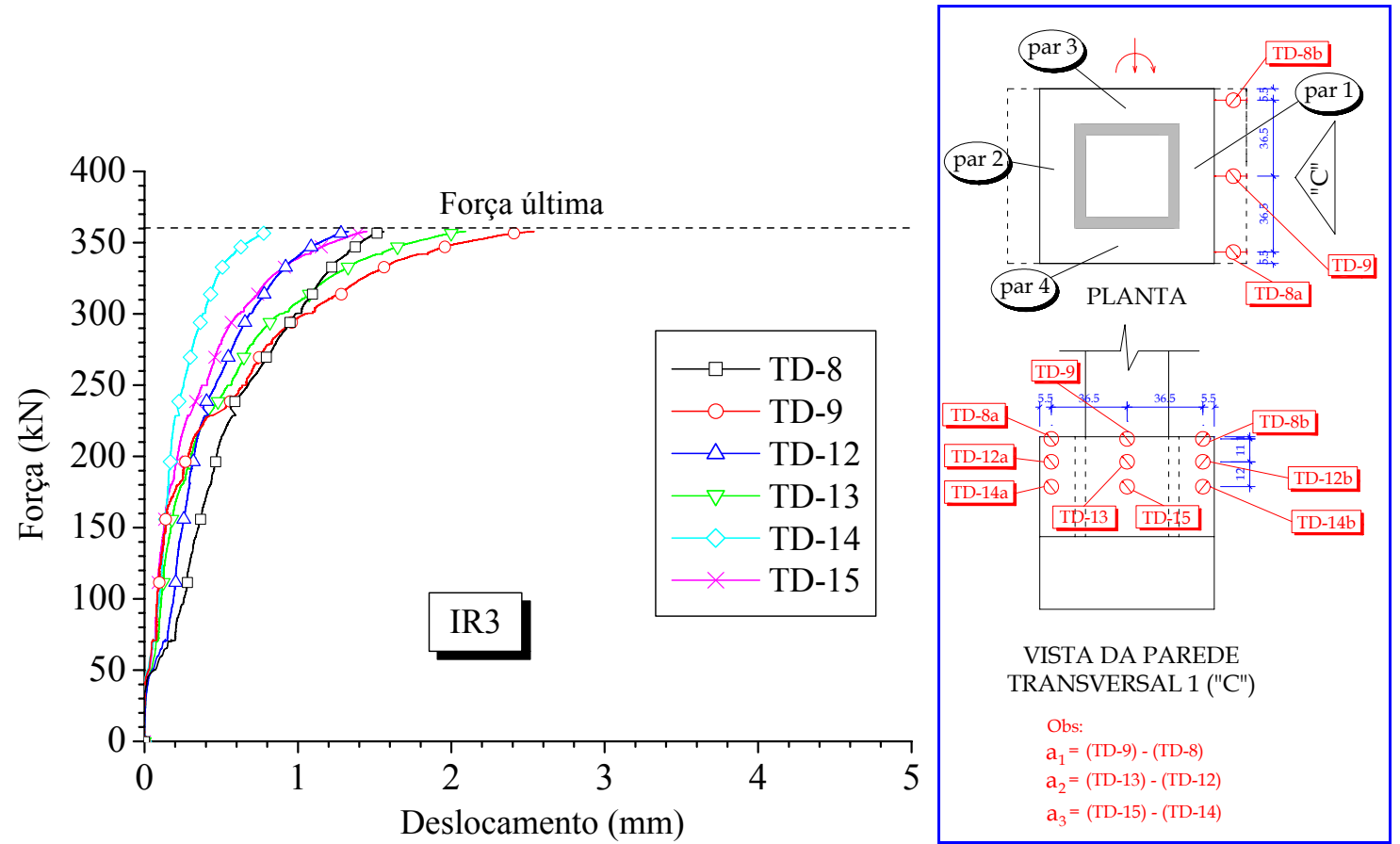

Figura 4.9 - Curva força aplicada versus deslocamento na parede transversal 1 - Modelo IR3

\subsubsection{FISSURAÇÃO}

Nota-se, pela fissuração apresentadas na Figura 4.10, que os esforços solicitantes por flexo-tração ocorridos no topo da parede transversal 1 do Modelo IL4 foram mais intensos do que no Modelo IR3.

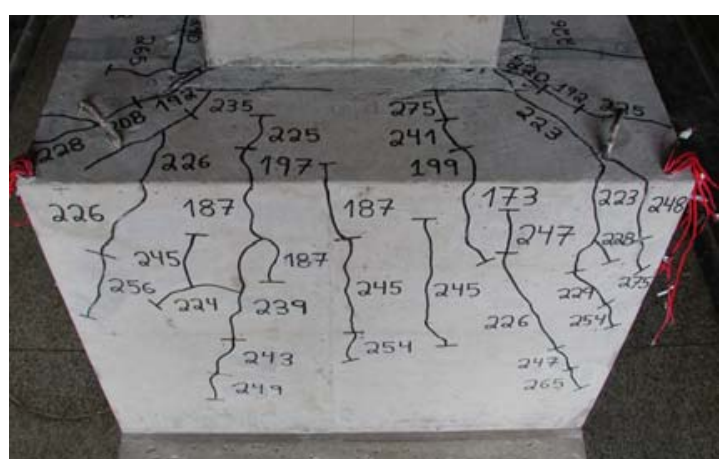

Modelo IL4

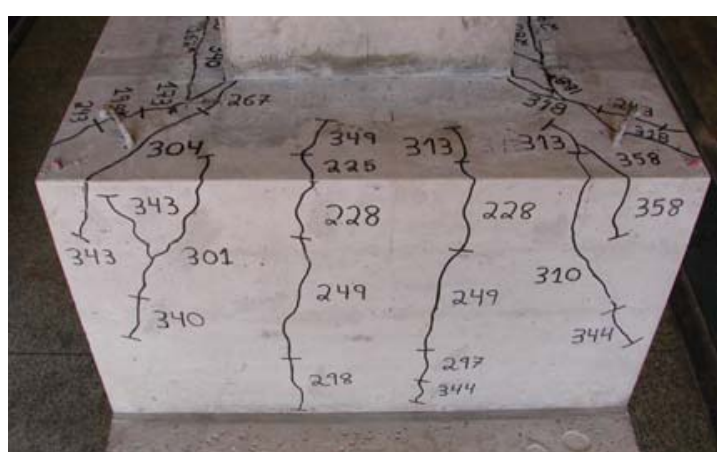

Modelo IR3

Figura 4.10 - Fissuração no topo da parede transversal 1 dos Modelos IL4 e IR3

Essas fissuras indicam também que parte da pressão oriunda do pilar é direcionada para os cantos dessa parede, como se pode perceber pela sua inclinação na 
região de encontro da parede transversal 1 com as paredes longitudinais 3 e 4 . Como foi visto no Capítulo 2, o modelo de cálculo sugerido por CANHA (2004) para o dimensionamento das armaduras $A_{s, h f t}$, indica que a maior parte da resultante de pressão $H_{\text {sup }}$ é direcionada diretamente para os cantos da parede transversal 1.

\subsection{COMPORTAMENTO DA REGIÃO SUPERIOR DA PAREDE TRANSVERSAL 2}

\subsubsection{DEFORMAÇÃO NA ARMADURA HORIZONTAL PRINCIPAL}

Como foi comentado no Capítulo 3, percebeu-se, analisando os modelos ensaiados por CANHA (2004), que na região superior da parede transversal 2 ocorreram fissuras que indicaram uma possível flexão dessa parede. Como a armadura horizontal principal dessa parede não foi instrumentada na pesquisa anterior, resolveu-se instrumentá-la nos dois protótipos aqui analisados.

Na Figura 4.11, ilustra-se o comportamento da armadura horizontal principal localizada na região superior da parede transversal 2 no Modelo IL4. Nota-se que, após o descolamento da interface, o topo da parede transversal 2 foi submetido a pequenos esforços por flexo-tração, ou seja, essas armaduras horizontais dispostas no topo desta parede não foram totalmente solicitadas.

Já no Modelo IR3, conforme Figura 4.12, os ramos externos dessas armaduras foram bastante solicitados, com deformação máxima no extensômetro HST-2 equivalente a 2,0\%o, comprovando portanto, elevados esforços por flexo-tração no topo da parede transversal 2 nos modelos rugosos. Isso é explicado pelo forte travamento das chaves de cisalhamento dos elementos, ou seja, como já foi mencionado, o pilar, a junta e o cálice; nos lados comprimidos e longitudinais, trabalharam em conjunto ao longo do carregamento por causa do travamento das chaves, e, consequentemente, a região superior dessa parede foi submetida à flexo-tração em alguns trechos e principalmente a flexão. Nota-se também que não houve uma diferença considerável entra as deformações medidas na primeira e terceira camada dessa armadura, mostrando que essa solicitação ocorreu em toda sua faixa de distribuição. 


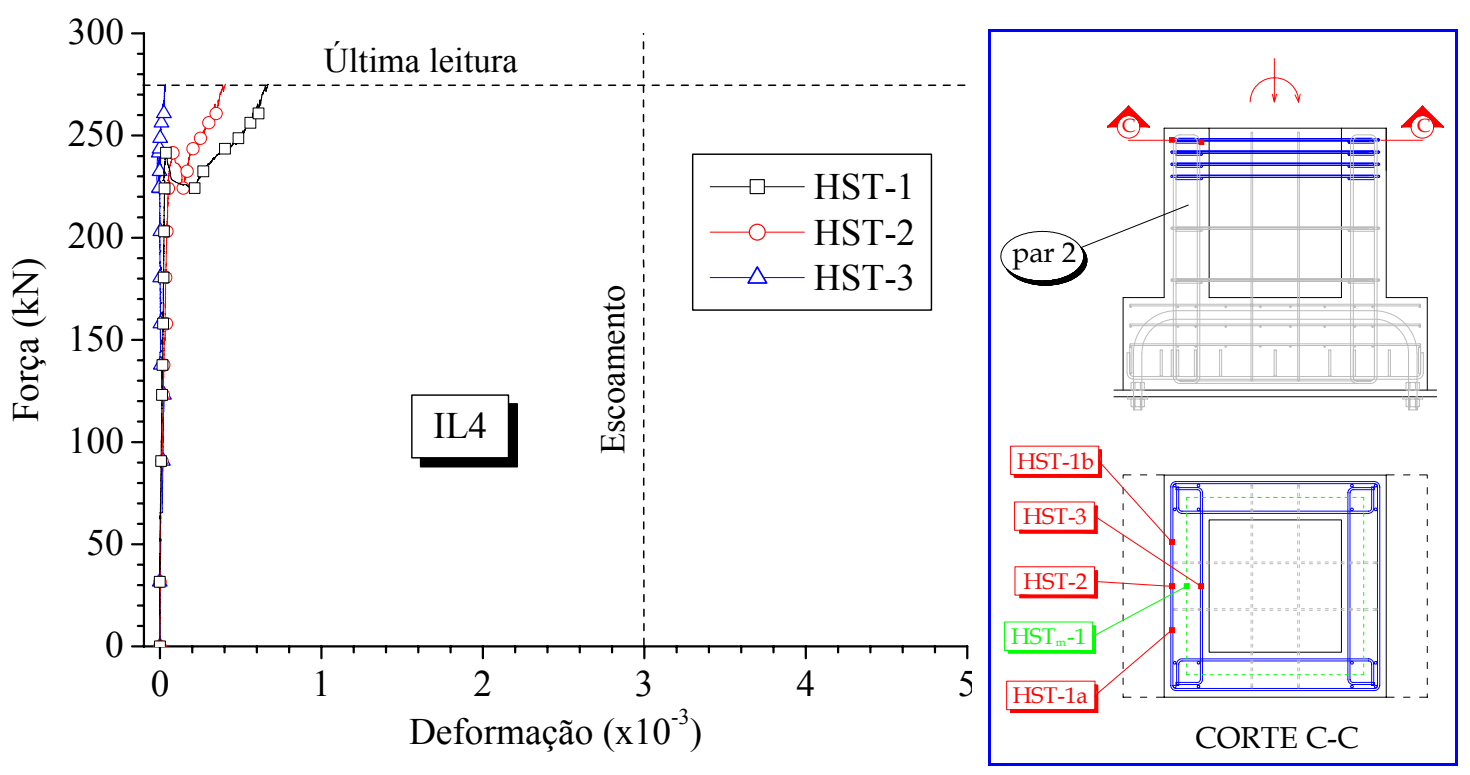

Figura 4.11 - Curva força aplicada versus deformação na armadura horizontal principal disposta no topo da parede transversal 2 - Modelo IL4
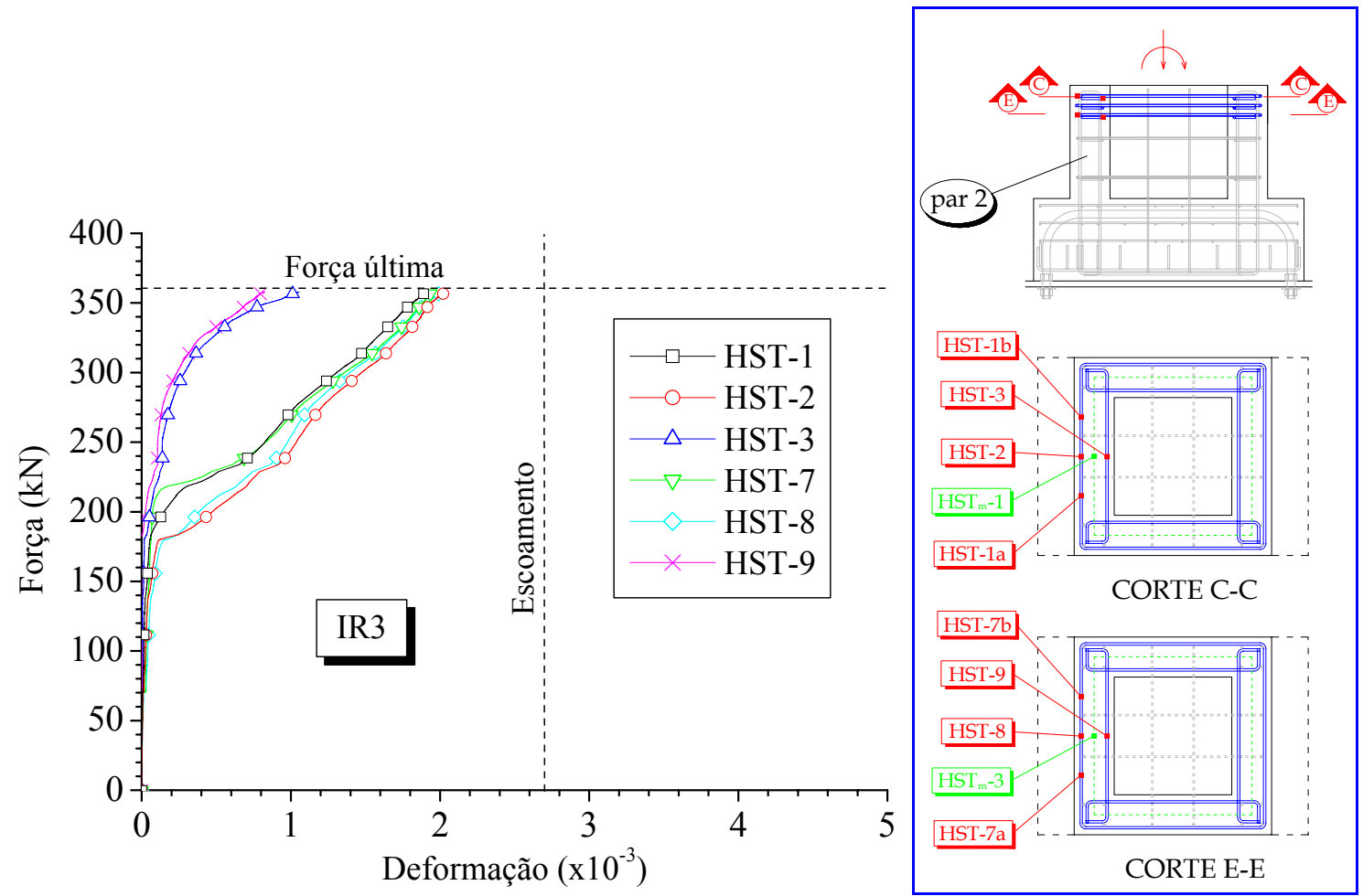

Figura 4.12 - Curva força aplicada versus deformação na armadura horizontal principal disposta no topo da parede transversal 2 - Modelo IR3

$\mathrm{Na}$ Figura 4.13, apresenta-se comparativamente os resultados médios $\mathrm{HST}_{\mathrm{m}}-1$ dos modelos ensaiados.

Observa-se que a armadura em questão do Modelo IR3, no final do ensaio, foi a que mais se deformou e no Modelo IL4 ela quase não trabalhou. 




Figura 4.13 - Curva força aplicada versus deformação média na armadura horizontal principal disposta no topo da parede transversal 2 - Comparação entre os Modelos IL4 e IR3

É possível visualizar também que a rigidez representada pela curva força aplicada versus deformação dessa armadura foi elevada nos dois modelos, ou seja, praticamente não houve uma significativa deformação até um certo valor do carregamento. No Modelo IR3, o valor desse carregamento foi de aproximadamente 175 $k N$, onde a partir daí teve uma considerável redução da rigidez, possivelmente devido a fissuração do concreto nessa região e permaneceu praticamente constante até atingir a capacidade ultima do modelo. Já no Modelo IL4, essa armadura foi solicitada quando ocorreu o deslizamento do pilar, mas, no entanto se deformou muito pouco até a última leitura do ensaio.

\subsubsection{DESLOCAMENTO}

Na Figura 4.14 e Figura 4.15 estão ilustrados os deslocamentos ao longo do carregamento medidos na parte superior da parede transversal 2 dos dois modelos, visando capturar melhor o comportamento da flexo-tração ocorrida nessa parede.

No Modelo IL4, aconteceu um fato estranho na leitura dos deslocamentos, os transdutores situados no alinhamento das paredes longitudinais 3 e 4 localizados próximos ao topo dessa parede (TD-6), registraram menores deslocamentos do que os situados na camada mais afastada do topo (TD-10). Isso pode ser explicado por consequência de algum problema ocorrido no transdutor. 

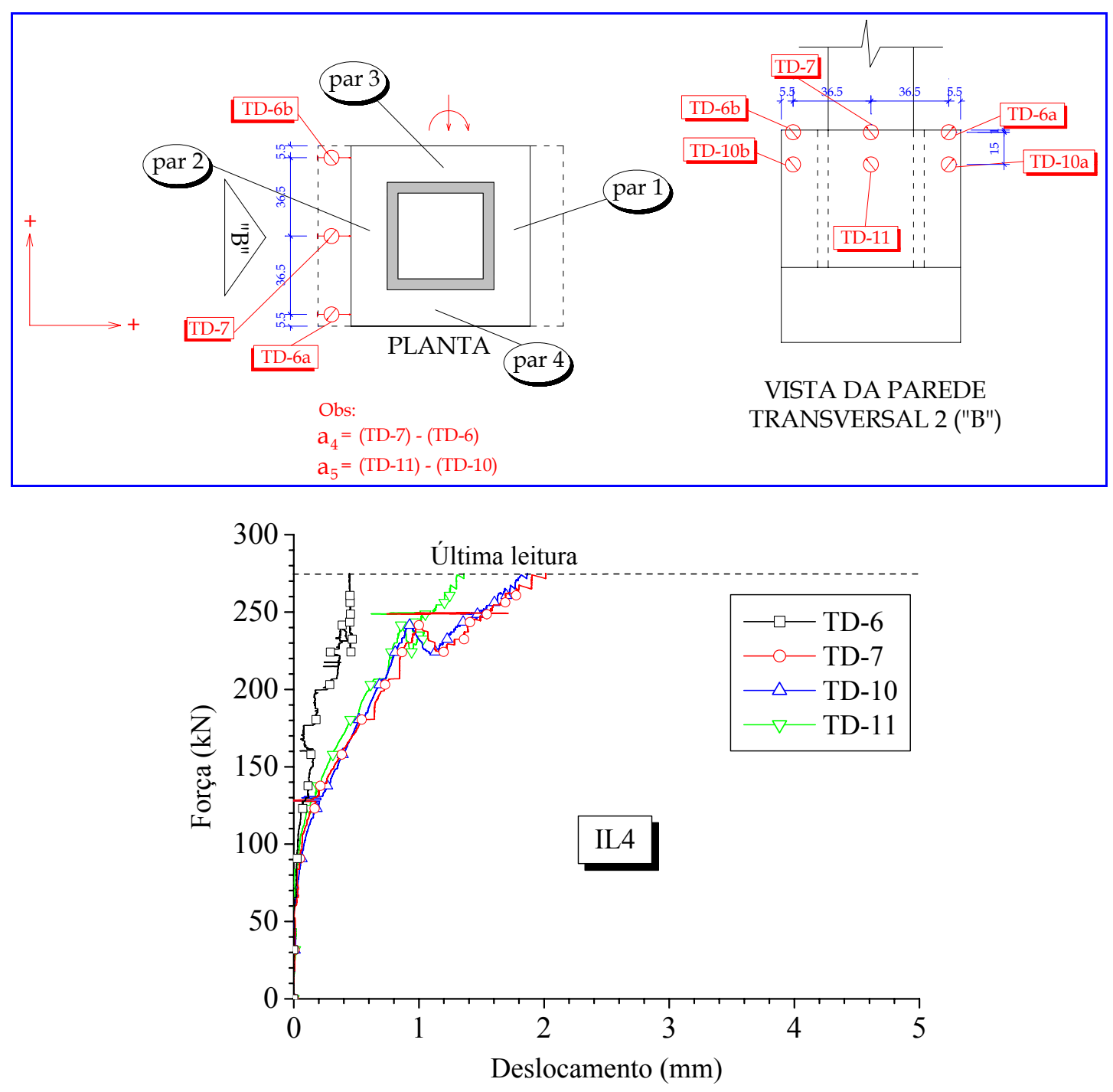

Figura 4.14 - Curva força aplicada versus deslocamento na parede transversal 2 - Modelo IL4

Já os transdutores localizados no meio da parede transversal 2 resultaram num comportamento mais coerente, ou seja, na região próxima ao topo da parede o transdutor TD-7 registrou um deslocamento maior que o TD-11, localizado mais distante do topo dessa parede. Mas, no entanto, não houve um deslocamento considerável dessa parede durante o ensaio, comprovando que nos modelos lisos os esforços causados pela flexão são pequenos.

No Modelo IR3 (Figura 4.15), os deslocamentos medidos na parede transversal 2 foram mais significativos em relação ao Modelo IL4, com os transdutores centrais TD-7 e TD-11 registrando valores negativos de deslocamentos, ou seja, a parte central da parede se deslocou para esquerda. Isso se deve pelo fato da intensidade do travamento das chaves de cisalhamento, provocando intensos esforços por flexo-tração nessa 
parede, que pode ser observada por meio das fissuras ocorridas nessa região, mostradas mais adiante.


Figura 4.15 - Curva força aplicada versus deslocamento na parede transversal 2 - Modelo IR3

Para melhor comparar os deslocamentos ocorridos na parte superior da parede transversal 2, são apresentados na Figura 4.16 os deslocamentos centrais relativos dos dois modelos sem se preocupar com a sua direção, ou seja, apresentando apenas a diferença de deslocamento entre os cantos dessa parede (mais rígido) e o meio (mais flexível).

Nota-se que há uma diferença entre os deslocamentos centrais relativos $a_{4}$ e $a_{5}$ no Modelo IL4, apresentando maior deslocamento próximo à extremidade superior da parede transversal $2\left(a_{4}\right)$ e diminui consideravelmente na camada mais distante do topo $\left(a_{5}\right)$, mostrando que os esforços causados pela flexo-tração são mais significativos na 
região superior dessa parede e se tornam menores quando se dirige em direção ao meio desta. Já no Modelo IR3 isto não acontece, já que esses deslocamentos centrais relativos nas duas camadas foram praticamente os mesmos e maiores que os do Modelo IL4 próximo a força última experimental.

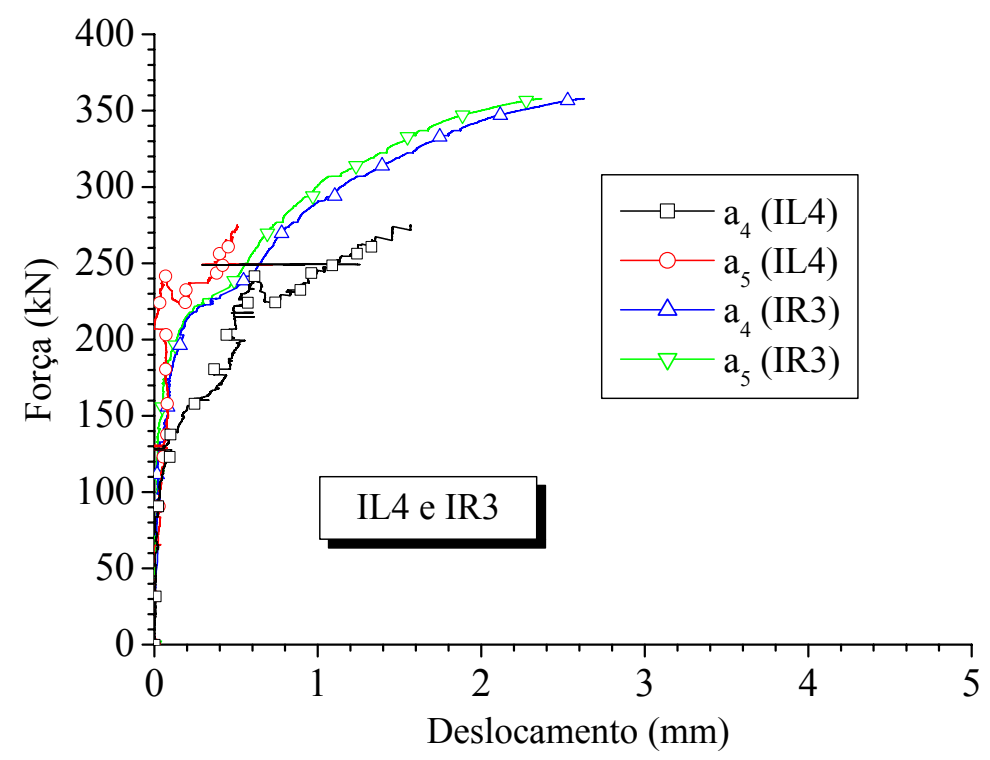

Figura 4.16 - Curva força aplicada versus deslocamento relativo na parede transversal 2 Comparação entre os Modelos IL4 e IR3

\subsubsection{FISSURAÇÃO}

Na Figura 4.17, onde é ilustrado o desenvolvimento da fissuração dos modelos na região superior da parede transversal 2, percebe-se claramente a flexo-tração ocorrida no topo dessa parede no Modelo IR3.

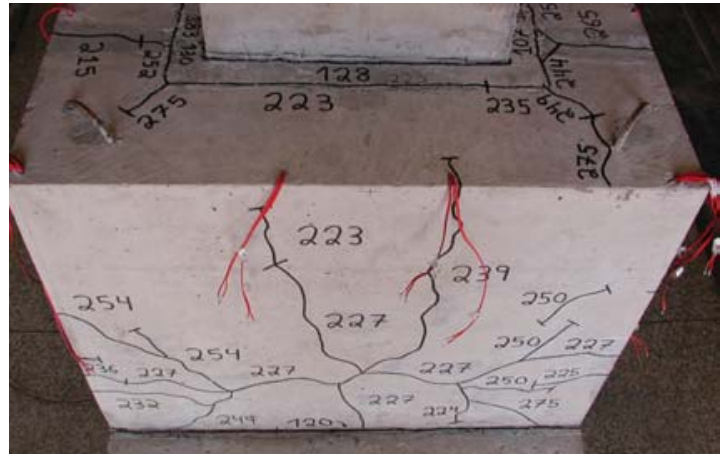

Modelo IL4

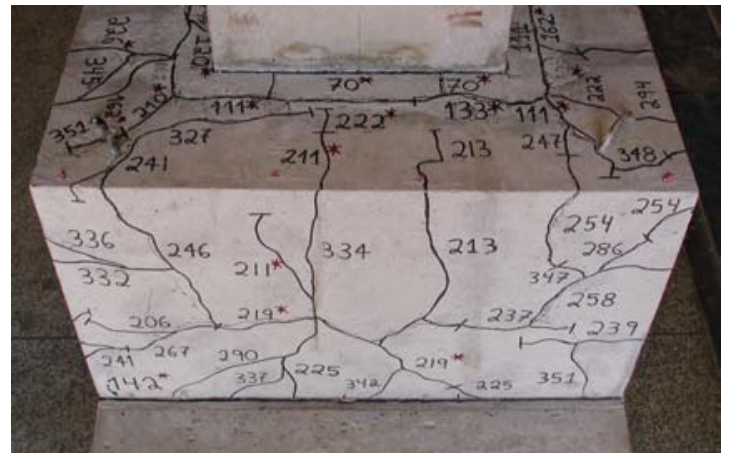

Modelo IR3

Figura 4.17 - Fissuração no topo da parede transversal 2 dos Modelos IL4 e IR3

Nota-se também, que esse fenômeno ocorreu com maior intensidade neste 
modelo, pois no Modelo IL4 ocorreram poucas fissuras nessa região.

\subsection{COMPORTAMENTO DA REGIÃO SUPERIOR DAS PAREDES LONGITUDINAIS 3 E 4}

\subsubsection{DEFORMAÇ̃̃O NA ARMADURA HORIZONTAL PRINCIPAL}

Como nas paredes transversais 1 e 2 , as paredes longitudinais 3 e 4 também foram submetidas à flexo-tração, como mostra a Figura 4.18 e Figura 4.19 onde estão indicadas as curvas força aplicada versus deformação nas armaduras horizontais principais situadas no topo dessas paredes nos Modelos IL4 e IR3, respectivamente.

Os ramos internos dessas armaduras nos dois modelos sofreram maiores deformações que os ramos externos.

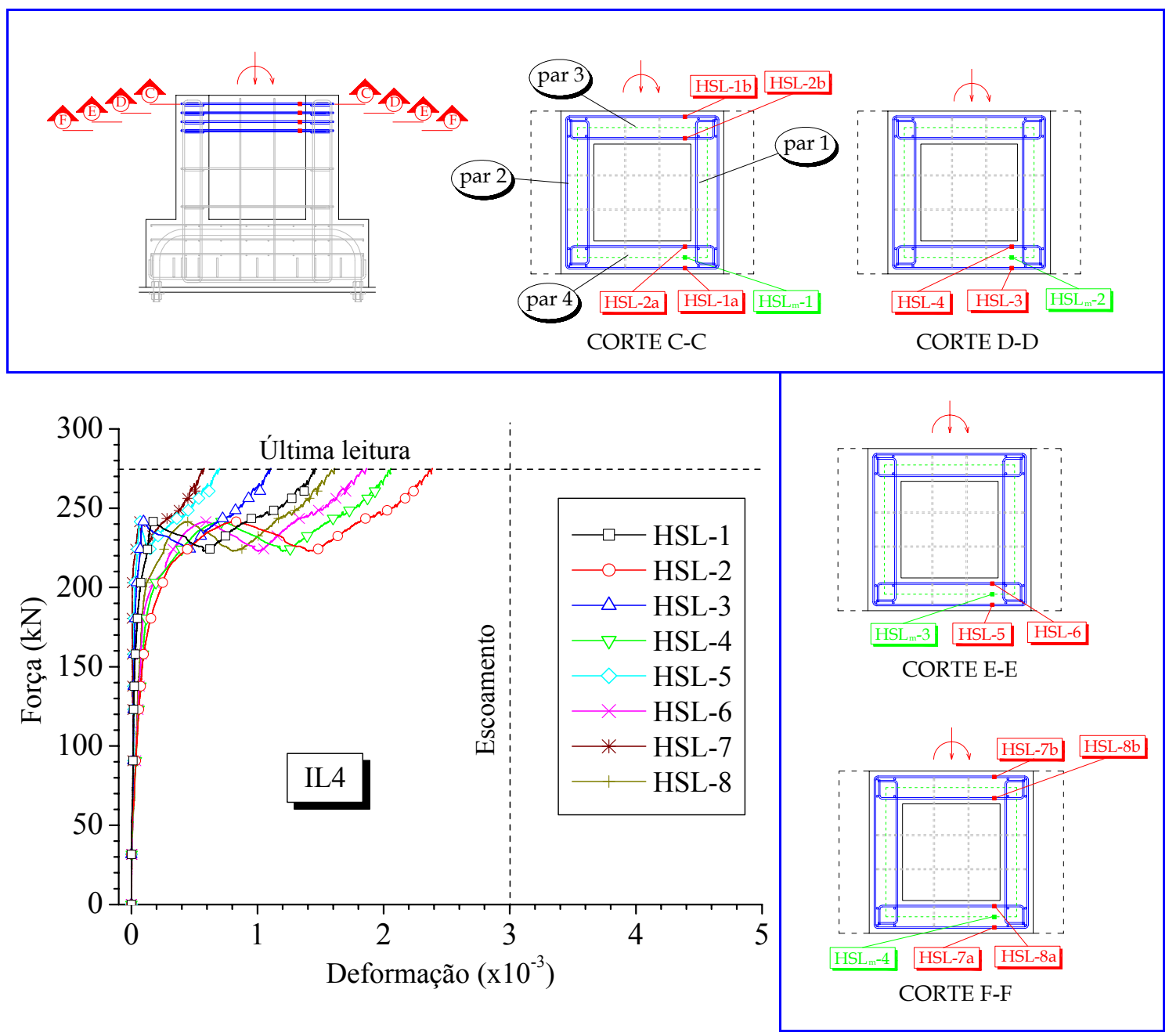

Figura 4.18 - Curva força aplicada versus deformação na armadura horizontal principal disposta no topo das paredes longitudinais 3 e 4 - Modelo IL4 


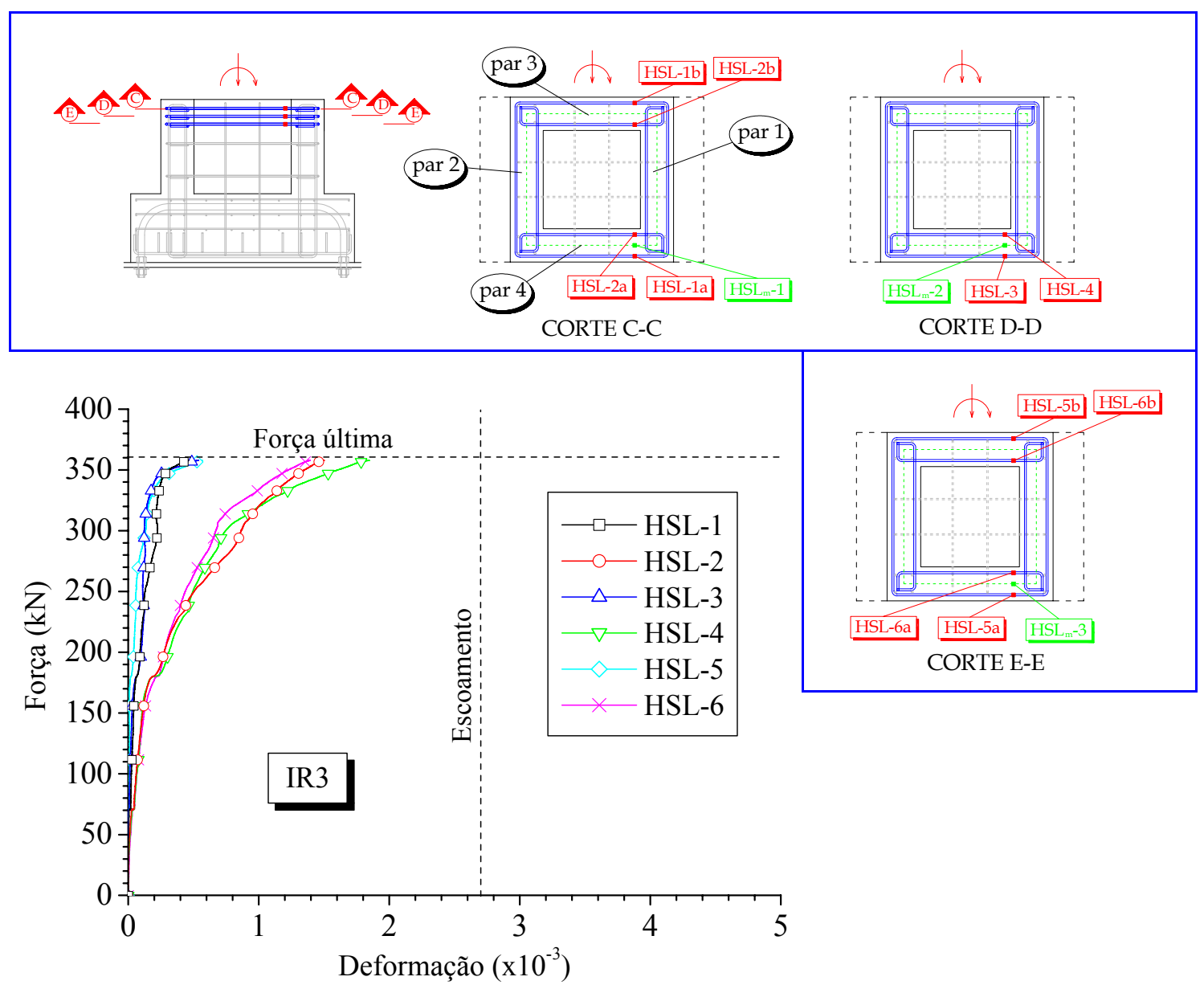

Figura 4.19 - Curva força aplicada versus deformação na armadura horizontal principal disposta no topo das paredes longitudinais 3 e 4 - Modelo IR3

No Modelo IL4 (Figura 4.18), vale lembrar que essas armaduras só foram efetivamente solicitadas a partir do instante no qual ocorreu o deslizamento repentino do pilar na região de embutimento, ou seja, após esse fenômeno a parede transversal 1 foi efetivamente solicitada pela resultante de pressão $H_{\text {sup }}$ e consequentemente as paredes longitudinais 3 e 4 foram tracionadas. É possível visualizar que, após a redistribuição dos esforços ocorrida nesse modelo, ou seja, a partir da retomada de força, a curva força aplicada versus deformação sofreu uma queda de rigidez, mas mantendo uma certa inclinação e com isso essas armaduras continuaram a absorver uma parcela razoável dos esforços mostrando que se o ensaio não fosse interrompido poderiam chegar ao escoamento, mas volta-se a afirmar que esse modelo já estava próximo a sua capacidade limite. Os esforços por flexo-tração ocorridos nas paredes longitudinais desse modelo se deram pelo motivo que além dessa tração ocasionada pela resultante de pressão $H_{\text {sup }}$, existe um momento resultante da transmissão dessa resultante no topo da parede transversal 1 para as paredes longitudinais 3 e 4 . 
Já no Modelo IR3 (Figura 4.19), além do mecanismo comentado anteriormente, atua a força de atrito $F_{a t, l o n g}$ entre a junta e os elementos nas paredes longitudinais 3 e 4 e o seu respectivo momento por causa da sua excentricidade em relação ao centro dessas paredes.

Foi possível visualizar a tendência de diminuição das deformações dos estribos inferiores em relação aos superiores no Modelo IL4, fato que não ocorreu no Modelo IR3, onde a deformação entre os três níveis de estribos foram praticamente as mesmas para o mesmo ramo.

$\mathrm{Na}$ Figura 4.20, apresenta-se a análise comparativa do comportamento da armadura horizontal principal longitudinal média $\mathrm{HSL}_{\mathrm{m}}-1$ entre os dois modelos.

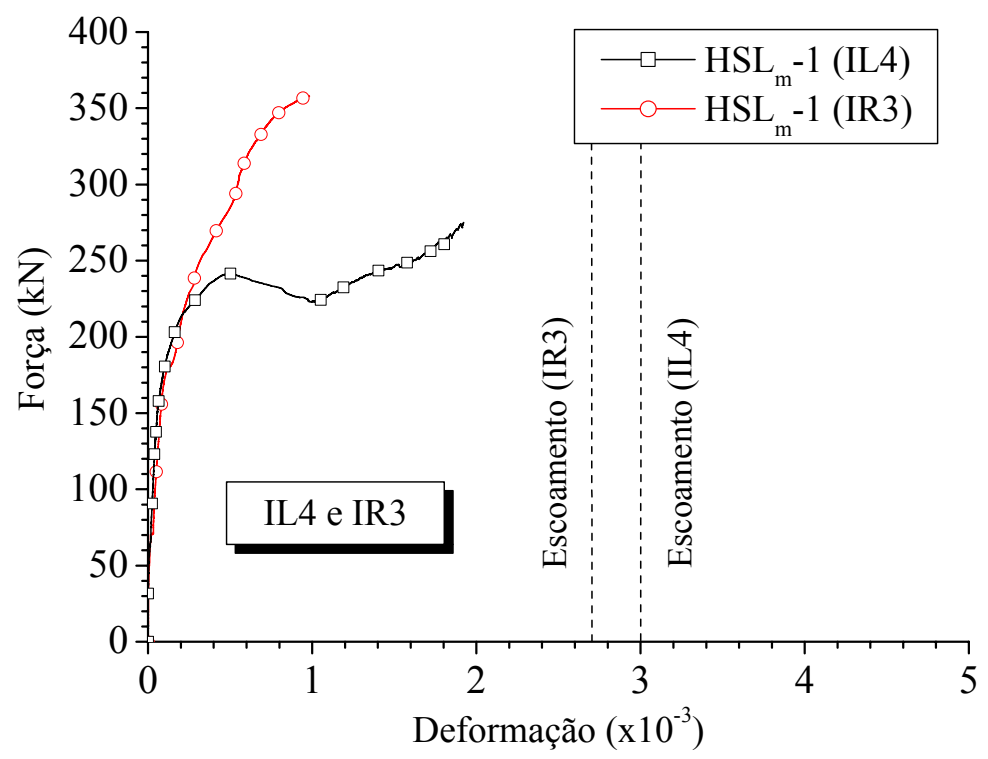

Figura 4.20 - Curva força aplicada versus deformação média na armadura horizontal principal média disposta no topo das paredes longitudinais 3 e 4 -Comparação entre os Modelos IL4 e IR3

No Modelo IL4, na última leitura de ensaio, as deformações nessa armadura foram maiores que no Modelo IR3, apesar da rigidez dos dois modelos serem iguais até o carregamento que ocasionou o rompimento total da adesão e consequentemente o deslizamento do pilar, onde então, há um grande aumento na deformação dessa armadura (Modelo IL4) sem alteração significativa da força e depois com uma menor rigidez a força volta subir novamente até a ultima leitura de ensaio. No Modelo IR3, a rigidez foi diminuindo gradativamente. 


\subsubsection{FISSURAÇÃO}

Na Figura 4.21 está ilustrado o desenvolvimento da fissuração no topo das paredes longitudinais 3 e 4 dos Modelos IL4 e IR3.

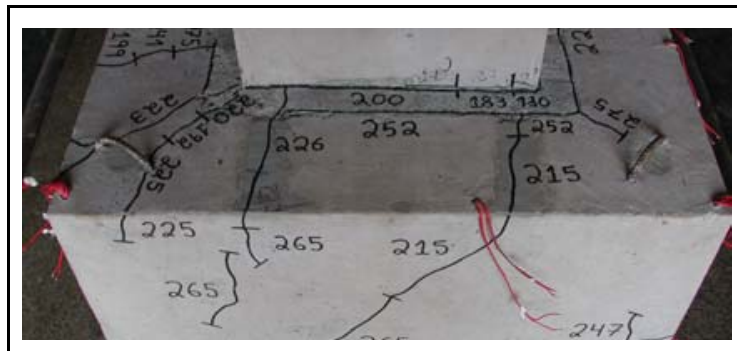

Parede 3

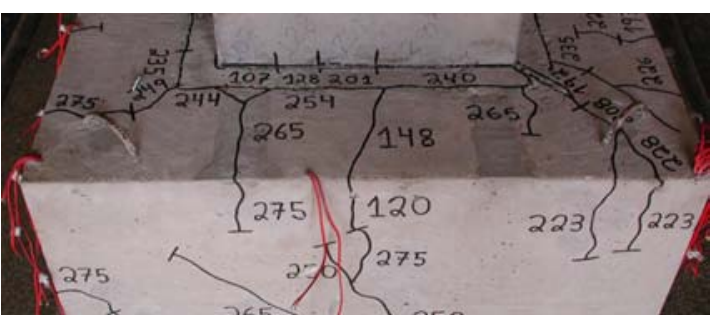

Parede 4

Modelo IL4

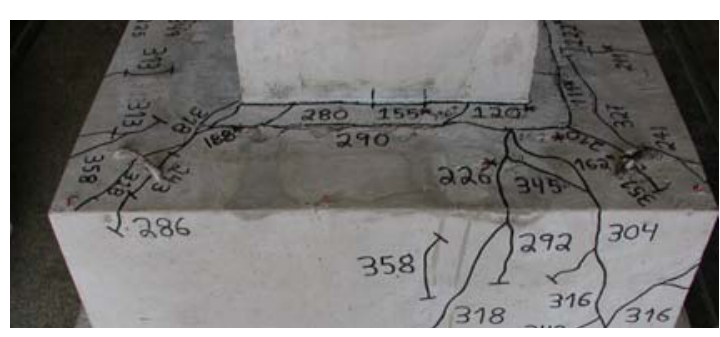

Parede 3

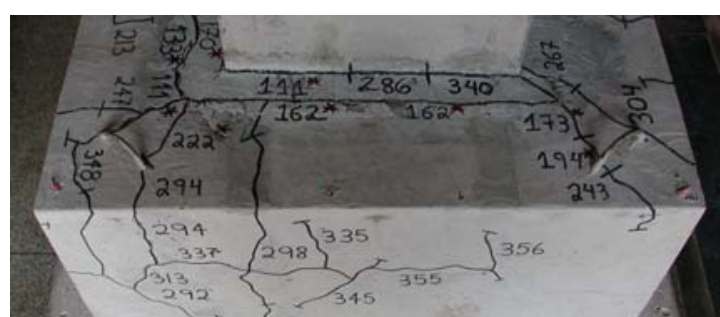

Parede 4

Modelo IR3

Figura 4.21 - Fissuração na região superior das paredes longitudinais 3 e 4 dos Modelos IL4 e IR3

Nota-se que no Modelo IL4 essas fissuras foram melhores definidas do que no Modelo IR3, cujo comportamento se aproximou bastante ao de uma ligação monolítica.

É possível visualizar também por meio da fissuração, que no Modelo IL4 as fissuras encontradas entre o pilar e a junta e entre essa e as paredes longitudinais se deu de forma gradativa observando os valores de força anotada no modelo, ou seja, essa fissura apareceu primeiramente na região próximo a parede transversal 2 e se desenvolveu em direção a parede transversal 1 , indicando que o descolamento total da interface não se deu logo no inicio do ensaio. Isso explica as poucas deformações ocorridas nas armaduras horizontais principais até atingir o carregamento que gerou o descolamento total entre o pilar e a junta.

No Modelo IR3, as fissuras observadas no topo das paredes longitudinais 3 e 4 surgiram mais pelos esforços por flexo-tração sofridos pela parede transversal 2 do que propriamente pelos ocorridos no topo dessas paredes, pois a maior concentração das fissuras foi na região de encontro entre essas paredes e a parede transversal 2. 


\subsection{COMPORTAMENTO DAS ARMADURAS VERTICAIS PRINCIPAIS E SECUNDÁRIAS}

Durante o ensaio do Modelo IL4, houve um acidente com o cabo que liga o extensômetro T-2 ao sistema de aquisição, comprometendo a leitura das deformações de todos os outros extensômetros ligados ao mesmo canal, no total de cinco. Os extensômetros afetados foram: T-1a, T-1b, T-2, T-3 e T-4a, ou seja, todos eles posicionados nas armaduras verticais principais. No entanto, após um determinado instante, as leituras foram normalizadas ficando apenas um intervalo do carregamento sem valores de deformação, conforme ilustrado na Figura 4.22.

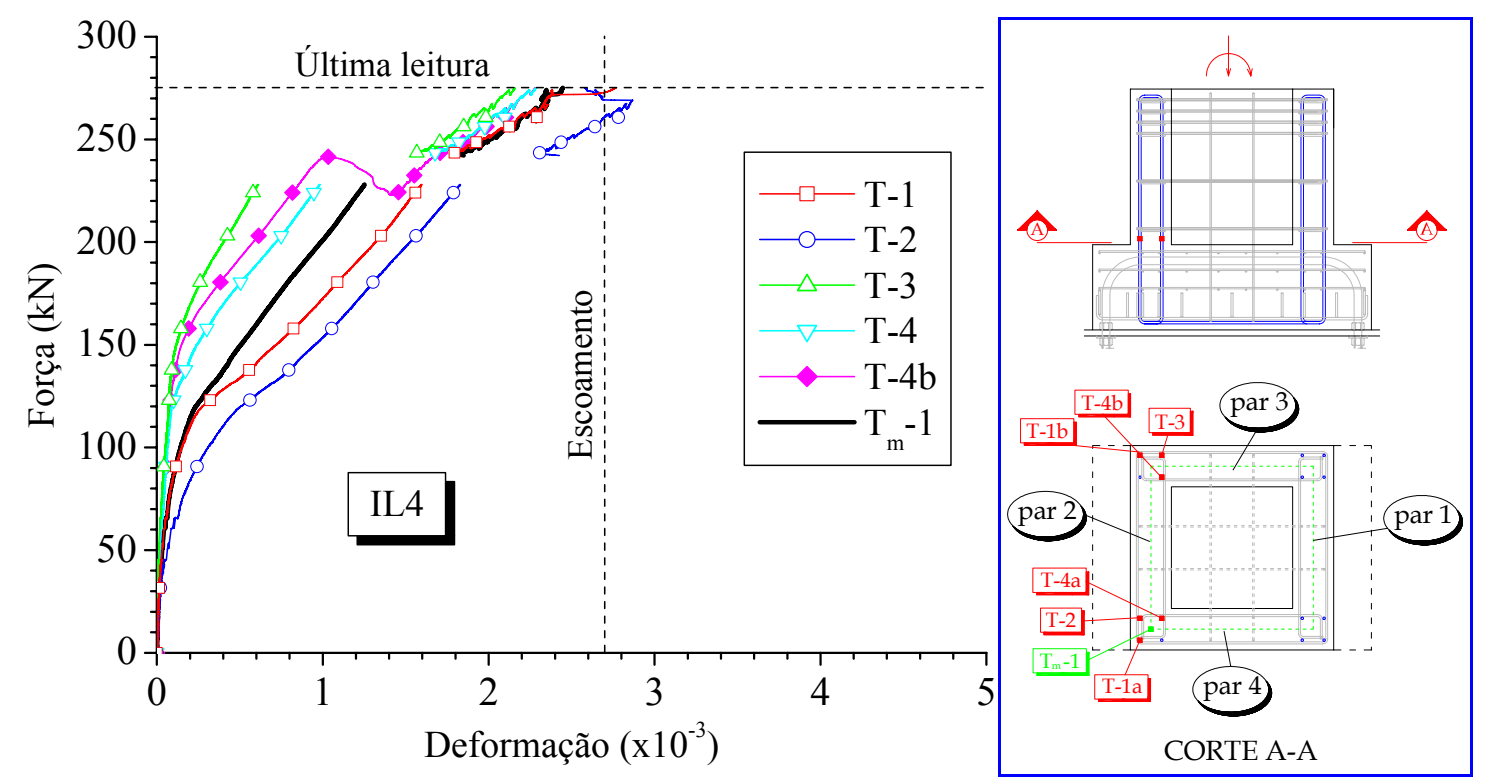

Figura 4.22 - Curva força aplicada versus deformação na armadura vertical principalModelo IL4

Nesta figura foi acrescentada a curva força aplicada versus deformação lida pelo extensômetro que não foi afetado (T-4b), por estar em outro canal, com a finalidade de observar o comportamento dessa armadura durante a falha das leituras. Observou-se que durante essa lacuna, o extensômetro $\mathrm{T}-4 \mathrm{~b}$ registrou uma diminuição do carregamento e posterior redução da rigidez, ou seja, o problema na leitura das deformações das demais armaduras verticais principais aconteceu coincidentemente durante o rompimento total da adesão e o conseqüente deslizamento do pilar em relação à junta de ligação, o qual foi comentado anteriormente. Portanto, assumiu-se que todas as armaduras sofreram o mesmo fenômeno e suas respectivas curvas força aplicada versus deformação serão apresentadas com esse salto no seu desenvolvimento. 
Visto isso, no Modelo IL4, apesar de apenas uma das armaduras verticais principais ter escoado (T-2), as outras ficaram próximas de atingirem o escoamento.

Em relação às armaduras verticais secundárias da parede transversal 2 (CT-1 e CT-2), conforme Figura 4.23, ambas escoaram e com CT-1 atingindo a plastificação.

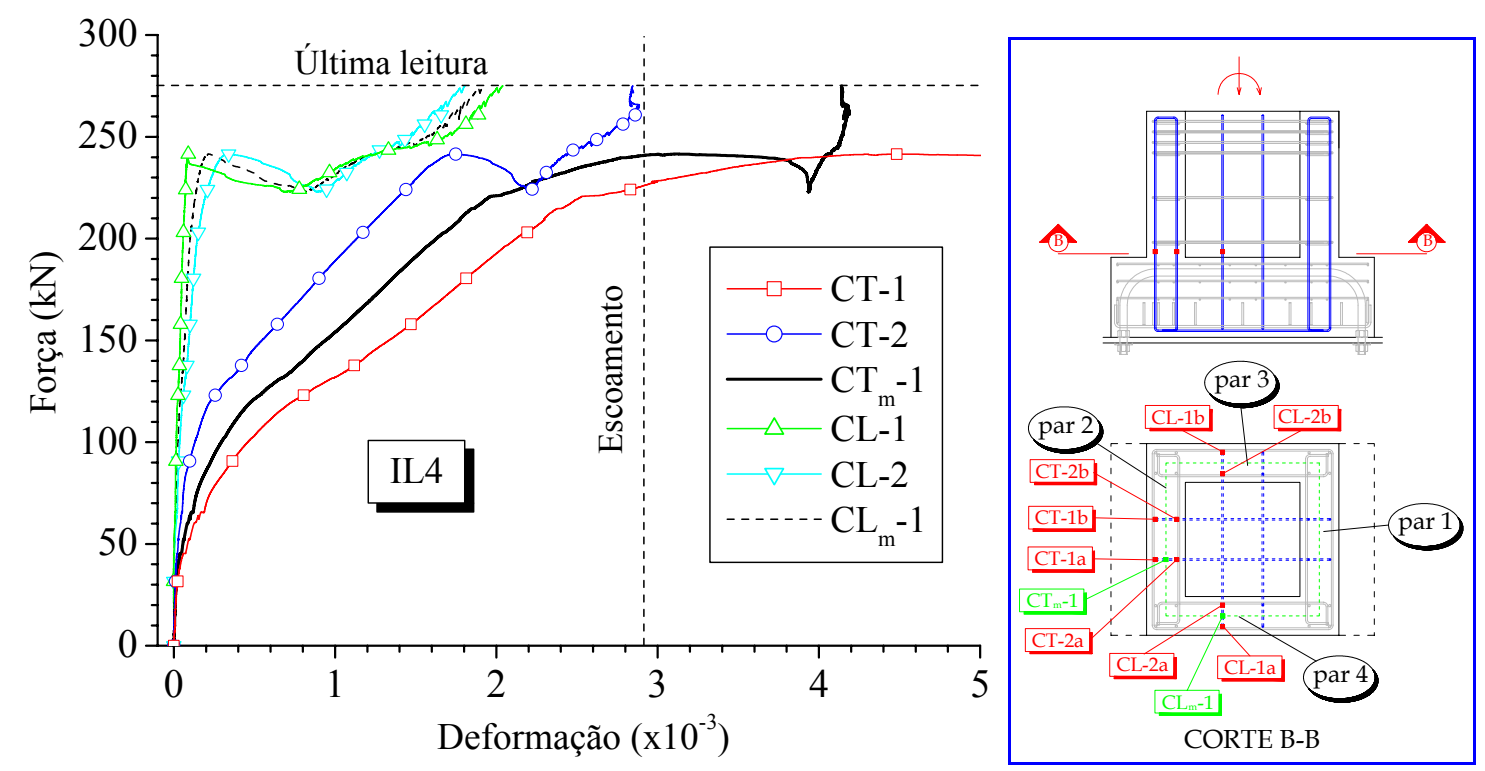

Figura 4.23 - Curva força aplicada versus deformação nas armaduras verticais secundárias Modelo IL4

Nota-se que toda curva que alcançou o carregamento que levou ao completo rompimento da adesão sofreu o fenômeno da perda de força (CT-2).

Já as armaduras posicionadas nas paredes longitudinais 3 e 4 (CL-1 e CL-2) (Figura 4.23), só foram realmente solicitadas após a ruptura completa e repentina da adesão entre a junta e os elementos, mas não chegaram a escoar, com uma deformação média $\left(\mathrm{CL}_{\mathrm{m}}-1\right)$ de aproximadamente $1,9 \%$, ou seja, essas armaduras foram pouco solicitadas em relação as outras armaduras verticais, mas também contribuindo para resistência do modelo.

Na Figura 4.24, estão ilustradas as curvas força aplicada versus deformação média nas armaduras verticais principais e secundárias do Modelo IL4. Conclui-se então que as armaduras verticais da parede transversal 2 contribuíram na resistência da peça e que a armadura vertical secundária disposta nas paredes longitudinais 3 e 4 não foi solicitada até o carregamento que gerou o descolamento da interface $(240 \mathrm{kN})$ onde, a partir daí, atingiu uma deformação na última leitura do ensaio de aproximadamente $1,9 \%$ o 


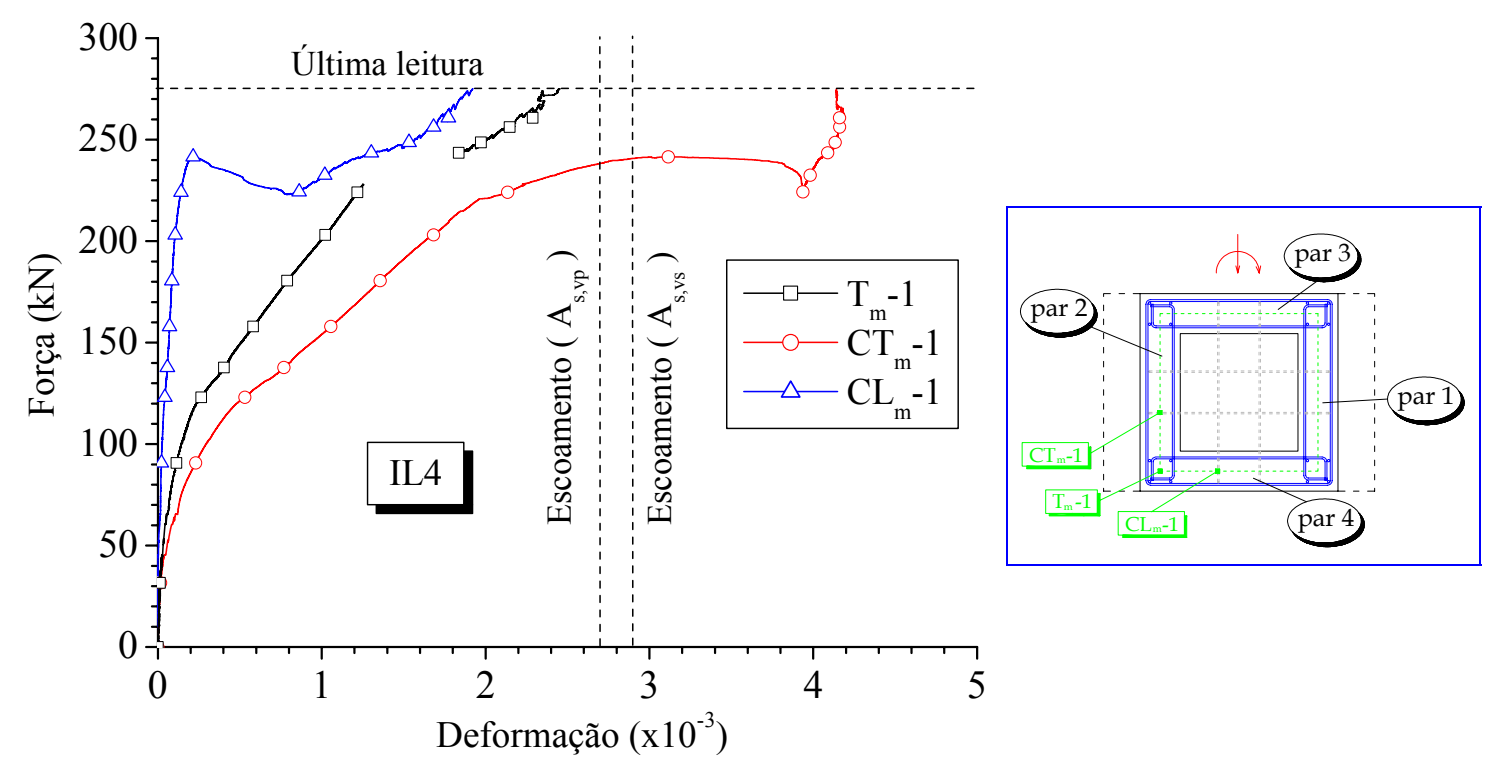

Figura 4.24 - Curva força aplicada versus deformação média nas armaduras verticais principais e secundárias - Modelo IL4

A mesma placa danificada durante o ensaio do Modelo IL4, onde estavam conectado os cincos extensômetros posicionados nas armaduras verticais principais (T1a, T-1b, T-2, T-3 e T-4a), não registrou as deformações sofridas por essas armaduras durante o ensaio do Modelo IR3, ou seja, não se tem o registro desses valores ao longo de todo o ensaio deste modelo. Com isso, será mostrado o valor medido pelo extensômetro $\mathrm{T}-4 \mathrm{~b}$, o único representante dessas armaduras que registrou as deformações, mas que no entanto é bastante representativo. Na Figura 4.25, ilustra-se o comportamento da armadura vertical principal lido pelo extensômetro T-4b ao longo do ensaio do Modelo IR3.

Essa armadura foi muito solicitada, atingindo a plastificação, comprovando que esse modelo teve um comportamento semelhante a uma ligação monolítica, com as armaduras verticais sendo bastante solicitadas.

No caso armaduras verticais secundárias (Figura 4.26), as mais tracionadas (CL1 e CL-2) em média atingiram o escoamento, enquanto que as outras (CL-3 e CL-4) foram menos solicitadas, mas também contribuíram para resistência dessa ligação.

Em resumo, na Figura 4.27, apresenta-se as curvas força aplicada versus deformação média de todas as armaduras verticais do Modelo IR3. Com exceção das armaduras menos tracionadas das paredes longitudinais 3 e 4 , todas as outras armaduras verticais atingiram o escoamento, contribuindo na resistência do modelo. 


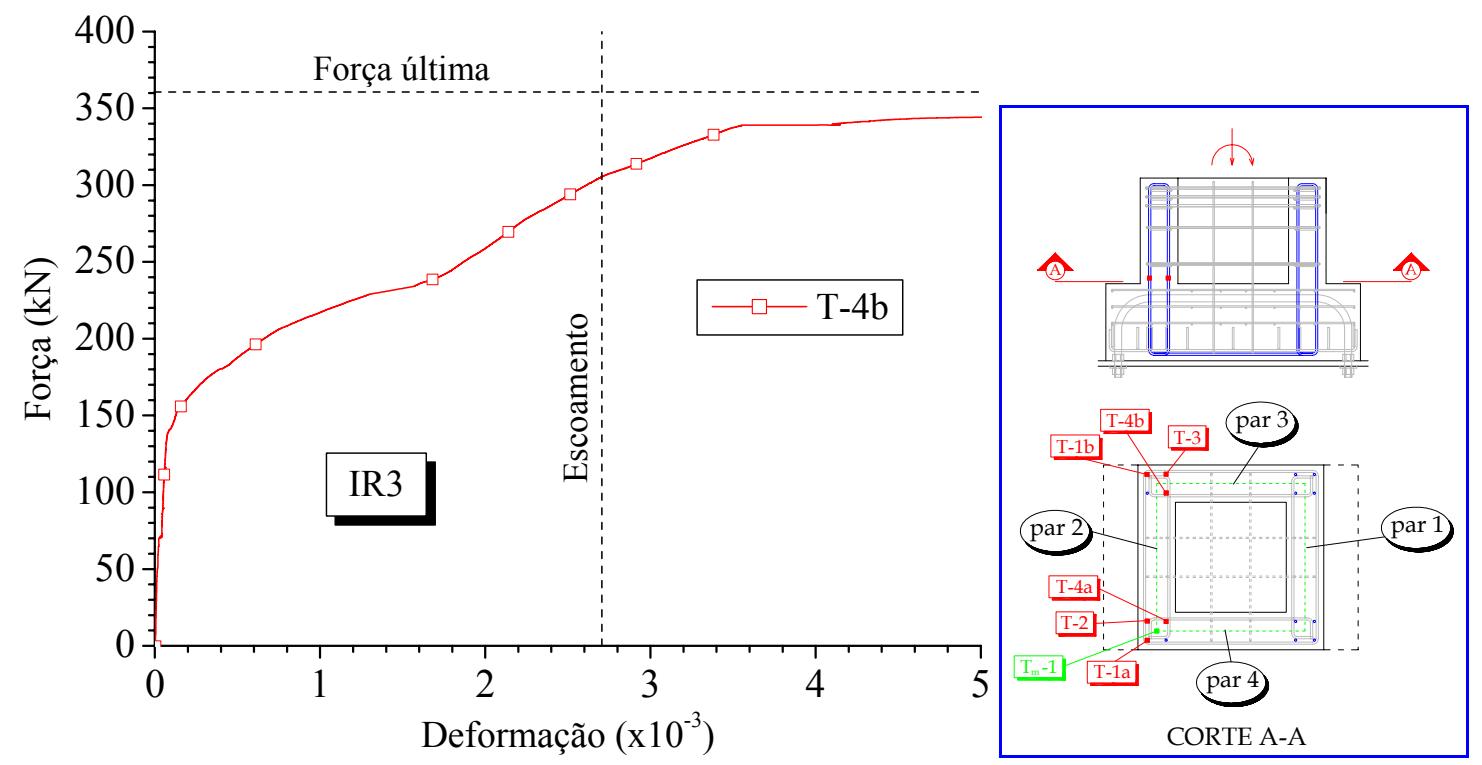

Figura 4.25 - Curva força aplicada versus deformação na armadura vertical principal Modelo IR3



Figura 4.26 - Curva força aplicada versus deformação nas armadura verticais secundárias Modelo IR3

Para efeito de comparação entre os dois modelos analisados e a fim de visualizar a plastificação da armadura do Modelo IR3, a Figura 4.28 ilustra o comportamento da armadura vertical principal registrado pelo extensômetro T-4b dos dois modelos, pois como foi mencionado, foi o único que funcionou no Modelo IR3.

Percebe-se, que até a força de aproximadamente $180 \mathrm{kN}$, a curva força aplicada versus deformação da armadura vertical principal dos dois modelos possuem a mesma inclinação, e após esse carregamento o Modelo IL4 segue com uma maior rigidez se 
igualando ao Modelo IR3 após o descolamento total do pilar por conseqüência da ruptura da adesão na interface.

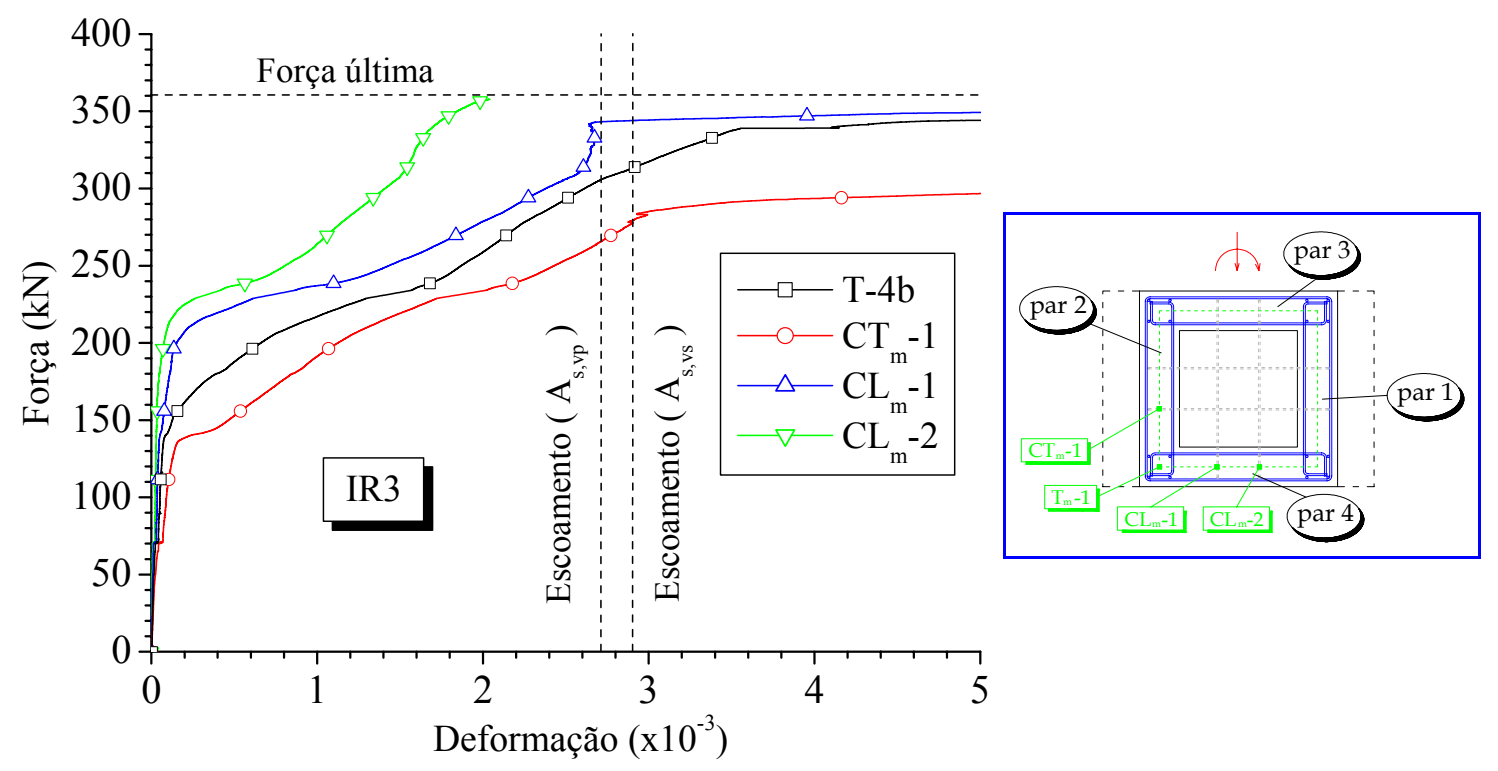

Figura 4.27 - Curva força aplicada versus deformação média nas armaduras verticais principais e secundárias - Modelo IL4



Figura 4.28 - Curva força aplicada versus deformação na armadura vertical principal Comparação entre os Modelos IL4 e IR3

Em relação às armaduras verticais secundárias, com exceção da armadura vertical secundária longitudinal mais tracionada do Modelo IL4 e a menos tracionada do Modelo IR3, todas escoaram e/ou plastificaram, conforme Figura 4.29. 


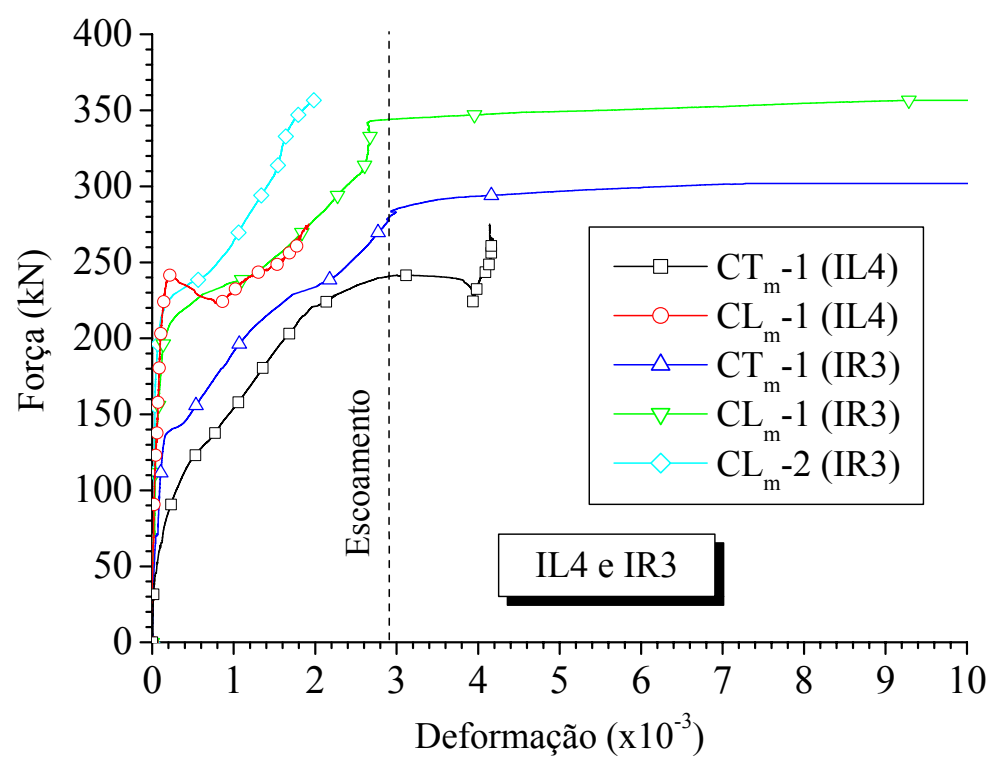

Figura 4.29 - Curva força aplicada versus deformação média nas armaduras verticais secundárias - Comparação entre os Modelos IL4 e IR3

Observa-se que apenas no Modelo IR3, com interface rugosa, essas armaduras atingiram a plastificação. Percebe-se que a armadura vertical secundária posicionada na parede transversal 2 do Modelo IL4 $\left(\mathrm{CT}_{\mathrm{m}}-1\right)$ foi mais solicitada do que a do Modelo IR3 para o mesmo carregamento, ou seja, essa armadura se deformou praticamente desde o inicio do carregamento.

Tendo isso, constata-se que no Modelo IL4 as forças atuantes nessa ligação foram transferidas do pilar para o colarinho, e no colarinho esse caminho foi determinado pela transmissão simultânea de grande parte dos esforços diretamente para a região inferior da ligação colarinho-base da fundação solicitando as armaduras verticais secundárias dispostas na parede transversal 2. Isto ocorre por conseqüência da adesão entre a junta e os elementos não ter sido rompida por completo durante um determinado carregamento e com isso a maior parte dos esforços devido ao atrito e a adesão foram transferidos para a parede transversal 2 e uma pequena parte para o topo da parede transversal 1 .

Quanto as armaduras verticais secundárias localizadas nas paredes longitudinais 3 e 4 , as mais solicitadas $\left(\mathrm{CL}_{\mathrm{m}}-1\right)$ dos dois modelos tiveram comportamentos bem parecidos até o carregamento que gerou a ruptura total da adesão no Modelo IL4, onde então a força aplicada teve uma redução e o modelo sofreu uma redistribuição dos esforços e a curva força aplicada versus deformação dessa armadura voltou a se comportar igual ao do Modelo IR3 até o final do ensaio. 
Já as armaduras verticais secundárias menos tracionadas das paredes longitudinais 3 e 4, foram apenas instrumentadas no Modelo IR3, mas, no entanto não chegaram a atingir o escoamento.

Tendo visto as análises dos itens anteriores, no Modelo IL4, a transferência dos esforços do pilar para o cálice se deu da mesma forma que no Modelo IR3, no que se refere às armaduras verticais, ou seja, as únicas diferenças entre esses modelos foi o comportamento das armaduras horizontais e a resistência última alcançada pela ligação, que no Modelo IR3 foi maior.

\subsubsection{FISSURAÇÃO}

Na Figura 4.30, está indicada a fissuração ocorrida na região mais solicitada das armaduras verticais nos dois modelos ensaiados.

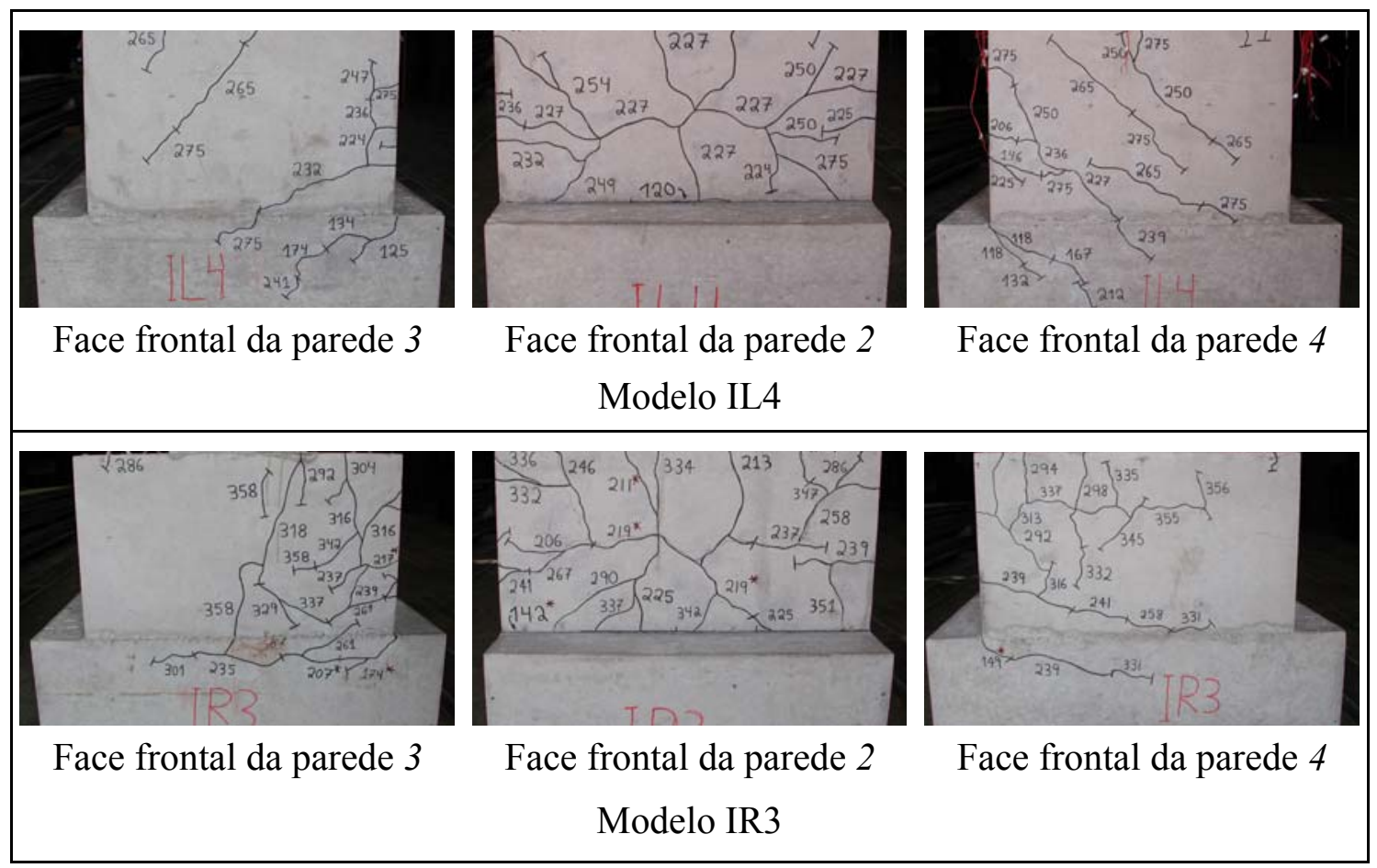

Figura 4.30 - Fissuração na região mais solicitada das armaduras verticais tracionadas dos Modelos IL4 e IR3

Em todos os modelos apareceram fissuras com tendências horizontais próximas a essas armaduras analisadas. Nota-se que na parede transversal 2 dos dois modelos, as fissuras ficaram mais concentradas nos cantos dessa parede, por conseqüência da maior rigidez e taxa de armadura $A_{s, v p}$ nessa região. No Modelo IR3, a fissuração foi mais intensa do que no Modelo IL4, pois como já foi mencionado, com exceção da armadura 
vertical menos tracionada das paredes 3 e 4 , todas plastificaram.

\subsection{DESLOCAMENTO HORIZONTAL E VERTICAL DAS EXTREMIDADES DAS PAREDES LONGITUDINAIS 3 E 4}

Na Figura 4.31, estão ilustrados os deslocamentos ao longo do carregamento dos quatros pontos de extremidades das paredes longitudinais 3 e 4 dos Modelos IL4 e IR3.

No Modelo IL4, os pontos pouco se deformaram para baixo (TD-5) comparando-se com o deslocamento para cima registrado pelo transdutor TD-4. Quanto ao deslocamento horizontal, o deslocamento TD-8 foi maior que o TD-6, oriundo dos esforços por flexo-tração da parede transversal 1 serem mais intensos do que os constatados na parede transversal 2.

Já no Modelo IR3, o deslocamento TD-5 para baixo foi maior que o deslocamento para cima TD-4, comprovando que o pilar, a junta e o cálice no lado comprimidos e tracionado, trabalharam em conjunto ao longo do carregamento, por conseqüência do travamento entre as chaves. No que se refere aos deslocamentos horizontais, as medidas TD-6 e TD-8 foram praticamente iguais até um determinado ponto onde então o ponto TD-6 se desloca para esquerda indicando a elevada solicitação de flexo-tração na parede transversal 2 . 

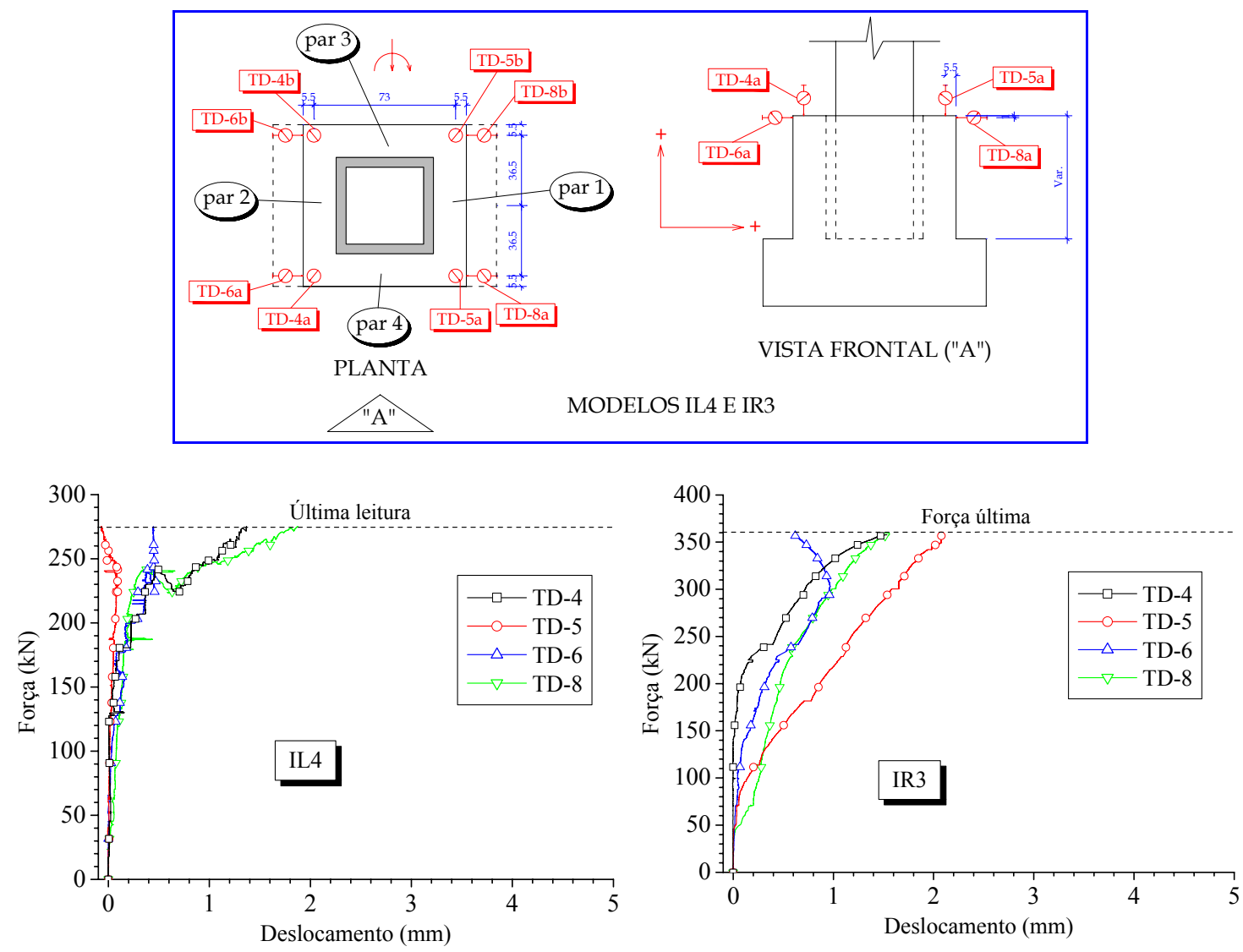

Figura 4.31 - Curva força aplicada versus deslocamento nas extremidades do cáliceModelos IL4 e IR3

\subsection{COMPORTAMENTO GERAL DOS MODELOS}

\subsubsection{COMPORTAMENTO CONJUNTO DAS ARMADURAS}

Na Figura 4.32 e Figura 4.33 é apresentada a resposta média das armaduras em conjunto dos Modelos IL4 e IR3, respectivamente, com o objetivo de analisar a transferência de esforços no colarinho de uma maneira geral.

No Modelo IL4 (Figura 4.32), a transferência de esforços para o cálice de fundação se deu primeiramente pela transmissão desses esforços para as armaduras verticais da parede transversal $2\left(2 A_{s, v p}\right.$ e $\left.A_{s, v s}\right)$, e após a ruptura completa da adesão, onde o pilar sofreu um deslizamento e com isso passou a transmitir a resultante de pressão $H_{s u p}$ por flexo-tração para a parede transversal 1 , foi acionada a armadura $A_{s, h f t}$ que por sua vez transferiu a parcela restante dos esforços em conjunto das forças de atrito paras as paredes longitudinais 3 e $4\left(A_{s, h p}\right)$. 


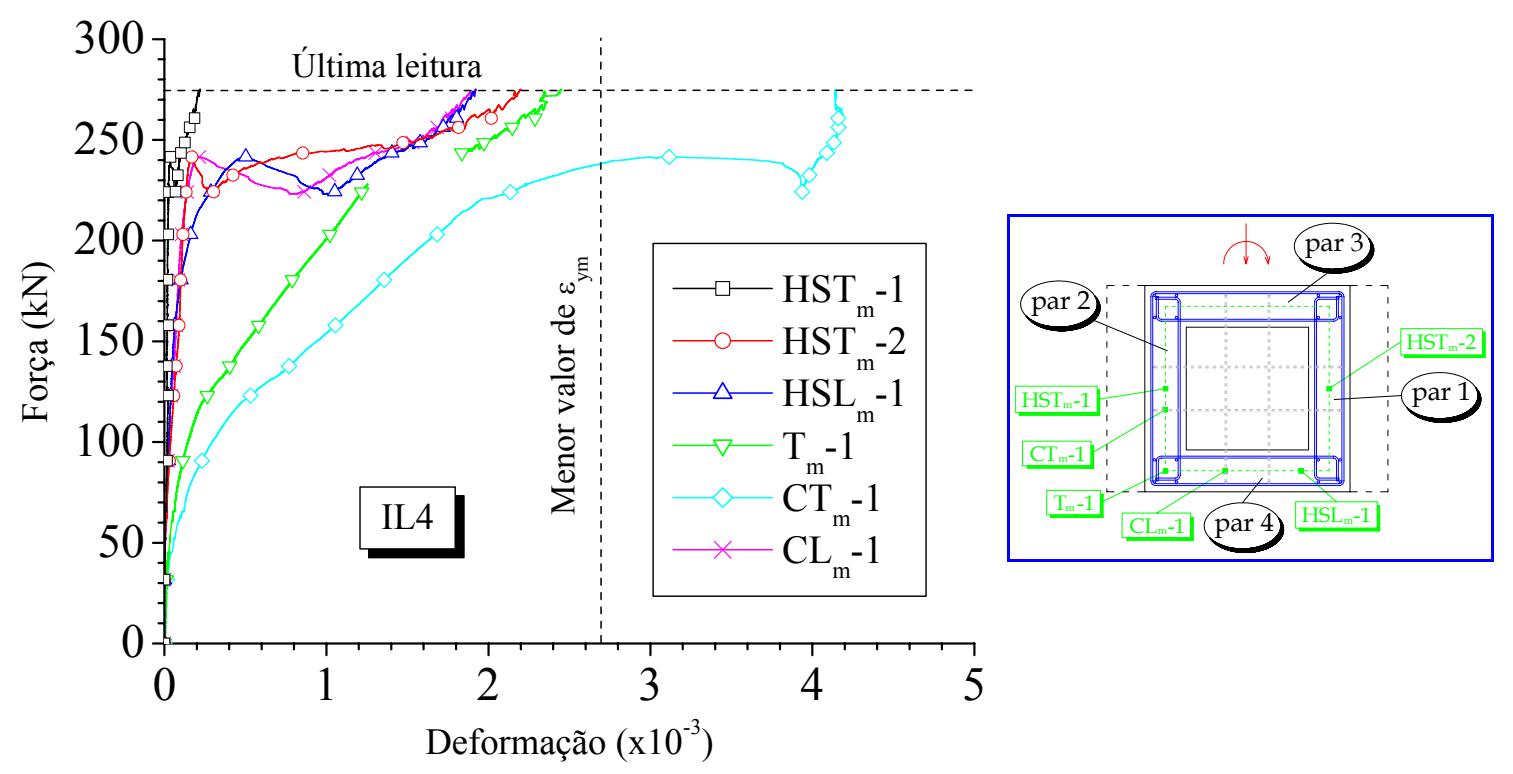

Figura 4.32 - Curva força aplicada versus deformação média nas armaduras verticais principais e secundárias - Modelo IL4

Nota-se que o mecanismo não segue o descrito em LEONHARDT \& MÖNNIG (1977), ou seja, as armaduras verticais e horizontais principais deveriam ser solicitadas simultaneamente e desde o início do carregamento, com os esforços oriundos da resultante de pressão $H_{\text {sup }}$ absorvidos pela armadura $A_{s, h f t}$, seguindo para a armadura $A_{s, h p}$ e desta para $A_{s, v p}$ com as paredes longitudinais 3 e 4 funcionando como consolos.

Mas, até o instante do deslizamento do pilar, o único mecanismo resistente da ligação foram as armadura verticais situadas na parede transversal 2 e a adesão entre a junta e os elementos, fazendo com que o modelo se comportasse até um determinado instante como uma ligação com chaves de cisalhamento, onde as armaduras verticais são solicitadas desde o início e as armaduras horizontais pouco se deformam.

Após o rompimento total da adesão, as armaduras horizontais são então solicitadas e depois de uma elevada deformação se equilibram com as armaduras verticais criando assim um outro mecanismo resistente. Pode-se observar que, após ter criado esse mecanismo, essas armaduras mantiveram uma determinada tendência em continuar absorvendo força, ou seja, indicando que se o ensaio não fosse interrompido, o modelo resistiria mais um certo tempo, mas no entanto, o atuador já não conseguia aplicar mais uma força considerável, indicando que esse modelo estava próximo da sua capacidade resistente.

Já no Modelo IR3 (Figura 4.33), as armaduras verticais da parede transversal 2 e 
as mais tracionadas das paredes longitudinais 3 e 4 foram efetivamente solicitadas, ou seja, esse modelo teve um comportamento próximo ao de uma ligação monolítica, com as armaduras horizontais pouco solicitadas em relação as verticais, as quais plastificaram.

Será mostrado no Capítulo 5 que, apesar desse comportamento rígido, esse modelo não poderá ser dimensionado considerando a transferência total dos esforços atuantes no pilar para o cálice, pois sua capacidade resistente foi menor que a calculada pelo modelo da teoria de flexão, ou seja, considerando a ligação como monolítica.

Com a instrumentação da armadura horizontal principal da parede transversal 2, foi possível perceber que os esforços por flexo-tração ocorridos nessa parede foram elevados por causa do travamento das chaves, esforços esses mais intensos do que os sofridos pela parede transversal 1 .

No que se refere as armaduras horizontais principais situadas no topo das paredes longitudinais 3 e 4 , elas foram pouco solicitadas, o que já era de se esperar.

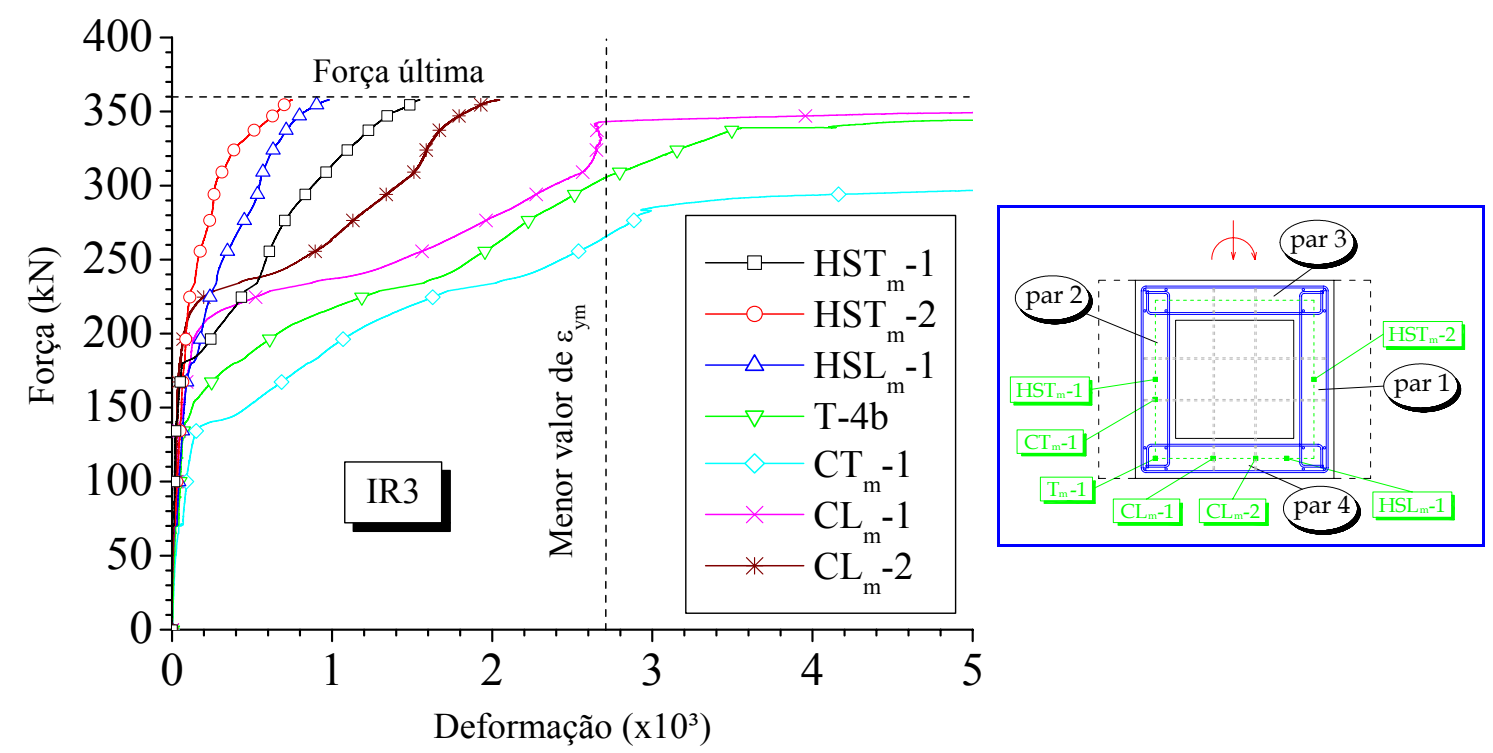

Figura 4.33 - Curva força aplicada versus deformação média nas armaduras verticais principais e secundárias - Modelo IR3

\subsubsection{ANÁLISE DA FISSURAÇÃO}

Na Figura 4.34 e Figura 4.35, estão ilustradas as fissuras dos dois modelos físicos, com o objetivo de analisar de uma maneira global o comportamento no que diz 
respeito à fissuração desses protótipos

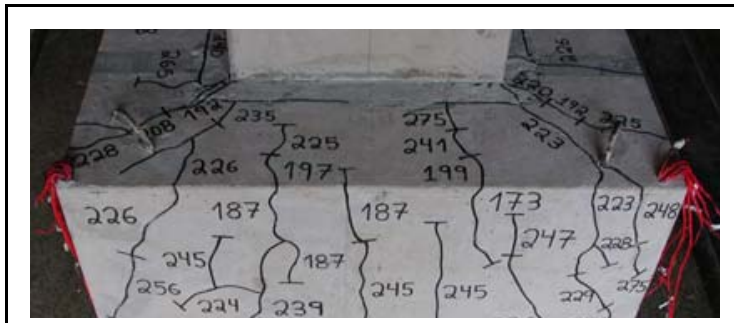

Vista de topo da parede 1
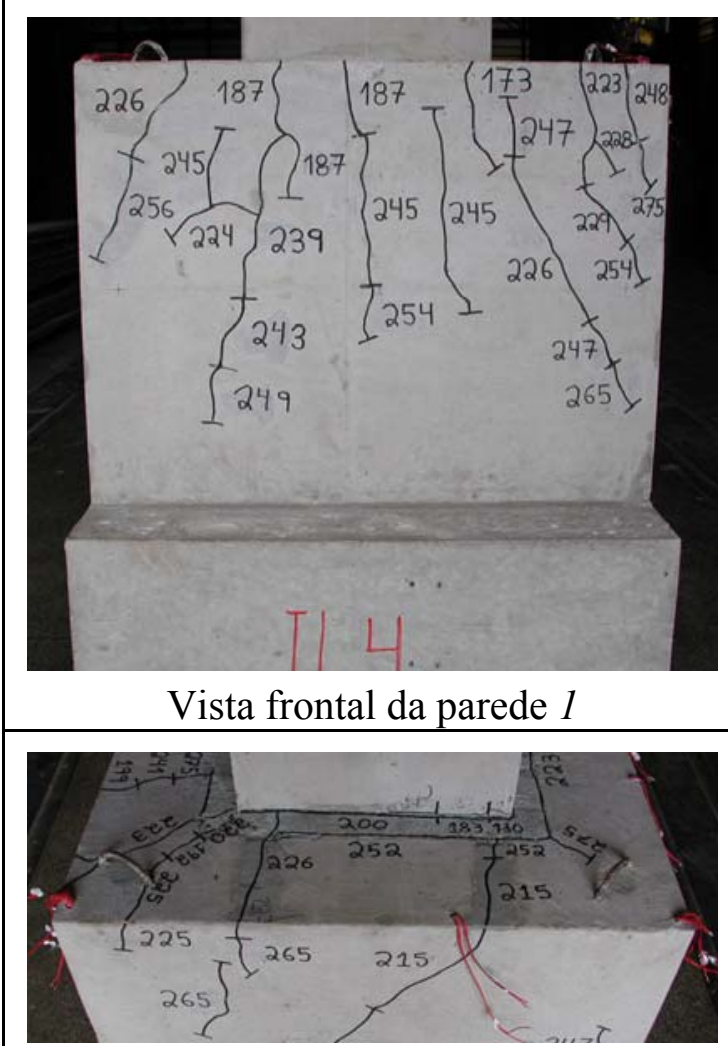

Vista de topo da parede 3

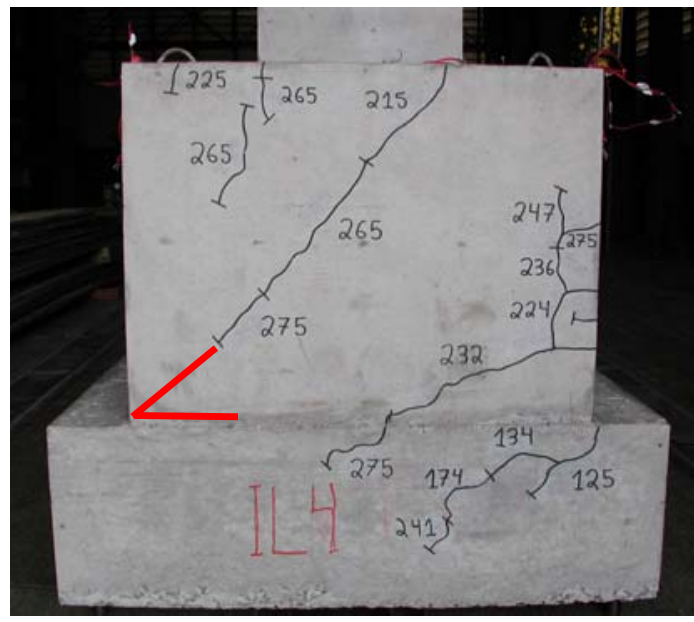

Vista frontal da parede 3

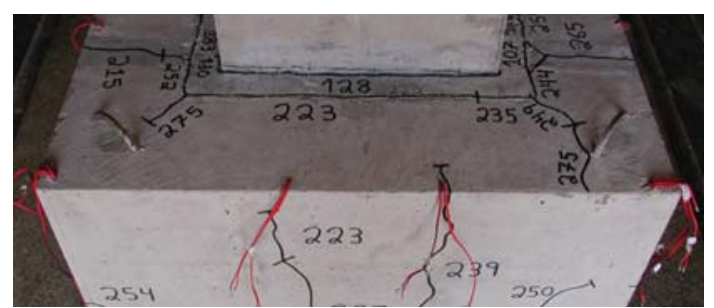

Vista de topo da parede 2

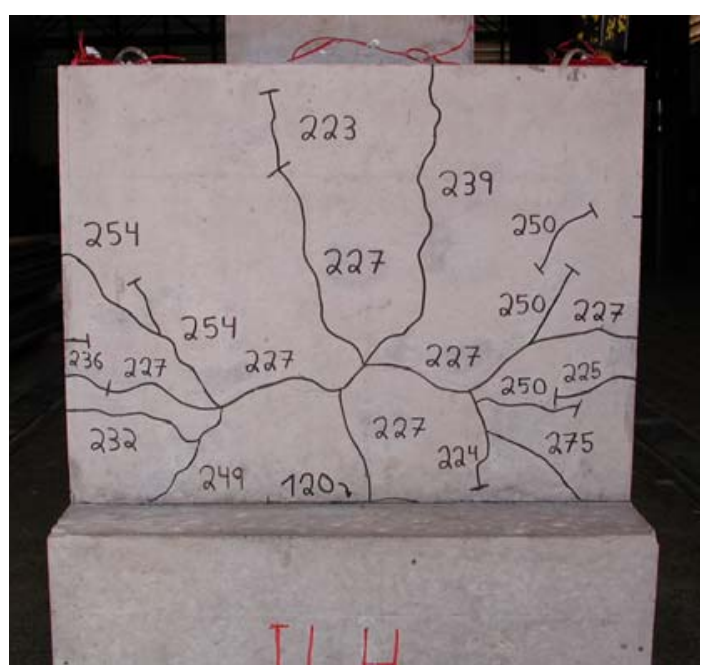

Vista frontal da parede 2

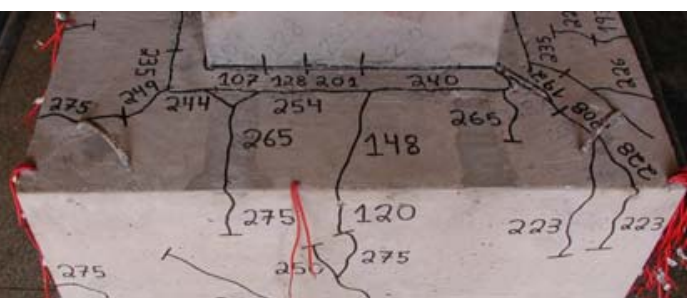

Vista de topo da parede 4

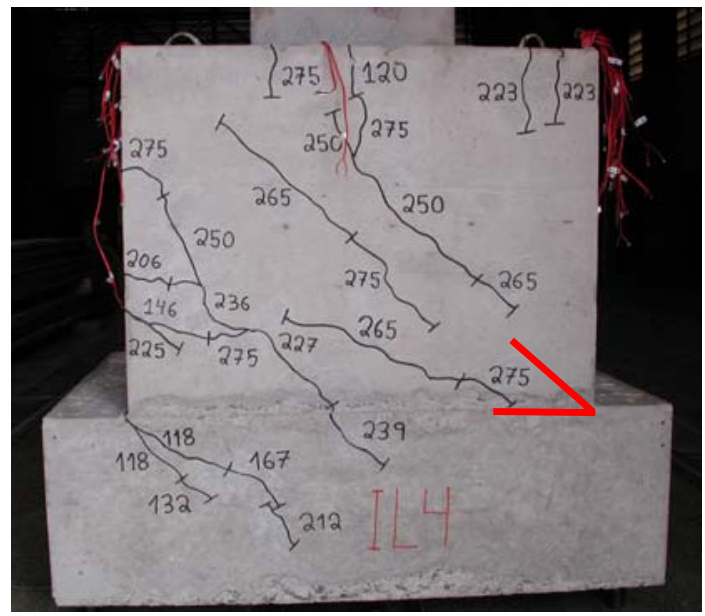

Vista frontal da parede 4

Figura 4.34 - Fissuração do Modelo IL4 


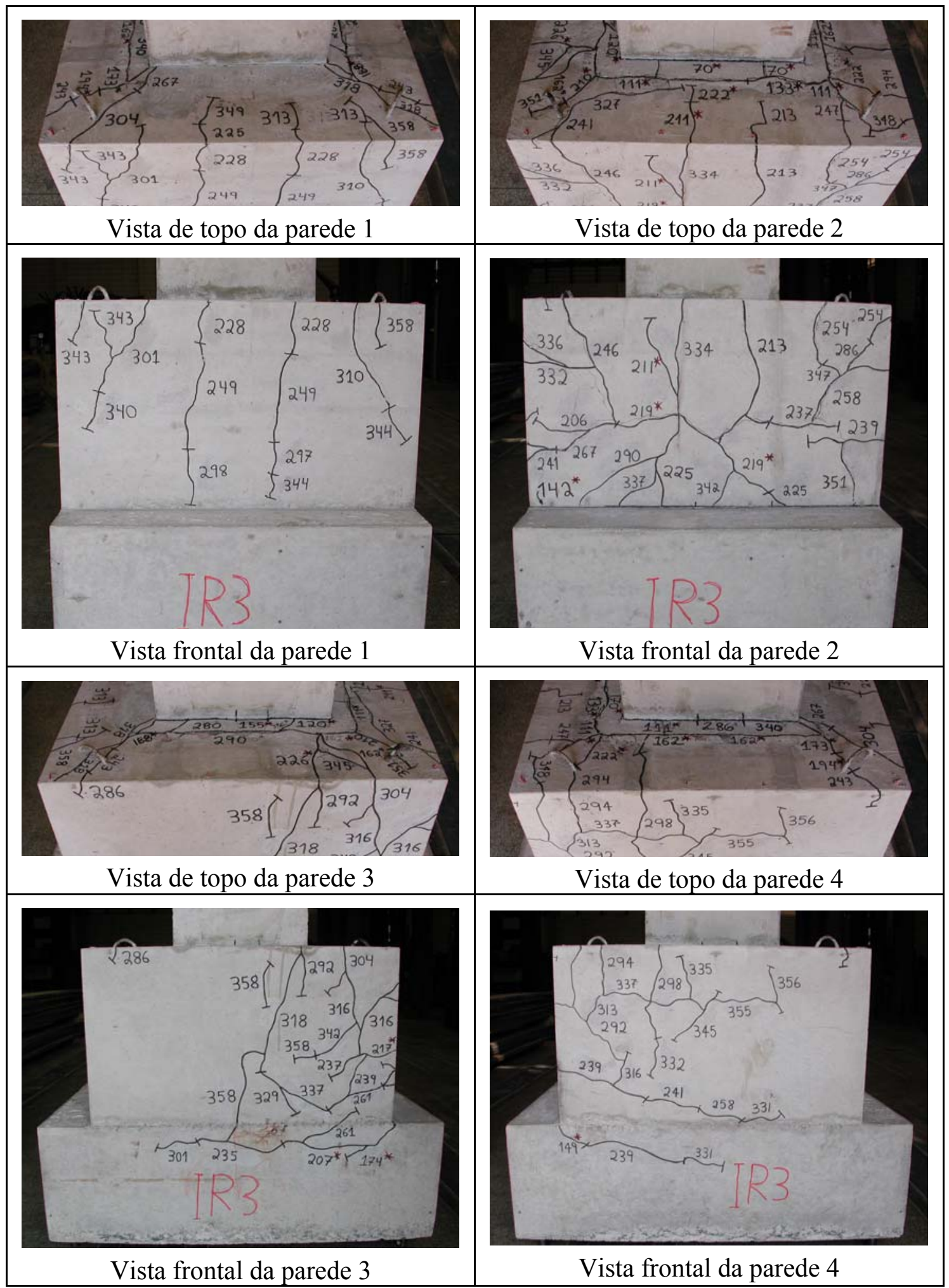

Figura 4.35 - Fissuração do Modelo IR3

No Modelo IL4 (Figura 4.34), as primeiras fissuras surgiram no lado tracionado da ligação no encontro da parede transversal 2 com a base da fundação, se estendendo para a base no lado das paredes longitudinais 3 e 4, resultantes das elevadas solicitações de tração nessa região. 
No decorrer do ensaio, foram surgindo algumas fissuras na interface da junta com os elementos na região do topo das paredes transversais 3 e 4 , indicando o descolamento da ligação, ou seja, o rompimento da adesão entre os concretos. Ao mesmo tempo, a parede transversal 1 começou a ser solicitada por flexo-tração surgindo então algumas fissuras no topo dessa parede, mas ainda em pequena quantidade.

No instante em que ocorreu o rompimento total e repentino da adesão da interface, consequentemente o deslizamento do pilar, há uma redistribuição de esforços onde a parede transversal 1 passa a receber com maior intensidade a resultante de pressão $H_{\text {sup }}$, transmitindo por flexo-tração para o topo das paredes longitudinais 3 e 4 e essas funcionando como consolos engastados na fundação.

Com isso, na parede transversal 1 , surgiram fissuras decorrentes da transferência por flexo-tração da força $H_{\text {sup }}$ para as paredes longitudinais, onde parte de $H_{\text {sup }}$ é direcionada para os cantos da parede transversal 1 com diferentes inclinações e outra parcela ocasiona a flexão dessa parede, mesmo fenômeno observado nos modelos lisos ensaiados por CANHA (2004). Segundo a autora, por consequência dessas fissuras nos cantos, a região superior da parede transversal 1 funciona como uma viga bi apoiada.

Como foi visto no comportamento da armadura $A_{s, h p}$, na zona superior das paredes longitudinais 3 e 4, observaram-se algumas fissuras causadas por esforços de flexo-tração, ou seja, pela força $H_{\text {sup }}$ atuando com carregamento indireto no consolo das paredes longitudinais 3 e 4 e pelo momento oriundo da transmissão da pressão superior com resultante $H_{\text {sup }}$ no topo da parede transversal 1 para essas paredes longitudinais.

Na região frontal da parede transversal 2, além da primeira fissura visualizada no encontro do colarinho com a base de fundação, outra fissura principal com tendência horizontal surgiu logo acima desta. Essa fissura é resultante da transferência dos esforços por flexo-compressão na ligação e da força nas armaduras verticais principais e secundárias localizadas nessa parede. Como já foi mencionado, é possível perceber a maior concentração das fissuras nos cantos dessa parede, por causa da maior rigidez e taxa de armadura $A_{s, v p}$ nessa região. Também na região frontal da parede transversal 2 , observaram-se duas fissuras com tendência vertical oriunda da flexão dessa parede.

Após o rompimento completo da adesão na interface e consequentemente a transferência de esforços para a fundação por meio de consolo pelas paredes longitudinais, surgiram fissuras com diferentes ângulos de inclinação em relação à 
horizontal, que indicam a formação da biela de compressão do consolo na região frontal das paredes longitudinais 3 e 4 .

No Modelo IR3 (Figura 4.35), vale lembrar que o ensaio foi interrompido e no dia seguinte re-ensaiado por motivos já comentado. Já no $1^{\circ}$ ensaio, o qual atingiu um carregamento de $228 \mathrm{kN}$ (63\% da força última), surgiram fissuras, que com o objetivo de diferenciá-las das visualizadas no $2^{\circ}$ ensaio, colocou-se asteriscos $\left(^{*}\right)$ na cor vermelha em cima da força anotada nesse modelo.

As primeiras fissuras surgiram na região tracionada das interfaces da junta com o cálice e pilar (topo da parede 2). Como o pilar, a junta e o cálice nos lados comprimidos e longitudinais trabalharam em conjunto ao longo do carregamento, por causa do travamento das chaves, essa fissura na interface da junta e dos elementos apareceu no topo da parede transversal 2 e, consequentemente, a região superior dessa parede foi solicitada por esforços de flexo-tração em alguns trechos e principalmente a flexão, onde se pôde observar a intensa fissuração, comprovada também pela deformação nas armaduras horizontais principais localizadas nessa região.

Também por consequência do travamento das chaves de cisalhamento na interface da ligação, a parede transversal 1 foi pouco solicitada, apresentando poucas fissuras por conseqüência dos esforços por flexo-tração oriundas da transferência dos esforços do pilar para a parede transversal 1, e desta para as paredes longitudinais 3 e 4 , em relação ao Modelo IL4.

Como esse modelo teve um comportamento similar à de uma ligação monolítica, durante o ensaio as fissuras predominantes surgiram na face frontal da parede transversal 2, se estendendo para as faces frontais das paredes 3 e 4 com uma tendência horizontal, ou seja, perpendicular à solicitação de tração. Pelo mesmo motivo ocorrido no Modelo IL4, a concentração de fissuras foi mais elevada nos cantos da parede transversal 2 que na região central, devido a maior taxa de armadura $A_{s, v p}$.

As fissuras ocorrida por conseqüência da flexo-tração na região superior das paredes longitudinais 3 e 4 , se deu pela atuação da resultante de pressão $H_{\text {sup }}$, a força de atrito $F_{\text {at,long }}$ atuando nas paredes 3 e 4 e os momentos ocasionados pela transferência de $H_{\text {sup }}$ da parede transversal 1 para essas paredes longitudinais, e, principalmente pela força de atrito $F_{a t, l o n g}$ excêntrica.

$\mathrm{Na}$ região frontal das paredes longitudinais 3 e 4 , ficou evidenciado o 
surgimento de bielas de compressão menos inclinadas, ou seja, como já tinha sido afirmado em LEONHARDT \& MÖNNIG (1977). As fissuras nessas paredes tiveram uma tendência horizontal resultante das forças de tração nas armaduras verticais principais e das verticais secundárias mais solicitadas, conforme foi constatado.

A ruína desse modelo foi determinada pelo escoamento ou plastificação das armaduras verticais por causa da transferência dos esforços por flexo-compressão na ligação. 


\section{ANÁLISE COMPARATIVA ENTRE OS MODELOS DAS SÉRIES IL E IR}

\subsection{CONSIDERAÇÕES INICIAIS}

Como o principal objetivo deste trabalho é analisar o comportamento da ligação pilar-fundação por meio de cálices com profundidades de embutimento inferiores aos recomendados pela norma brasileira, neste item será mostrado uma análise comparativa entre os protótipos ensaiados nesta pesquisa (IL4 e IR3), cuja profundidade de embutimento é inferior ao recomendado pela NBR 9062: (1985), e os protótipos estudados na pesquisa de doutorado realizada por CANHA (2004) (IL1, IL2, IL3, IR1 e IR2), cuja profundidade segue a recomendada por norma.

\subsection{PROPRIEDADES FÍSICAS E GEOMÉTRICAS DOS MODELOS E A RESISTENNCIA EXPERIMENTAL ALCANÇADA PELAS LIGAÇÕES}

Como já foi mostrado no Capítulo 3, a Figura 3.2 e a Tabela 3.1 representadas novamente adiante como Figura 5.1 e Tabela 5.1, apresentam respectivamente, a nomenclatura e o resumo das dimensões de todos os modelos físicos ensaiados nesta pesquisa e os analisados por CANHA (2004).

Vale lembrar, que o Modelo IL1 foi feito com a concretagem normal da junta, de forma a verificar se ocorria a transferência total do momento e força normal do pilar para o cálice. Já nos outros modelos da Série IL (interface lisa) e IR (interface rugosa), aplicou-se desmoldante objetivando retirar a adesão entre a junta e os elementos.

Repetindo o que foi mencionado no Capítulo 3, as excentricidades de força normal dos primeiros modelos ensaiados por CANHA (2004) (IL1 e IL2), com o objetivo de garantir a ruptura do cálice de fundação e por causa da limitação da capacidade de carga do atuador, foi igual a $1,85 \mathrm{~m}$. 


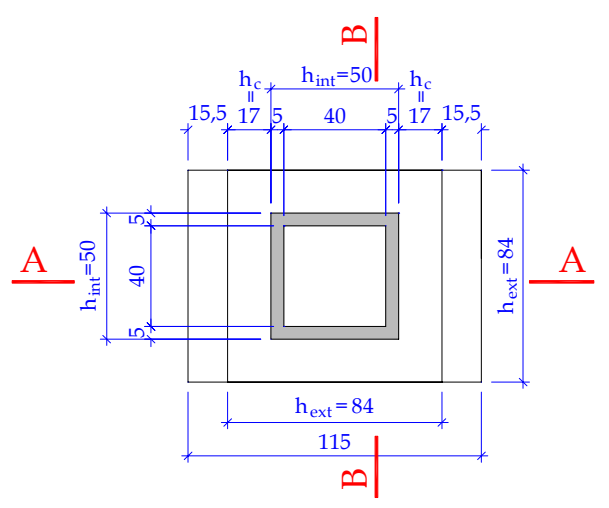

PLANTA

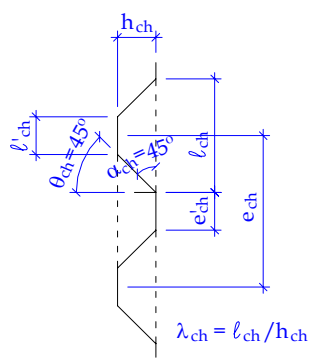

Detalhe das chaves de cisalhamento

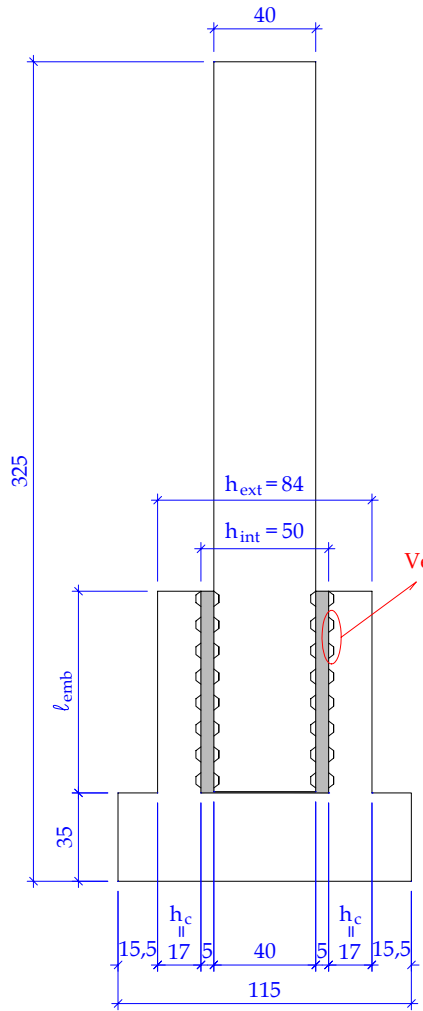

CORTE A-A

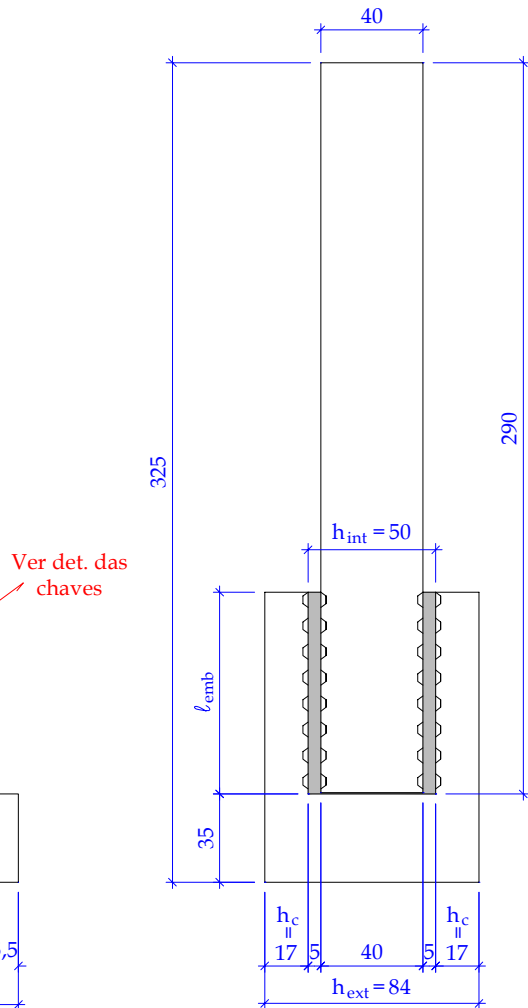

CORTE B-B

Obs.: dimensões em cm

Figura 5.1 - Nomenclatura das dimensões adotada para os modelos físicos ensaiados

Tabela 5.1 - Resumo das propriedades geométricas dos modelos físicos ensaiados

\begin{tabular}{|c|c|c|c|c|c|c|c|c|c|}
\hline Série & Modelo & Interface & $\begin{array}{c}e \\
(\mathrm{~cm})\end{array}$ & $\begin{array}{l}\ell_{e m b} \\
(\mathrm{~cm})\end{array}$ & $\begin{array}{c}h_{c} \\
(\mathrm{~cm})\end{array}$ & $\alpha_{c h}$ & $\begin{array}{c}h_{c h} \\
(\mathrm{~cm})\end{array}$ & $\begin{array}{c}\ell_{c h} \\
(\mathrm{~cm})\end{array}$ & $\begin{array}{c}e_{c h}^{\prime} \\
(\mathrm{cm})\end{array}$ \\
\hline \multirow{4}{*}{ IL } & IL1 & Lisa & 185 & $80(2,0 h)$ & \multirow{4}{*}{17} & \multirow{4}{*}{ - } & \multirow[t]{4}{*}{$(-\infty}$, & \multirow[t]{4}{*}{10.} & \multirow[t]{4}{*}{10.} \\
\hline & IL2 & Lisa & 185 & $80(2,0 h)$ & & & & & \\
\hline & IL3 & Lisa & 120 & $80(2,0 h)$ & & & & & \\
\hline & IL4 & Lisa & 120 & $64(1,6 h)$ & & & & & \\
\hline \multirow{3}{*}{ IR } & IR1 & Rugosa & 120 & $64(1,6 h)$ & \multirow{3}{*}{17} & $45^{\circ}$ & 1 & 6 & 4 \\
\hline & IR2 & Rugosa & 120 & $64(1,6 h)$ & & $45^{\circ}$ & 1 & 3 & 1 \\
\hline & IR3 & Rugosa & 120 & $48(1,2 h)$ & & $45^{\circ}$ & 1 & 6 & 4 \\
\hline
\end{tabular}


Conhecida a capacidade experimental do Modelo IL2, reduziu-se para 1,2 $\mathrm{m}$ para o restante dos modelos, no qual é um valor mais próximo da realidade das estruturas em concreto pré-moldado e por isso também adotada para os Modelos IL4 e IR3 indicados na cor vermelha.

Com já foi descrito em relação aos comprimentos de embutimento adotados, os valores utilizados nos modelos ensaiados por CANHA (2004) seguiram os recomendados pela NBR 9062: (1985), ou seja, 2,0h para Série IL e 1,6h para Série IR. Nos modelos analisados neste trabalho, adotaram-se os valores iguais a 1,6h para IL4 e $1,2 h$ para IR3, com o intuito de verificar se a formulação proposta para o dimensionamento do cálice de fundação poderia ser utilizada em cálices com esses comprimentos de embutimento.

$\mathrm{Na}$ Figura 5.2 estão apresentados a nomenclatura e posicionamento das principais armaduras do cálice e na Tabela 5.2 seus respectivos valores.

Percebe-se que apenas a quantidade da armadura horizontal principal $A_{s, h p}$ é modificada com a alteração da profundidade de embutimento $\left(\ell_{e m b}\right)$, pois, como já foi mencionado, para fins de comparação entre os modelos, utilizou-se o processo inverso de dimensionamento, com a armadura vertical principal $A_{s, v p}$ adotada igual para todos os protótipos e a partir desse valor, calculou-se as armaduras secundárias e com o processo inverso, a armadura horizontal principal $A_{s, h p}$.

Quanto as propriedades mecânicas dos concretos utilizados para construção dos protótipos, na Tabela 5.3 estão apresentados os valores médios de três corpos-de-prova da resistência à compressão $f_{c m}$ e do módulo de elasticidade tangente $E_{c m}$ para os três “concretos”, que são eles: cálice, pilar e junta.

Já na Tabela 5.4, são indicados os valores médios da resistência de escoamento $f_{y m}$, da deformação de início de escoamento $\varepsilon_{y m}$ e da resistência à tração $f_{s t m}$ para as principais armaduras do cálice de todos os modelos.

Quanto a resistência experimental alcançada pelos modelos, a Tabela 5.5 indica a força normal e o momento ultimo alcançado pelos protótipos da Série IL e IR. Nota-se que os modelos físicos com menores comprimentos de embutimento (IL4 e IR3) resistiram menos aos esforços do que aqueles com profundidade de embutimento 
indicado pela NBR 9062: (1985), ou seja, os ensaiados na pesquisa de doutorado realizada por CANHA (2004) (IL1, IL2, IL3, IR1 e IR2).

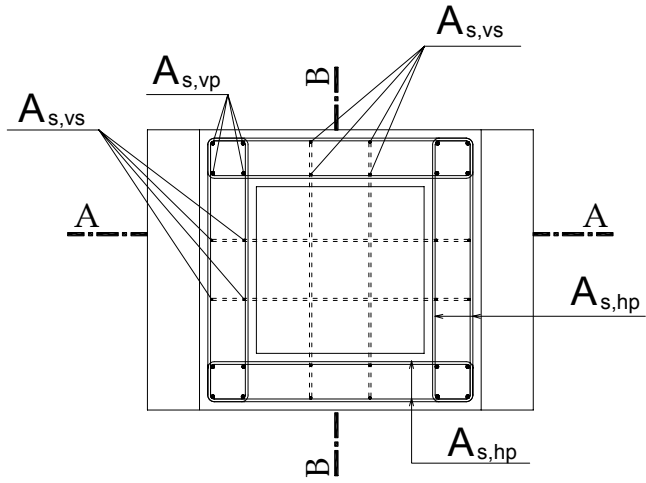

PLANTA

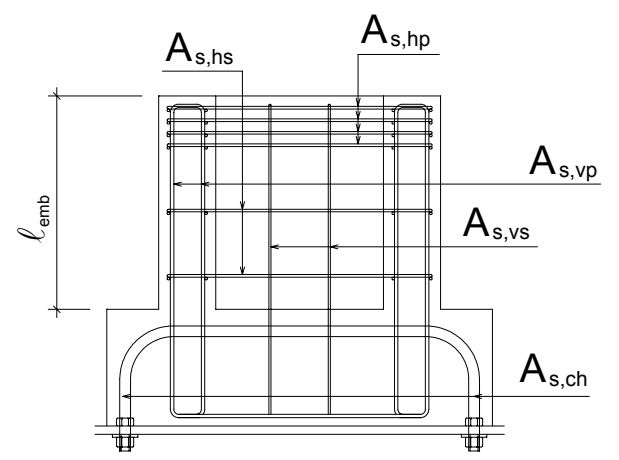

CORTE A-A
$A_{s, h p}$ - armadura horizontal principal

$A_{s, v p}$ - armadura vertical principal

$A_{s, h s}$ - armadura horizontal secundária

$A_{s, v s}$ - armadura vertical secundária

$A_{s, c h}$ - chumbador

Figura 5.2 - Nomenclatura e posicionamento das armaduras do cálice

Tabela 5.2 -Valores das principais armaduras do cálice

\begin{tabular}{|c|c|c|c|c|c|c|c|}
\hline Série & Modelo & $\begin{array}{l}\ell_{e m b} \\
(\mathrm{~cm})\end{array}$ & $\begin{array}{l}\mathrm{A}_{\mathrm{s}, \mathrm{hp}}{ }^{*} \\
\left(\mathrm{~cm}^{2}\right)\end{array}$ & $\begin{array}{l}\mathrm{A}_{\mathrm{s}, \mathrm{vp}} \\
\left(\mathrm{cm}^{2}\right)\end{array}$ & $\begin{array}{l}\mathrm{A}_{\mathrm{s}, \mathrm{hs}}{ }^{*} \\
\left(\mathrm{~cm}^{2}\right)\end{array}$ & $\begin{array}{l}\mathrm{A}_{\mathrm{s}, \mathrm{vs}} \\
\left(\mathrm{cm}^{2}\right)\end{array}$ & $\begin{array}{l}A_{\mathrm{s}, \mathrm{ch}} \\
\left(\mathrm{cm}^{2}\right)\end{array}$ \\
\hline \multirow{4}{*}{ IL } & IL1 & $80(2,0 h)$ & \multirow{3}{*}{$\begin{array}{c}3,02 \\
(3 Ф 8)\end{array}$} & \multirow{4}{*}{$\begin{array}{c}3,14 \\
(4 \Phi 10)\end{array}$} & \multirow{4}{*}{$\begin{array}{c}2,01 \\
(2 \Phi 8)\end{array}$} & \multirow{4}{*}{$\begin{array}{c}1,25 \\
(4 \Phi 6,3)\end{array}$} & \multirow{4}{*}{8,04} \\
\hline & IL2 & $80(2,0 h)$ & & & & & \\
\hline & IL3 & $80(2,0 h)$ & & & & & \\
\hline & IL4 & $64(1,6 h)$ & $\begin{array}{c}4,02 \\
(4 Ф 8)\end{array}$ & & & & \\
\hline \multirow{3}{*}{ IR } & IR1 & $64(1,6 h)$ & \multirow{2}{*}{$\begin{array}{c}4,02 \\
(4 Ф 8)\end{array}$} & \multirow{3}{*}{$\begin{array}{c}3,14 \\
(4 \Phi 10)\end{array}$} & \multirow{3}{*}{$\begin{array}{c}2,01 \\
(2 \Phi 8)\end{array}$} & \multirow{3}{*}{$\begin{array}{c}1,25 \\
(4 \Phi 6,3)\end{array}$} & \multirow{3}{*}{8,04} \\
\hline & IR2 & $64(1,6 h)$ & & & & & \\
\hline & IR3 & $48(1,2 h)$ & $\begin{array}{c}4,71 \\
(3 \Phi 10)\end{array}$ & & & & \\
\hline
\end{tabular}


Tabela 5.3 - Propriedades mecânicas do concreto dos elementos e da junta

\begin{tabular}{|c|c|c|c|c|c|c|}
\cline { 2 - 7 } \multicolumn{1}{c|}{} & \multicolumn{2}{c|}{ Cálice } & \multicolumn{2}{c|}{ Pilar } & \multicolumn{2}{c|}{ Junta } \\
\hline Modelo & $\begin{array}{c}f_{c m} \\
(\mathrm{MPa})\end{array}$ & $\begin{array}{c}E_{c m} \\
(\mathrm{GPa})\end{array}$ & $\begin{array}{c}f_{c m} \\
(\mathrm{MPa})\end{array}$ & $\begin{array}{c}E_{c m} \\
(\mathrm{GPa})\end{array}$ & $\begin{array}{c}f_{c m} \\
(\mathrm{MPa})\end{array}$ & $\begin{array}{c}E_{c m} \\
(\mathrm{GPa})\end{array}$ \\
\hline IL1 & 29,08 & 28,6 & 50,37 & 36,2 & 65,99 & 41,0 \\
\hline IL2 & 29,08 & 28,6 & 50,37 & 36,2 & 57,03 & 37,3 \\
\hline IL3 & 35,44 & 29,1 & 59,37 & 36,8 & 65,01 & 40,7 \\
\hline IL4 & 25,60 & 28,9 & 39,50 & 34,5 & 43,34 & 32,3 \\
\hline IR1 & 25,94 & 24,9 & 41,34 & 30,5 & 54,07 & 37,8 \\
\hline IR2 & 25,94 & 24,9 & 41.34 & 30,5 & 52,34 & 34,2 \\
\hline IR3 & 26,50 & 29,1 & 41,20 & 34,8 & 44,28 & 34,2 \\
\hline
\end{tabular}

Tabela 5.4 - Propriedades mecânicas das principais armaduras do cálice

\begin{tabular}{|c|c|c|c|c|c|c|}
\cline { 2 - 7 } \multicolumn{1}{c|}{} & \multicolumn{3}{c|}{ IL1, IL2, IL3, IR1, IR2 } & \multicolumn{3}{c|}{ IL4, IR3 } \\
\hline$\Phi(\mathrm{mm})$ & 6,3 & 8 & 10 & 6,3 & 8 & 10 \\
\hline $\begin{array}{c}f_{y m} \\
(\mathrm{MPa})\end{array}$ & 593 & 584 & 639 & 603 & 640 & 602 \\
\hline $\begin{array}{c}\varepsilon_{y m} \\
\left(\mathrm{x} 10^{-3}\right)\end{array}$ & 2,82 & 2,78 & 3,04 & 2,90 & 3,00 & 2,70 \\
\hline $\begin{array}{c}f_{\text {stm }} \\
\mathrm{MPa})\end{array}$ & 720 & 710 & 732 & 706 & 732 & 717 \\
\hline
\end{tabular}

Tabela 5.5 - Resistência experimental

\begin{tabular}{|c|c|c|c|}
\hline Modelo & $\begin{array}{c}\text { Excentricidade } \\
e(\mathrm{~m})\end{array}$ & $\begin{array}{c}\text { Força normal última } \\
N_{u}(\mathrm{kN})\end{array}$ & $\begin{array}{c}\text { Momento último } \\
M_{u}(\mathrm{kN} . \mathrm{m})\end{array}$ \\
\hline IL1 & 1,85 & 241 & 446 \\
\hline IL2 & 1,85 & 203 & 376 \\
\hline IL3 & 1,20 & 336 & 403 \\
\hline IL4 & 1,20 & 275 & 330 \\
\hline IR1 & 1,20 & 448 & 538 \\
\hline IR2 & 1,20 & 469 & 563 \\
\hline IR3 & 1,20 & 360 & 432 \\
\hline
\end{tabular}




\subsection{COMPORTAMENTO DOS MODELOS NO QUE SE REFERE ÀS ARMADURAS DO COLARINHO}

Será apresentado nesse item o comportamento das armaduras durante o ensaio de cada modelo, fazendo uma análise comparativa entre eles. Para facilitar as análises, são apresentados os resultados médios dos extensômetros e no caso das armaduras horizontais, apenas os da primeira camada.

Como alguns modelos foram ensaiados com excentricidades da força normal diferentes, resolveu-se apresentar todos os resultados numa curva momento aplicado versus deformação na armadura, ao invés de força normal, como foi feito até agora.

\subsubsection{SÉRIE IL}

Com o objetivo de melhor visualizar a transferência de esforços no colarinho dos cálices lisos, na Figura 5.3 esta apresentada a resposta média de algumas armaduras em conjunto de todos os modelos que compõe a Série IL.

O Modelo IL1 (Figura 5.3 (a)), cuja concretagem da junta foi normal, ou seja, sem a colocação de óleo entre os elementos, segundo CANHA (2004) teve um comportando misto entre uma ligação monolítica e os Modelos IL2 e IL3, ou seja, apenas as armaduras verticais do cálice $\left(\mathrm{T}_{\mathrm{m}}-1, \mathrm{CT}_{\mathrm{m}}-1\right.$ e $\left.\mathrm{CL}_{\mathrm{m}}-1\right)$ foram realmente solicitadas, com as armaduras horizontais principais $\left(\mathrm{HST}_{\mathrm{m}}-1\right.$ e $\left.\mathrm{HSL}_{\mathrm{m}}-1\right)$ deformadas apenas pelo efeito da força mantida e não por essas armaduras serem bastantes solicitadas. Após o escoamento das armaduras verticais o modelo não conseguiu absorver mais força, chegando a sua capacidade limite. Conforme a autora, as fissuras ocorridas nesse modelo apareceram sem se conseguir o aumento da força, mas no entanto esta foi mantida aplicada no modelo ao longo de um certo tempo para se observar o comportamento desse protótipo.

Nos Modelos IL2 e IL3 (Figura 5.3 (b) e (c)), conforme CANHA (2004), institui-se que as forças atuantes nestas ligações foram transferidas do pilar para o colarinho, e no colarinho esse caminho foi determinado pela transmissão simultânea de pequena parte dos esforços diretamente para a região inferior da ligação colarinho-base da fundação das armaduras verticais secundárias da parede $2 A_{s, v s}\left(\mathrm{CT}_{\mathrm{m}}-1\right)$ e por flexotração do topo da parede transversal 1 para o topo das paredes longitudinais que se comportaram como consolo. 




Figura 5.3 -Curva momento aplicado versus deformação média nas armaduras - Série IL

A partir da suspensão da força $H_{\text {sup }}$ nas paredes longitudinais 3 e 4 do canto da parede transversal 1 para o canto da parede transversal 2, o mecanismo de resistência foi formado pela biela de compressão inclinada do consolo e pelos tirantes dispostos nos cantos tracionados da ligação, levando em consideração a atuação simultânea de forças de atrito. Simplificando, o caminho percorrido pelos esforços no colarinho se deu pela armadura $A_{s, h f t}\left(\mathrm{HST}_{\mathrm{m}}-1\right)$ para $A_{s, h p}\left(\mathrm{HSL}_{\mathrm{m}}-1\right)$, e desta para $A_{s, v p}\left(\mathrm{~T}_{\mathrm{m}}-1\right)$, seguindo o caminho do modelo de LEONHARDT \& MÖNNIG (1977). 
$\mathrm{O}$ estranho comportamento registrado pelo extensômetro $\mathrm{HSL}_{\mathrm{m}}-1$ do Modelo IL3 (Figura 5.3 (c)) foi conseqüência das fissuras surgidas nessa região, danificando com isso a leitura, mas admite-se no entanto, que essa armadura também tenha escoado.

Já no Modelo IL4 (Figura 5.3 (d)), como foi comentado no Capítulo 4, a transferência de esforços para o cálice de fundação se deu primeiramente pela transmissão desses esforços para as armaduras verticais da parede transversal $2\left(2 A_{s, v p t}\right.$ $\left(\mathrm{T}_{\mathrm{m}}-1\right)$ e $\left.A_{s, v s}\left(\mathrm{CT}_{\mathrm{m}}-1\right)\right)$, e após a ruptura completa da adesão, onde o pilar sofreu um deslizamento e com isso passou a transmitir a resultante de pressão $H_{\text {sup }}$ para a parede transversal 1 , foi acionada a armadura $A_{s, h f t}\left(\mathrm{HST}_{\mathrm{m}}-2\right)$ que por sua vez transferiu a parcela restante dos esforços em conjunto das forças de atrito paras as paredes longitudinais 3 e $4\left(A_{s, h p}\left(\mathrm{HSL}_{\mathrm{m}}-1\right)\right)$.

Como foi descrito anteriormente, o mecanismo não segue o caminho do modelo de LEONHARDT \& MÖNNIG (1977), ou seja, as armaduras verticais e horizontais principais deveriam ser solicitadas simultaneamente e desde o inicio do carregamento, como aconteceu nos Modelos IL2 e IL3. No entanto, após o escorregamento do pilar, o mecanismo resistente se altera e as armaduras horizontais sofrem uma deformação considerável com pouca variação da força se igualando a deformação da armadura vertical principal, com ambas chegando próximo ao escoamento.

A diferença entre o Modelo IL4 e o Modelo IL1 é que neste modelo não houve um aumento na força após as armaduras horizontais terem sidas solicitadas, pois as armaduras verticais já haviam sido escoadas e com isso as horizontais se deformaram apenas pela manutenção da força aplicada, com a curva momento aplicado versus deformação dessa armadura formando uma assíntota horizontal com a linha da força última. Isso mostra que essas armaduras só foram solicitadas pelo efeito da manutenção da força, pois como foi comentado anteriormente, a capacidade desse protótipo se aproximou da resistência de uma ligação monolítica. Já no Modelo IL4, se caracteriza outro fenômeno, o do comportamento inicial semelhante ao Modelo IL1, mas que após um determinado carregamento, o modelo sofreu uma redistribuição de esforços criando um mecanismo resistente característico de uma ligação com interface lisa, ou seja, as armaduras horizontais e verticais trabalhando juntas. Acredita-se que isso só foi possível pois no instante que as armaduras horizontais foram realmente solicitadas, a armadura vertical principal não havia escoado ainda, permitindo com isso que essas armaduras se 
equilibrassem entre si e continuassem absorvendo força, mas por um curto intervalo de tempo, pois como já foi comentado, o atuador hidráulico não conseguiu mais aplicar uma quantidade de força significativa, ou seja, este protótipo já estava próximo da sua capacidade resistente.

No que diz respeito à capacidade experimental dos modelos, nota-se que a força última alcançada pelo Modelo IL1 foi maior que a dos outros modelos, pois a adesão não foi eliminada, embora CANHA (2004) recomenda não utilizar esse modelo para projeto, ou seja, não contar com a adesão entre o concreto da junta e dos elementos.

Já os Modelos IL2 e IL3 tiveram capacidades resistentes próximas entre si e pode ser calculado pelo modelo proposto por CANHA (2004) para o cálice liso (Equação (2.111)).

No caso do Modelo IL4, a resistência alcançada foi inferior aos demais, apesar de ter tido um comportamento inicial bastante rígido. Isso pode ser explicado pelo fato desse modelo possuir um comprimento de embutimento inferior em relação aos outros protótipos, podendo com isso ter influenciado na sua resistência. No entanto, o comportamento da transferência de esforços ocorrida no Modelo IL4 não é desejável no que diz respeito ao dimensionamento da ligação, pois o rompimento total da adesão leva a uma redistribuição dos esforços que não pode ser previsto no dimensionamento, ou seja, a capacidade real desse modelo pode ser considerada como sendo o momento que gerou o descolamento do pilar, pois a partir daí, a fissuração foi alta e com pouca força absorvida.

Teoricamente, todos os modelos deveriam possuir resistências próximas, pois a diminuição da altura de embutimento do Modelo IL4 foi compensada pelo acréscimo de armadura horizontal de acordo com o modelo teórico de LEONHARDT \& MÖNNIG (1977). Isso comprova que este modelo de cálculo não representa bem o comportamento de cálices com comprimentos de embutimento inferiores aos recomendados pela NBR 9062: (1985).

Na Figura 5.4, estão apresentados os valores médios de deformação para cada tipo de armadura para todos os modelos da Série IL, com o objetivo de melhor visualizar o comportamento dessas armaduras no decorrer do ensaio. 


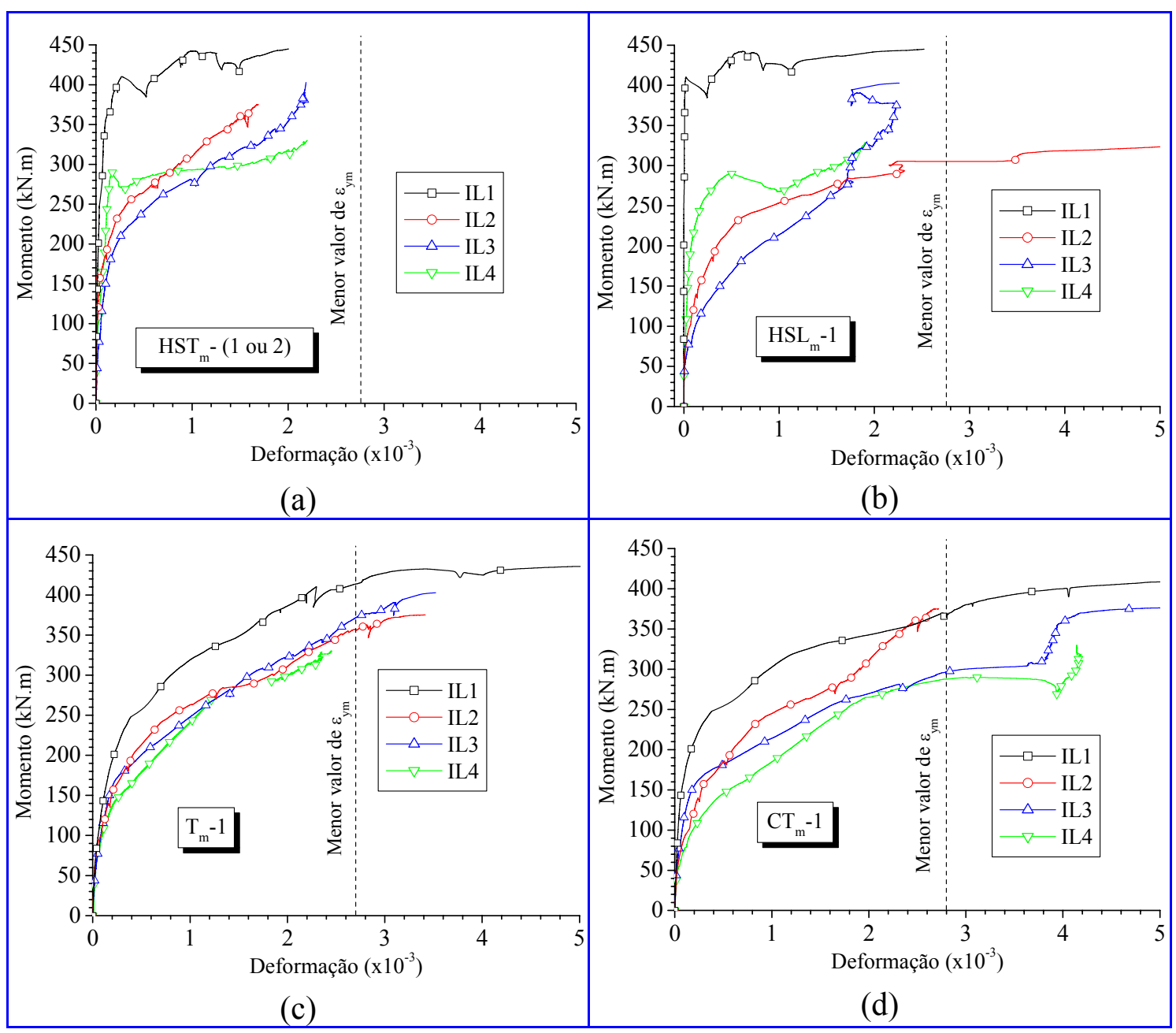

Figura 5.4 -Curva momento aplicado versus deformação média separadamente para cada tipo de armadura - Série IL

No que se refere as armaduras horizontais principais (Figura 5.4 (a) e (b)), notase que a rigidez representada pela curva momento aplicado versus deformação dessas armaduras foi bastante elevada nos Modelos IL1 e IL4, enquanto nos Modelos IL2 e IL3, a rigidez diminuiu gradativamente ao longo do ensaio.

Na Figura 5.4 (c) e (d), é possível visualizar a maior rigidez do Modelo IL1, cuja resistência se aproximou de uma ligação monolítica, e nos Modelos IL2, IL3 e IL4, uma menor rigidez e com um comportamento muito próximo entre si. Em todos os modelos, a ruptura do cálice se deu pelo escoamento das armaduras verticais pertencentes à parede transversal 2 na ligação colarinho-base de fundação, com exceção do Modelo IL4 que chegou bem próximo a isso.

Resumindo, com a análise do comportamento das armaduras dos modelos da Série IL, percebeu-se que os Protótipos IL2 e IL3 seguiram o caminho do modelo de LEONHARDT \& MÖNNIG (1977), ao contrário do Modelo IL4, no qual as armaduras 
horizontais pouco se deformaram até o carregamento que gerou a ruptura total da adesão na interface, enquanto as verticais foram solicitadas desde o início do ensaio.

\subsubsection{SÉRIE IR}

Na Figura 5.5, apresenta-se para todos os modelos da Série IR o comportamento médio das principais armaduras do cálice de fundação.

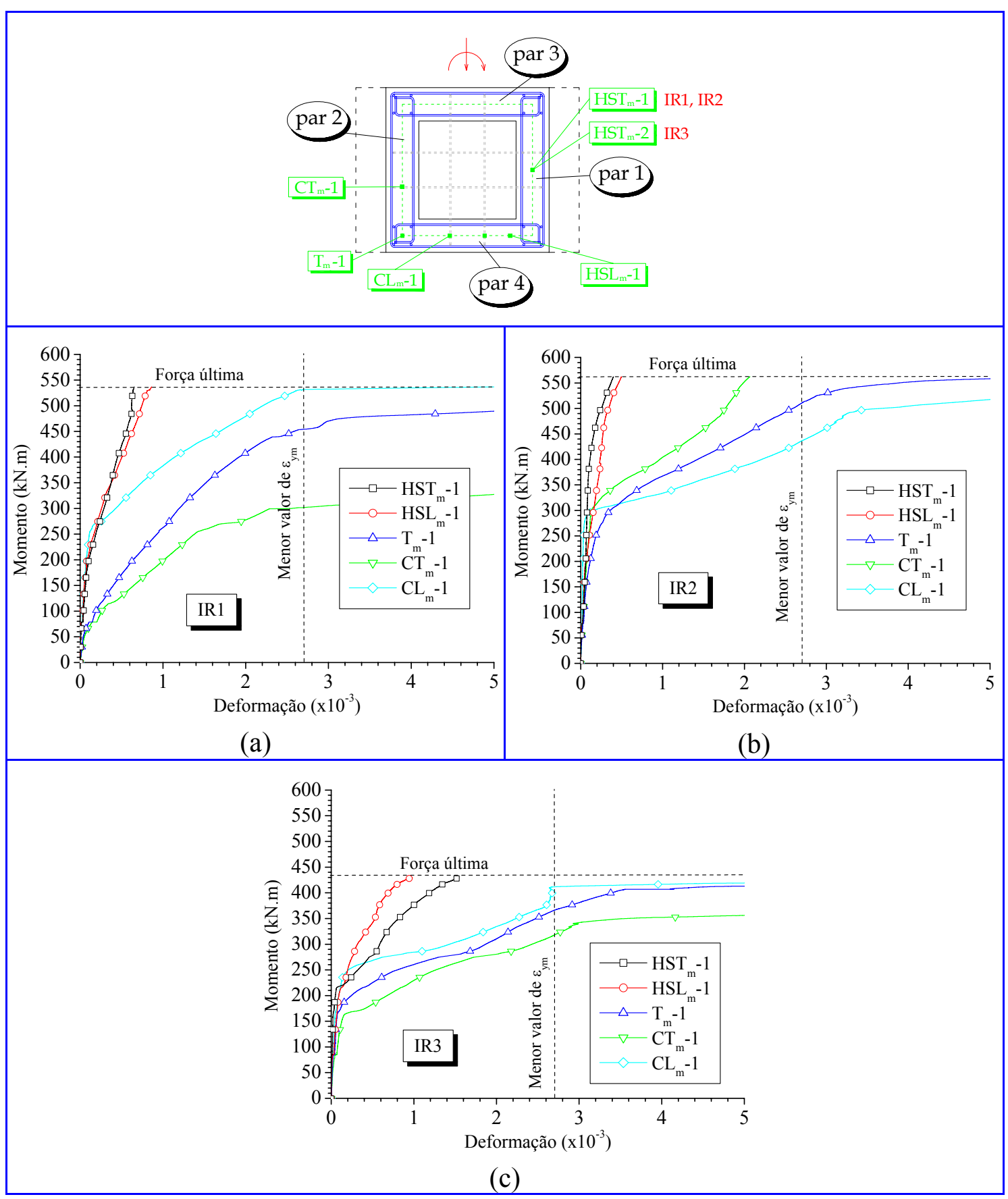

Figura 5.5 -Curva momento aplicado versus deformação média nas armaduras - Série IR

Como era de se esperar, todos os modelos com chaves de cisalhamento tiveram 
um comportamento muito próximo ao de uma ligação monolítica, ou seja, os esforços de flexo-compressão atuantes no pilar foram transmitidos na sua maior porcentagem para as armaduras verticais $A_{s, v p}$ e $A_{s, v s}\left(\mathrm{~T}_{\mathrm{m}}-1, \mathrm{CT}_{\mathrm{m}}-1\right.$ e $\left.\mathrm{CL}_{\mathrm{m}}-1\right)$ com essas atingindo o escoamento e/ou plastificação enquanto as armaduras horizontais $A_{s, h f t}$ e $A_{s, h p}\left(\mathrm{HST}_{\mathrm{m}}-1\right.$ e $\mathrm{HSL}_{\mathrm{m}}$-1) pouco foram solicitadas.

Vale lembrar que a configuração das chaves de cisalhamento dos Modelos IR1 e IR3 são iguais ao valor mínimo recomendado pela NBR 9062: (1985), ou seja, possuem menos chaves e maiores, e o Modelo IR2 com mais chaves e menores. Nota-se então que nos Modelos IR1 e IR3 as armaduras horizontais foram mais solicitadas do que as do Modelo IR2, mostrando que naqueles modelos o travamento entre o pilar, a junta e a parede do colarinho na região da parede transversal $l$ foi menos intenso do que no Modelo IR2, e consequentemente as armaduras horizontais localizadas nessa parede e nas paredes longitudinais 3 e 4 foram mais solicitadas do que no Modelo IR2 cujo travamento das chaves foi mais intenso.

Quanto a capacidade resistente atingida pelos modelos com chaves de cisalhamento, os Modelos IR1 e IR2, com comprimentos de embutimento adotados de acordo com a indicação da norma brasileira, foram praticamente iguais, enquanto no Modelo IR3 com comprimento de embutimento reduzido o protótipo teve uma menor resistência.

Como será visto no item seguinte, a determinação da resistência dos Modelos IR1 e IR2 pela teoria de flexão se aproximou da resistência experimental alcançada por esses modelos. Isso não se repete para o Modelo IR3, pois a resistência teórica é a mesma pra todos, já que suas armaduras verticais são as mesmas, e portanto a resistência experimental resultou num valor menor do que a teórica, ou seja, subestimando a capacidade desse modelo.

Na Figura 5.6, apresentam-se as curvas momento versus deformação em cada armadura separadamente, com o objetivo de melhor visualizar o seu comportamento em cada modelo.

Percebe-se que os resultados das armaduras horizontais e verticais dos Modelos IR1 e IR3, com menos chaves e maiores, foram menos rígidos do que o do Modelo IR2.

A maior rigidez inicial do Modelo IR3, que teoricamente é mais flexível, em 
relação ao Modelo IR1, pode ser explicada pela maior resistência do concreto do cálice daquele modelo, mas, após a fissuração, essa rigidez foi diminuindo e ficou menor que a do Modelo IR1, com exceção da armadura $\mathrm{CT}_{\mathrm{m}}-1$, porem com as curvas bem próximas entre sí.



Figura 5.6 -Curva momento aplicado versus deformação média nas armaduras - Série IL

\subsection{APLICAÇÃO DOS MODELOS DE PROJETO DA LITERATURA NOS MODELOS FÍSICOS}

Com a finalidade de observar qual modelo de projeto apresentado no Capítulo 2 mais se aproxima da resistência última experimental, e também analisar a capacidade resistente dos Modelos IL4 e IR3 cujas profundidades de embutimento são inferiores às recomendadas pela NBR 9062: (1985), foram aplicados esses modelos de projeto nos protótipos da Série IL e IR.

Serão apresentados os valores dos modelos das duas séries separadamente. 


\subsubsection{SÉRIE IL}

Para determinação do momento último por meio dos modelos de projeto referente aos protótipos com interface lisa, calculou-se a força $H_{\text {sup }}$ levando em conta o escoamento da armadura horizontal principal $A_{s, h p}$ das paredes longitudinais 3 e 4 , e pelo processo inverso, encontrou-se o momento máximo resistido por cada protótipo e para cada modelo de projeto. Embora os ramos externos desses estribos não tenham escoado nos Modelos IL2 e IL3, simplificam-se as aplicações de projeto utilizando-se o valor médio das deformações nessa armadura, que na sua maioria atingiu o escoamento.

Já no Modelo IL4, nenhum dos ramos dessa armadura chegou a escoar, no entanto, acredita-se que esse modelo já estava próximo a sua capacidade resistente quando o ensaio foi interrompido, como foi descrito anteriormente. Mesmo assim, considerou-se o escoamento dessas armaduras para a determinação do momento último desse protótipo, pois para efeito de dimensionamento, qualquer que seja o modelo utilizado, seria feito dessa maneira.

No caso do Modelo IL1, como já foi mencionado anteriormente, a armadura horizontal principal só se deformou pelo efeito da força mantida, mas no entanto, aplicou-se os modelos de projeto objetivando ilustrar a reserva de segurança embutida do mesmo em relação aos demais protótipos, nos quais a adesão tentou-se eliminar.

Na Figura 5.7, apresentam-se os valores das resistências experimentais e da aplicação teórica para os protótipos da Série IL, incluindo o modelo de projeto proposto por CANHA (2004) para o cálice com interface lisa apresentado no Capítulo 2.

Resolveu-se variar o coeficiente de atrito $\mu$ adotando os valores $0,3,0,6$ e 1,0 , pois com isso varrem-se os valores mais próximos aos recomendados na literatura.

Com o objetivo de padronizar os resultados, foi considerado o valor recomendado por CANHA (2004) para a excentricidade da reação normal na base do pilar $e_{n b}$ equivalente a $h / 4$ nos modelos que a considera no dimensionamento.

Não foi levada em conta nessas análises a resistência última determinada pelo modelo da CNR 10025 (1998), pois a expressão de $H_{\text {sup,d }}$ é idêntica a de LEONHARDT \& MÖNNIG (1977).

Percebe-se que no Modelo IL1, o qual não se retirou a adesão na interface da 
ligação, com exceção do modelo de LEONHARDT \& MÖNNIG (1977), os momentos últimos determinados pelos outros modelos só resultaram em valores próximos ao obtido experimentalmente quando se utilizou um coeficiente de atrito $\mu$ igual a unidade, valor esse comumente utilizado no cálice com interface rugosa. Isso comprova que a resistência desse protótipo se aproximou ao de uma ligação monolítica por conseqüência da elevada adesão na interface da ligação, embora CANHA (2004) não recomende a utilização desse modelo para projeto, conforme comentado anteriormente.
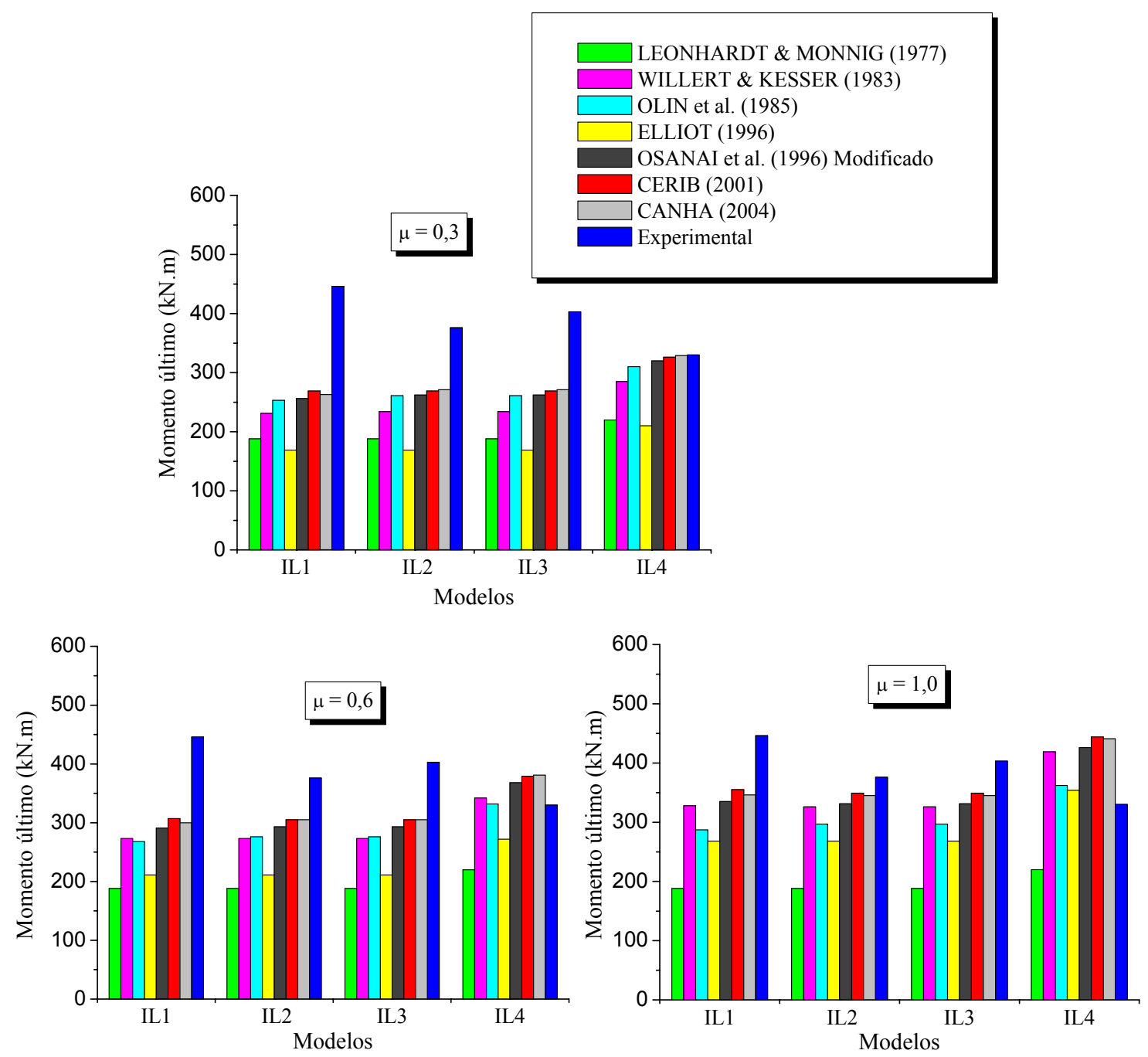

Figura 5.7 - Capacidade resistente dos protótipos conforme os modelos de projeto - Série IL

Nos Modelos IL2 e IL3, com profundidade de embutimento recomendado pela NBR 9062: (1985) e teoricamente sem adesão na interface, a capacidade resistente pelo modelo de LEONHARDT \& MÖNNIG (1977) foi subestimada em 99\% para o Protótipo IL2 e em $114 \%$ para o Protótipo IL3, deixando claro a importância de se considerar o atrito no projeto do cálice. 
Já entre os modelos que consideram o atrito, CANHA (2004) e CERIB (2001) foram os que mais se aproximaram da resistência experimental, com uma reserva de segurança no caso do modelo de CANHA (2004) de 9\% para o Protótipo IL2 e de $17 \%$ para o Protótipo IL3 considerando o coeficiente de atrito $\mu$ igual a unidade. No entanto, vale lembrar que no caso de cálice com interface lisa, CANHA (2004) e o CERIB (2001) recomendam a utilização de $\mu=0,6$ e $\mu=0$ respectivamente. A única diferença entre esses modelos é que no primeiro o braço $z$ é um pouco menor do que no último e também leva em conta a excentricidade da reação normal na base da fundação $e_{n b}$, por isso a pequena diferença entre seus valores. Em ambos os modelos, considera-se a força de atrito em todos os lados da interface $\left(F_{a t, s u p, d}, F_{a t, i n f, d}\right.$ e $\left.F_{a t, b f, d}\right)$, tornando os menos conservadores.

O modelo de OSANAI et al. (1996) modificado, com a utilização $\mu=1,0$, também se aproximou bastante do valor experimental com uma diferença de $13 \%$ e $22 \%$ nos Modelos IL2 e IL3 respectivamente. Neste caso, a utilização do coeficiente de atrito igual a unidade é também recomendada pelo autor, pois conforme foi mencionado no Capítulo 2, a partir das análises experimentais realizadas, verificou-se que quando a profundidade de embutimento $\ell_{e m b}$ for igual ou superior a $1,5 h$ e a interface da ligação for lisa, os valores determinados utilizando o coeficiente de atrito $\mu=1,0$ ficaram próximos aos experimentais.

Já os modelos de WILLERT \& KESSER (1983) e OLIN et al. (1985) resultaram em valores um pouco menores, o primeiro por não levar em conta a excentricidade da reação normal na base da fundação $e_{n b}$, embora considere as forças de atrito agindo em todo o contorno e o segundo por não considerar as forças de atrito inferior $F_{a t, i n f, d}$ da parede transversal 2 e da base $F_{a t, b f, d}$. Levando em conta as recomendações referentes aos coeficientes de atrito desses modelos, WILLERT \& KESSER (1983) e OLIN et al. (1985) sugerem para interface lisa a utilização de $\mu=0,67$ e $\mu=0,3$ respectivamente, ou seja, utilizando os valores recomendados, o primeiro se aproxima mais dos valores experimentais com uma segurança embutida de $38 \%$ e $48 \%$ nos Modelos IL2 e IL3 respectivamente, e o último resulta em valores mais conservadores, com diferença de até $54 \%$ do valor experimental. Vale lembrar que, além disso, OLIN et al. (1985) recomenda um valor de comprimento de embutimento igual a $1,3 \mathrm{~h}$, diferente dos 
adotados nos protótipos $(2,0 h)$.

O modelo de ELLIOT (1996), com exceção dos valores referentes ao coeficiente de atrito $\mu$ igual a 0,3 , foi o mais conservador depois de LEONHARDT \& MÖNNIG (1977), pois esse modelo além de não levar em conta a excentricidade da reação normal na base da fundação $e_{n b}$ e a força de atrito $F_{a t, b f, d}$ na região inferior do pilar, o braço $z$ entre as forças $H_{s u p}$ e $H_{i n f}$ é inferior aos demais modelos. Utilizando $\mu=0,6$, valor mais próximo ao recomendado por ELLIOT (1996) que é $\mu=0,7$, o momento último resultou em um valor distante do obtido experimentalmente para o Protótipo IL2 e IL3 em $78 \%$ e $91 \%$ respectivamente. Aqui se faz também uma observação quanto ao valor do comprimento adotado pelo autor que é de $1,5 \mathrm{~h}$, inferior aos adotados nos protótipos ensaiados.

Em sumo, para os Protótipos IL2 e IL3, com comprimento de embutimento recomendado pela norma brasileira, os modelos de projeto que resultaram em valores mais próximos dos obtidos experimentalmente, levando em conta as recomendações feitas por cada autor, foram os de CANHA (2004), no qual foi calibrado justamente para esses modelos, CERIB (2001) e OSANAI et al. (1996) modificado. A reserva de segurança da resistência experimental em relação à calculada pelo modelo de CANHA (2004) foi de 25\% para o Protótipo IL2 e de 32\% para o Protótipo IL3, utilizando o valor recomendado de $\mu=0,6$.

O Modelo IL4, com profundidade de embutimento inferior a recomendada pela NBR 9062: (1985), com exceção dos valores determinados com $\mu=0,3$ e os resultantes dos modelos de LEONHARDT \& MÖNNIG (1977) e ELLIOT (1996) $(\mu=0,3$ e $\mu=0,6$ ), todos os modelos de projeto apresentaram resistências maiores que a resistência última experimental, ou seja, superestimando a capacidade dessa ligação.

Vale lembrar que na determinação do momento último utilizando os modelos de projeto, considerou-se no cálculo toda armadura horizontal superior $A_{s, h p}$ escoando, fato que não ocorreu no ensaio desse modelo. No entanto, não se pode afirmar que esse protótipo ainda teria uma reserva de resistência pelo fato de suas armaduras horizontais e verticais principais ainda não terem escoado, pois como foi visto no item anterior, esse modelo já não conseguia mais absorver uma força considerável. Entretanto, como já foi comentado, para projeto não se leva em consideração esse comportamento, pois o 
rompimento repentino da adesão, e consequentemente a redistribuição dos esforços, não se pode prever, pois necessitaria de maiores estudos sobre os parâmetros relativos a interface da ligação.

Os modelos de OSANAI et al. (1996) modificado, CERIB (2001) e CANHA (2004), adotando $\mu=0,3$, resultaram em valores praticamente iguais aos obtidos experimentalmente. Embora o primeiro e o último não utilizem este valor do coeficiente de atrito $\mu$, a CERIB (2001) recomenda adotar o coeficiente de atrito nulo para interface lisa, ou seja, utilizando o valor zero na expressão desse modelo chega-se a valores próximos e com uma margem de segurança em relação ao experimental.

Conforme foi mencionado anteriormente, OLIN et al. (1996) recomenda para interface lisa adotar $\mu=0,3$, que neste caso do Modelo IL4 resultou em um valor teórico próximo ao experimental com uma diferença de $6 \%$, embora se recomende neste modelo adotar um comprimento de embutimento igual a $1,3 \mathrm{~h}$.

Levando em conta que o valor usual do coeficiente de atrito para interface lisa é de 0,6, percebe-se que o modelo de ELLIOT (1996), cujo valor recomendado para o coeficiente de atrito e comprimento de embutimento é 0,7 e $1,5 h$ respectivamente, resultou em um valor inferior e próximo ao experimental, com uma segurança embutida de aproximadamente $21 \%$.

Em resumo, pode-se afirmar que o Protótipo IL4, com profundidade de embutimento inferior aos recomendados pela NBR 9062: (1985), não foi bem representado pelos modelos de projeto encontrado na literatura, com a maioria superestimando a capacidade resistente desse modelo.

Portanto, pode-se concluir, a partir das análises feitas neste item, que o Modelo IL1 teve uma resistência próxima a de uma ligação monolítica e que os modelos de projeto só apresentaram uma boa aproximação quando se utilizou o coeficiente de atrito igual a unidade.

Quanto aos Modelos IL2 e IL3, os modelos que mais se aproximaram dos valores experimentais, respeitando as recomendações feitas por cada um, foi o modelo de CANHA (2004) $\left(\mu=0,6\right.$ e $\left.\ell_{e m b}=2,0 h\right)$ com uma margem de segurança de $25 \%$ e $32 \%$ respectivamente e o modelo de OSANAI et al. (1996) modificado ( $\mu=1,0$ para $\left.\ell_{e m b}>1,5 h\right)$ com uma diferença de $13 \%$ e $22 \%$ respectivamente. 
Já no Modelo IL4, o modelo de projeto que resultou no valor mais próximo ao obtido experimentalmente, levando em conta também as recomendações feitas por cada modelo, foi o de ELLIOT (1996) $\left(\mu=0,7\right.$ e $\left.\ell_{e m b}=1,5 h\right)$ cujo momento último teve uma diferença para o experimental de $21 \%$.

\subsubsection{SÉRIE IR}

Semelhante ao descrito anteriormente para os modelos lisos, a determinação do momento último dos modelos rugosos foi determinada levando em consideração o escoamento da armadura horizontal principal $A_{s, h p}$ para resistir à força $H_{s u p}$, e pelo processo inverso, determinou-se o momento máximo resistido pelos protótipos para cada modelo de projeto. No entanto, como foi visto no item 5.3.2, as armaduras horizontais foram pouco solicitadas, mas no procedimento dos modelos teóricos, o dimensionamento é feito por meio deste principio, que, como será visto a seguir, levará a valores conservadores.

Igualmente aos modelos da Série IL, variou-se o coeficiente de atrito $\mu$ em 0,3 , 0,6 e 1,0 e também adotou-se o valor recomendado por CANHA (2004) para a excentricidade da reação normal na base do pilar $e_{n b}$ equivalente a $h / 4$.

Vale lembrar que em alguns modelos de projeto nada foi descrito sobre a ligação com cálice rugoso, mas para efeito de comparação, foram feitas as análises aplicando-se os modelos que consideram o atrito em sua formulação. Já em outros modelos, é recomendado o dimensionamento das armaduras verticais do cálice rugoso como se a ligação fosse monolítica, no entanto nenhum modelo de cálculo é sugerido, e, portanto, para efeito de comparação, aplicou-se a teoria de flexão conforme descrito em CANHA (2004).

A Figura 5.8 ilustra os valores das capacidades resistentes teóricas e experimentais para todos os modelos da Série IR, incluindo o modelo de projeto proposto por CANHA (2004) com os parâmetros alterados para o cálice rugoso, que nada mais é do que a formulação para o cálice liso com a modificação de alguns parâmetros para adaptar ao modelo rugoso.

Como nos modelos com interface lisa, o modelo de LEONHARDT \& MÖNNIG (1977) apresentou resultados bastante conservadores com relação aos modelos rugosos, 
com uma diferença de até $125 \%$ no caso do Protótipo IR2. Isto é explicado pelo fato desse modelo não considerar as forças de atrito agindo na interface, sendo que única diferença deste para o modelo liso é o braço de alavanca $z$ entre as forças $H_{s u p}$ e $H_{i n f}$, que neste caso é $25 \%$ superior ao liso.
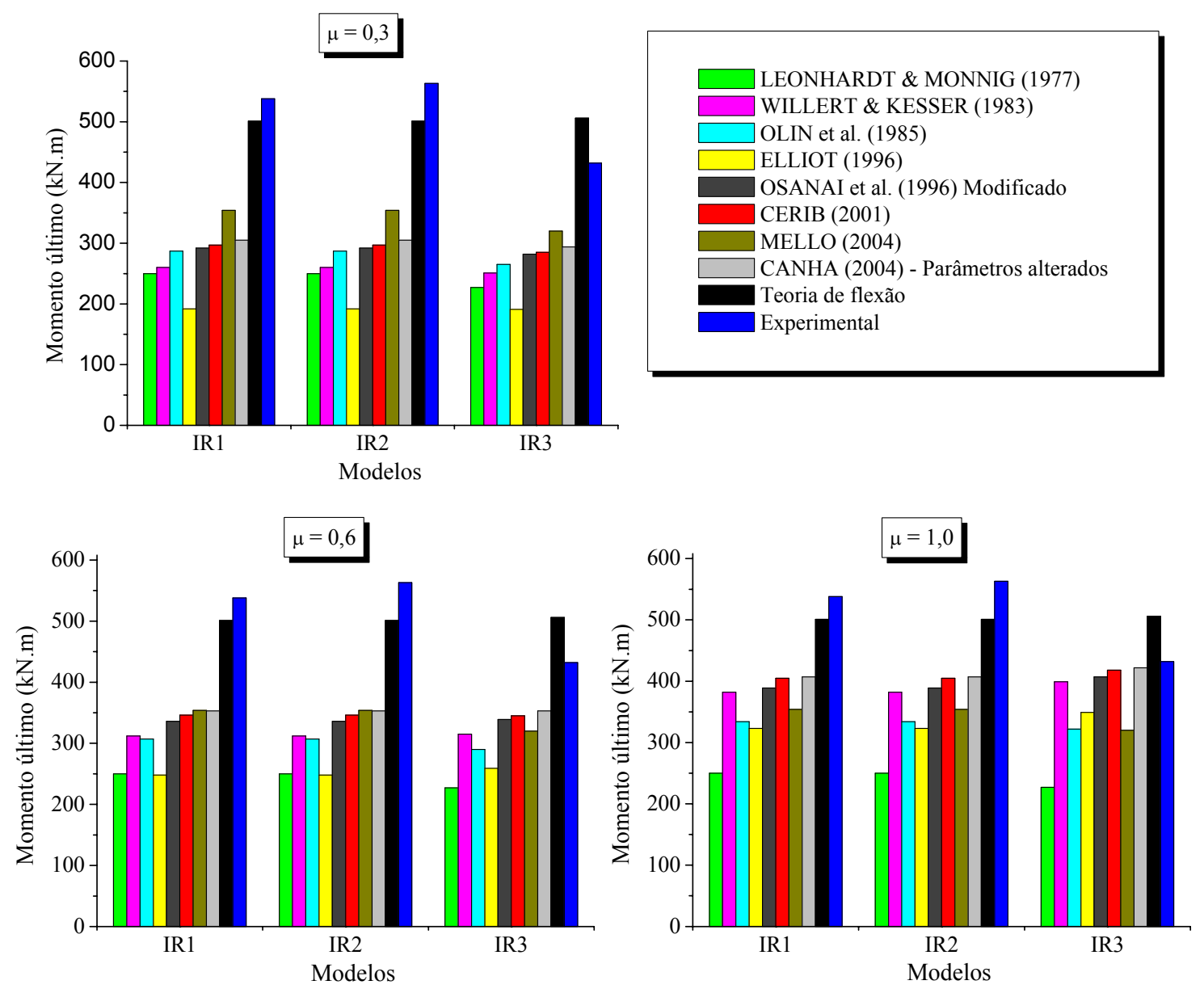

Figura 5.8 - Capacidade resistente dos protótipos conforme os modelos de projeto - Série IR

Nos Modelos IR1 e IR2, cujo comprimento de embutimento é o recomendado pela NBR 9062: (1985), a aplicação dos modelos de projeto resultou em valores mais próximos aos experimentais utilizando o coeficiente de atrito igual a unidade, comprovando que este valor é o mais apropriado para interface rugosa.

No entanto, como foi apresentado no Capítulo 2, a maioria dos autores recomendam para o cálice rugoso valores inferiores a esse, com exceção do modelo de OSANAI et al. (1996) modificado e CANHA (2004) com os parâmetros alterados, onde o primeiro sugere a utilização de $\mu=1,0$ quando o cálice for rugoso e possuir $\ell_{e m b}>1,25 h$, e o último recomenda diretamente a utilização de $\mu=1,0$ e $\ell_{e m b}=1,60 h$. 
Levando isso em consideração, os valores de momento último calculados utilizando o coeficiente de atrito $\mu$ igual a unidade, tiveram um segurança embutida sobre os experimentais na ordem de até $45 \%$ e $38 \%$ utilizando o modelo de OSANAI et al. (1996) modificado e CANHA (2004) com os parâmetros alterados, respectivamente, valores esses referentes ao Protótipo IR2.

Mas, como alguns autores recomendam que o dimensionamento do cálice com interface rugosa (com chaves de cisalhamento) seja feito como se a ligação fosse monolítica, para determinação da capacidade limite dos modelos físicos, utilizou-se o modelo 2 da Figura 2.44 sugerido por CANHA (2004), ou seja, considerando a contribuição apenas das armaduras verticais da parede transversal 2. Tendo isso, percebeu-se que as resistências determinadas por esse modelo tiveram uma boa aproximação entre os resultados experimentais, com um excesso de segurança embutido de $7 \%$ e $11 \%$ para IR 1 e IR2 respectivamente, mostrando que esse modelo representou bem a capacidade desses protótipos.

Em relação aos outros modelos de projeto, levando em conta as recomendações feitas por cada autor, não resultaram em valores próximos aos obtidos experimentalmente, mostrando, principalmente para os cálices rugosos, o conservadorismo existente nestes modelos.

No caso do Modelo IR3, cujo comprimento de embutimento é inferior ao recomendado pela norma brasileira, ao contrário dos outros protótipos, o modelo da teoria de flexão resultou num valor contra a segurança, mostrando que para cálices com comprimentos de embutimento $\ell_{e m b}$ inferiores a $1,6 \mathrm{~h}$ esta teoria não se aplicou.

Quanto aos outros modelos de projeto, com exceção do modelo de LEONHARDT \& MÖNNIG (1977) e aqueles considerando $\mu=1,0$, resultaram em valores praticamente iguais aos obtidos experimentalmente, embora, como já foi comentado anteriormente, apenas os modelos de OSANAI et al. (1996) modificado e CANHA (2004) com os parâmetros alterados recomendam esse valor para o coeficiente de atrito. No entanto, como foi escrito anteriormente, CANHA (2004) recomenda também que se utilize uma profundidade de embutimento $\ell_{\text {emb }}$ igual a $1,6 h$, diferente da adotada no Protótipo IR3 (1,2h), enquanto OSANAI et al. (1996) sugere que a partir de um comprimento igual ou superior a $1,25 \mathrm{~h}$ no caso de cálice rugoso, a utilização de $\mu=1,0$ representa bem o modelo físico. 
O modelo de MELLO (2004), no qual não se pode aplicar um valor para o coeficiente de atrito, alcançou um momento último com uma diferença do experimental de $35 \%$, embora se saiba que a recomendação quanto ao comprimento de embutimento $\ell_{e m b}$ é igual ou superior a $1,6 h$, ou seja, superior ao do Protótipo IR3, que é de $1,2 h$.

Feito essas análises, pode-se dizer que os Modelos IR1 e IR2, com profundidade de embutimento recomendada pela NBR 9062: (1985), apresentaram uma resistência muito próxima a de uma ligação monolítica, ou seja, considerando que houve a transferência total das forças atuantes no pilar transmitidas para o cálice de fundação.

Já o Modelo IR3, com um comprimento de embutimento reduzido, não atingiu a resistência calculada pela teoria de flexão e o modelo de projeto que mais se aproximou da resistência experimental desse protótipo, levando em conta as recomendações quanto ao comprimento de embutimento e o coeficiente de atrito, foi o de OSANAI et al. (1996) modificado, com uma segurança embutida de $6 \%$.

\subsubsection{COMPARAÇÃO ENTRE AS RESISTENCIAS EXPERIEMNTAIS DOS PROTÓTIPOS}

Na Figura 5.9 estão ilustrados os valores últimos experimentais alcançado pelos modelos lisos e rugosos.

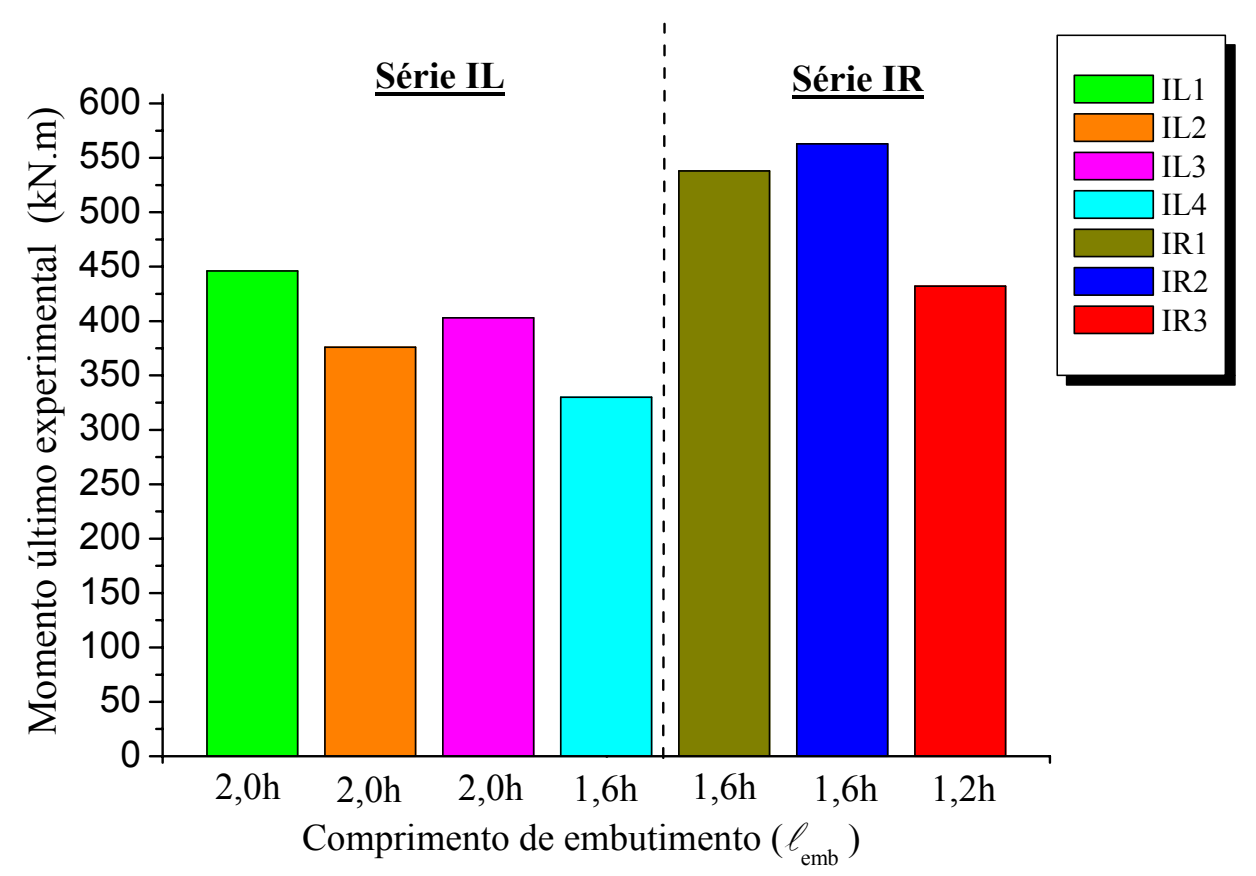

Figura 5.9 - Capacidade resistente dos protótipos conforme os modelos de projeto - Série IR 
Entre os modelos com interface lisa, nota-se que o Modelo IL1 com concretagem normal da junta teve uma maior resistência do que os demais onde foi aplicado o desmoldante na interface e também uma resistência maior do que o Modelo IR3 com interface rugosa, mostrando que a influência da adesão no comportamento da ligação é muito importante.

Percebe-se que, com a redução do comprimento de embutimento de 2,0h (IL2 e IL3) para 1,6h (IL4), a capacidade resistente da ligação diminuiu em média $15 \%$, mesmo com um aumento de $33 \%$ na armadura horizontal principal, mostrando a importância de se obter um modelo de cálculo que se aproxime da capacidade da ligação para cálice com comprimento de embutimento reduzido.

Entre os modelos com comprimento de embutimento iguais, mas com interfaces diferentes (IL4, IR1 e IR2), observa-se um aumento da resistência determinada experimentalmente em média de $67 \%$ quando se utiliza chaves de cisalhamento na interface entre os elementos, já que esses protótipos possuem a mesma quantidade de armadura. Isso comprova que com a utilização das chaves de cisalhamento, aumenta-se a capacidade resistente da ligação.

Nota-se também que a resistência experimental alcançada pelos Modelos IR1 e IR2 foi praticamente a mesma, mesmo possuindo diferentes configurações de chaves, ou seja, não influenciou na resistência final dos modelos.

Com a redução do comprimento de embutimento de 1,6h (IR1) para 1,2h (IR3) (mesma configuração de chaves) observou-se uma queda na resistência experimental de aproximadamente $20 \%$, ainda que, com a redução do comprimento de embutimento, a armadura horizontal principal tenha aumentado em $17 \%$. 


\section{CONSIDERAÇÕES FINAIS E CONCLUSÕES}

\subsection{CONSIDERAÇÕES FINAIS}

Este trabalho foi feito com o objetivo de dar continuidade a pesquisa em nível de doutorado no mesmo tema iniciado por CANHA (2004), com o intuito de avançar de uma maneira geral o conhecimento a respeito do comportamento de ligações pilarfundação por meio de cálice em concreto pré-moldado e especificamente estudar a possibilidade de redução do comprimento de embutimento recomendado pela NBR 9062: (1985).

Tendo isso, a fim de padronizar a nomenclatura dos modelos ensaiados nessa pesquisa e os analisados na pesquisa anterior, denominou-se o protótipo com interface lisa e com interface rugosa de IL4 e IR3 respectivamente, seguindo a seqüência determinada por CANHA (2004). Esses modelos foram então subdivididos em duas séries (IL e IR), variando-se as condições e tipo de interface, a excentricidade da força normal e altura do comprimento de embutimento.

Com os resultados experimentais dos Modelos IL4 e IR3, foi possível demonstrar o comportamento desses protótipos com profundidade de embutimento reduzida e compará-los com os analisados anteriormente.

Com a aplicação dos modelos de projeto encontrados na literatura, foi possível verificar a incoerência nos valores da resistência última teórica com relação a experimental, quando se adota valores de comprimento de embutimento inferiores aos recomendados pela NBR 9062: (1985).

\subsection{CONCLUSÕES}

Tendo em vista os resultados obtidos com o desenvolvimento desse trabalho, puderam-se fazer as seguintes conclusões: 


\section{Modelo IL4:}

O Modelo IL4, cuja profundidade de embutimento é inferior a recomendada pela NBR 9062: (1985), apresentou um comportamento inicial semelhante a uma ligação com interface rugosa até um carregamento de $87 \%$ da última leitura do ensaio, com apenas as armaduras verticais da parede transversal $2\left(2 A_{s, v p}\right.$ e $\left.A_{s, v s}\right)$ efetivamente solicitadas, onde então ocorreu a ruptura total da adesão na interface da junta e dos elementos, causando o descolamento do pilar e conseqüentemente a redistribuição dos esforços no modelo. Após esse fenômeno, o pilar passou a transferir efetivamente a resultante de pressão $H_{\text {sup }}$ para a parede transversal 1 onde foi acionada a armadura $A_{s, h f t}$ que por sua vez transferiu a parcela restante dos esforços em conjunto das forças de atrito para a armadura $A_{s, h p}$.

Pode-se concluir que esse protótipo não teve um comportamento típico de uma ligação com interface lisa, pois as armaduras horizontais e verticais deveriam ter sido solicitadas simultaneamente e desde o inicio do carregamento, como aconteceu nos Modelos IL2 e IL3 ensaiados por CANHA (2004).

Com a instrumentação da armadura horizontal principal localizada no topo da parede transversal 2 e também a disposição dos transdutores posicionados nessa parede, percebeu-se que essas armaduras não foram efetivamente solicitadas e os deslocamentos medidos foram pequenos, ou seja, constatou-se pequenos esforços por flexo-tração no topo dessa parede.

Quanto a aplicação dos principais modelos de projeto encontrados na literatura e apresentados no Capítulo 2, a maioria apresentou resistências maiores que a resistência última experimental, ou seja, superestimando a capacidade dessa ligação, inclusive o sugerido por CANHA (2004).

O modelo de projeto que resultou no valor mais próximo ao obtido experimentalmente, levando em conta também as recomendações feitas por cada modelo, foi o de ELLIOT (1996) $\left(\mu=0,7\right.$ e $\left.\ell_{e m b}=1,5 h\right)$ cujo momento último teve uma diferença para o experimental de $21 \%$.

Em relação a comparação dos modelos ensaiados nesta pesquisa com os analisados em CANHA (2004), percebeu-se que, com a redução do comprimento de embutimento de 2,0h (IL2 e IL3) para 1,6h (IL4), a capacidade resistente da ligação 
diminuiu em média $15 \%$, mesmo com um aumento de $33 \%$ na armadura horizontal principal, mostrando a importância de se obter um modelo de cálculo que realmente represente bem capacidade da ligação para cálice com comprimento de embutimento inferior ao recomendado pela NBR 9062: (1985)

\section{Modelo IR3:}

O Modelo IR3 teve um comportamento próximo a uma ligação monolítica, ou seja, com as armaduras verticais da parede transversal 2 e as mais tracionadas das paredes longitudinais 3 e 4 contribuindo para resistência da ligação.

Foi comprovado que apesar desse comportamento, o cálculo da sua resistência considerando a transferência total dos esforços do pilar para o cálice, ou seja, pelo modelo da teoria de flexão, resultou em um valor superior ao determinado experimentalmente, necessitando de um modelo de cálculo mais coerente para cálices rugosos com profundidade de embutimento inferior a $1,6 \mathrm{~h}$.

Com a instrumentação da armadura horizontal principal da parede transversal 2, foi possível perceber os elevados esforços por flexo-tração ocorridos nessa parede causada pelo travamento das chaves, esforços esses mais intensos do que os sofridos pela parede transversal 1 , onde as armaduras foram pouco solicitadas.

O modelo de projeto que mais se aproximou da resistência experimental desse protótipo, levando em conta as recomendações quanto ao comprimento de embutimento e o coeficiente de atrito, foi o de OSANAI et al. (1996) modificado, com uma segurança embutida de $6 \%$.

Os valores obtidos utilizando o modelo de CANHA (2004) com os parâmetros alterados também resultou em valores próximos aos experimentais, embora a autora recomende para cálices rugosos a utilização de $\ell_{e m b}=1,6 h$ e o dimensionamento pela teoria de flexão, que conforme já foi comentada resultou num valor incoerente para esse modelo com $\ell_{e m b}=1,2 \mathrm{~h}$.

Conforme a comparação feita entre os Protótipos IR3 e os ensaiados por CANHA (2004), observou-se que a redução do comprimento de embutimento de 1,6h (IR1) para 1,2h (IR3) (mesma configuração de chaves) implicou em uma queda de resistência de aproximadamente $20 \%$, ainda que, com a redução do comprimento de embutimento, a armadura horizontal principal tenha aumentado em $17 \%$. 
Diferente dos Modelos IR1 e IR2, cuja a capacidade resistente se aproximou bastante da ligação monolítica, o Modelo IR3, cujo comprimento de embutimento foi reduzido, resistiu menos.

\subsection{SUGESTÕES PARA FUTURAS PESQUISAS}

O objetivo deste trabalho foi alcançado, pois foram fornecidos resultados experimentais inéditos, dando continuidade as pesquisas do mesmo tema e contribuindo com o meio técnico e acadêmico. No entanto, o tema é extremamente amplo e necessita de mais estudos experimentais de maneira a calibrar os modelos de projeto e as simulações numéricas. Com a intenção de orientar a realização de futuras pesquisas, são feitas algumas sugestões:

- Refinar a modelagem apresentada por CANHA (2004) para o comportamento do topo da parede transversal 1 , baseando-se nos resultados experimentais apresentados nesse trabalho e nos apresentados na pesquisa anterior;

- Avaliar o dimensionamento das armaduras horizontais principais do cálice com interface rugosa, inclusive as situadas no topo da parede transversal 2 , pois como foi constatado foi submetida a elevados esforços por flexo-tração;

- Analisar o comportamento e o dimensionamento da armadura do pilar na região de embutimento;

- Investigar a ligação do pilar embutido na fundação sem colarinho;

- Refinar a modelagem numérica iniciada por CANHA (2004) a partir dos resultados experimentais apresentados até o momento, de maneira a extrapolar para outras situações;

- Explorar o comportamento do colarinho, variando-se a relação entre os esforços e a excentricidade da força normal.

- Analisar experimentalmente e numericamente o comportamento do cálice submetido à força cortante, além do momento fletor e força normal já vistos. 


\section{REFERÊNCIAS BIBLIOGRÁFICAS}

ASSOCIAÇÃO BRASILEIRA DE NORMAS TÉCNICAS (1985). NBR 9062 Projeto e execução de estruturas de concreto pré-moldado. Rio de Janeiro. ASSOCIAÇÃO BRASILEIRA DE NORMAS TÉCNICAS (2003). NBR 6118 Projeto de estruturas de concreto - Procedimento. Rio de Janeiro.

CANHA, R.M.F. (2004). Estudo teórico-experimental da ligação pilar-fundação por meio de cálice em estruturas de concreto pré-moldado. 279p. Tese (Doutorado) Escola de Engenharia de São Carlos, Universidade de São Paulo, São Carlos, 2004.

CENTRE D'ETUDES ET DE RECHERCHES DE L'INDUSTRIE DU BÉTON (2001). CERIB (Ref. DDE 09) - Recommandations professionnelles pour les assemblages entre elements d'ossature. Epernon. p.13-21.

CONSIGLIO NAZIONALE DELLE RICHERCHE (1984). CNR-10025 - La normativa sui prefabbricati. Milano.

CONSIGLIO NAZIONALE DELLE RICHERCHE (1998). CNR-10025 - Istruzioni per il progetto, l'esecuzione ed il controllo delle strutture prefabricate in calcestruzzo. ITEC/La prefabricazione. Roma.

EL DEBS, M.K. (2000). Concreto pré-moldado: fundamentos e aplicações. São Carlos: EESC/USP.

ELLIOTT, K.S. (1996). Multi-story precast concrete framed structures. Oxford: Blackwell Sience.

EUROPEAN COMMITTEE FOR STANDARTIZATION (2001). Eurocode 2: design of concrete structures - part 1: general rules and rules for buildings. Brussels: CEN/TC $250 /$ SC 2

LEONHARDT, F.; MONNIG, E. (1977). Construções de concreto: princípios básicos sobre armação de estruturas de concreto armado. Rio de Janeiro: Interciência. v.3.

MELO, C.E.E. (2004). Manual munte de projetos em pré-fabricados de concreto. São 
Paulo: Pini.

OLIN, J.; HAKKARAINEN, T.; RAMA, M. (1985). Connections and joints between precast concrete units. Espoo: Julkaisija-Utgivare.

OSANAI, Y.; WATANABE, F.; OKAMOTO, S. (1996). Stress transfer mechanism of socket base connectios with precast concrete columns. ACI Structural Journal, Detroit, v.93, n.3, p.266-276, May/June.

WILLERT, O.; KESSER, E. (1983). Foundations for bottn-end fixed precast concrete columns. Betonwerk und Fertigteil-Technik, Wiesbaden, v.49, n.3, p.137-142. 